\title{
Impact of the local environmental variability on the patterns of coral recruitment on Indo-Pacific reefs
}

\author{
Simona Tiziana Boschetti \\ A thesis Submitted to the Victoria University of Wellington \\ in fulfilment of the requirements \\ for the degree of Doctor of Philosophy in Science
}




\section{Acknowledgments}

This thesis was possible due to the help of many people I met in the recent years.

I would like to thank my supervisor, Associate Prof James J Bell, for allowing me to come to New Zealand to conduct my research, for his guidance, feedback, honest opinions and for keeping me going during all this time, not to mention the long time spent proofreading my drafts and editing my grammar. Thank also to my second supervisor Prof David J Smith for the help and feedback on the field.

I am very grateful to Victoria University of Wellington for granting me the Victoria Doctoral Scholarship and the Submission Scholarship, Operation Wallacea for funding my fieldwork and New Zealand Marine Sciences Society for providing additional funds for my research.

I would like to thank Opwall staff; Philippa Mansell for running the research station and all the local staff for facilitating the logistic and any other issues that came up, and the kitchen ladies for feeding me. A big thank you to Chiara Franco, Julius Pierce, Abi Powell, Theresa Dabruzzi and Shawn Kovacs for all the precious advices they gave me, especially in the first year, and for keeping up the spirit high in the bad moments that sometime occur during fieldwork periods, and thanks to all my diving buddies for their assistance.

My research at Victoria University was facilitated by the efficient work of the School of Biology administration and Patricia Stein at the Faculty of Science for walking me through the university bureaucracy several times. I am also grateful to Victoria University Coastal Ecology Laboratory staff for providing me resources and training for my research.

I would like to thank Alex Sébastien, Catarina Silva, Leighton Thomas for their invaluable friendship, beyond their support and feedback; and I thank all the people who shared with me enjoyable moments and supported me in different ways over the past years. Paul Vincent for proofreading my work. A special thank you to Balam Jimenez, whose help was essential for submitting my thesis from abroad, I could not make it without you!

This thesis would not be possible without the love and support of my sister, Florinda; beyond having always a good advice any time I was in need of directions, her dedication to follow her passions has always been highly inspirational to me. 


\begin{abstract}
Coral reefs are threatened by a range of human activities at both local and global scales. The result of these impacts has resulted in a worldwide decline in the coral reef ecosystems. Corals are the principle reef builders and the maintenance of their populations is fundamental for healthy reef ecosystems. Local environmental factors are critically important in shaping coral populations, particularly at the post-settlement phase, when young coral colonies are most vulnerable to disturbances. In this context, understanding the environmental factors that drive coral recruitment and affect coral survivorship in the early life history stages is vital to effectively manage coral reefs.

In this thesis I began by investigating the effect of abiotic and biological factors on coral recruitment and juvenile coral life history stages using settlement panels deployed in the Wakatobi Marine National Park (SE Sulawesi, Indonesia). My objectives were to assess the spatio-temporal variability in coral recruitment rates and juvenile abundance. I used a modelling approach to identify the environmental factors that affected the distribution and abundance patterns of corals. Then, I focused on the main environmental factors, identified from previously published research, affecting coral recruitment. I conducted a caging experiment to assess the impact of fish predation on coral juveniles. Finally, I analysed the development of the benthic community and the interactions between corals and benthic organisms in the first two years of colonisation of artificial bare surfaces.

I found high spatial and temporal variability in recruitment rates over seven years of data, values were lower than on other Indo-Pacific reefs and ranged from $9.6( \pm 8.21 \mathrm{SE})$ to 317.19 $( \pm 12.76 \mathrm{SE})$ rec. $\mathrm{m}^{-2}$; while juvenile abundance ranged from $4.2( \pm 1.49 \mathrm{SE})$ to $33( \pm 6.36 \mathrm{SE})$ juv. $\mathrm{m}^{-2}$. The local characteristics of the sites, such as coral cover, influenced the distribution of coral colonies in early life history stages; furthermore differences in coral density between the two life history stages (juvenile and recruits) were consistent over time. However, no single or combination of factors adequately explained abundance patterns for either recruits or juveniles. Fish predation did not appear to be the main cause of coral post-settlement mortality in the Wakatobi and it affected only $10.8 \%$ of the coral juveniles in the experiment. In contrast, $58.51 \%$ of the coral juveniles were found to be overgrown by algae and other invertebrates, however only turf and green encrusting algae affected coral survivorship. Coral colony abundance and the number of interactions with other benthic organisms, especially crustose
\end{abstract}


coralline algae (CCA) and sponges, increased over time on panels and they were different between the front and back side of the panels, which was attributed to differences in light and predation regimes. Coral recruitment was higher on older benthic communities, although none of the known coral recruitment promoters, such as CCA, or competitors, such as turf algae, were correlated with coral abundance.

My results show that changes in coral populations between the recruit and juvenile stages are likely driven by small-scale processes. The site characteristics determine the final patterns, which vary over time following temporal fluctuations in environmental factors. The effect of the interactions between algae and sponges with coral recruits and their influence on juvenile survivorship suggests these organisms having a role in coral recruitment success and highlight their importance as a focus for reef management. Furthermore, the use of long term studies allowed a better understanding of the high variability present in coral recruitment and the trends of the recruitment process, which are useful information for conservative purposes. 


\section{Table of Contents}

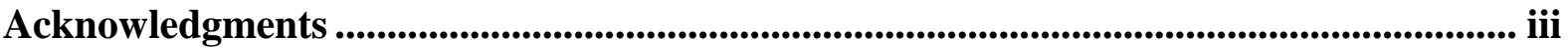

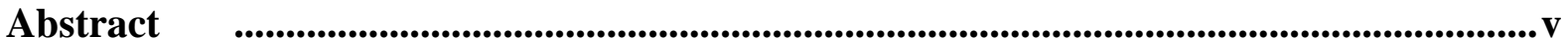

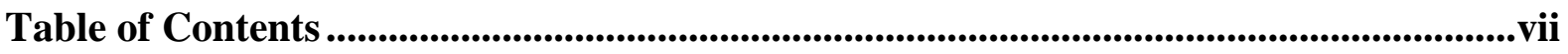

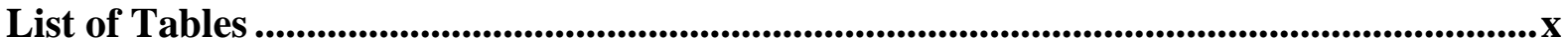

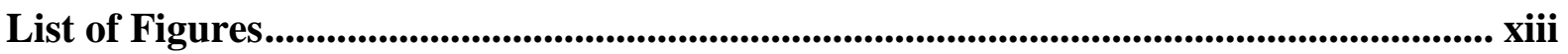

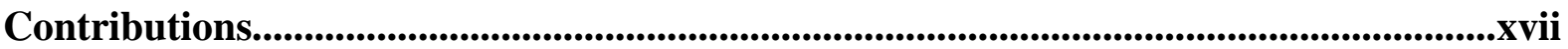

Chapter 1 Introduction .............................................................................................................1 1

1.1 Coral connectivity and regulation of larval dispersal..............................................2

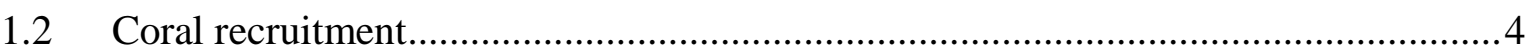

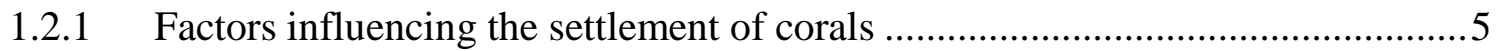

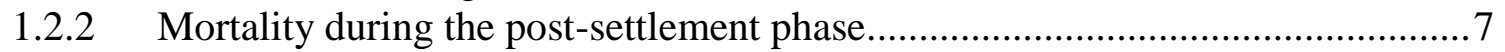

1.3 Coral reefs in the Wakatobi Marine National Park ...................................................9

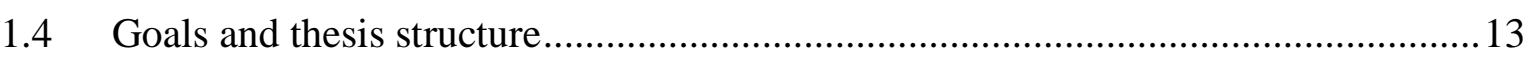

Chapter 2 Spatial variability in patterns of coral recruitment in the Wakatobi Marine

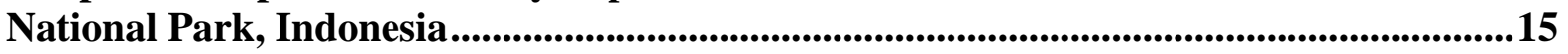

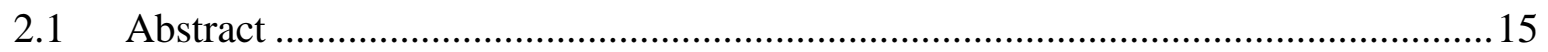

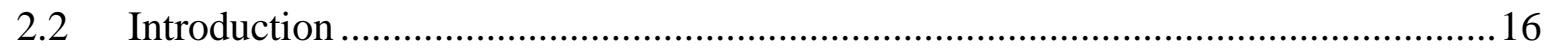

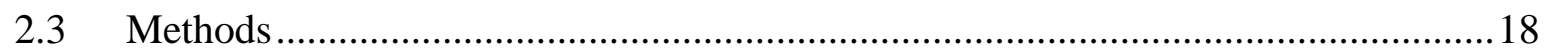

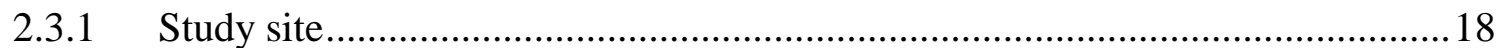

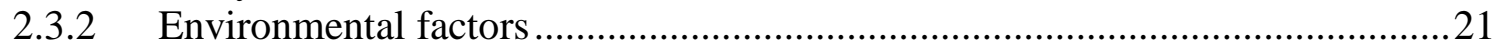

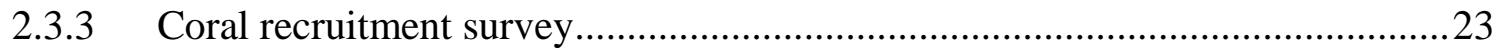

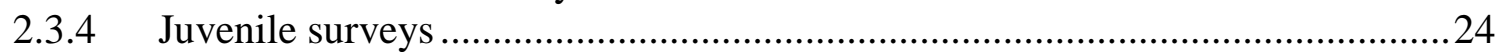

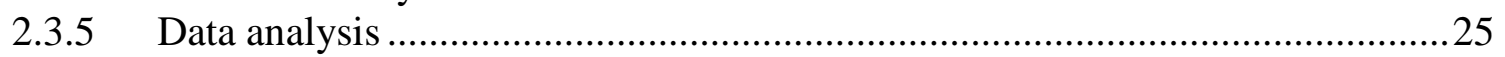

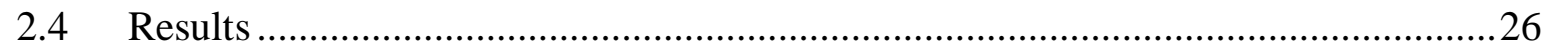

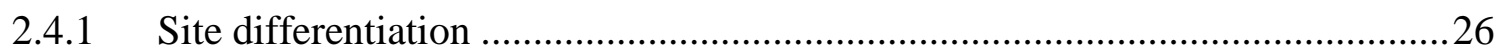

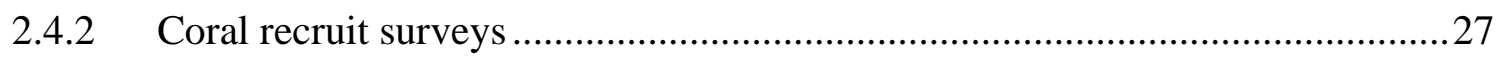

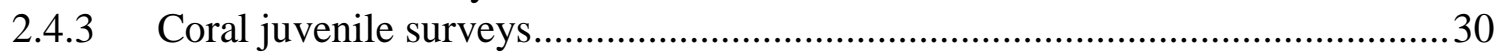

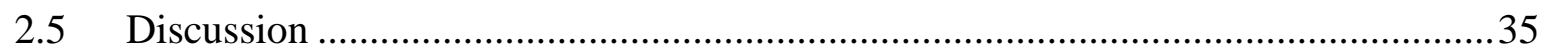

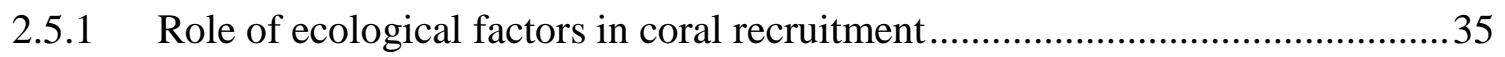

2.5.2 Coral juvenile abundance patterns across sites and depths............................... 38

Chapter 3 Temporal variability in coral recruitment in the Wakatobi Marine National

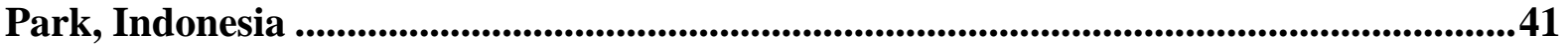

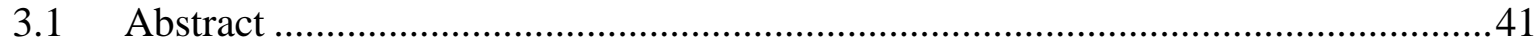

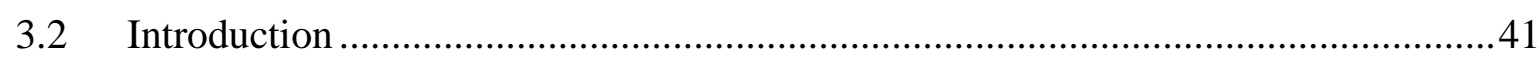

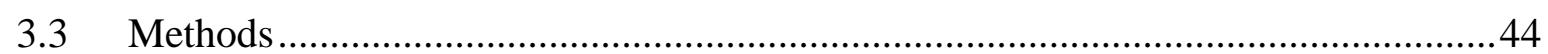

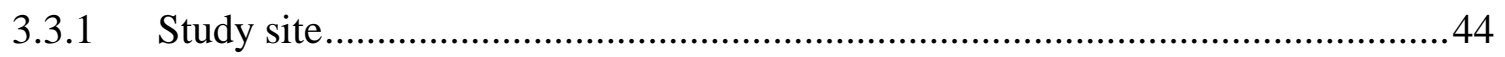

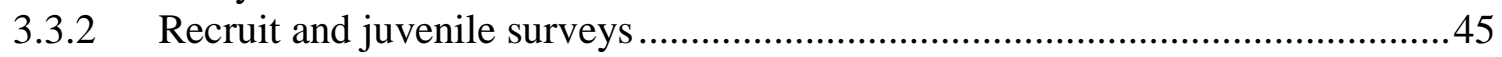

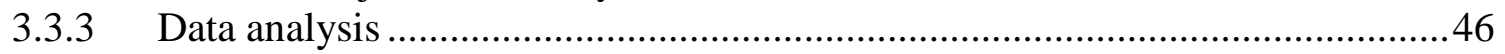


3.4.1 Short-term recruitment survey: Temporal variability in coral recruitment over two years

3.4.2 Long-term survey on coral recruitment among two reef systems over seven years 50

3.4.3 Temporal variation in coral juvenile abundance and assemblage composition. 53

3.5 Discussion

3.5.1 Absence of trends in temporal variability in coral recruitment abundance and assemblage

3.5.2 Temporal variability in the juvenile population............................................57

3.5.3 Impact of thermal anomalies on coral recruitment in the Wakatobi...................58

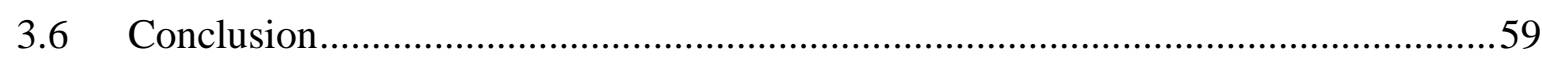

Chapter 4 Importance of fish grazing to coral juvenile mortality ....................................61

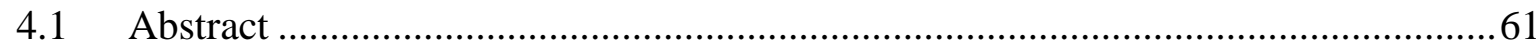

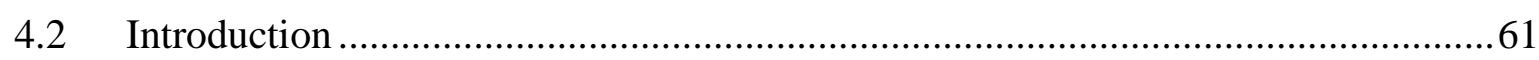

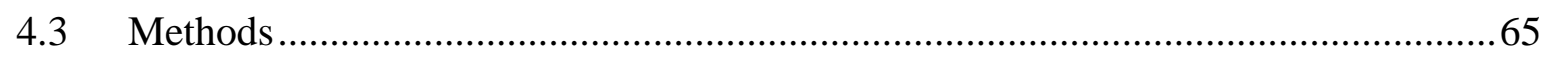

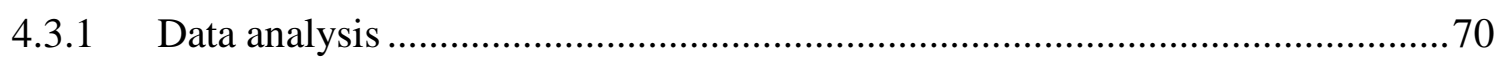

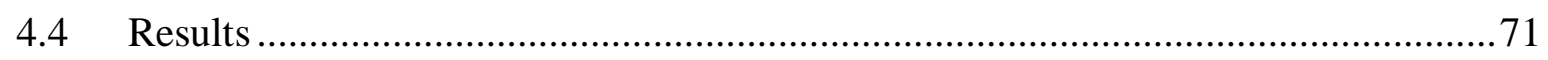

4.4.1 Distribution pattern of coral juveniles at the start of the experiment ................ 71

4.4.2 Mortality of juveniles and importance of colony size ................................... 71

4.4.3 Effect of fish exclusion treatment on variation in coral colony size..................73

4.4.4 Assessment of the main benthic categories overgrowing coral juveniles...........77

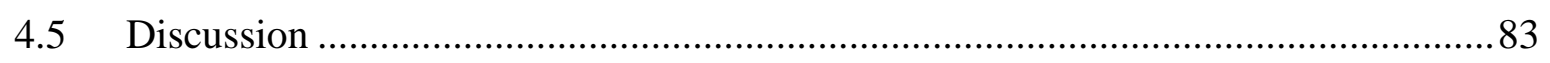

4.5.1 Low impact of grazing fish on juvenile survivorship ...................................... 83

4.5.2 Consistent change in size in coral colonies between treatments........................ 85

4.5.3 Low competence of coral juveniles for competition with other benthic organisms 85

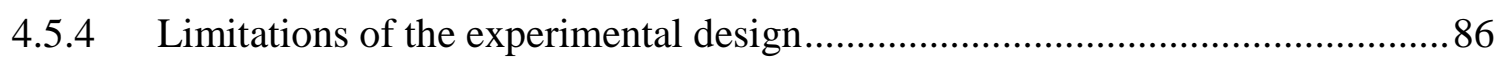

Chapter 5 Influence of ecological succession on coral recruitment .................................89

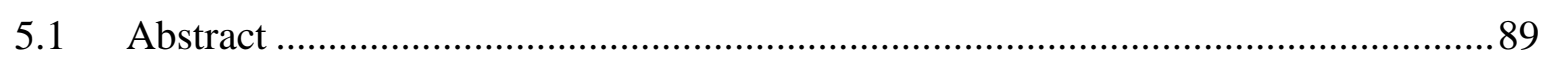

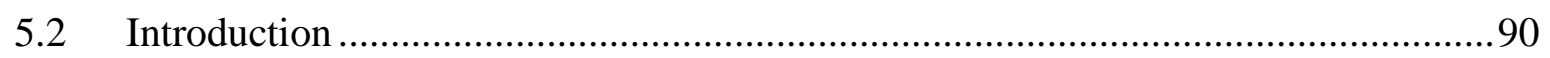

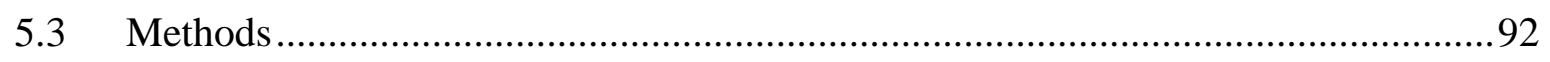

5.3.1 Assessment of benthic community coverage ................................................. 93

5.3.2 Coral recruitment rate ............................................................................ 93

5.3.3 Interactions between coral juveniles and benthic neighbours...........................94

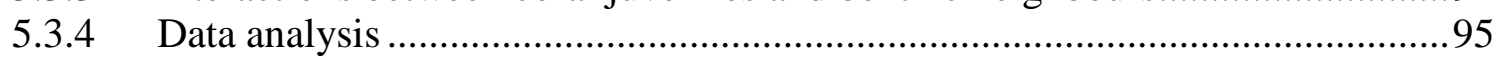

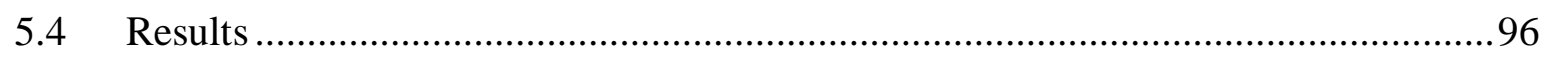

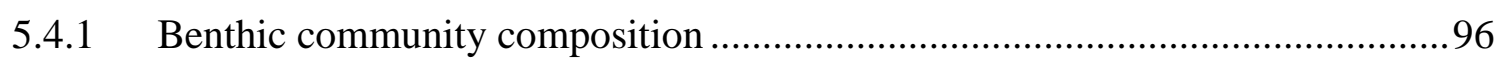

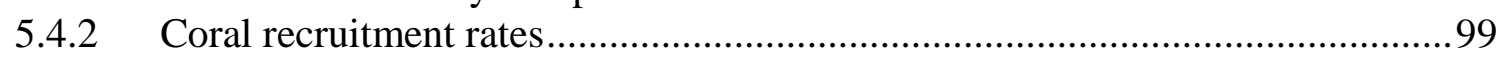

5.4.3 Relationship between benthic community and coral recruitment pattern........... 101

5.4.4 Interactions between coral juveniles and benthic neighbours........................... 103

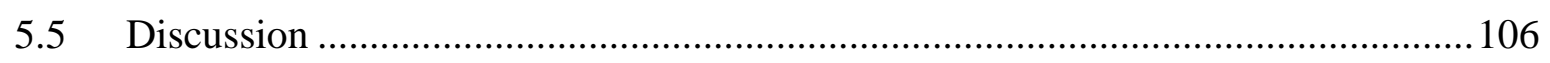

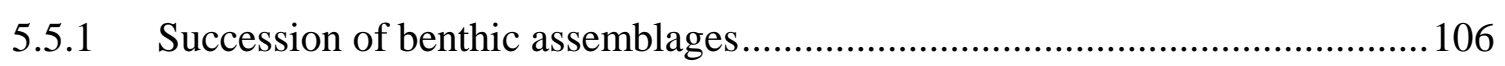


5.5.2 Relationship between coral recruitment and benthic community composition 108

5.5.3 Interactions between coral juveniles and benthic neighbours.......................... 109

\section{Chapter 6 General discussion .............................................................................................113}

6.1 Changes in spatial variability in coral population along recruitment...................... 113

6.2 Importance of different environmental factors at different phases of the coral

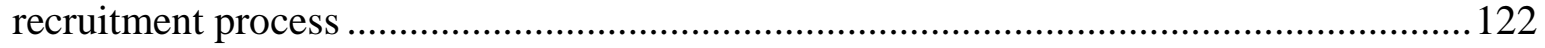

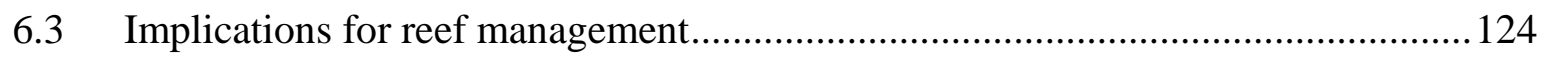

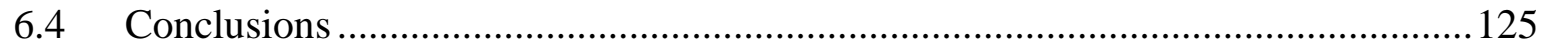

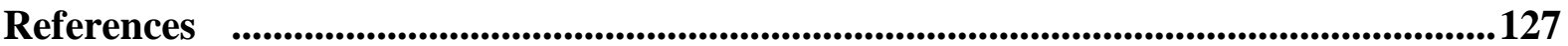

Appendix I ...............................................................................................................................149

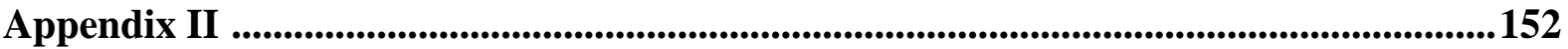




\section{List of Tables}

Table 2.1 Summary of the main characteristics of the study sites in the Wakatobi MNP, Indonesia (Powell 2013)

Table 2.2 Ecological factors measured at each study site in the Wakatobi MNP (Indonesia). Data source: Powell et al. 2014.

Table 2.3 Result of the PERMANOVA analysis for the spatial distribution of coral recruits between sites, depths and sides of the settlement panels deployed at $6 \mathrm{~m}$ for one year ..........28

Table 2.4 Percentage of total coral recruits from different families across all sites and at two depths (6 m and $12 \mathrm{~m})$, and percentage of orientation preference of overall coral recruits. ...29

Table 2.5 Summary table of the result of the DistLMbest analysis for coral recruits. Each recruit pattern was explained by a different combination of variables, however they all explain just a small amount of the overall variability. The table show the AICc value, where ower values show a better fit of the data to the model; the percentage of the overall variability explained by the predictors and the contribute of each predictor; pseudo-F and $\mathrm{P}$ are the results of the PERMANOVA test. 30

Table 2.6 Result of the PERMANOVA analysis of the spatial variation in coral juvenile abundance between nine sites and depths ( 6 and $12 \mathrm{~m}$ ). 31

Table 2.7 Diversity of juvenile corals at the nine study sites in the Wakatobi MNP. The table report the overall values by site and in the row below the values separated by depth. $S=$ species number; $\mathrm{N}=$ total abundance, $\mathrm{H}^{\prime}=$ Shannon-Wiener; $\mathrm{d}=$ Margalef index; J'= Pilou's evenness. Data were not collected at $12 \mathrm{~m}$ at Sampela 1 (S1) and Sampela 2 (S2) for $12 \mathrm{~m}$ 32

Table 2.8 Result of the PERMANOVA analysis comparing the assemblage composition of coral juvenile families across nine sites and two depths, 6 and $12 \mathrm{~m}$ (nested in site)

Table 2.9 Summary of the result of the DistLMbest analysis at family level for coral juveniles. Each coral family pattern was explained by a different combination of variables. For every group of coral juvenile family or single families, listed in the 'Response' column, is showed the model that fit better with low AICc value and the percentage of juvenile distribution explained by the model. Predictor column lists the factors included in the best model and their contribution to the overall model 34

Table 3.1 Coral recruit and juvenile data collection by year and number of sites surveyed in the Wakatobi MNP. Data from 2008 and 2009 were collected by Salinas De León et al. (2011, 2012a); data from 2014 were collected by Operation Wallacea.

Table 3.2 Result of the PERMANOVA analysis for the spatial distribution of coral recruits between two years (2012 and 2013) and nine sites in the Wakatobi MNP 47

Table 3.3 Result to the PERMANOVA analysis for the spatial distribution of coral recruits between five years, two reefs (Hoga and Sampela) with four replicate sites (Buoy 3 and Buoy 4 at Hoga reef and Sampela 1 ans Sampela 2 at Sampela reef) in the Wakatobi MNP.............52

Table 3.4 Result of the PERMANOVA analysis for the spatial distribution of coral recruit families (Acroporidae, Pocilloporidae and Poritidae) between years, reefs, and replicate sites. 
Table 3.5 Result of the PERMANOVA analysis for the spatial distribution of coral juveniles between years, reefs, and replicate sites

Table 3.6 Mean ( \pm Standard Error) number of coral juveniles per $\mathrm{m}^{2}$ recorded at each site with data pooled for each reef system. In the grey column the percentage of the variation in juvenile abundance is compared to the previous juveniles survey. The last column on the right shows the total variation in juvenile abundance between 2009 and 2013. .54

Table 4.1 Summary of the total number of coral juveniles present in each treatment (cage, half-cage and control) at the beginning of the experiment and the abundance of the colonies affected by mortality: full (missing coral colonies), partial (tissue loss sometimes followed by skeleton loss) and overall mortality 72

Table 4.2 Result of the PERMANOVA analysis assessing differences in coral juvenile mortality between three treatments (cage, half-cage and control) in a fish exclusion experiment. Experiment was conducted at $6 \mathrm{~m}$ depth for 6 weeks in the Wakatobi MNP .72

Table 4.3 Result of the PERMANOVA analysis assessing the effect of size on the differences in mortality between treatments. Colony size was used as covariate and treatment as the main factor..... .73

Table 4.4 Result of the PERMANOVA analysis assessing the differences in the variation in area in coral juvenile colonies divided in three treatments (cage, control and half cage) between the beginning and the end of a fish exclusion experiment. Treatments were applied to settlement panels deployed on the reef at $6 \mathrm{~m}$ depth for 6 weeks in the Wakatobi MNP .74

Table 4.5 Result of the PERMANOVA analysis detecting the effect of the initial size of juvenile colonies on the change in size for three different treatment groups (cage, control and half cage) in a fish exclusion experiment 74

Table 4.6 Pair-wise post hoc comparison to detect the treatments responsible for the differences found with the PERMANOVA analysis that detected the effect of the initial size of juvenile colonies on the change in size for three different treatment groups (cage, control and half cage) 75

Table 4.7 Variation in photosynthetic efficiency (Fv/Fm) values occurred in coral juveniles located in three treatments (cage, half-cage and control) during a fish exclusion experiment. Coral juveniles were placed on settlement panels deployed at $6 \mathrm{~m}$ depth on the reef, treatments were applied to the panels haphazardly and the experiment pasted 6 weeks .76

Table 4.8 Result of the PERMANOVA analysis assessing variations in photosynthetic efficiency $(\mathrm{Fv} / \mathrm{Fm})$ values in coral juveniles kept in three different treatments (cage, half-cage and control) occurred in a fish exclusion experiment lasted 6 weeks and conducted at $6 \mathrm{~m}$ depths

Table 4.9 Pair-comparisons between variation in average Fv/Fm values of coral juveniles between the beginning and end of a fish exclusion experiment using three different treatments (cage, half-cage and control).

Table 4.10 Variation in Fv/Fm values between the beginning and the end of the experiment in coral juveniles overgrown by different benthic groups. Coral juvenile colonies were divided by treatment (cage, control and half-cage) and overgrown benthic group 79

Table 4.11 Summary of the average values of Fv/Fm recorded in coral juveniles subjected to three different treatments (cage, half-cage and control) and overgrown by different benthic organisms during a fish exclusion experiment. Because of the nature of this study, cases are distributed haphazardly between treatments and benthic groups 81 
Table 4.12 Results of the PERMANOVA analysis assessing the variation in Fv/Fm in coral juveniles subjected to three different treatments (cage, control and half cage) and overgrown by different benthic organisms during a fish exclusion experiment

Table 5.1 Summary of the percentage of average benthic coverage across sites on settlement panels deployed at $6 \mathrm{~m}$ on the reef for one and two year periods respectively

Table 5.2 Result of the PERMANOVA analysis examining differences in community composition between the front and back sides of settlement panels submerged at $6 \mathrm{~m}$ depth for one and two year periods respectively

Table 5.3 Summary of the overall coral juvenile colonies recorded in the Wakatobi MNP (Indonesia) on settlement panels submerged for one and two year periods respectively (data combined from two sites). Columns report the abundance and relative percentage values on different sides of the panels (front and back) and total values. 100

Table 5.4 Result of the PERMANOVA analysis examining differences in coral recruitment rates between the two sides of settlement panels submerged for one and two year periods respectively .....

Table 5.5 Summary of the overall outcomes of the interactions occurring between coral juveniles and benthic organisms on both sides of settlement tiles submerged for one and two year periods respectively at $6 \mathrm{~m}$ (data of two replicate sites combined) 103

Table 5.6 Summary of the interactions between coral colonies families and benthic organisms. Data were collected from settlement panels deployed at $6 \mathrm{~m}$ at two replicate sites (Buoy 3 and Buoy 4) in the Wakatobi MNP 105

Table 6.1 Summary of the studies on coral recruitment conducted in the last decade in the Indo-Pacific regions and the Caribbean. Since the Coral Triangle is known for its richness and high diversity in corals, research from this area was separated from the rest of the Indo-Pacific region in order to more easily compare the data. For each study I report location, the depth at which the settlement panels were deployed, the distance between sites used in the study, the mean coral recruit density, the outcome of the analysis on the differences in spatial variation in coral recruits between sites, the preference for orientation (side of the settlement panels presenting more settled coral recruits) and the assemblage composition of the coral recruit population 117

Table 6.2 Summary of studies on coral juvenile abundance conducted in the last decade in the Indo-Pacific region and the Caribbean. For each study I report location, the depth where the survey was carried out, the definition of juvenile used in the data collection (maximum diameter in $\mathrm{mm}$ ), the mean coral juvenile density, the outcome of the analysis on differences in spatial variation in coral juveniles between sites, the number of families/genera/species detected and the assemblage composition of the coral juvenile population 120 


\section{List of Figures}

Figure 1.1 Diagrammatic representation of recruitment process and the factors that influence this process at different life stages. Black arrows: transformation from coral larvae to juvenile and adult colonies; red arrows: factors that influence different phases of recruitment that will be considered in this study. Adults: coral colony able to reproduce; Larvae: early freeswimming life history stage; Spat/recruits: recently settled and metamorphosed corals smaller than $10 \mathrm{~mm}$; Juveniles: multi-polyps units with total length between 10 and $50 \mathrm{~mm}$ .8

Figure 1.2 On the top: map of Indonesia. On the bottom: map of the Wakatobi Marine National Park (Indonesia)

Figure 1.3 The Bajau settlement of Sampela, on the reef flat of Kaledupa Island in the Wakatobi Marine National Park. Huts are built on stilt on a basement composed by coral rock. Coral mining for building purposes is highly practised all around the area of Sampela, ........ 11

Figure 2.1 Map of the sites used in this study in the Wakatobi MNP, Indonesia (B1= Buoy 1; B3= Buoy 3; B4= Buoy 4; PK= Pak Kasim's; R1= Ridge 1; S1= Sampela 1; S2= Sampela 2; $\mathrm{K} 1=$ Kaledupa 1; KDS= Kaledupa Double Spur). Light grey line outlines the coral reef boarders.

Figure 2.2 Scheme of the settlement panel and method of attachment to the reef. These panels were developed by Salinas De León and they have been used to monitor the recruitment rate in the Wakatobi MNP previously (From Salinas De León et al. (2011)....

Figure 2.3 Coral recruits of different coral families observed with a dissecting microscope during the analysis of the settlement panels. Panels were bleached to remove the organic material and expose the skeleton of the recruit. The size of the polyp were estimated by positioning a piece of graph paper next to the coral recruit. 24

Figure 2.4 Results of the Canonical Analysis of Principal coordinates (CAP) showing the differences in physical and biological characteristics between sites in the Wakatobi MNP. The differences between sites and the correlation with the environmental factors are shown separately. Axes are the combination of the principle components that give them more variations. The spread of the samples shows the direction of the higher variance existent between the samples. In the graph on the right hand, the direction and the length of the vectors represent their correlation to the samples. Only factors correlated to the sample with Spearman's $r>0.2$ are shown in the graph. Algae category pooled data of all the algal groups investigated.

Figure 2.5 Mean ( \pm Standard Error) number of recruits per $\mathrm{m}^{2}$ found on settlement panels deployed at $6 \mathrm{~m}$ and $12 \mathrm{~m}$ from July-August 2012 to June-July 2013 at nine study sites in the Wakatobi MNP

Figure 2.6 Unconstrained non-metric multidimensional scaling (nMDS) showing the differences in the distribution of coral recruit families across 9 sites and two depths in the Wakatobi MNP. The legend describes the depth at which the panels were deployed (6 or $12 \mathrm{~m}$ ) followed by the site. The distance between the points reproduces the distances on the BrayCurtis matrix on a bidimensional plot, while the stress value estimate how well the configuration fit to the observed distance matrix, where 0.15 is an acceptable value. 29 
Figure 2.7 Mean ( \pm Standard Error) coral juvenile abundance per $\mathrm{m}^{2}$ at each site using 20 quadrats of $0.5 \mathrm{~m}^{2}$ deployed along a $50 \mathrm{~m}$ transect deployed at 6 and $12 \mathrm{~m}$ at nine sites in the Wakatobi MNP

Figure 2.8 Mean ( \pm Standard Error) abundance of coral juvenile families per $\mathrm{m}^{2}$ at nine sites in the Wakatobi MNP. Data from 6 and $12 \mathrm{~m}$ depths were pooled

Figure 2.9 Multidimensional scaling (MDS) plot exploring the difference in the distribution of juveniles of the five main families (Pocilloporidae, Acroporidae, Poritidae, Faviidae, and Agariciidae) at $6 \mathrm{~m}$ (left hand graph) and $12 \mathrm{~m}$ (right handgraph) across sites at the Wakatobi MNP

Figure 2.10 Distance-based redundancy analysis (dbRDA) plot visualising the fitted model for coral juvenile abundance pattern with the lowest AICc. 34

Figure 3.1 Mean ( \pm Standard Error) recruitment rates per $\mathrm{m}^{2}$ recorded on settlement panels deployed for 12 months in 2012 and 2013 in the Wakatobi MNP (Indonesia) across nine sites (see Figure 1 in Chapter 2 for the information about the abbreviations used in the legend) ... 48

Figure 3.2 Multidimensional Scaling (MDS) plot to examine any differences in the assemblage composition of the main coral recruit families at each of the nine sites in two years. The legend describes the year of data collection (2012 or 2013) followed by the site. The distance between the points reproduces the distances on the Bray-Curtis matrix on a bidimensional plot, while the stress value estimate how well the configuration fit to the observed distance matrix, where 0.12 is an acceptable value. 48

Figure 3.3 Percentage of coral recruits from different families recorded in 2012 and 2013 on settlement plates deployed for 12 months at $6 \mathrm{~m}$ depth at nine sites in the Wakatobi MNP (Indonesia)

Figure 3.4 Mean ( \pm Standard Error) number of coral recruits per $\mathrm{m}^{2}$ for the most common coral families recorded in 2012 and 2013 at nine sites in the Wakatobi MNP..... .50

Figure 3.5 Mean ( \pm Standard Error) number of coral recruits per $\mathrm{m}^{2}$ recorded a) at the two reef systems (Hoga and Sampela) with two replicate sites each and b) overall mean at each reef system (Hoga: B3 and B4; and Sampela: S1 and S2) between 2008 and 2014. In 2010 and 2011 no data were collected, while in 2014 data were collected only at one site per reef . .51

Figure 3.6 Percentage of the assemblage comprised of the main coral recruit families identified at two reef systems (Hoga and Sampela) between 2008 and 2014 in the Wakatobi MNP. In 2010 and 2011 no data were collected.

Figure 3.7 Mean ( \pm Standard Error) number of coral recruits for each of the three main families, Pocilloporidae, Poritidae and Acroporidae, per $\mathrm{m}^{2}$ recorded between 2008 and 2014 at two reef systems: Hoga and Sampela

Figure 3.8 Mean ( \pm Standard Error) number of coral juveniles per $\mathrm{m}^{2}$ recorded across five years at Hoga and Sampela reef systems. Data were not collected in 2010 .54

Figure 3.9 Mean ( \pm Standard Error) number of coral juveniles per $\mathrm{m}^{2}$ belonging to the five main families per $\mathrm{m}^{2}$ recorded at a) Hoga and b) Sampela reef systems between 2009 and 2013

Figure 4.1 Primary polyps (indicated by white arrows) settled on settlement panel used for the fish exclusion experiment. The circular walls (corallites) with the septa of the polyps are visible in the image. .66 
Figure 4.2 Set-up of the I-PAM in the laboratory. The MAXI version of the I-PAM used in my study consisted of: a multi control unit (1) that connects the measuring heads to the camera (2) and is powered by an external battery (3). Measuring heads are positioned on a mounting stand with a bottom plate where the sample is positioned. On the top is the CCD camera. The $\mathrm{MCU}$ is also connected to the computer

Figure 4.3 The output of the I-PAM analysis. The images were taken of the same tile before (top) and after (bottom) the manipulative experiment. In both digital image the surface of the tile is visible, while the coloration corresponds to the Fv/Fm values for each point of the image (below each digital image is reported the scale bar with the corresponding Fv/Fm values). The red labels indicate the mean $\mathrm{Fv} / \mathrm{Fm}$ values of three different measurements taken for each of the two coral juveniles present on the tile 68

Figure 4.4 Photos of the cage treatments used for the fish exclusion experiment; 1) full cage 2) half-cage, built with a PVC mesh. Full cages completely exclude predation by large fish on the tiles, half-cages have the top side open. The settlement panels were first fixed on the reef wall, treatments (cage, half-cages or control) were then applied haphazardly to the panels... 69

Figure 4.5 Coral juvenile area measured in June 2013, at the beginning of the experiment, in $\mathrm{cm}^{2}( \pm \mathrm{SE})$ of coral juveniles in the three treatments (cage, half-cage and control) used in the experiment. Circles and stars indicate minor and major outlier values, respectively .............. 72

Figure 4.6 Variation in size of coral juvenile colonies showed by treatment (cage, half-cage and control). The average variation by treatment correspond to the black line in the box plots, while the bars show the range of the fluctuation. Circles and stars represents outlier values. Circles and stars indicate minor and major outlier values, respectively .73

Figure 4.7 Mean ( \pm Standard Error) photosynthetic efficiency $(\mathrm{Fv} / \mathrm{Fm})$ values for coral juveniles placed in three treatments (cage, half-cage and control) at $6 \mathrm{~m}$ depth at Buoy 3 and Buoy 4 in a fish exclusion experiment that lasted 6 weeks. Values were measured at the beginning (dark gray bars) and at the end (light gray bars) of the experiment. A decrease in the mean Fv/Fm values was recorded across all treatments and was more evident in the control and half-cage treatments

Figure 4.8 Percentages of the coral juveniles colonies overgrown by benthic families in three treatments (cage, half-cage and control) during a fish exclusion experiment conducted at $6 \mathrm{~m}$ depth. On the left: overall juvenile colonies found overgrown at the end of the experiment; on the right: juveniles colonies overgrown during the 6 weeks of experimental period.

Figure 4.9 Variation in mean ( \pm Standard Error) Fv/Fm values in coral juveniles overgrown by benthic organisms and subjected to three different treatments (cage, control and half cage) in a fish exclusion experiment for 6 week at $6 \mathrm{~m}$ depth

Figure 4.10 Mean ( \pm Standard Error) Fv/Fm values in coral juveniles overgrown by different benthic organisms during a fish exclusion experiment for 6 weeks. Ascidian and tunicate data are based on only one sample and therefore do not have error bars. The difference between the bars at the beginning and at the end of the experiment show the variation in Fv/Fm value that occurred for each benthic group involved in the interaction with coral juveniles

Figure 5.1 The digital images show the settlement panels at the moment of the analysis in the laboratory. Panels were deployed for one or two years at $6 \mathrm{~m}$ depths; after collection both front and back side of the panels were analysed in order to identify the benthic organisms and their coverage and all the coral recruits and juveniles present on the tiles (here showed in light blu circles). 
Figure 5.2 Example of a cell of the contact matrix. Interactions between coral juveniles and benthic organisms were recorded. Each cell of the matrix corresponded to the sum of the different interactions between coral colonies and benthic organisms. Rows represent each coral family, while columns represent the different non-coral benthic organisms

Figure 5.3 CAP plots showing a) the differences between benthic community composition on settlement panels submerged for one and two year periods respectively in the Wakatobi MNP. CAP axes discriminate between the samples data and show the maximum variability (see correlation of axes to data cloud inAppendix II); b) the benthic community composition separated by side of the panel in order to better visualise the differences in benthic communities on the front and back of panels; plots on the left side represent the front side of the panels, while those on the right side represent the back side. Samples (tiles) with and without recruitment are coloured differently; c) recruitment rates which have been imposed as bubbles on the CAP plots; and d) vectors representing Spearman's rank correlation of individual benthic groups with the CAP axes showing which factors are characteristics of the benthic community in each year 103

Figure 5.4 Correlations between the main benthic groups present on the settlement tiles and known to interact with corals, and the overall number of interactions with coral juveniles .105

Figure 5.5 Diagram of the development of the benthic community on the artificial settlement panels deployed on the reef for one and two year periods respectively in the Wakatobi MNP (Indonesia).

Figure 6.1 Summary of the main findings of my research (modified from Pineda et al. 2008). In the top half of the figure, the arrows show the correlations that were already known to exist before my study between environmental factors with coral populations at different stages of the coral recruitment process. The lack of studies were coral life history stages were studied separately did not allowed to understand the role and impact of factors, such as coral cover, fish predation, sedimentation and spatial competition, at different stages of the recruitment process. In the bottom half, the arrows show the outcomes of my study. No clear correlation was found between coral cover and recruitment rates, no evidence of self-recruitment, although coral cover might be correlated to the larvae availability. Mortality by fish grazing activity is likely to impact on coral recruit, no information about predation of coral larvae by fish. Sedimentation might have a role at coral settlement, but more investigations are needed about further effects on coral recruit survivorship. Spatial competition influences coral spatial variability from settlement across all the life history stages. Interactions and correlations between coral colonies and benthic organisms play an important role in determining the final composition and pattern of coral population. Black lines: knowledge before my study. Black dotted line: suggested correlation. Red lines: findings of this study; grey lines: correlations not found. Red dotted line: correlations that need more investigation. 


\section{Contributions}

All fieldwork, analyses and writing were carried out by the author with the following exceptions:

\section{Chapter 2}

Project design: Author with guidance from Assoc Prof James Bell

Data collection: Author with exception of the environmental data sourced from studies performed by Dr Abigail Powell

Analysis: Author

Writing and editing: Author with editing by Assoc Prof James Bell

\section{Chapter 3}

Project design: Author with guidance from Assoc Prof James Bell

Data collection: Author with exception for the coral recruitment data collected in 2008 and 2009 sourced from separate studies performed by Dr Pelayo Salinas de León and 2014 data collected by the monitoring team of Opwall

Analysis: Author

Writing and editing: Author with editing by Assoc Prof James Bell

\section{Chapter 4}

Project design: Author with guidance from Assoc Prof James Bell

Data collection: Author

Analysis: Author

Writing and editing: Author with editing by Assoc Prof James Bell

\section{Chapter 5}

Project design: Author with guidance from Assoc Prof James Bell

Data collection: Author

Analysis: Author

Writing and editing: Author with editing by Assoc Prof James Bell 


\section{Chapter 1 Introduction}

Coral reefs are characterised by biodiversity patterns that are the result of the interaction of different physical and biological factors that determine the distribution patterns of individual species (Connell 1997). However, coral reefs are under threat; global scale effects such as climate change and ocean acidification have already resulted in the loss of key species, reducing overall biodiversity (Hoegh-Guldberg et al. 2007; IPCC 2007). These impacts will likely change reef structure and composition in the future (Hughes 1994; Marshall \& Baird 2000; Pandolfi et al. 2003; Bellwood et al. 2004; Feary et al. 2007; Norström et al. 2009; De'ath et al. 2012). Furthermore, these global stressors combined with local scale impacts from tourism, overfishing, mineral extraction, and the release of nutrients and sediment from the land, are significantly impacting tropical marine systems (Hughes 1994; Jackson 1997; Nyström et al. 2000; Dulvy et al. 2003; Hughes et al. 2003; Halpern et al. 2008). It has been estimated that more than $60 \%$ of coral reefs are threatened by local activities while $75 \%$ of reefs worldwide have already been impacted by a combination of local factors and temperature stress (Burke et al. 2012) and this is going to increase to $90 \%$ by 2030 (Burke et al. 2012).

The degradation of coral reefs results in a loss of coral cover and overall biodiversity (Gardner et al. 2003; Bruno \& Selig 2007). Such deterioration causes damage to all reef species and also effects humans, who often depend on the marine resources provided by reefs (Dulvy et al. 2003; Munday 2004). In fact, coral reefs provide an important livelihood for local communities through the trade and export of marine products, such as food and aquarium species, and they also have an important role in the tourism industry (e.g. recreational diving and cruises) (Edwards \& Gomez 2007; Hoegh-Guldberg et al. 2009). Many studies have tried to estimate the economic value of coral reefs by looking at fisheries productivity, tourism, coastal development and all the services derived from the reef and it is estimated they are worth over a hundred billion dollars annually (Burke et al. 2012). Such valuations are important for promoting better management (Cesar 2000) and influencing political decisions to prevent further declines in coral reef quality (Burke et al. 2012). However, new polices are needed in many regions to protect reefs from further degradation, particularly to improve water quality and control nutrient inputs (De'ath et al. 2012). To make these interventions effective, more information is required about the processes that drive the distribution patterns of coral reef species, and particularly the factors that influence the recruitment and survivorship in the first 
stages post-settlement of scleractinian coral living in shallow water, especially of the coral families more commonly found in coral early life history stages, such as Pocilloporidae, Poritidae, Acroporidae, Faviidae and Agariciidae. This information is important to understand coral population ecology and for the management of coral reefs (Sponaugle et al. 2002). Little is currently known about the biological and physical factors that regulate the distribution patterns of coral and how these patterns change through time. Understanding the processes that are responsible for the generation of population structure is fundamental for the design of marine reserve networks (Palumbi 2003; McLeod et al. 2010).

\subsection{Coral connectivity and regulation of larval dispersal}

Connectivity is defined as the degree of linkage between different populations (Saenz-Agudelo et al. 2011). From an evolutionary perspective, connectivity can be defined as the degree to which gene flow affects the evolutionary processes within populations (genetic connectivity) (Waples \& Gaggiotti 2006). From an ecological perspective, demographically connected populations are those in which population growth rates are affected by dispersal (Lowe \& Allendorf 2010; Saenz-Agudelo et al. 2011). In marine ecosystems, populations are connected by the exchange of larvae or the migration of adults, which maintains their abundance and genetic variability (Cowen \& Sponaugle 2009; Ritson-Williams et al. 2009a). For most benthic marine organisms, larval dispersal is the most important process whereby larvae travel from a source population to their final destination. However, connectivity is a broad term and includes all the processes from reproduction to the settlement phase. It is fundamental to keep populations 'healthy' and larval dispersal has a primary role in preventing local extinction (Cowen et al. 2007; Pineda et al. 2007). It is considered to be the life history stage that permits the expansion of populations and is essential for population maintenance (Strathmann et al. 2002; Cowen \& Sponaugle 2009). For coral populations exposed to different environmental threats, and where local ecological factors have a negative influence on larval availability, an external supply of larvae is vital to maintain coral communities.

Although marine populations were traditionally thought to be well connected by the long distance dispersal of planktonic larvae (Heck \& McCoy 1978; Cowen et al. 2000), and for this reason marine populations have historically been considered as 'open populations' (Roberts 1997), there are multiple barriers to dispersal both over short and long distances (Almany et al. 2007; Jones 1997). Cowen (2000) suggested that populations can be classified as 'open' or 'closed', where in 'close' system new individuals are provided through self-recruitment with 
no exchange of larvae and genetic material with other populations (Hixon et al. 2002). However, recently Christie (2010) suggested that the levels of connection are more complex because of the continuous interaction between larval retention and exchange, the influence of different environmental factors, and the different life history strategies of marine species (Bak \& Engel 1979; Adjeroud et al. 2007a).

The different life histories and reproduction strategies used by marine species are connected to the distance of larval transport and therefore gene flow (Hellberg 1996), and to the duration of their pelagic phase before they settle or metamorphose (Cowen \& Sponaugle 2009). The length of the larval stage varies for each species; it can last from less than an hour (Carlon \& Olson 1993) to several years (Steneck et al. 2009). It might be expected that larvae with a long planktonic period have the potential for long distance dispersal using oceanic currents (Bohonak 1999; Shanks et al. 2003), and can therefore maintain connectivity between geographically isolated populations. For example, in the Hawaiian Archipelago, Grigg (1981) estimated the larval duration of Acropora sp. to be 91 days, which is quite long compared to most coral species, and he suggested that those larvae could reach Johnson Atoll, $720 \mathrm{~km}$ from the parental reef (Harrison et al. 1984), thereby maintaining connectivity across the Hawaiian archipelago. This hypothesis was confirmed in a genetic study on Porites lobata in the same area conducted by Polato et al. (2010) showed that the longer the larval stage the further larvae were dispersed. In contrast, in a study of Acropora tenuis and Seriatopora hystix, larvae disperse less than $20 \mathrm{~km}$ from the source reef. This distance is in the lower part of the range of the model developed by Cowen (2006), which was based on the typical larval dispersal distance using biophysical data taken in the Caribbean region (Underwood et al. 2009).

There are some disadvantages to a long pelagic larval duration (PLD) as a result of environmental and biological interactions which vary in time and space (Nyström et al. 2000; Largier 2003). Physical variables such as hydrodynamic process, water currents (Roberts 1997), larval behaviour (Koehl et al. 2007), temperature, salinity, reproduction strategy (Hohenlohe 2004), latitude and acoustics (Vermeij et al. 2010b) regulate larval dispersal. Different research methods have been used to better understand the importance of these barriers. Direct methods include observational studies, which might involve tagging individuals when it is possible and mapping the larvae routes (see Hedgecock et al. 2003; Jones et al. 2005; Hellberg 2007). Indirect methods include genetic surveys, biogeographic analysis and models based on the physical, biophysical and larval properties (Nathan et al. 2003). The application of these methods allows the effective dispersal distance to be estimated. For 
example, research conducted at Ryukyus Island in southern Japan using population genetic analysis on the spawning coral species Acropora tenuis found connections between two reefs $150 \mathrm{~km}$ apart, and it was possible to identify which reef was the larval source, which helped in the recovery of one of the two reefs after a bleaching event (Nishikawa et al. 2003). The use of molecular analyses has also shown the existence of genetic connectivity between populations of the same species up to $500 \mathrm{~km}$ distance (Nishikawa et al. 2003).

Research conducted using mark and recapture techniques on the reef fish Pomacentrus amboinensis has shown that the 15-60\% of the larvae remain close to the original reef (Jones et al. 1999, 2005). This finding supports the suggestion that the interaction of environmental factors and larval behaviour can result in larvae being retained close to their natal population and promoting the self-recruitment (Jones et al. 1999; Swearer et al. 1999; Almany et al. 2007; Kinlan \& Gaines 2007). As a consequence, if self-seeding is the main source of larvae, the whole recruitment process depends completely on local environmental factors, such as sedimentation, predation, eddies (Leis 2000; Andutta et al. 2012), tides, waves and surface water movements (Largier 2003), available substrate, spatial competition, light, water turbidity, chemical gradients and depth (Baird \& Hughes 1997; Dunstan \& Johnson 1998; Hughes et al. 1999a; Glassom et al. 2004). A combination of these factors will therefore influence population dynamics. Factors, such as currents, temperature and spawning period, change seasonally and may have a different effect on the recruitment rate at different times of the year. Ultimately, the final distribution patterns and population demography of marine organisms are influenced by a combination of all these different physical and biological factors that can modify the structure of the communities at different spatial-temporal scales (Jackson 1992; Karlson \& Hurd 1993).

\subsection{Coral recruitment}

In scleractinian corals, the main reef builders, reproduction and recruitment are the most important factors for controlling the growth of populations, driving the maintenance of reef health, resilience to disturbance, and the recovery of degraded reefs (Babcock \& Mundy 1996; Caley et al. 1996; Mora \& Sale 2002; Warner \& Cowen 2002; Fox 2004). Recruitment is the process of adding new individuals to a population (Caley et al. 1996); it includes the settlement of coral larvae and the deposition of the skeleton and can last up to 4 months (Wallace 1985a). Recruitment is critical for the maintenance of populations of sessile marine organisms (Connolly \& Roughgarden 1999; Roughgarden 1988) and is fundamental for the reproduction, 
variability and health of corals (Gaines \& Bertness 1992; Caley et al. 1996).

The distribution pattern of coral larvae on reefs is driven by different environmental factors which are likely to have different influences and importance on the settlement and postsettlement survivorship of coral recruits (Maida et al. 1994; Mundy \& Babcock 1998a).

\subsubsection{Factors influencing the settlement of corals}

Regardless of the dispersal potential of coral larvae, most coral reefs are self-seeding (Harriott \& Fisk 1988; Sammarco \& Andrews 1988). A positive correlation has been found between coral cover, larvae production and juvenile abundance by a number of authors (Sammarco \& Andrews 1988; Harriott 1992; Johnson 1992; Harriott \& Banks 1995; Chiappone \& Sullivan 1996; Underwood et al. 2007, 2009). As a consequence, populations are not likely to be dependent on distant sources for the availability of coral larvae (Kinlan \& Gaines 2007; Jones et al. 2009). However, impacted coral reefs that rely solely on self-seeding are likely to be at high risk as distant larval sources are unable to accelerate the recovery time (Bellwood et al. 2004; Fox 2004). Understanding the dependence of a coral reef on self-recruitment is critically important for conservation and restoration projects and knowledge of the larvae population source is fundamental for developing effective management plans. However, the choice made by larvae about where to settle on the reef is also determined by the combination of larvae behaviour and environmental preferences; coral larvae are able to distinguish between different environments (Ritson-Williams et al. 2009b).

According to Fisk and Harriott (1990), the primary driver of coral recruitment rate is the availability of suitable settlement surfaces that are free from sedimentation and grazing pressure and have sufficient exposure to light. Sedimentation has an important role in both the settlement and post-settlement process (Hodgson 1990). An earlier laboratory recruitment experiment with surfaces differently affected by sedimentation showed how even a small increase in sedimentation rate can produce a significant change in the larval settlement patterns (Babcock \& Davies 1991). Coral larval settlement rate is higher where grazers, such as sea urchins, fish, gastropods, and starfish, feed on reef surfaces as they clear it of filamentous and non-coralline algae that are usually effective competitors for the available space with the coral recruits (Brock 1979; Dart 1972). In addition, light intensity determines the depth range at which coral larvae will settle (Erftemeijer 2012; Mundy \& Babcock 1998). As a consequence, recruits show different distribution patterns across reefs and even between sites on the same reef. These patterns can be observed by looking at both the abundance of recruits and the 
taxonomic composition of the settlers. The combination of the overall environmental factors explains in part the spatial variation of coral recruits. Recently the importance of crustose coralline algae (CCA) has been recognised as another important factor in determining the final coral cover and composition (Golbuu \& Richmond 2007; Buenau et al. 2011, 2012). Depending on the species, CCA can have an inhibitive or facilitating effect on coral larvae settlement.

There is considerable temporal variation in the abundance of coral recruits (Wallace 1985b; Dunstan \& Johnson 1998; Ho \& Dai 2014). While seasonal variability has been connected to different reproduction behaviours, such as spawning season (Fox 2004), annual variation has been explained in a number of different ways, such as fluctuations in environmental factors (e.g. effects of El Niño Southern Oscillation; ENSO) or events connected to these factors (e.g. Acanthaster placi outbreaks) (Wallace 1985b; De'ath et al. 2012). The identification of annual variation in recruitment patterns in scleractinian corals is important in order to understand the overall trend and the scales at which such trends operate.

Many research on coral recruitment used artificial surfaces, particularly settlement panels deployed on the reef, with several studies showing that they have similar recruitment rates as the natural reef (Mundy 2000; Salinas De León et al. 2011). A major advantage of panels is that they can be taken out of the water for microscopic examination, facilitating estimation of recruitment rates and taxonomic identification through the skeleton calcium that coral larvae release in the first hours after settlement (Babcock et al. 2003). At this stage of recruitment process, most recruits present only a single polyp or a few, sometimes slightly elevated on the panel, according to the morphology of the adult coral species. The coral families Pocilloporidae, Acroporidae, Poritidae, Faviidae and Agariciidae already presents the characteristics of the family at the single polyp stage, while other families develop later. Pocilloporidae is a branching coral with polyp diameter up to $1.0 \mathrm{~mm}$ and usually; Acroporidae can be branching, tabular or bushy as an adult species. Poritidae can be flat, massive or branching, with polyps. Faviidae can be massive, branching, encrusting, it has big polyps, while Agariciidae has poorly defined walls and its polyps seems interconnected, forming massive adult corals.

The deployment of panels in specific positions, with the front side exposed to predation and sedimentation, and the back side less affected by these factors, has shown that coral larvae, despite the lack of light, generally prefer to settle on the back side of the panels in cryptic 
locations, which are more protected (Wallace 1985a; Mundy 2000; Babcock et al. 2003; Salinas De León et al. 2012a). These kinds of studies have been carried out in different environmental conditions allowing the factors that influence coral recruitment and determine the distributional pattern to be determined.

\subsubsection{Mortality during the post-settlement phase}

The post-settlement phase begins when the coral recruits metamorphose and fix permanently to the substratum. Some authors define this phase more precisely, like Vermeji (2008), who extends in the post-settlement stage to the point at which each coral recruit has at least two polyps separated by a wall and with a developed skeleton. The post-settlement stage is a very delicate phase for coral recruits (Edmunds 2007), and involves high mortality. This early postsettlement mortality shapes adult coral populations (Penin et al. 2011).

In this early stage of their life history, coral recruits are particularly vulnerable to environmental factors that affect their survivorship and growth to the adult phase. In recent years, in situ observations and laboratory experiments have been conducted to understand the tolerance and limits of coral recruits to predation (Baria et al. 2010; Penin et al. 2011), sedimentation (Birrell et al. 2005; Granja Fernandez \& Lopez 2008), spatial competition (e.g. algae overgrowth, CCA) (Jackson \& Buss 1975; Benzoni et al. 2011) and light (Anthony \& Connolly 2004). These studies have provided a better understanding of the role of environmental factors have on the final distribution pattern of corals and have shown the importance of these factors in the different life history stages of corals (Figure 1.1). These factors have a stronger influence on the survivorship of settlers due to the limited energy available for recruits to resist to stress, such as competitive interactions with other organisms. 


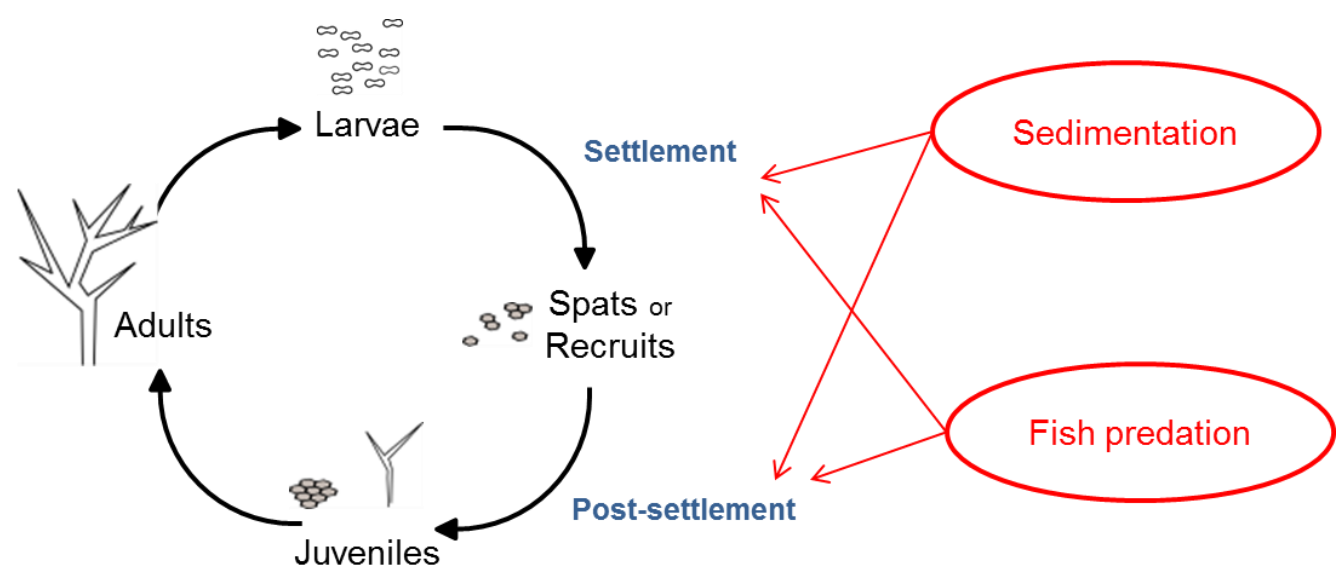

Figure 1.1 Diagrammatic representation of recruitment process and the factors that influence this process at different life stages. Black arrows: transformation from coral larvae to juvenile and adult colonies; red arrows: factors that influence different phases of recruitment that will be considered in this study. Adults: coral colony able to reproduce; Larvae: early freeswimming life history stage; Spat/recruits: recently settled and metamorphosed corals smaller than $10 \mathrm{~mm}$; Juveniles: multipolyps units with total length between 10 and $50 \mathrm{~mm}$

Predation is one of the most important factors influencing the survivorship of small coral colonies (Penin et al. 2010, 2011). Grazers keep the reef clear of algae, but while they feed on algae positioned near settlers they can accidentally damage the polyps. A laboratory experiment conducted with Pocillopora damicornis and blenny fish (Blennidae) showed how single polyps are damaged the most by blennies; in contrast colonies composed of 6-8 polyps have a higher resilience to predation (Christiansen et al. 2008). This result confirmed previous studies that suggested that the small size of recruits makes them more vulnerable to predation than bigger colonies (Zilberberg \& Edmunds 2001; Golbuu \& Richmond 2007).

Juvenile growth rate also affects the time it takes for coral community to change; as juveniles reach the adult phase, they contribute to population dynamics through reproduction. Knowledge of coral growth rates is important for estimating the time required by the reef to recover from disturbances (Bellwood et al. 2004). Research in the Virgin Islands, where the growth of juvenile corals has declined in recent years, has shown that recruits whose postsettlement phase lasted longer than the average time for individuals of the same species had a reduced survival probability (Edmunds 2007). Furthermore, recruits that do not grow above 3 $\mathrm{mm}$ in their first two or three months, against an average growth rate of $10-34 \mathrm{~mm} \mathrm{y}^{-1}$, have only a $20 \%$ chance of survival (Rylaarsdam 1983). This means that an understanding of any factors that decrease juvenile growth and increase mortality rate in the post-settlement phase is important in measuring recruitment. 
Survival rate can be influenced by the direct and indirect effects of many factors. For example, a positive correlation has been found between anthropogenic pressure and sedimentation rate; human activities in coastal environments and river catchments generally increase the amount of suspended sediment in the water. Finer sediment grains contribute to water turbidity, with sediments settling on the reef covering the polyps and reducing light further; this last effect can suffocate corals and reduce growth rate (Richmond 1993). Sediment also contains microbes whose metabolism leads to anoxia in the areas of the coral in contact with the bacteria as a consequence of sulphur reduction process (Erftemeijer et al. 2012; Weber et al. 2012). The sediment tolerance of corals is species-specific, and it is likely to vary across seasons and locations (Erftemeijer et al. 2012). Over longer periods, high sedimentation induces stress, decreasing the recovery potential (Nyström et al. 2000) and coral density and causing changes in coral community composition (Rogers 1990; Dubinsky \& Stambler 1996; Gilmour 1999; Gilmour et al. 2006).

The estimation of post-settlement mortality requires an initial understanding of the overall coral recruitment rates, established by a preliminary assessment of the abundance of recruits and juveniles (Penin et al. 2010). The comparison of these densities with adult colony density can give an estimation of the mortality rate at different stages of the coral lifecycle, and potentially identify those stages being most affected by human impacts. In order to explain the main drivers of the mortality process, many experiments examined the different ecological factors that might be responsible for juvenile mortality in the post-settlement phase (Christiansen et al. 2008; Penin et al. 2010, 2011), but their interaction and the limit of resilience compared to coral recruits are still unknown.

\subsection{Coral reefs in the Wakatobi Marine National Park}

Indonesia is at the centre of the Coral Triangle region, which is famous for its high biodiversity and richness (Barber 2009). The Wakatobi Marine National Park (WMNP) in South Sulawesi, covering 1.39 million hectares, is the second largest marine park in Indonesia and UNESCO nominated it as a World Biosphere Reserve in July 2012. The Wakatobi MNP is a coral reef system (see Figure 1.2) in the Banda Sea eco-region, which is an area crossed by complex water currents and with high reef diversity (McMellor \& Smith 2010). Four main islands and smaller atolls compose the Wakatobi MNP; they are characterised by different coral cover and composition and vary in their topography (e.g. reef flat depth and distance from the coast) and ecological factors that affect each reef, such as optical depth and sedimentation rate (Hennige 
et al. 2008). Previous research has recorded a continued decline in the abundance of coral in the park and found that anthropogenic disturbances resulting from the discharging of waste water, fishing activities and exploitation of the local marine area (e.g. use of coral as a building material) impact the marine environment surrounding human settlements (Crabbe \& Smith 2005; Cullen 2007; Haapkylä 2007).
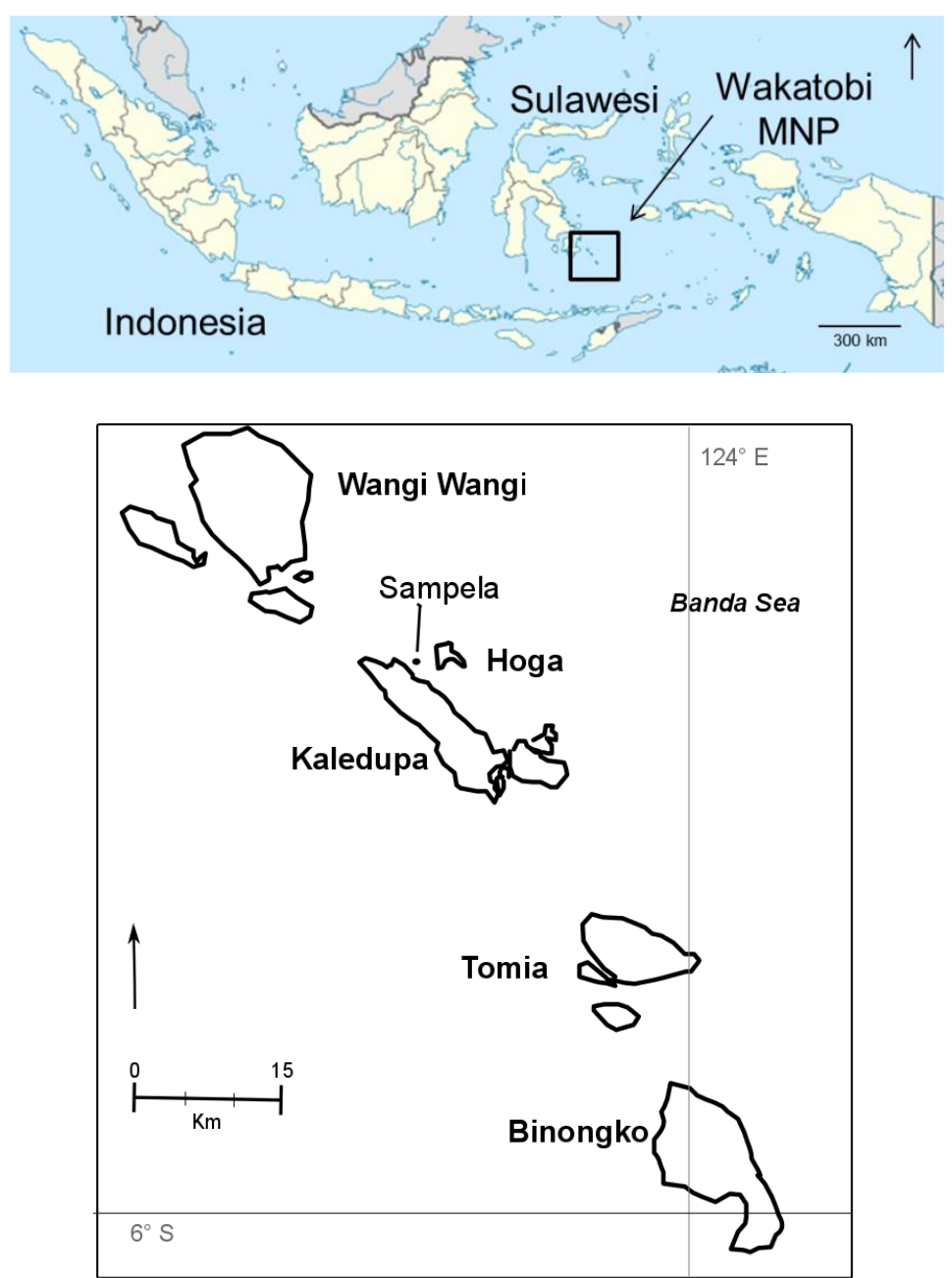

Figure 1.2 On the top: map of Indonesia. On the bottom: map of the Wakatobi Marine National Park (Indonesia)

Particularly, the reef on the North East of Kaledupa Island is highly impacted in correspondence to a Bajau (sea gypsies) settlement of about 2,000 people located on the reef flat and seagrass area (Figure 1.3). Bajau are a traditionally nomad population that usually move on houseboats between Malaysia, Philippines and Indonesia. The livelihood and food of Bajau population depend completely on resources coming from the ocean and Bajau are 
specialized in exploiting the reef using artisanal coral mining, fishing blasting and other activities (Cullen 2007). In contrary to the nomad life, where Bajau exploit a marine area and then leave it to use a new one, giving time to the reef to recover, the permanent village of Sampela modified not only the landscape, but the overall reef close to the village.

The activities of the Bajau population are recognised as one of the major problem for the conservation of marine resources in the Wakatobi (Cullen 2007). For instance, coral rock is used to build the basement of the hut on stills on the reef flat (Figure 1.3). The reef next to Sampela present high levels of degradation, with high sedimentation rate and water turbidity. Sampela reef lost the $80 \%$ of its coral cover between 2002 and 2011 (Curtis-Quick 2013). Despite the entitlement as marine national park, the low control and poor management of the Wakatobi allowed the practise of destroying human activities(McMellor 2007).

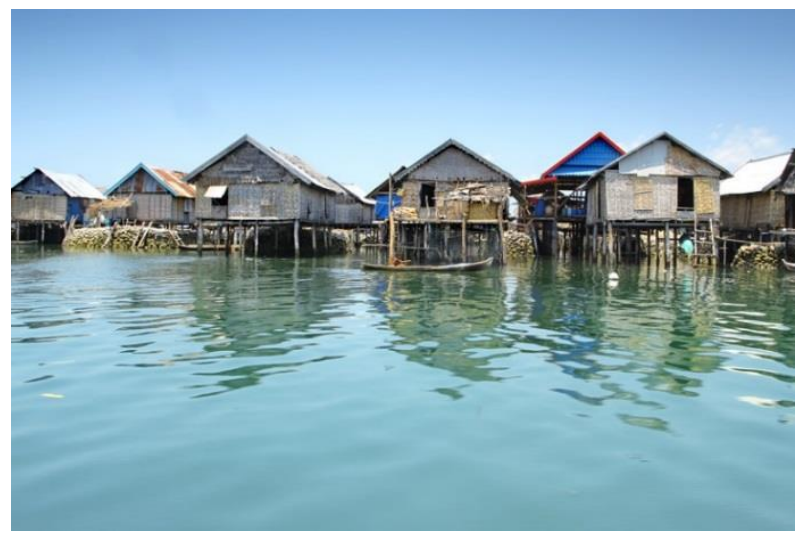

Figure 1.3 The Bajau settlement of Sampela, on the reef flat of Kaledupa Island in the Wakatobi Marine National Park. Huts are built on stilt on a basement composed by coral rock. Coral mining for building purposes is highly practised all around the area of Sampela,

Salinas De León et al. (2011, 2012a) conducted several studies in the Wakatobi MNP looking at coral recruitment rate using two sites characterised by different coral cover and ecological factors: one with relatively high coral cover (Hoga) and another impacted by disturbance, with low coral cover and experiencing high sedimentation (Sampela). Seasonal and annual surveys of coral recruitment have been conducted by using settlement panels made of terracotta, based on a modification of the method used by Mundy (2000). A preliminary study in the Wakatobi MNP showed that recruitment rate on panels is comparable to natural reef (Salinas De León et al. 2011) and that there is variation in coral abundance and species composition across different reefs and seasons. In accordance with the research conducted by Nzali et al. (1998), these authors also hypothesised that a relationship existed between coral cover and recruitment rate, 
which suggests that most of the available larvae settle in close proximity to their parents, maintaining the local coral population. Furthermore, as in earlier studies (Baggett \& Bright 1985; Carleton \& Sammarco 1987; Harriott \& Fisk 1987; Mundy 2000) higher recruit abundance was recorded on the back surfaces of the panels compared to the front. The front sides of the panels were likely more exposed to environmental factors, especially in Sampela where the front sides collected a thick layer of sediments that may inhibit settlement (Salinas De León et al. 2012a). Importantly, the presence of this heavy sedimentation, along with differences in grazer abundance between the sites, meant it was not possible to separate the effects of coral cover, sedimentation and grazing on recruitment rate. Finally, post-settlement mortality rates have also been estimated by measuring the abundance of coral juveniles at Sampela and Hoga, and there were clear differences in the final abundance, pattern and families composition of corals. Spatial and temporal variation in recruitment rate suggests that environmental factors are very important in driving the recruitment process and that habitat differences might explain differences in post-settlement mortality rate across different sites rather than larval availability (Salinas De León et al. 2012a).

Based on these studies in the Wakatobi MNP, three main factors have been recognised as having primary importance in determining coral recruitment patterns: adult coral colony abundance, sedimentation, and predation. Chronic sedimentation seems to have a high impact in Sampela, while suspended sediments affect recruit survival by reducing the amount of light reaching coral polyps. Different predation rates could also explain differences in recruitment rates, especially because there are different fish abundances and species present on the two reefs (Salinas De León et al. 2012a), but since most of the recruits settled on the back side of the panel, the effect of fish predation is not easily studied (Salinas De León et al. 2012a). To date there have been no studies considering the interaction between these two factors. Since the possibility of the reefs recovering from degradation is strictly correlated to the success of the recruitment process of hard corals, additional research is required to understand how these factors affect the ecology of scleractinian coral populations and drive coral post-settlement mortality. 


\subsection{Goals and thesis structure}

The main goal of this research was to investigate the ecological factors that drive the settlement and post-settlement survival in scleractinian corals at local scales in the Wakatobi MNP. I investigated how these factors influence the distribution pattern of coral settlers on reefs with different physical and biological conditions. Specifically, I conducted surveys and manipulative experiments to assess the factors influencing corals at different life history stages. Initially I explored the spatial and temporal variability in coral recruitment across sites characterised by different environmental factors. Chapter 2 describes the large-scale recruitment study modelling the biological and physical factors that correlate with the recruitment rates of reef corals. I used nine sites located on two reef systems characterised by different environmental factors (e.g. coral cover, sedimentation rate).

Specific objectives included:

1. To characterize the study sites through the collection of data on physical and biological factors (e.g. coral cover, sedimentation, predation, and water flow).

2. To survey the distribution patterns of scleractinian coral recruits and juveniles.

3. To determine any relationships between environmental factors on coral recruit and juvenile density and diversity using a modelling approach.

Chapter 3 describes an investigation into the temporal variation in abundance and assemblage composition of different coral life history stages in order to identify temporal trends in coral recruitment.

Specific objectives included:

1. To determine coral recruitment rates across nine sites characterised by different environmental conditions over two consecutive years.

2. To determine coral recruitment rates and juvenile abundance over a seven-year period at two reef systems of different environmental qualities.

The second part of this thesis explores the role of specific environmental factors on coral recruitment distribution pattern. In Chapter 4 I assessed the impact of fish predation on coral recruit and juvenile survival by conducting a manipulative experiment (fish exclusion by caging). 
Specific objectives included:

1. To examine the impact of fish grazing activity on coral recruit and juvenile abundance by assessing the overall full and partial mortality rate in coral populations.

2. To assess any correlation between coral colony size and mortality rate in order to detect coral colony sizes that have a higher probability of being accidentally removed from the surface or damaged.

3. To investigate effect of overgrowing on variation in coral size and variation in photosynthetic efficiency of coral recruit and juvenile mortality.

In Chapter 5 I investigated the first stages of the benthic community development over two years and the effect of spatial competition on coral recruit and juvenile abundance, and assemblage composition.

Specific objectives included:

1. To determine any associations between the main benthic families and coral colonies after one and two years of benthic community development.

2. To assess the interactions between benthic organisms and coral colonies, and to investigate the outcome of the interactions in order to detect relationships between benthic groups and coral recruits.

The overall outcomes of this research are discussed in the final chapter in the context of the high dynamism present in the coral recruitment process and the implications for coral reef management. 


\section{Chapter 2 Spatial variability in patterns of coral recruitment in the Wakatobi Marine National Park, Indonesia}

\subsection{Abstract}

Coral recruitment is an important process for reef maintenance and is driven by a suite of abiotic and biological factors. These factors also strongly influence corals at different life history stages and determine the final patterns of coral abundance and diversity. The impact of local variables on recruitment processes has previously been shown across sites characterised by different environmental conditions. However, there is little understanding of the effect of disturbance on the abundance patterns of different coral life history stages. I therefore investigated the influence of environmental variables on coral distribution patterns by analysing the abundance of recruits (less than 1 year old) settled on artificial panels and juveniles $(<40 \mathrm{~mm})$ on natural reef across nine sites characterised by different abiotic and biological factors in the Wakatobi Marine National Park (South-East Sulawesi, Indonesia). Significant spatial variation was found in recruit abundance between sites and orientation (top or bottom) of settlement panels, but not among depths. No single variable that were measured adequately explained the variability and distribution patterns of the coral recruits. High postsettlement mortality occurred between the recruit and juvenile stages with a large decrease in overall density, which changed from $112.97( \pm 11.16 \mathrm{SE})$ recruits $\mathrm{m}^{-2}$ to $9.63( \pm 0.24 \mathrm{SE})$ juveniles $\mathrm{m}^{-2}$. There was significant spatial variation in juvenile abundance across sites and depths (PERMANOVA; $\mathrm{df}=8, \mathrm{P}<0.05$ ). None of the variable or combinations of variables explained the patterns of juvenile abundance. There was a shift in the coral assemblage structure between different life history stages, suggesting differential mortality patterns between different coral families. Despite the lack of correlation between coral abundance patterns and the variables I measured, the orientation of the recruits and the variation in family distribution patterns between life history stages suggests that there might be a variable that was not included in this study that strongly influences these patterns, such as light availability. Elucidating the factors responsible for the patterns observed will help local managers to promote specific interventions at local scales in order to improve coral reef management. 


\subsection{Introduction}

Coral recruitment is fundamental for maintaining healthy coral populations and promoting reef restoration after disturbance (Dulvy et al. 2003; Munday 2004). In recent decades surveys conducted on coral reefs worldwide have highlighted high levels of spatial variability in coral recruitment patterns (Hughes \& Connell 1999; Adjeroud et al. 2007a; Penin \& Adjeroud 2013) at different scales: oceanic, regional (Soong et al. 2003), and local (O'Leary \& Potts 2011).

The dispersal of coral larvae can connect reefs at different scales, depending on the reproductive strategy of the species being considered (broadcasting versus brooding of larvae), the duration of spawning season (Underwood et al. 2009), larval abundance (Potts et al. 1985), larvae navigation (Edmunds 2000b; Pineda et al. 2007), and pelagic larval duration (Graham et al. 2008). Sammarco \& Andrews (1989) found that recruitment is likely to be mostly a local scale phenomenon. Despite the long larvae dispersal potential for most coral species, most larvae appear to settle close to their natal reef, meaning that the recruit composition should be similar to the adult population. However, this correlation has only been found in a few studies as local environmental factors affect the abundance and distribution patterns of corals (Chiappone \& Sullivan 1996; Nzali et al. 1998; Vermeij \& Sandin 2008; Salinas De León et al. 2012a).

Coral larvae have preferences for specific settlement sites (Hughes et al. 1999a). They can follow chemical (Miller \& Mundy 2003) and physical cues, such as the light intensity optimal for growth (Fisk \& Harriott 1993), low turbidity (Browne et al. 2012) and water flow (Goldenheim \& Edmunds 2011), which can affect their physiology and growth rates. A primary condition required for settlement is the availability of surfaces free from sedimentation (Hodgson 1990; Gilmour 1999; Edmunds et al. 2014a), however exposed surfaces are more accessible to grazers and coral predators, and as a consequence some larvae prefer to settle in cryptic environments (Wallace 1985a; Mundy 2000; Adjeroud et al. 2007b) that offer more protection from predation and are less impacted by sedimentation (Penin et al. 2010; Edmunds et al. 2014b). Edmunds et al. (2014a) reported that in the presence of an equal distribution of refuges on exposed and more sheltered positions, larvae preferred the more exposed sites, which had higher light availability.

Earlier research reported a decrease in coral abundance rates in young coral populations during the recruitment process, where high differential mortality rates affect the coral colonies of various life history stages (Babcock et al. 1986; Wilson \& Harrison 2005; Penin et al. 2010). 
Overall the mortality rate has been inversely correlated with the age of the colonies and this rate appears to be different among coral taxa, causing variation in the patterns of coral family composition (Nozawa et al. 2013; Penin \& Adjeroud 2013).

A number of studies have compared the abundance and assemblage structure of coral various life history changes (recruits, juveniles and adults) at sites with different environmental conditions (Wilson \& Harrison 2005; Penin et al. 2010), and have highlighted a relationship between abiotic and biological variables and the survival of coral life history stages. It is likely that different factors affect coral survival at different life history stages. These correlations between coral survival and local ecological factors have been assessed using a combination of observations, surveys and manipulative experiments (Edmunds 2000a; Fox 2004; Linares et al. 2012; Trapon et al. 2013a).

Penin et al. (2010b) found that coral recruit mortality was associated with local fish abundance, while predation rate by corallivorous fish was negatively correlated with the size of coral colonies (Christiansen et al. 2008). Christiansen et al. (2008) found a positive correlation between the size of coral recruit and the possibility of being eaten by fish; single polyp recruits were more susceptible to grazers and predators than colonies composed of a few polyps (Vermeij \& Sandin 2008) because multi-polyp colonies are better able to deal with partial predation (Edmunds 2007). There are a number of other environmental factors and interactions that have been correlated to colony size or life history stages. For example, spatial competitors are likely to have increasing importance to the growth of the coral colony (Babcock \& Mundy 1996). As the colony increases in size, more space is required, especially for encrusting and massive species, and their relationship with the other benthic organisms present on the reef will influence survival, direction and growth rate of corals (Box \& Mumby 2007; Sandin \& McNamara 2012). Algae, and marine invertebrates such as sponges, soft corals ascidians and molluscs, also cover reefs and are strong competitors for space, and can overgrow and suffocate the coral recruits (Lenihan et al. 2011).

Recently, reef ecologists have begun investigating the interacting impacts of multiple disturbances on coral recruits and juveniles (Hixon 2011; Lenihan et al. 2011; Erftemeijer et al. 2012; Ban et al. 2014). Experimental studies conducted to assess the impact of sedimentation and predation on coral juveniles (Baria et al. 2010; Penin et al. 2011; Davies et al. 2013; Trapon et al. 2013c) have found differences in responses depending on the size of colony or the coral taxa (Penin et al. 2011). Composition, intensity and interactions between 
local co-existing disturbances differently affect the recruit and juvenile populations. These disturbances affect not only the abundance, but also the coral assemblage composition (Benayahu \& Loya 1984; Erftemeijer et al. 2012; Ban et al. 2014) and it is likely that the importance of individual variables varies at each life history stage (Penin et al. 2007). These previous studies suggest that local factors influence the success of the coral recruitment process and determine spatial variability at small localised scales. However, there is still a lack of information on the role and importance of the ecological variables that affect reefs at small scales.

This research was conducted in the Wakatobi Marine National Park (WMNP) in South Sulawesi, Indonesia, which is situated in the middle of the Coral Triangle, an area well known for its high diversity and richness in coral species. The WMNP supports reefs of different qualities, which, despite the short distance between them, have high variability in coral distribution and abundance patterns. A previous coral recruitment study by Salinas De León et al. (2012a) in this region found spatial variability in the abundance of recruits between two reefs characterised by different environmental factors. The positive association between coral cover and recruitment rate suggested that the reefs were mostly self-seeding and that recruitment occurred at the local scale. A high mortality was also reported in the postsettlement phase along with a shift in dominance from the Pocilloporidae family at the recruit stage to the Faviidae family in the juvenile stage (Salinas De León et al. 2011, 2012a). Sedimentation and predation were suggested as the main drivers of the overall recruitment process. However, because this study was conducted only at a limited number of sites and included only two reef systems chosen for their different reef qualities, it is unknown whether the same patterns would be observed across a varying environmental conditions.

The aims of this study were to measure the spatial variability and patterns of coral recruitment to artificial panels and quantify juvenile abundance across sites and depths characterised by different coral coverage and environmental conditions; and to model the factors explaining the spatial variability found in the recruit and juvenile coral populations.

\subsection{Methods}

\subsubsection{Study site}

The Wakatobi Marine National Park, covering 1.39 million hectares, is the second largest marine park in Indonesia and UNESCO nominated it as a World Biosphere Reserve in July 
2012. The WMNP is a coral reef system (see Figure 2.1) in the Banda Sea eco-region, which is an area crossed by complex water currents with high reef-associated diversity (McMellor \& Smith 2010). Four main islands and a number of smaller atolls are found in the WMNP; sites in this area are characterised by different coral cover and composition and vary in their topography (e.g. reef flat depth and distance from the coast) and the ecological factors that affect each reef, such as optical depth and sedimentation rate (Hennige et al. 2008) (see Table 2.1).

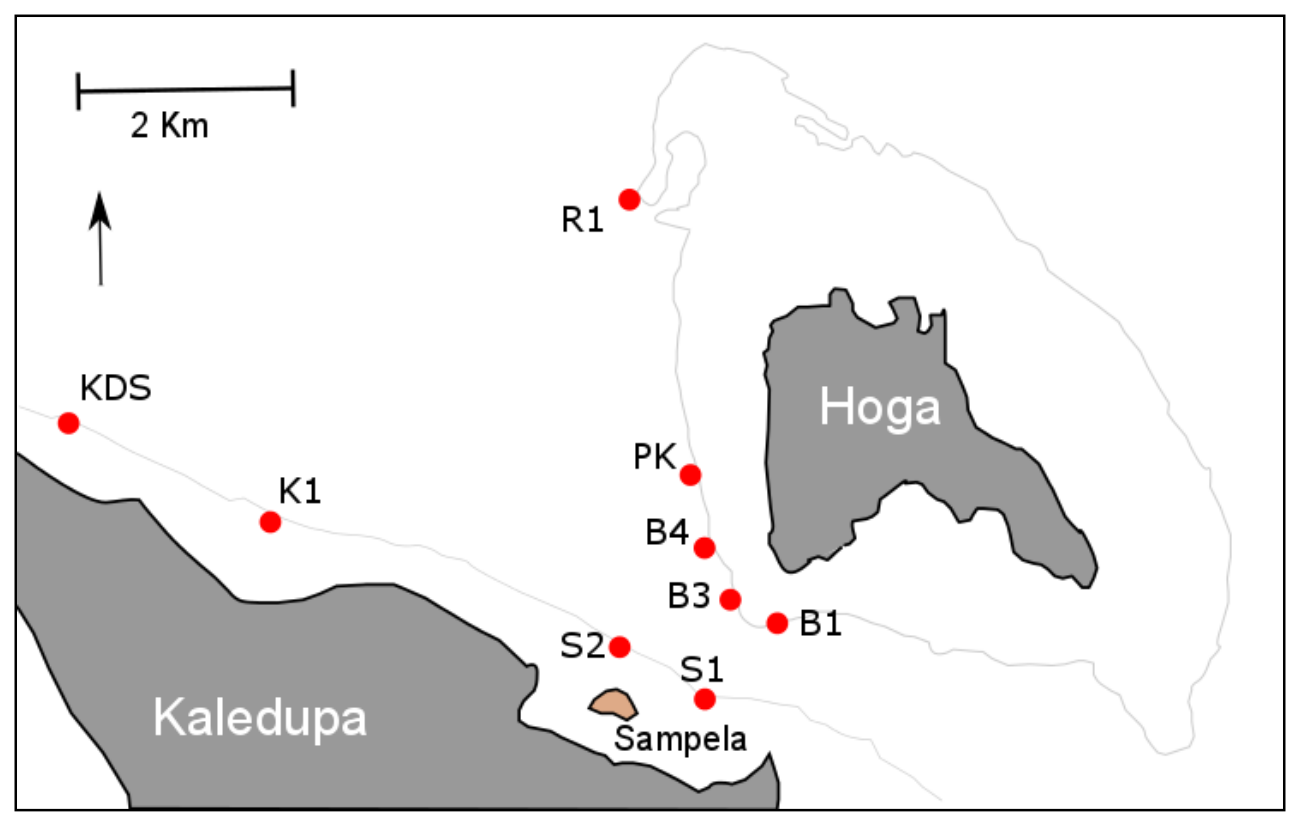

Figure 2.1 Map of the sites used in this study in the Wakatobi MNP, Indonesia (B1= Buoy 1; B3= Buoy 3; B4= Buoy 4; $\mathrm{PK}=$ Pak Kasim's; R1= Ridge 1; $\mathrm{S} 1=$ Sampela 1; $\mathrm{S} 2=$ Sampela 2; K1= Kaledupa 1; KDS= Kaledupa Double Spur). Light grey line outlines the coral reef boarders.

The nine sites included in this study were selected based on their variability in ecological characteristics and are located on two separate reef systems, Hoga and Kaledupa. The distance between any two study sites ranged from $250 \mathrm{~m}$ to approximately $5 \mathrm{~km}$. 
Table 2.1 Summary of the main characteristics of the study sites in the Wakatobi MNP, Indonesia (Powell 2013)

\begin{tabular}{|c|c|c|c|c|}
\hline Site & Topography & Coral cover & $\begin{array}{c}\text { Main abiotic } \\
\text { characteristics }\end{array}$ & $\begin{array}{l}\text { Main biological } \\
\text { characteristics }\end{array}$ \\
\hline $\begin{array}{l}\text { Buoy } 1 \\
5^{\circ} 28^{\prime} 48.22^{\prime \prime S} \\
123^{\circ} 45^{\prime} 35.01^{\prime \prime} \mathrm{E}\end{array}$ & $\begin{array}{l}\text { Southern site on Hoga } \\
\text { reef, slope up to } 30 \mathrm{~m} \text {, } \\
\text { sandy bottom. }\end{array}$ & Coral cover $\sim 20-30 \%$ & $\begin{array}{l}\text { Low sedimentation, } \\
\text { low flow and } \\
\text { moderate turbidity. }\end{array}$ & $\begin{array}{l}\text { Average fish } \\
\text { abundance. }\end{array}$ \\
\hline $\begin{array}{l}\text { Buoy } 3 \\
5^{\circ} 28^{\prime} 29.57^{\prime \prime S} \\
123^{\circ} 45^{\prime} 29.40^{\prime \prime} \mathrm{E}\end{array}$ & $\begin{array}{l}\text { Positioned about } 150 \mathrm{~m} \\
\text { from the shore, steep slope } \\
\text { up to } 30 \mathrm{~m} \text {, sandy bottom. } \\
\text { Presents caves and } \\
\text { hangovers. High diving } \\
\text { activity. }\end{array}$ & $\begin{array}{l}\text { Coral cover } \sim 23-32 \% \\
\text { mostly Pocilloporidae, } \\
\text { Poritidae and Acroporidae } \\
\text { spp. }(93 \%)\end{array}$ & $\begin{array}{l}\text { Average } \\
\text { sedimentation. }\end{array}$ & $\begin{array}{l}\text { High crustose coralline } \\
\text { algae cover. }\end{array}$ \\
\hline $\begin{array}{l}\text { Buoy } 4 \\
5^{\circ} 28^{\prime} 20.42^{\prime \prime} \mathrm{S} \\
123^{\circ} 45^{\prime} 26.48^{\prime \prime} \mathrm{E}\end{array}$ & $\begin{array}{l}\text { About } 250 \text { m north of B3, } \\
30 \text { m depth, sandy bottom. } \\
\text { It present caves and } \\
\text { hangovers, and areas } \\
\text { covered by coral rubble. }\end{array}$ & High coral cover $\sim 45 \%$, & $\begin{array}{l}\text { Average } \\
\text { sedimentation }\end{array}$ & $\begin{array}{l}\text { High sponge } \\
\text { abundance and low } \\
\text { algae }\end{array}$ \\
\hline $\begin{array}{l}\text { Pak Kasim's } \\
5^{\circ} 28^{\prime} 1.30^{\prime \prime} \mathrm{S} \\
123^{\circ} 45^{\prime} 20.49^{\prime \prime} \mathrm{E}\end{array}$ & $\begin{array}{l}\text { About } 400 \mathrm{~m} \text { north of B4, } \\
\text { wall up to } 50 \mathrm{~m} \text { depth, } \\
\text { about } 100 \mathrm{~m} \text { from the buoy } \\
\text { it turns to gentle sandy } \\
\text { slope. Sandy bottom and } \\
\text { rubble patches. }\end{array}$ & $\begin{array}{l}\text { High coral cover } \sim 55 \% \text {, } \\
\text { Poritidae dominance. }\end{array}$ & $\begin{array}{l}\text { Low sedimentation } \\
\text { and moderate } \\
\text { turbidity. }\end{array}$ & $\begin{array}{l}\text { Low sponge } \\
\text { abundance, low algae, } \\
\text { average fish }\end{array}$ \\
\hline $\begin{array}{l}\text { Ridge } 1 \\
5^{\circ} 27^{\prime} 10.76^{\prime \prime S} \\
123^{\circ} 45^{\prime} 8.82^{\prime \prime} \mathrm{E}\end{array}$ & $\begin{array}{l}\text { Northern site on Hoga } \\
\text { island, wall up to } 50 \mathrm{~m} \\
\text { depth. }\end{array}$ & $\begin{array}{l}\text { Coral cover } \sim 26-33 \% \text {, } \\
\text { mostly foliose and } \\
\text { massive species; } \\
\text { Acroporidae, Poritidae } \\
\text { and Gorgonians. }\end{array}$ & $\begin{array}{l}\text { Low turbidity, low } \\
\text { sedimentation, and } \\
\text { high flow }\end{array}$ & $\begin{array}{l}\text { High soft coral } \\
\text { coverage, average } \\
\text { sponge and average } \\
\text { fish abundance. }\end{array}$ \\
\hline $\begin{array}{l}\text { Sampela } 1 \\
5^{\circ} 29^{\prime} 4.47^{\prime \prime} \mathrm{S} \\
123^{\circ} 45^{\prime} 13.78^{\prime \prime} \mathrm{E}\end{array}$ & $\begin{array}{l}\text { Southern site on Kaledupa } \\
\text { island. Gentle sandy } \\
\text { bottom, rarely reaches } 16 \\
\text { m. Sandy bottom. Close to } \\
\text { Bajau village (sea gypsy) } \\
\text { and fish fences. }\end{array}$ & $\begin{array}{l}\text { Coral cover } \sim 5-17 \% \text {, } \\
\text { mostly massive species, } \\
\text { the most common are } \\
\text { Poritidae and Faviidae } \\
60 \%\end{array}$ & $\begin{array}{l}\text { High sedimentation, } \\
\text { turbidity, and flow. }\end{array}$ & $\begin{array}{l}\text { High soft coral, } \\
\text { sponge and algae } \\
\text { abundance. }\end{array}$ \\
\hline $\begin{array}{l}\text { Sampela } 2 \\
5^{\circ} 28^{\prime} 59.76^{\prime \prime} S \\
123^{\circ} 44^{\prime} 54.75^{\prime \prime} \mathrm{E}\end{array}$ & $\begin{array}{l}\text { Similar to Sampela } 1 \text {, } \\
\text { gentle sandy slope, large } \\
\text { coral rubble patches. }\end{array}$ & $\begin{array}{l}\text { Low coral cover } 7 \% \text {, coral } \\
\text { assemblage similar to } \\
\text { similar to Sampela } 1 .\end{array}$ & $\begin{array}{l}\text { High sedimentation } \\
\text { and turbidity. }\end{array}$ & $\begin{array}{l}\text { High soft coral, } \\
\text { sponge and algae } \\
\text { coverage. Low fish } \\
\text { abundance. }\end{array}$ \\
\hline $\begin{array}{l}\text { Kaledupa } 1 \\
5^{\circ} 28^{\prime} 19.18^{\prime \prime} \mathrm{S} \\
123^{\circ} 43^{\prime} 32.64 " \mathrm{E}\end{array}$ & $\begin{array}{l}\text { About } 300 \mathrm{~m} \text { from the } \\
\text { shore and mangrove } \\
\text { forest, presence of fish } \\
\text { fences. Slope up to } 50 \mathrm{~m} \text {, } \\
\text { sandy bottom. }\end{array}$ & $\begin{array}{l}\text { Coral cover } \sim 6-16 \% \text {, } \\
\text { Poritidae dominance, } \\
\text { Acroporidae common. } \\
\text { Gorgonians on the slope. }\end{array}$ & $\begin{array}{l}\text { Low flow and average } \\
\text { sedimentation. }\end{array}$ & $\begin{array}{l}\text { High soft coral and } \\
\text { sponge, high fish } \\
\text { abundance. }\end{array}$ \\
\hline $\begin{array}{l}\text { Kaledupa Double } \\
\text { Spur } \\
5^{\circ} 27^{\prime} 56.16^{\prime \prime} \mathrm{S} \\
123^{\circ} 42^{\prime} 14.29^{\prime \prime} \mathrm{E}\end{array}$ & $\begin{array}{l}\text { Northern site on Kaledupa } \\
\text { island, steep wall. Flat } \\
\text { covered by coral rubble } \\
\text { due to recent fish bombing. }\end{array}$ & $\begin{array}{l}\text { Coral cover } \sim 20-30 \% \text {. } \\
\text { Gorgonians on the slope. }\end{array}$ & $\begin{array}{l}\text { Low sedimentation } \\
\text { and average flow. }\end{array}$ & $\begin{array}{l}\text { Moderate soft coral } \\
\text { coverage low sponge, } \\
\text { high CCA. High fish } \\
\text { abundance. }\end{array}$ \\
\hline
\end{tabular}




\subsubsection{Environmental factors}

Data for environmental variables identified as influencing coral recruitment patterns in previous studies were collected between 2011 and 2013; abiotic and biological variables were measured between June-August 2011 by Powell et al. (2014) and data on fish abundance were collected as part of the ongoing monitoring program at the research station on Hoga Island between June-August 2013 (Operation Wallacea, unpublished data). The abiotic variables measured were: steepness of the reef slope, temperature, sedimentation, turbidity, water flow and depth, and the biological variables were: abundance of hard coral, soft coral, sponge, corallivorous fish, crustose coralline algae (CCA), non-coralline algae, and chlorophyll- $\alpha$. For full details of how these data were collected see Table 2.2 from Powell et al. (2014).

Three variables, turbidity, temperature, and chlorophyll- $\alpha$, were recorded by deploying a data logger set (RBR XR-420) on each reef slope at about $10 \mathrm{~m}$ for 24 hours at three different time periods, leaving at least $5 \mathrm{~m}$ between the deployment sites. Sediment traps were deployed on the reef and were collected after 3 days. Traps were brought to the laboratory where sediments were filtered using filter papers, dried at $100^{\circ} \mathrm{C}$ in an oven for at least 24 hours, separated into different size fractions, and then weighed (see English et al. 1997). Reef angle was measured on site using a protractor mounted on a spirit level and the inclination of the reef was measured by rotating the protractor from the horizontal position at $0^{\circ}$, verified by a spirit level, until it reached a parallel position to the reef. The gradient of the inclination was then read on the protractor. Water flow was measured by deploying a current meter (Valeport Model 106) for 24 hours at three different time periods.

Benthic composition was measured using $1 \times 1 \mathrm{~m}^{2}$ quadrats on the reef slope at approximately $10 \mathrm{~m}$. The photographs of the quadrats were then analysed by Coral Point Count (Kohler \& Gill 2006) using 100 random points distributed on the quadrat area. The main benthic categories identified were: sponges, hard coral, soft coral, crustose coralline algae, other noncoralline algae, rock, rubble, sand, and others. 
Table 2.2 Ecological factors measured at each study site in the Wakatobi MNP (Indonesia). Data source: Powell et al. 2014.

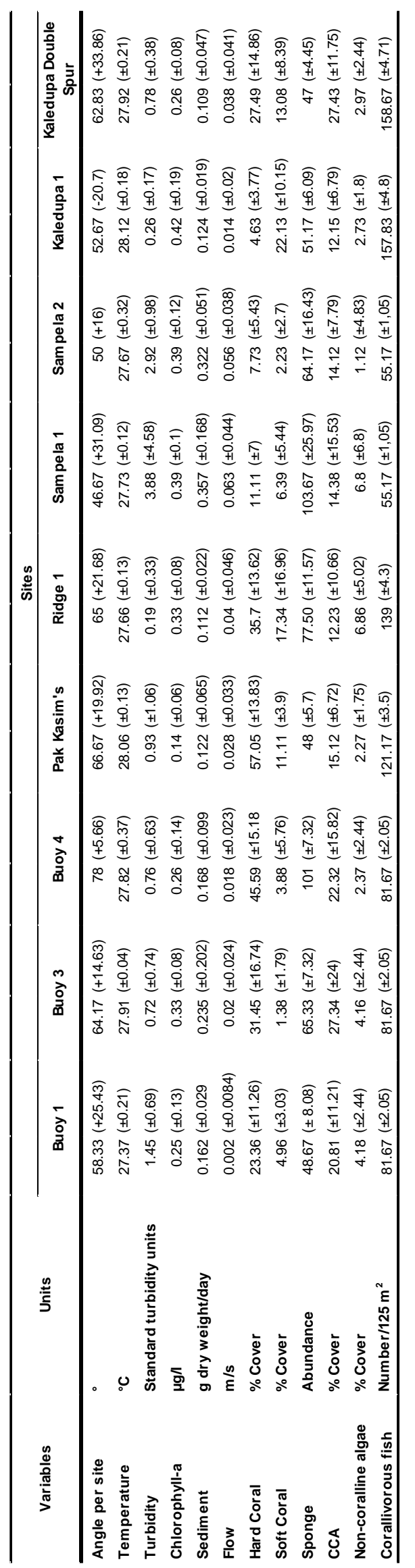


Fish surveys were conducted by deploying a $50 \mathrm{~m}$ transect tape at 6 and $12 \mathrm{~m}$ depth. After leaving the tape for 5 minutes to allow the fish to acclimate (Fowler 1987), all fish within the transect area of $50 \mathrm{~m}$ length, $5 \mathrm{~m}$ wide and $5 \mathrm{~m}$ high, were recorded. Three replicate transects were conducted at each site and depth at times randomly chosen between 7 am and $4 \mathrm{pm}$. Due to logistic constraints it was not possible to carry out all the measurements at the same time at each site.

\subsubsection{Coral recruitment survey}

Artificial panels are widely used to study coral recruitment (e.g. Harriott \& Fisk 1988; Tomascik et al. 1996; Dunstan \& Johnson 1998; Fox 2004; Glassom et al. 2004; Adjeroud et al. 2007a; Green \& Edmunds 2011). A previous study in the same locality as the present one tested various coral recruitment methodologies using artificial settlement plates (see Salinas De León et al. 2011). This previous study demonstrated that settlement rates to the back of terracotta tiles show no significant difference compared to those on natural substrata, and the authors have therefore suggested the tile settlement rates are a suitable surrogate for natural recruitment rates. Settlement panels can be deployed on the reef in an optimal position and orientation, and can also be easily removed for inspection.

My survey was conducted using terracotta tiles $(20 \times 10 \times 0.7 \mathrm{~cm})$ sourced locally. The tiles were deployed between July-August 2012 and collected in June-July 2013. Between 6 and 8 panels were deployed at each site, for a total of 120 panels at least $2 \mathrm{~m}$ from each other. A gap of about $2 \mathrm{~cm}$ was left between the panels and the reef to facilitate the recruitment (Harriott $\&$ Fisk 1987). Seventy-two panels were deployed at $6 \mathrm{~m}$ at 9 sites and 48 panels at $12 \mathrm{~m}$ across seven sites. Panels could not be placed at $12 \mathrm{~m}$ at the Sampela sites as the sites extends out to $11 \mathrm{~m}$. Tiles were attached directly to the reef using a modified method described by Mundy (2000) and used by Salinas De León et al. (2011) (see Figure 2.2).

Panels were retrieved and taken in seawater to the laboratory to be labelled and analysed by examining while still fresh each tile under a dissecting microscope. The tiles were then left in a chlorine solution for $24 \mathrm{~h}$ to dissolve the organic material present on the surface (after Salinas De León et al. 2011). After the tiles were rinse in freshwater and air-drying, they were analysed again using a microscope to identify the skeleton of the coral recruits. 


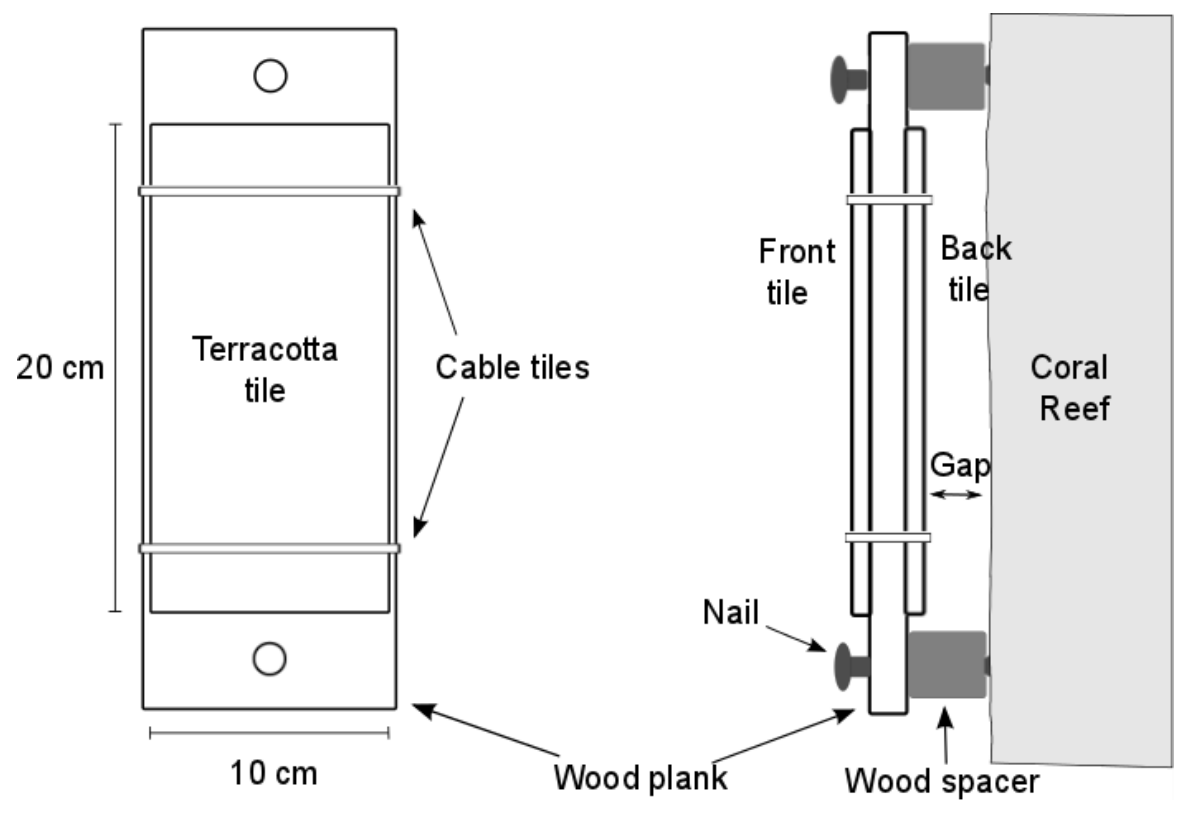

Figure 2.2 Scheme of the settlement panel and method of attachment to the reef. These panels were developed by Salinas De León and they have been used to monitor the recruitment rate in the Wakatobi MNP previously (From Salinas De León et al. (2011)

Recruits were identified to family level and wherever possible to genus level. Acroporidae, Pocilloporidae and Poritidae are all easy to identify in their early life history stage and have been described by English et al. (1997), Baird \& Babcock (2000) and Babcock et al. 2003 (Figure 2.3). The remaining recruits that were either damaged or not identifiable were categorised as 'Others'. Recruit density was standardised as number of recruits per square meter $\left(\right.$ rec. $\left.\mathrm{m}^{-2}\right)$.
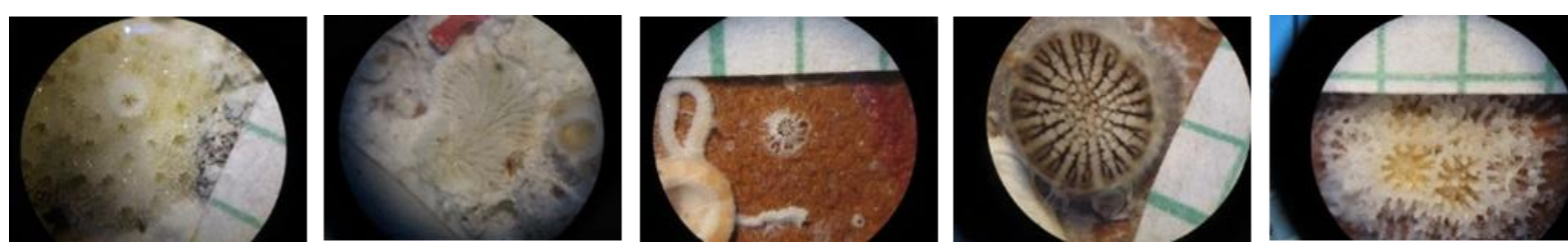

Figure 2.3 Coral recruits of different coral families observed with a dissecting microscope during the analysis of the settlement panels. Panels were bleached to remove the organic material and expose the skeleton of the recruit. The size of the polyp were estimated by positioning a piece of graph paper next to the coral recruit. Graph paper used in the digital images shows one line per two millimeters

\subsubsection{Juvenile surveys}

In this study juvenile colonies were those measuring $<40 \mathrm{~mm}$ in diameter that were attached to the reef substratum and did not display the fractured surface characteristic of asexual recruits (see Edmunds 2000a). I used the same method as described by Salinas De León et al. (2011) to estimate juvenile abundance. The survey was conducted between June and August 2013. 
Juvenile abundance was assessed at each site using 20 quadrats $(0.5 \times 0.5 \mathrm{~m})$ along a $50 \mathrm{~m}$ transect at 6 and $12 \mathrm{~m}$ depths. At the two Sampela sites the survey was conducted only at $6 \mathrm{~m}$. Juveniles were photographed underwater and identified to genus level. Juvenile density was standardised to abundance per square meter (juv. $\mathrm{m}^{-2}$ ).

\subsubsection{Data analysis}

Coral recruit and juvenile data were analysed within the software package PRIMER v.6 (Plymouth Marine Laboratory, UK). Recruitment data were root-squared transformed to normalise the data and analysed with Jaccard resemblances. This metric considers the presence or absence of the category and is used to deal with datasets containing a large number of zeros. Individual panels were considered as replicates within the sites. Juvenile abundance data were root-squared transformed and the similarity matrix was calculated using the zero-adjusted Bray-Curtis coefficient (Clarke et al. 2006). Bray-Curtis is commonly used for biological data and works with non-metric similarities (Anderson \& Willis 2003). Constrained canonical analysis of principal coordinates (CAP) was used to examine differences in ecological variables between the sites relative to differences in community structure. Differences across sites were ascertained with 9999 random permutations on the Bray-Curtis matrix and the result was plotted in a two-dimensional plot. The correlation between the environmental factors and the CAP axes was measured by Spearman's rank correlation and visualised in multivariate space with vectors. The length of each vector represents the importance of the specific variable in differentiating the sites, while the direction shows a positive or negative correlation. The circle shows the threshold for a correlation of 1 .

A non-parametric permutational multivariate analysis of variance (PERMANOVA) based on the resemblance matrix using 9999 random permutations was used to analyse the spatial variability in recruitment and juvenile abundance across all sites. This method was used because of its flexibility, as no assumptions need to be made about the data distribution and it can be used with small sample sizes (Anderson 2001). Two fixed factors were used: site (nine levels) and depth (two levels).

Diversity indices were used to examine the diversity present at each site based on the number of the genera present and the abundance of each genus. Juvenile diversity differences between sites and depth were measured with three different diversity indices: the Shannon-Wiener Index (H'), richness with Margalef Index (d), and evenness with Pilou's Index (J'). Multidimensional scaling (MDS) was used to explore any differences in coral assemblages between sites. 
Distance-based multiple linear regression (DistLM) allows any correlation between multivariate data and single and combinations of predictor variables, such as environmental factors (Mc Ardle \& Anderson 2001), to be identified. Predictors can be categorical or continuous and data normality is not a requirement. The variables I used were first analysed with a Draftsman Plot to identify any correlations. Sedimentation and turbidity were found to be highly correlated and therefore turbidity was excluded from the analysis. The remaining factors were normalised by ranking. I chose to conduct the analysis with the Best procedure, which identifies the best fitted model for $n$-variables, using the $\mathrm{AIC}_{\mathrm{c}}$ criterion selection. $\mathrm{AIC}_{\mathrm{c}}$ is a modification of Akaike's (1973) coefficient AIC that considers all the possible permutations and gives the most parsimonious model for each number of predictor variables; lower AIC values correspond to a best fit model, however this criterion is penalised when considering a high number of variables (Symonds \& Moussalli 2011). The $\mathrm{AIC}_{\mathrm{c}}$ formula is modified from the AIC formula by the addition of a correction factor that adjusts it in order to be more efficient in all cases when the number of samples is small compared to the number of predictor variables, such as in the present study.

The DistLM test output gives the best-fitted and the overall best model with the best $\mathrm{R}^{2}$ and lowest $\mathrm{AIC}_{\mathrm{c}}$. Results of the DistLMbest analysis were visualised on a two-dimensional plot using a Distance-based redundancy analysis (dbRDA), where the axes are correlated to the fitted values. Spearman's rank correlation was used to explore the relationships between the samples and the principal coordinate axes.

\subsection{Results}

\subsubsection{Site differentiation}

The results of the CAP showed differences in the ecological characteristics between the sites. The factors that were different between sites were coral cover, site steepness, chlorophyll- $\alpha$ concentration, and sedimentation rate. The sites can be grouped based on similarities in their ecological characteristics: Ridge 1, Kaledupa Double Spur, Buoy 1 and Pak Kasim's are characterized by high hard and soft coral abundance, fish abundance, and algal abundance; Sampela 1 by high abundance of soft corals, algae and high current flow; Kaledupa and 

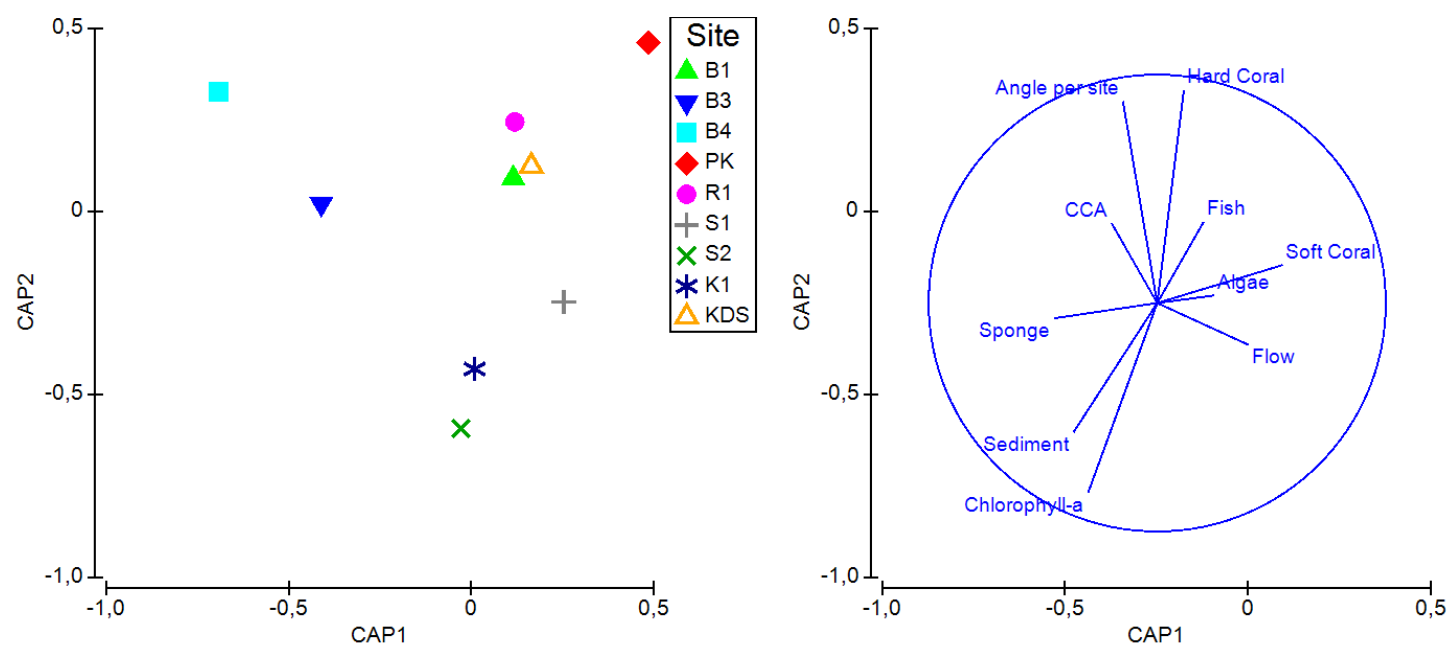

Figure 2.4 Results of the Canonical Analysis of Principal coordinates (CAP) showing the differences in physical and biological characteristics between sites in the Wakatobi MNP. The differences between sites and the correlation with the environmental factors are shown separately. Axes are the combination of the principle components that give them more variations. The spread of the samples shows the direction of the higher variance existent between the samples. In the graph on the right hand, the direction and the length of the vectors represent their correlation to the samples. Only factors correlated to the sample with Spearman's r $>0.2$ are shown in the graph. Algae category pooled data of all the algal groups investigated.

Sampela 2 by high current flow and high levels of chlorophyll- $\alpha$; and Buoy 3 and Buoy 4 by high CCA abundance and steeper slopes (see Figure 2.4).

\subsubsection{Coral recruit surveys}

A total of 118 out of 120 panels were retrieved; 70 at $6 \mathrm{~m}$ and 48 deployed at $12 \mathrm{~m}$; the two missing panels were lost from B1 and PK. The total number of recruits across all sites was 317; 181 at $6 \mathrm{~m}$ and 136 at $12 \mathrm{~m}$. The number of recruits found on a single panel ranged from 0 (at least one tile without recruits was found at each site) to 19 (found at B1) at $6 \mathrm{~m}$, and from 0 (tiles without any recruits were found at all sites) to 23 (at R1) at $12 \mathrm{~m}$.

The overall mean number of recruits across all sites with data from 6 and $12 \mathrm{~m}$ pooled was $112.97( \pm 11.16 \mathrm{SE}) \mathrm{rec} . \mathrm{m}^{-2}$; the maximum mean was $200( \pm 51.89 \mathrm{SE}) \mathrm{rec} . \mathrm{m}^{-2}$ at $\mathrm{B} 1$ and the minimum was $12.50( \pm 4.23 \mathrm{SE})$ rec. $\mathrm{m}^{-2}$ at $\mathrm{S} 1$. At $6 \mathrm{~m}$ the overall mean recruit abundance on tiles was $64.08( \pm 9.69 \mathrm{SE})$ rec. $\mathrm{m}^{-2}$. The mean recruit abundance ranged from $135.71( \pm 70.26$ $\mathrm{SE})$ rec. $\mathrm{m}^{-2}$ found at $\mathrm{B} 1$ to $6.25( \pm 4.23 \mathrm{SE})$ rec. $\mathrm{m}^{-2}$ recorded at $\mathrm{S} 1$. At $12 \mathrm{~m}$ the mean recruit abundance was $70.78( \pm 13.05 \mathrm{SE})$ rec. $\mathrm{m}^{-2}$. Only at two sites, B4 and $\mathrm{K} 1$, recruits abundance was higher at $12 \mathrm{~m}$ than at $6 \mathrm{~m}$. The values ranged from $110.71( \pm 48.84 \mathrm{SE})$ rec. $\mathrm{m}^{-2}$ at PK to $39.29( \pm 45.83 \mathrm{SE})$ rec. $\mathrm{m}^{-2}$ at R1 (Figure 2.5$)$. Overall, $64.15 \%$ of the recruits found had settled on the back side of the panels. 


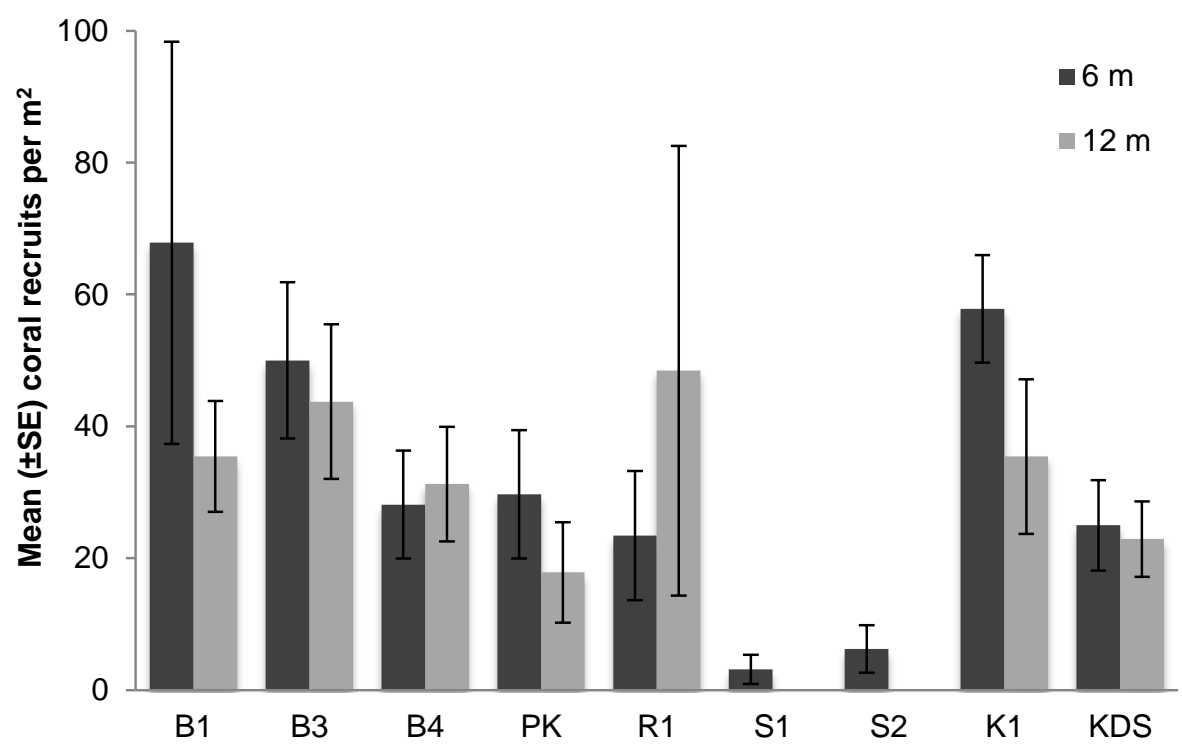

Figure 2.5 Mean ( \pm Standard Error) number of recruits per $\mathrm{m}^{2}$ found on settlement panels deployed at $6 \mathrm{~m}$ and $12 \mathrm{~m}$ from July-August 2012 to June-July 2013 at nine study sites in the Wakatobi MNP

The overall recruit abundance was significantly different across sites (PERMANOVA, df=8, $\mathrm{P}=0.02$ ), but not between depths. When looking at the assemblage composition, no significant differences in coral recruitment were found across sites (PERMANOVA, $\mathrm{df}=8, \mathrm{P}>0.05$ ) or between depths (PERMANOVA, $\mathrm{df}=7 \mathrm{P}>0.05$ ). Significant differences were found in the composition of the recruit families between the front and the back sides of the tiles, but not across depths (Table 2.3).

Table 2.3 Result of the PERMANOVA analysis for the spatial distribution of coral recruits between sites, depths and sides of the settlement panels deployed at $6 \mathrm{~m}$ for one year

\begin{tabular}{|c|c|c|c|c|c|}
\hline Factor & df & SS & MS & Pseudo-F & $\mathbf{P}$ \\
\hline \multicolumn{6}{|c|}{ Overall abundance } \\
\hline Site & 8 & 15176 & 1897 & 4.9123 & 0.0216 \\
\hline Side & 1 & 1004.2 & 1004.2 & 2.9647 & 0.1145 \\
\hline Depth (Site) & 7 & 2680.9 & 383 & 0.9721 & 0.4546 \\
\hline Site ${ }^{\star}$ Side & 8 & 6001.5 & 750.2 & 2.2201 & 0.1440 \\
\hline Depth $(\text { Site })^{\star}$ Side & 7 & 2353.7 & 336.2 & 0.8534 & 0.5444 \\
\hline \multicolumn{6}{|c|}{ Recruit assemblage } \\
\hline Site & 8 & 23813 & 2976.6 & 1.0887 & 0.3963 \\
\hline Side & 1 & 15042 & 15042 & 13.1650 & 0.0005 \\
\hline Depth (Site) & 7 & 13133 & 1876.1 & 1.6602 & 0.1145 \\
\hline Site*Side & 8 & 15097 & 1887.1 & 1.6643 & 0.1108 \\
\hline Depth $(\text { Site })^{\star}$ Side & 7 & 7910.1 & 1130 & 0.8891 & 0.6146 \\
\hline
\end{tabular}


Of the total recruits, $73.6 \%$ could be identified to family level and were from five main families: Acroporidae, Pocilloporidae, Poritidae, Agariciidae and Faviidae (see Table 2.4). The differences in the distribution of coral families between sites are shown in Figure 2.6; no obvious patterns were found in the distribution of the coral recruits between sites and depths.

Table 2.4 Percentage of total coral recruits from different families across all sites and at two depths (6 m and $12 \mathrm{~m})$, and percentage of orientation preference of overall coral recruits.

\begin{tabular}{lccccc}
\hline \multirow{2}{*}{ Coral families } & \multirow{2}{*}{ Overall } & \multirow{2}{*}{$\mathbf{m}$} & \multirow{2}{*}{$\mathbf{2} \mathbf{~}$} & \multicolumn{2}{c}{ Orientation } \\
\cline { 5 - 6 } & & & & Back side & Front side \\
\hline Acroporidae & 8.50 & 8.8 & 8.1 & 44.4 & 55.6 \\
Agariciidae & 4.71 & 5.5 & 3.7 & 70.4 & 29.6 \\
Faviidae & 15.72 & 11.5 & 21.3 & 42.6 & 57.4 \\
Pocilloporidae & 25.47 & 29.7 & 19.9 & 33.3 & 66.7 \\
Poritidae & 19.18 & 19.8 & 18.4 & 0.0 & 100.0 \\
Others & 26.42 & 24.7 & 28.6 & 16.7 & 83.3 \\
\hline
\end{tabular}

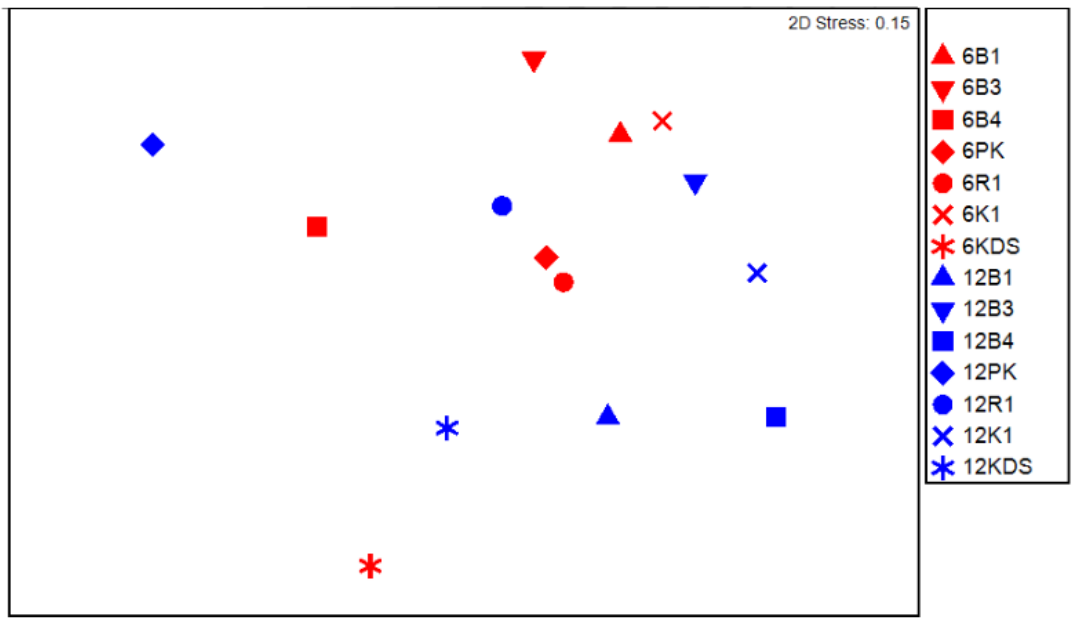

Figure 2.6 Unconstrained non-metric multidimensional scaling (nMDS) showing the differences in the distribution of coral recruit families across 9 sites and two depths in the Wakatobi MNP. The legend describes the depth at which the panels were deployed ( 6 or $12 \mathrm{~m}$ ) followed by the site. The distance between the points reproduces the distances on the Bray-Curtis matrix on a bidimensional plot, while the stress value estimate how well the configuration fit to the observed distance matrix, where 0.15 is an acceptable value.

Pocilloporidae was the most common family in the overall recruit assemblage and it was also the most abundant at both depths. In addition, recruits belonging to the Pocilloporidae were more common on the upper side of the panels across all sites and depths, while Faviidae recruits were never located on front sides. 
DistLMbest analysis explored the correlations between the coral pattern and the ecological factors distruibution across sites. The result of this analysis provided only weak evidence to support the predictor variables being responsible for the overall variability in recruit distribution as they each explained only a small amount of the variability (DistLMbest, AICc= 1439.6, $\mathrm{R}^{2}=0.11$ ). The best model explaining the spatial distribution for the overall abundance of recruits across sites included just one predictor variable, which was flow. An additional DistLMbest analysis was performed, where settlement on the front and back side of the panels was analysed separately. This was conducted in order to find which ecological factors most affected the larvae in choosing the orientation. The best model only explained $8 \%$ of the variation in the coral recruits on the front side of the panels across all sites and depths. The variables responsible were flow (4.2\%), CCA (1.5\%) and soft coral (1.3\%) (AICc=785.17, $\left.\mathrm{R}^{2}=0.08\right)$. However, the predictor variables identified in the best model as significant for the back side of the tiles were flow (5.5\%) and chlorophyll- $\alpha(0.8 \%)$, which together explained only $7.43 \%$ of the variation in recruit distribution $\left(\mathrm{AICc}=821.16, \mathrm{R}^{2}=0.07\right)$ (Table 2.5).

Table 2.5 Summary table of the result of the DistLMbest analysis for coral recruits. Each recruit pattern was explained by a different combination of variables, however they all explain just a small amount of the overall variability. The table show the AICc value, where ower values show a better fit of the data to the model; the percentage of the overall variability explained by the predictors and the contribute of each predictor; pseudo-F and P are the results of the PERMANOVA test.

\begin{tabular}{lcclcccc}
\hline \multicolumn{1}{c}{ Response } & AlCc & $\begin{array}{c}\text { \% Total } \\
\text { variation } \\
\text { explained }\end{array}$ & Predictors & $\begin{array}{c}\text { \% Variability } \\
\text { explained by each } \\
\text { predictor }\end{array}$ & Pseudo-F & P \\
\hline $\begin{array}{l}\text { Overall coral recruit } \\
\text { abundance }\end{array}$ & 1439.60 & 11 & Flow & 11 & 30.37 & 0.1136 \\
$\begin{array}{l}\text { Total recruits abundance } \\
\text { on the front sides }\end{array}$ & 785.17 & 8 & Flow & 4 & 52619 & $\mathbf{0 . 0 0 2 6}$ \\
& & & CCA & 1.5 & 19.08 & 0.1392 \\
$\begin{array}{l}\text { Total recruits abundance } \\
\text { on the back sides }\end{array}$ & 820.83 & 7 & Flow & 6 & 68.25 & $\mathbf{0 . 0 0 0 9}$ \\
& & & Chlorophyll- $\alpha$ & 1 & 10.02 & 0.3950 \\
\hline
\end{tabular}

\subsubsection{Coral juvenile surveys}

A total of 806 juveniles were recorded across all sites and depths: 451 at $6 \mathrm{~m}$ and 355 at $12 \mathrm{~m}$ (see Figure 2.6). The overall mean juvenile abundance was $9.63( \pm 0.24 \mathrm{SE})$ juv. $\mathrm{m}^{-2}$ across all sites and depths, and this value ranged from $4.20( \pm \mathrm{SE})$ juv. $\mathrm{m}^{-2}$ at $\mathrm{S} 1$ to $16.40( \pm \mathrm{SE}) \mathrm{juv} . \mathrm{m}^{-2}$ at $\mathrm{K} 1$. 


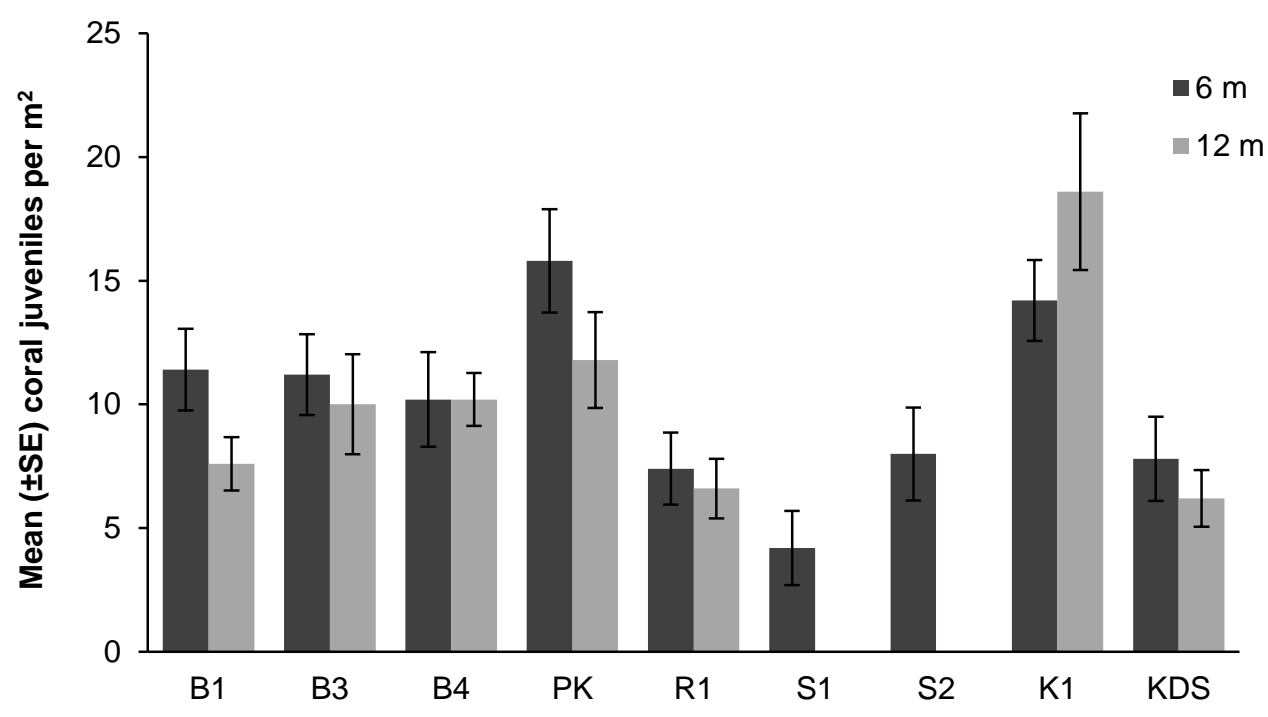

Figure 2.7 Mean ( \pm Standard Error) coral juvenile abundance per $\mathrm{m}^{2}$ at each site using 20 quadrats of $0.5 \mathrm{~m}^{2}$ deployed along a $50 \mathrm{~m}$ transect deployed at 6 and $12 \mathrm{~m}$ at nine sites in the Wakatobi MNP

There was significant variation in the abundance of coral juveniles across sites (PERMANOVA, $\mathrm{df}=8, \mathrm{P}=0.0015)$ and depths $(\mathrm{df}=7, \mathrm{P}=0.01)$ (Table 2.6).

Table 2.6 Result of the PERMANOVA analysis of the spatial variation in coral juvenile abundance between nine sites and depths (6 and $12 \mathrm{~m})$.

\begin{tabular}{lccccc}
\hline Factor & df & SS & MS & Pseudo-F & P \\
\hline Site & 8 & 7235.8 & 904.5 & 1.8867 & $\mathbf{0 . 0 0 6 1}$ \\
Depth & 1 & 2173.9 & 2174 & 4.5346 & $\mathbf{0 . 0 0 8 8}$ \\
\hline
\end{tabular}

A total of 49 genera from 15 families were found; one family was found at only three sites at $12 \mathrm{~m}$, two families were present at eight sites and six families were recorded at all the sites (see Table 2.7).

The total number of juvenile families recorded across locations ranged from 7 , found at Sampela 1 at $6 \mathrm{~m}$, to 12, found at Kaledupa 1 at both depths. The five most common families represented $71.22 \%$ of all the juveniles recorded: Agariciidae 20.84\% (2.02 $\mathrm{m}^{-2}$ across sites), Faviidae $19.85 \%\left(1.96 \mathrm{~m}^{-2}\right)$, Poritidae $13.77 \%\left(1.3 \mathrm{~m}^{-2}\right)$, Pocilloporidae $12.16 \%\left(1.17 \mathrm{~m}^{-2}\right)$ and Acroporidae $4.59 \%\left(0.44 \mathrm{~m}^{-2}\right)$ (see Figure 2.7$)$. 
Table 2.7 Diversity of juvenile corals at the nine study sites in the Wakatobi MNP. The table report the overall values by site and in the row below the values separated by depth. $\mathrm{S}=$ species number; $\mathrm{N}=$ total abundance, $\mathrm{H}$ '= Shannon-Wiener; $\mathrm{d}=$ Margalef index; J'= Pilou's evenness. Data were not collected at $12 \mathrm{~m}$ at Sampela 1 (S1) and Sampela 2 (S2) for $12 \mathrm{~m}$

\begin{tabular}{|c|c|c|c|c|c|c|c|c|c|c|c|c|}
\hline \multirow{3}{*}{ Sites } & \multirow{2}{*}{\multicolumn{2}{|c|}{$\begin{array}{c}\text { Families } \\
\text { Overall }\end{array}$}} & \multirow{2}{*}{\multicolumn{2}{|c|}{$\begin{array}{l}\text { Genera } \\
\text { Overall }\end{array}$}} & \multirow{2}{*}{\multicolumn{2}{|c|}{$\begin{array}{c}\text { Abundance } \\
\text { Overall }\end{array}$}} & \multirow{2}{*}{\multicolumn{2}{|c|}{$\begin{array}{c}\mathbf{H}^{\prime} \\
\text { Overall }\end{array}$}} & \multirow{2}{*}{\multicolumn{2}{|c|}{$\begin{array}{c}\text { d } \\
\text { Overall }\end{array}$}} & \multirow{2}{*}{\multicolumn{2}{|c|}{$\begin{array}{c}\mathbf{J} \\
\text { Overall }\end{array}$}} \\
\hline & & & & & & & & & & & & \\
\hline & $6 \mathrm{~m}$ & $12 \mathrm{~m}$ & $6 \mathrm{~m}$ & $12 \mathrm{~m}$ & $6 \mathrm{~m}$ & $12 \mathrm{~m}$ & $6 \mathrm{~m}$ & $12 \mathrm{~m}$ & $6 \mathrm{~m}$ & $12 \mathrm{~m}$ & $6 \mathrm{~m}$ & $12 \mathrm{~m}$ \\
\hline \multirow{2}{*}{ B1 } & \multicolumn{2}{|c|}{11} & \multicolumn{2}{|c|}{26} & \multicolumn{2}{|c|}{95} & \multicolumn{2}{|c|}{2.78} & \multicolumn{2}{|c|}{5.49} & \multicolumn{2}{|c|}{0.85} \\
\hline & 9 & 10 & 20 & 17 & 57 & 38 & 2.60 & 2.59 & 4.70 & 4.40 & 0.87 & 0.91 \\
\hline \multirow{2}{*}{ B3 } & \multicolumn{2}{|c|}{10} & \multicolumn{2}{|c|}{25} & \multicolumn{2}{|c|}{106} & \multicolumn{2}{|c|}{2.85} & \multicolumn{2}{|c|}{5.15} & \multicolumn{2}{|c|}{0.88} \\
\hline & 9 & 9 & 18 & 19 & 56 & 50 & 2.66 & 2.67 & 4.22 & 4.60 & 0.92 & 0.91 \\
\hline \multirow{2}{*}{ B4 } & \multicolumn{2}{|c|}{11} & \multicolumn{2}{|c|}{24} & \multicolumn{2}{|c|}{102} & \multicolumn{2}{|c|}{2.83} & \multicolumn{2}{|c|}{4.97} & \multicolumn{2}{|c|}{0.89} \\
\hline & 9 & 10 & 18 & 20 & 51 & 51 & 2.65 & 2.73 & 4.32 & 4.83 & 0.92 & 0.91 \\
\hline \multirow{2}{*}{ PK } & \multicolumn{2}{|c|}{11} & \multicolumn{2}{|c|}{26} & \multicolumn{2}{|c|}{138} & & & & & & \\
\hline & 10 & 9 & 18 & 18 & 79 & 59 & 2.54 & 2.49 & 3.89 & 4.17 & 0.88 & 0.86 \\
\hline R1 & & & & & & & & & & & & \\
\hline & 11 & 11 & 16 & 13 & 37 & 33 & 2.53 & 2.30 & 4.15 & 3.43 & 0.91 & 0.90 \\
\hline S1 & & & & & & & & & & & & \\
\hline & 7 & - & 11 & - & 21 & - & 2.28 & - & 3.28 & - & 0.95 & - \\
\hline S2 & & & & & & & & & & & & \\
\hline & 11 & - & 18 & - & 40 & - & 2.67 & - & 4.61 & - & 0.92 & \\
\hline $\mathrm{K} 1$ & & & & & & & & & & & & \\
\hline & 12 & 12 & 20 & 25 & 71 & 93 & 2.70 & 2.70 & 4.46 & 5.29 & 0.90 & 0.84 \\
\hline KDS & & & & & & & & & & & & \\
\hline & 9 & 9 & 12 & 12 & 39 & 31 & 2.22 & 2.21 & 3.00 & 3.20 & 0.89 & 0.89 \\
\hline
\end{tabular}

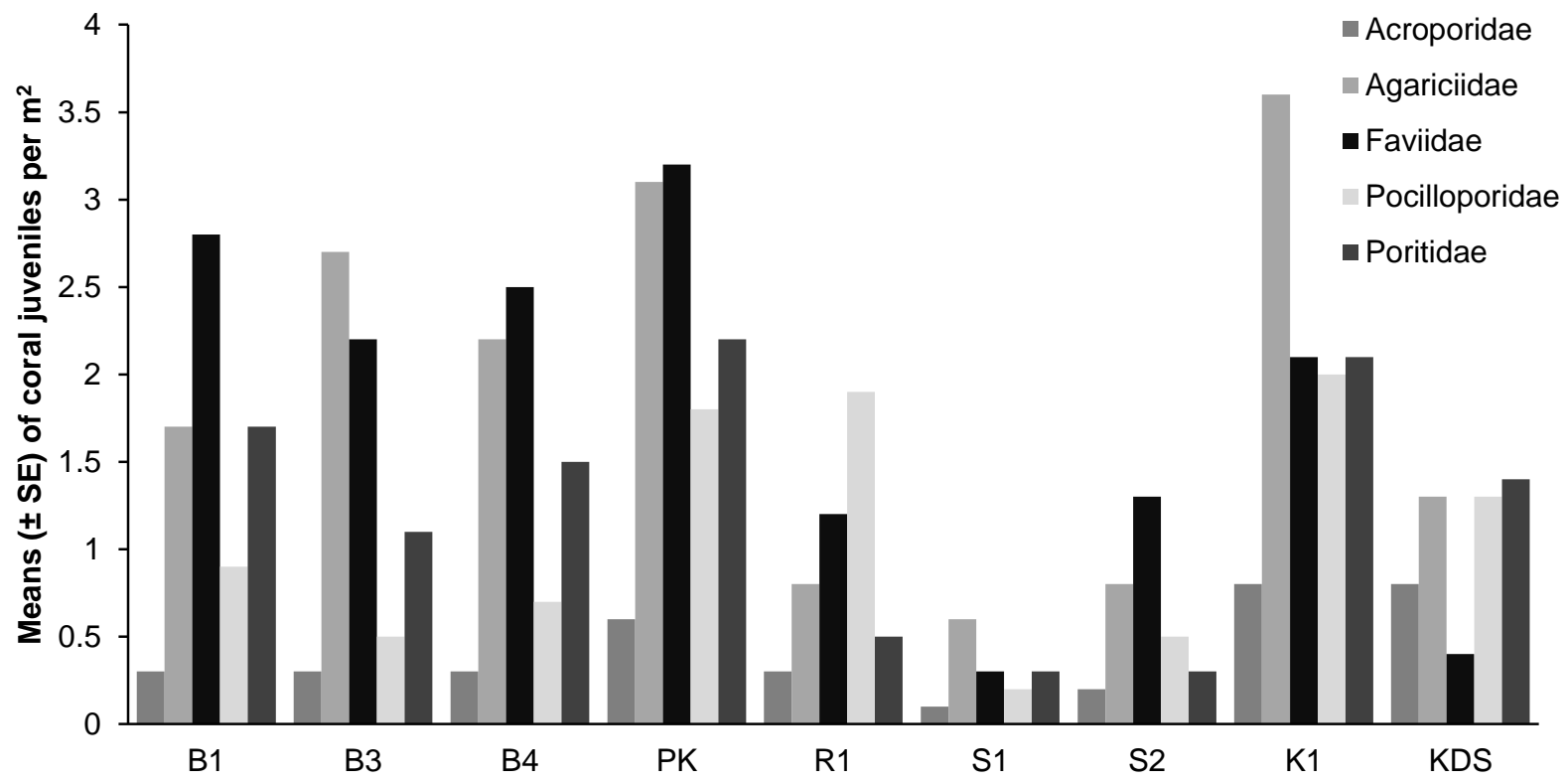

Figure 2.8 Mean ( \pm Standard Error) abundance of coral juvenile families per $\mathrm{m}^{2}$ at nine sites in the Wakatobi MNP. Data from 6 and $12 \mathrm{~m}$ depths were pooled 
Table 2.8 Result of the PERMANOVA analysis comparing the assemblage composition of coral juvenile families across nine sites and two depths, 6 and $12 \mathrm{~m}$ (nested in site)

\begin{tabular}{|c|c|c|c|c|c|c|c|c|c|c|}
\hline \multirow{2}{*}{ Families } & \multicolumn{5}{|c|}{ Site } & \multicolumn{5}{|c|}{ Depth } \\
\hline & df & SS & MS & Pseudo-F & $P$ & df & SS & MS & Pseudo-F & $P$ \\
\hline Acroporidae & 6 & 1082.7 & 180.45 & 12.8310 & 0.0082 & 7 & 98.5 & 14.06 & 0.1247 & 0.9965 \\
\hline Pocilloporidae & 6 & 3435.7 & 572.61 & 4.3399 & 0.0393 & 7 & 923.6 & 131.94 & 0.5524 & 0.7936 \\
\hline Poritidae & 6 & 2996.5 & 499.42 & 1.4636 & 0.3248 & 7 & 2388.6 & 341.23 & 1.3242 & 0.2372 \\
\hline Agariciidae & 6 & 7263.2 & 1210.5 & 1.6944 & 0.2411 & 7 & 5001.1 & 714.45 & 2.4519 & 0.0172 \\
\hline Faviidae & 6 & 7217.4 & 1202.9 & 1.9791 & 0.1937 & 7 & 4254.5 & 607.79 & 2.1543 & 0.0348 \\
\hline
\end{tabular}

Few families showed significant spatial variability across sites or among depths (see Table 2.8). Differences in the juvenile coral assemblage were found among depths (see Figure 2.9); the sites at $6 \mathrm{~m}$ were characterised by a higher abundance of all the main coral families, while sites at $12 \mathrm{~m}$.

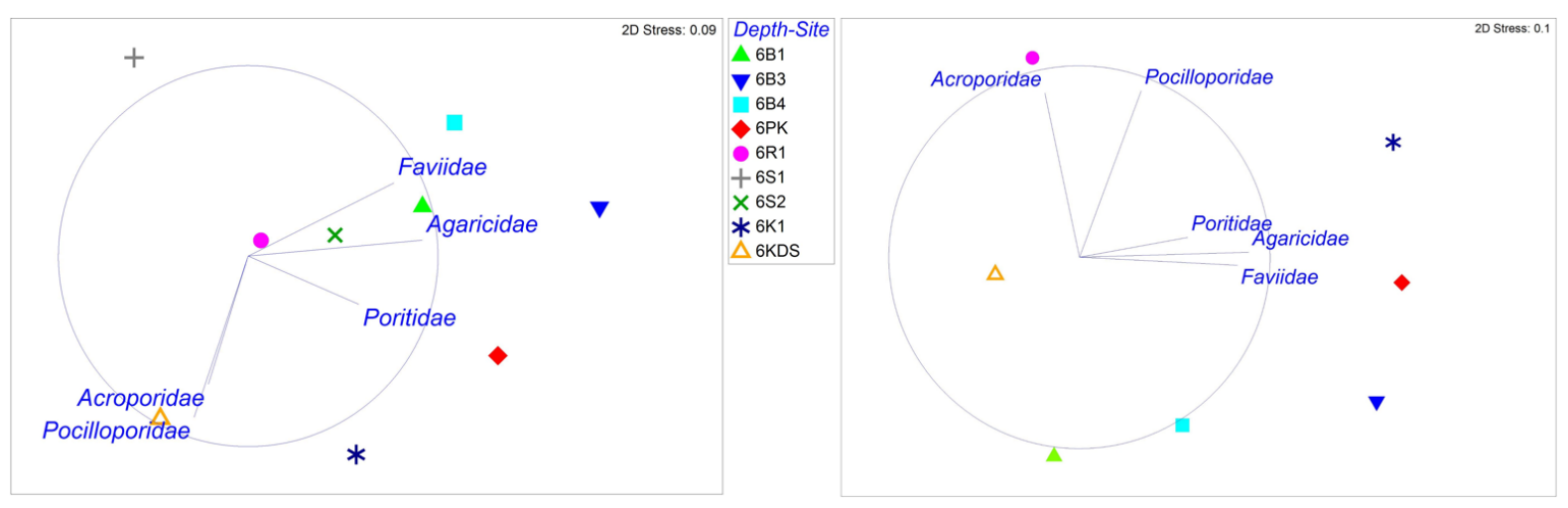

Figure 2.9 Multidimensional scaling (MDS) plot exploring the difference in the distribution of juveniles of the five main families (Pocilloporidae, Acroporidae, Poritidae, Faviidae, and Agariciidae) at $6 \mathrm{~m}$ (left hand graph) and $12 \mathrm{~m}$ (right handgraph) across sites at the Wakatobi MNP

The result of the DistLMbest analysis showed that five predictor variables were responsible for the distribution of coral juveniles across sites, but they only explained $6.5 \%$ of the spatial variability (see Figure 2.9). These predictors were water flow rate (1.94\%), temperature (1.65\%), soft coral abundance (1.57\%), algal abundance (1.54\%) and CCA abundance (1.54). Three more variables were found to have a weak significant correlation with the juvenile variability, although they were not included in the best model; they were corallivorous fish abundance $(1.54 \%)$, sediment rate $(1.50 \%)$ and sponge abundance $(1.25 \%)$. 


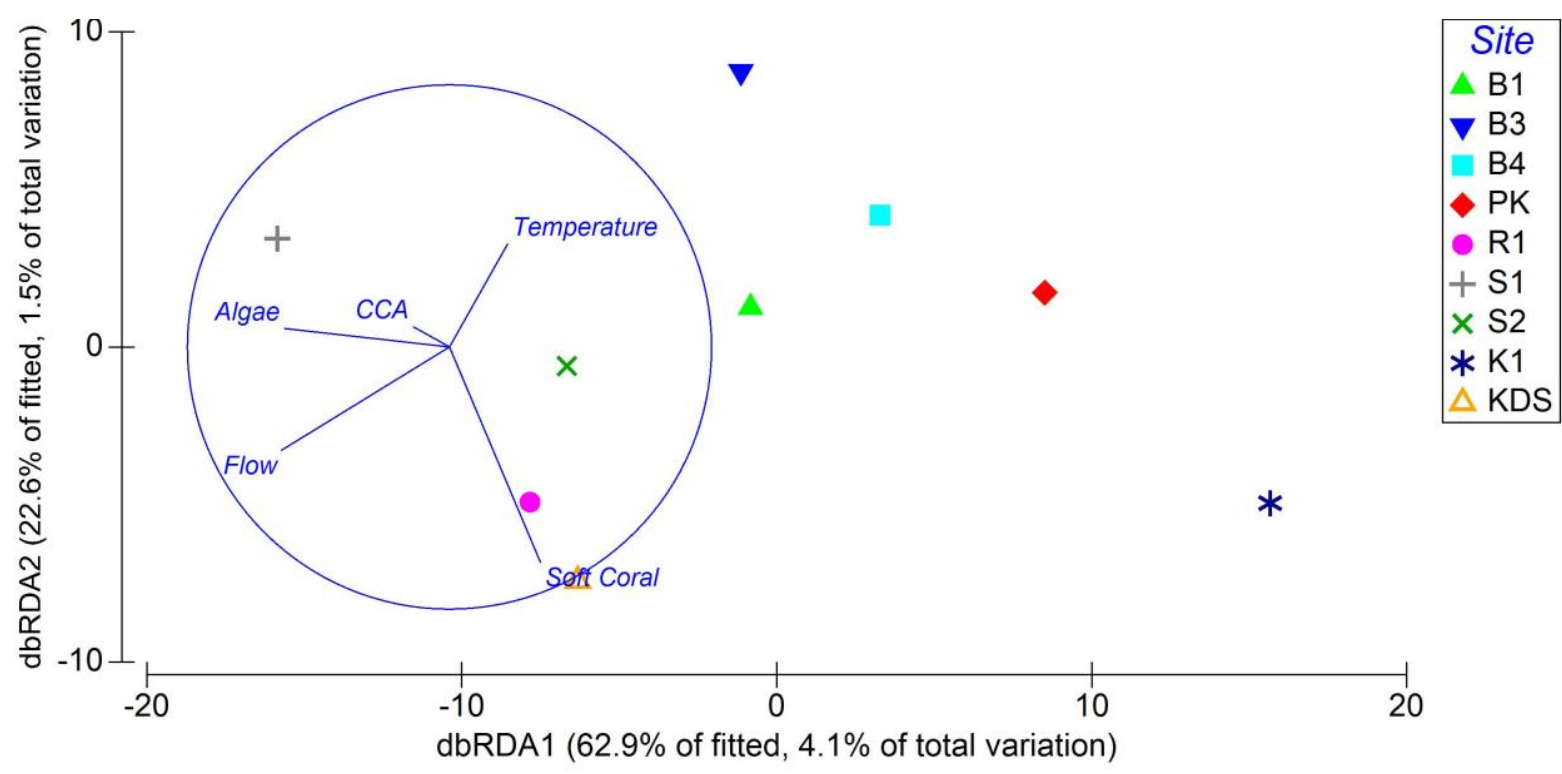

Figure 2.10 Distance-based redundancy analysis (dbRDA) plot visualising the fitted model for coral juvenile abundance pattern with the lowest AICc

Table 2.9 Summary of the result of the DistLMbest analysis at family level for coral juveniles. Each coral family pattern was explained by a different combination of variables. For every group of coral juvenile family or single families, listed in the 'Response' column, is showed the model that fit better with low AICc value and the percentage of juvenile distribution explained by the model. Predictor column lists the factors included in the best model and their contribution to the overall model

\begin{tabular}{|c|c|c|c|c|c|c|}
\hline Response & AICc & $\begin{array}{c}\text { \% Total variation } \\
\text { explained }\end{array}$ & Predictors & $\begin{array}{c}\% \text { variability } \\
\text { explained by each } \\
\text { predictor }\end{array}$ & $\begin{array}{l}\text { Pseudo- } \\
\text { F }\end{array}$ & $\mathbf{P}$ \\
\hline \multirow[t]{4}{*}{$\begin{array}{l}\text { Main coral juvenile } \\
\text { families abundance }\end{array}$} & & & Temperature & & & 0.0032 \\
\hline & & & Sedimentation & & & 0.0049 \\
\hline & & & Quadrat angle & & & \\
\hline & & & Fish & & & \\
\hline Acroporidae & 1488.8 & 2.5 & Fish & 2.5 & 8.18 & 0.0038 \\
\hline \multirow[t]{3}{*}{ Agariciidae } & 1833.9 & 7.1 & Temperature & 3.3 & 10.73 & 0.0012 \\
\hline & & & Algae & 3.2 & 10.50 & 0.0001 \\
\hline & & & Flow & 2.7 & 7.36 & 0.0077 \\
\hline \multirow[t]{4}{*}{ Faviidae } & 1023.8 & 8.4 & Flow & 3.6 & 11.83 & 0.0002 \\
\hline & & & Soft coral & 0.4 & 149.19 & 0.2238 \\
\hline & & & CCA & 0.2 & 1.55 & 0.2146 \\
\hline & & & Fish & 0.1 & 2.86 & 0.0875 \\
\hline Pocilloporidae & 1733.4 & 4.7 & Soft coral & 4.7 & 15.86 & 0.0002 \\
\hline \multirow[t]{2}{*}{ Poritidae } & 1763.0 & 3.6 & Flow & 2.5 & 8.14 & 0.0046 \\
\hline & & & Temperature & 0.1 & 2.98 & 0.0850 \\
\hline
\end{tabular}


The results of the DistLMbest analysis for the five main families and the factors explaining their distribution are shown in Table 2.9. The best model for each analysis includes many variables, but never explains more than the $8 \%$ of the spatial variability across sites.

\subsection{Discussion}

In this chapter I explored the spatial variability in coral early life history stages and the factors that explained these patterns in the Wakatobi MNP. The population dynamics of young corals are very important in maintaining reef health (Babcock \& Mundy 1996; Ritson-Williams et al. 2009a). Physical and biological factors are thought to drive the recruitment process at local scales and, especially in the post-settlement phase, these factors influence the abundance and patterns of coral recruits and juveniles, which subsequently shapes the adult population (Miller \& Weil 2000; van Woesik \& Jordán-Garza 2011). However, few studies have examined the interaction of multiple factors at different stages of coral recruitment (but see Raimondi \& Morse 2000; Davies et al. 2013; Trapon et al. 2013a). I found significant variability in recruit abundance across sites, but not between depths, and there was a preference for settling on the back side of the panels; however, no single predictor variables I measured adequately explained the distribution and abundance of coral recruits. Coral juvenile abundance and assemblage composition were significantly different across sites and depths, and a shift in assemblage composition occurred between the two life history stages. However, once again the interaction of several variables only explained a small amount of the variability.

My results showed small-scale variability in coral recruit abundance between sites with different habitat characteristics but were unable to identify any factor or combination of factors that explain the variability. The results suggest that other factors not considered here may explain the variability and should be examined in the future, such as nutrients availability. The identification of the main factors influencing coral recruitment will be important in planning future specific management actions at each site in order to increase the recruitment rate, especially in sites with low adult coral abundance.

\subsubsection{Role of ecological factors in coral recruitment}

The overall coral recruitment rate was $67.5( \pm 7.79)$ rec. $\mathrm{m}^{-2}$, which is lower than rates reported at other sites in the Indo-Pacific area (Dunstan \& Johnson 1998; Reyes \& Yap 2001; Quinn \& Kojis 2008; Green \& Edmunds 2011; Penin \& Adjeroud 2013; Ho \& Dai 2014); the mean recruit abundance at each site varied widely and the spatial variability was significant across 
sites. Despite this there was no significant difference in recruit abundance among depths, but at Kaledupa recruits were slightly more abundant at $6 \mathrm{~m}$ than in deeper waters, which is consistent with earlier studies where recruit abundance has been negatively correlated with depth (e.g. Quinn \& Kojis 2008; Ho \& Dai 2014).

The recruit families identified were found at most of the sites, although the taxonomic composition was highly variable; Pocilloporidae was the most abundant family at all the sites. This family is also dominant in other areas of the Coral Triangle, such as in Komodo (Fox 2004) and in the Philippines (Reyes \& Yap 2001), but not in Bunaken (Schmidt-Roach et al. 2008).

It was not possible to identify a dominant factor or a combination of factors that explained the variability found across sites by modelling the overall recruit abundance; none of the twelve variables analysed were included in the best model and each individual variable explained only a very small proportion of the recruit variability. In comparison to Salinas De León et al. (2012a) study, I did not observe the correlation between coral coverage, sedimentation rate, predation and recruitment rate found by, but I also found that overall sites characterised by high coral cover also had high recruitment rates.

The absence of a correlation between coral cover and recruitment rate has also been found in other studies in the Pacific area and it has been proposed that other processes regulate recruitment (Quinn \& Kojis 2003; Fox 2004; Penin \& Adjeroud 2013), for example mortality in the early days following settlement. High mortality occurs within the first 24 hours after coral recruit settlement. Martinez \& Abelson (2013) found that approximately 44\% of coral recruits do not survive the first day and only the $8-13 \%$ of the corals survive the first three months after settlement, however these values are influenced by local factors and different processes (Wilson \& Harrison 2005). Most recent investigations on recruitment have examined populations that have already been affected by local disturbances, which may explain the lack of correlation between coral cover and recruitment rate.

Recruitment in the Wakatobi occurs throughout the whole year, although the main spawning peak is thought to be between November and March, during the wet season (Salinas De León et al. 2012a). It is likely that if I had collected the settlement panels immediately after the peak season I would have found higher recruitment rates and potentially a correlation with the coral cover. Salinas De León et al. (2012a) suggested that sedimentation and predation explained the distribution and orientation of the recruits in the Wakatobi; the authors only found a few 
recruits on the front side of their panels, which were covered by turf algae and sediment and easily accessed by grazers and predators. In my study I found $36 \%$ of recruits on the front side of the panels; in addition two families showed a consistent preference with respect to orientation: Pocilloporidae settled mostly on the front side of the panels, Faviidae was only found on the back side; the other families had a preference for the back side. The higher abundance of recruits found on the exposed surface of the panels might be explained by a decline in predator abundance since the study by Salinas De León et al. (2012a) carried out between 2007 and 2009. This is supported by a recent study on fish populations in the Wakatobi conducted by Curtis-Quick (2013), who reported a decline of fish abundance at all my study sites between 2001 and 2012.

To date only a few studies have reported recruits settling on the front, or upper, side of panels (e.g. Nakamura \& Sakai 2009), and usually recruit abundance is too low to be considered relevant (e.g. Harriott \& Fisk 1988; Kuo \& Soong 2010; Salinas De León et al. 2012a). However, some studies have found patterns consistent with my study; for example Fox (2004) reported differences in preference for orientation in different families. In her study Acroporidae preferred to settle mostly on upper surfaces while Pocilloporidae was mostly found in the gap between panels and the reef. Recently, Ho \& Dai (2014) found that 53\% of the recruits settled on the top (front) side of the panels and this preference was negatively correlated with depth. They suggested that the driver of recruit distribution was likely to be light availability, which has also been proposed in similar studies (Rogers et al. 1984; Babcock \& Mundy 1996; Adjeroud et al. 2007a). However in my study, turbidity, strictly connected to light availability, was not identified by the DistLMbest as a potential predictor of coral pattern variability, suggesting that light might have a small or none role.

The presence of other benthic organisms is likely to influence recruit distribution. In my survey, the back side of the panels were covered by benthic organisms such as ascidians, bryozoans, sponges, molluscs and CCA. Some of these organisms, like CCA, have been previously found to increase the recruitment rate (Raimondi \& Morse 2000; Price 2010), while others are competitors for space and can grow faster than the recruits (Birkeland 1977; Birrell et al. 2005; Vermeij 2005; Box \& Mumby 2007; Benzoni et al. 2011). On the back side of the panels I observed recruits overgrown by CCA and sponges, similar to previous studies (e.g. Wilson \& Harrison 2005; Vermeij 2006). When recruit skeletons were found completely covered by other organisms, it was not possible to assess if the recruits had died before or after being overgrown as the skeleton was only detected after bleaching the panels for examination. An additional 
study is recommended to identify the causes of death of these corals in order to assess the effects of the individual disturbances on the recruit population.

In general, considering the overall disturbance present at each site, an explanation for the correlations between physical and biological variables and recruit distribution found by Salinas De León et al. (2011, 2012b), but not observed in my study, could be that the two reef systems used in the previous study represented two very different habitats; one reef had been heavily affected by disturbance while the other was moderately healthy. In my study I included more reefs across a broader environmental gradient.

In conclusion, I found that recruit abundance was variable across sites, but not depth, and that the ecological variables considered in this study did not explain very much of the variation in coral recruit abundance between sites. The orientation of the recruits suggests that future studies should include other variables in the analysis, such as nutrients availability (Weber et al. 2006; Risk 2014).

\subsubsection{Coral juvenile abundance patterns across sites and depths}

The overall density of juveniles across sites was among the lower values previously found in the Indo-Pacific (Roth \& Knowlton 2009; Salinas De León et al. 2012a) and it was variable both with respect to abundance and in family assemblage composition across sites and depths. The juvenile population diversity was high at most of the sites. Low diversity was found at Sampela 1, however, the 21 juveniles found at this site belonged to 11 different genera, suggesting that despite the low coral abundance, diversity was still moderate in the area.

As expected, the density of juveniles was much lower than the density of recruits; it changed from $112.97( \pm 11.16 \mathrm{SE}) \mathrm{m}^{-2}$ to $9.63( \pm 0.24 \mathrm{SE}) \mathrm{m}^{-2}$, presumably as a result of mortality (Penin et al. 2010; Salinas De León et al. 2012a). However, this decline will be an underestimate as the colonies counted in the juvenile surveys will have settled in different years and they do not represent the survival of a unique year of recruitment, as juveniles probably included colonies up to 2-4 years old, depending on the growth rate of each species (Schmidt-Roach et al. 2008). I found some evidence for differential mortality based on the variation in taxa assemblage composition, the dominant family being Pocilloporidae at the recruit stage with Agariciidae and Faviidae more common at the juvenile stage. Similar changes in coral assemblages in early life history stages have also been reported from Moorea (Penin et al. 2010) and Fiji (Quinn \& Kojis 2008). This shift can be explained by the characteristics of the Pocilloporidae family. This family has long-lived larvae and a high settlement rate, which is then followed by high 
mortality in the post-settlement phase. Other families are likely to produce fewer larvae and grow slower, but seem to be more resistant to disturbance.

When modelling the overall juvenile abundance, the interaction of different variables again explained only a small portion of the variation in the dataset, and no variable was found to be particularly important. A similar result was found when I analysed the five main families individually, where more predictor variables explained the variation in pattern. However, these variables differed for each family and the total amount of variability explained was always lower than $6.5 \%$, with most of the variability being unexplained. The absence of a higher correlation between the juvenile variability and the factors analysed might be due to the variable measurements. Data on the ecological factors, as described in the methods section, were collected over a limited time period and these values do not consider temporal variation, such as seasonal fluctuations (likely to affect temperature and sedimentation), and inter-annual variation. For example, during the wet season, after heavy rains sedimentation on the reef tends to increase as sediments are transported from inland to the reef. Moreover, measurements were taken just at one intermediate depth between the two depths used in this study for coral surveys, so the final data analysis was conducted by compiling the data from two different depths at the same sites. However, in order to even out some of this variability, the environmental variables were measured at different days and times.

In conclusion, I found that there was significant variation in the abundance pattern of corals at early life histories across sites, but it was not possible to find an overall model that explained the variation in density and the shift in taxonomic composition. Light availability was not included in this study and it is likely is not important in determining the coral recruitment pattern, although based on previous research it could have a role in recruit distribution (Mundy \& Babcock 1998b; Ho \& Dai 2014). Furthermore, to better analyse the relationship between young coral abundance patterns and local environmental factors, more measurements of the variables should be conducted throughout the year to assess their variation. 
Chapter 2 Spatial variability in patterns of coral recruitment 


\section{Chapter 3 Temporal variability in coral recruitment in the Wakatobi Marine National Park, Indonesia}

\subsection{Abstract}

Temporal variation in physical and biological factors, such as temperature and predation, can have strong effects on the abundance of shallow water coral fauna. Scleractinian corals have a primary functional role on coral reef and any variation in coral cover might influence recruitment rates, which are an important driver of population maintenance, for some coral species. Understanding temporal variation in coral recruitment patterns is important for effectively managing coral reefs. The main goal of the study described in this chapter was to investigate temporal variation in coral recruitment rates over a two-year period in the Wakatobi Marine National Park (Indonesia) at 1) sites with different environmental characteristics; and 2) two reef systems with different environmental conditions (Hoga and Sampela) over a seven year period, pooling data from previous study by Salinas De León et al. (2012a) in order to detect any temporal patterns in recruitment rates. In addition, surveys on juvenile corals were conducted at the same sites in order to assess any variation in assemblage composition between the recruit and juvenile stages. There was no significant temporal variation in coral recruitment patterns between sites with different environmental characteristics $(\mathrm{df}=1, \mathrm{P}>0.05)$, however spatial variation was evident $(\mathrm{df}=1, \mathrm{P}=0.003)$ and differences in assemblage composition between sites was consistent between years in the two-year study across many sites $(\mathrm{df}=1$, $\mathrm{P}=0.007)$. In the seven-year dataset at the two reefs, temporal and spatial variation in recruitment rate and assemblage composition was found $(\mathrm{df}=8, \mathrm{P}<0.005)$. The annual variation in recruitment rates between the two reefs was not consistent; Hoga had higher recruitment rates than Sampela in all the years of the study. Temporal and spatial variability was found in juvenile abundance between reefs $(\mathrm{df}=3, \mathrm{P}<0.05$, and $\mathrm{df}=1, \mathrm{P}<0.05)$ and there was a shift in assemblage composition over the course of the study. These results represent useful information to reef management in order to foreseen and prevent abnormal changes in the coral population, and allow the identification of the areas more important for coral recruitment.

\subsection{Introduction}

In recent decades climate change, ocean acidification, and localised anthropogenic activities, such as fishing, industrial development and tourism, have affected marine ecosystems 
worldwide (Hoegh-Guldberg et al. 2007). These activities produce ecosystem changes that can lead to the degradation of habitats and loss of diversity. Changes in ecosystems can affect not only local human communities, whose livelihoods are often based on marine resources, but also the global economy (Burke et al. 2012). For these reasons, it is important to understand changes that are occurring in the marine environment by monitoring key species and investigating the factors that affect their survivorship in order to conserve threatened ecosystems (Bellwood et al. 2004; Hoegh-Guldberg et al. 2007).

Environmental variation in marine ecosystems can cause changes in the abundance and composition of communities (van Woesik \& Jordán-Garza 2011). While some of these effects can be detected immediately, such as mortality, others are more subtle, especially when reproduction is disturbed. The consequences of disturbance can manifest months or even years later, depending on the reproductive frequency and growth rate of the organisms affected. Corals are one such taxa whose reproduction strongly depends on environmental conditions (Ritson-Williams et al. 2009a).

Corals are one of the main reef-building organisms in tropical marine ecosystems, and therefore any changes in population structure or survivorship will have an impact on the overall reef ecosystem (Bruno \& Selig 2007). Understanding inter-annual variation in coral populations is important for preventing reef degradation and managing reefs effectively. Coral recruitment has been recognised as a key process for coral reef maintenance, as the supply of new recruits maintains coral populations. However, as coral reproduction is strongly influenced by environmental variability there can be considerable temporal variability in recruitment patterns and subsequently coral assemblage structure (Ritson-Williams et al. 2009a).

Previous studies that have investigated temporal variation in coral recruitment have examined variation in density and assemblage composition between reefs of different typologies (e.g. fore-reef, back-reef, lagoon) and over different temporal scales (Fisk \& Harriott 1990; Dunstan \& Johnson 1998; Soong et al. 2003; Glassom et al. 2004). Considerable inter-annual variation was observed for coral recruitment, ranging from little to no variation to recruitment rates varying up to five times higher or lower between consecutive years. The variability in recruitment occurring between years and areas was characterised by different environmental conditions (e.g. Dunstan \& Johnson 1998; Edmunds 2000b; Soong et al. 2003; Glassom et al. 2004; Adjeroud et al. 2007a; Green \& Edmunds 2011). 
Coral gamete production, which is correlated with the reproductive mode of the corals (brooding or spawning) is subjected to strong seasonality (Edmunds 2000a; Ho \& Dai 2014). One previous study found that recruitment patterns were consistent across years for brooding species and more variable for broadcast spawners, depending on the time of spawning, larval dispersal, and larval duration (Dunstan \& Johnson 1998). Peak gamete release into the water usually occurs during the summer, when the warmer water temperature triggers reproduction and promotes higher gamete production; however, fecundity and recruitment rate are not linearly correlated (Hughes et al. 1999a, 2000; Edmunds 2000a).

Several environmental factors have been associated with temporal variation in coral recruitment rates, and particularly for specific coral families, including temperature (Edmunds et al. 2010; Green \& Edmunds 2011; Ho \& Dai 2014), water motion (Fisk \& Harriott 1990; Edmunds et al. 2010; Green \& Edmunds 2011), light availability (Ho \& Dai 2014), and competition with other benthic organisms, such as bryozoans, oysters, serpulids (Dunstan \& Johnson 1998; Glassom et al. 2004), turf algae and macroalgae (Edmunds 2000a). There is spatio-temporal variability at a range of spatial scales, from local to regional (Adjeroud et al. 2007a). In addition, recruitment rates vary at the same scale as environmental gradients (Adjeroud et al. 2007a; Green \& Edmunds 2011).

Most of the studies on temporal variation in coral recruitment have been based on data collected over two to four years. These studies found temporal variation in recruitment rates, but they did not cover a period of time sufficient to detect any recurrent patterns. For this reason, gather and compare results from different studies conduct in the same area in different times allow to investigate fluctuation and trends of coral recruitment. The importance of understanding how coral recruitment rate varies in time and how this variability affects reef maintenance is of primary important for coral reef management, however little is known about it. Therefore it is important to conduct longer-term surveys to allow fluctuations in coral recruitment rates to be detected and to further understand natural patterns of variability.

This study investigated temporal variability in coral recruit and juvenile abundance in order to assess any differences in variation between corals of different life histories and sizes. Understanding patterns of inter-annual variation in recruitment and survival of juvenile corals is important for understanding and managing coral reefs effectively. My study was conducted in the Wakatobi Marine National Park (WMNP; South Sulawesi, Indonesia. Coral reefs in this region are characterised by a range of different environmental conditions and have experienced 
different degrees of degradation. Over the last decade the overall coral cover in the Wakatobi has declined by $31.05 \pm 1.59 \%$, and in some areas, coral cover has decreased by up to $83 \%$ of initial cover (Curtis-Quick 2013).

Salinas De León et al. (2012a) measured temporal variation in coral recruitment in the Wakatobi between 2007 and 2009. Their study monitored two reef systems with different coral cover and quality for two consecutive years and found that overall recruitment rates were higher in the second year and that there was seasonality in recruitment rate, which was similar at both reefs, but with lower rates at the more degraded site. In all sampling seasons, the recruitment rates were always higher at the higher-quality reef, suggesting that rates were likely to be correlated with coral cover and with the level of impact by disturbance. Based on Salinas De León et al. (2012a), if coral cover is correlated with coral recruitment rates then decreases in coral cover, such as the coral decline that occurred in the Wakatobi between 2002 and 2011, should result in reduced coral recruitment. However, these authors found recruitment rates between 2007 and 2009 were twofold higher in the second year of the study. These outcomes highlight our poor understanding of the temporal variability in recruitment rates and the effects of the environmental conditions on coral recruitment.

In this study I conducted surveys to investigate the temporal variation in coral recruitment rate and assemblage composition 1) across a range of sites with different environmental conditions over two consecutive years (see Chapter 2); and 2) between two reef systems representing reefs of different qualities over a seven-year period. For the second survey I also collected data on the abundance and assemblage composition of coral juveniles in order to assess any temporal variability at different coral life stages.

\subsection{Methods}

\subsubsection{Study site}

This study was conducted in the Wakatobi MNP (see Chapter 2 for further site details), which lies between the Indian and the Pacific oceans. Species from both oceans co-exist, resulting in particularly high biodiversity. The Indo-Pacific region is characterised by the wet season, which occurs from October to March, with an average water temperature in the Wakatobi of $28.9^{\circ} \mathrm{C}$, and the dry season, from April to September, with an average temperature of $27.2^{\circ} \mathrm{C}$ (Crabbe \& Smith 2005). 
The nine sites used in this survey were located in the middle of the Wakatobi Archipelago, on two different reef systems, Hoga and Kaledupa (see Chapter 2 for a map of the sampling sites). The sites are located along the Hoga and Kaledupa Islands. The minimum distance between sites on the same reef was $200 \mathrm{~m}$, while the furthest distance between sites was $5 \mathrm{~km}$. Sites to the south of Kaledupa, including Sampela 1 and 2, are degraded and have been overexploited by human activities (particularly coral mining and overfishing). Overall, the sites are characterised by differences in exposure to waves and currents, topology, substratum composition, benthic community composition, rugosity and sedimentation rates (see Chapter 2 for full details).

\subsubsection{Recruit and juvenile surveys}

The data used for this study were collected from three different sources. Data from 2011-2013 were collected by myself; data from 2007-2008 were collected by Salinas De León (published in Salinas De León et al. 2011, 2012a) and data from 2014 are part of the ongoing monitoring program (Operation Wallacea, unpublished data) (Table 3.1).

Temporal variation was analysed a) between the nine sites experiencing different environmental variables across two years and b) between two reef systems with two replicate sites each: Hoga (replicate sites are Buoy 3 and Buoy 4) and Sampela (Sampela 1 and Sampela 2) over a seven-year period.

Table 3.1 Coral recruit and juvenile data collection by year and number of sites surveyed in the Wakatobi MNP. Data from 2008 and 2009 were collected by Salinas De León et al. (2011, 2012a); data from 2014 were collected by Operation Wallacea.

\begin{tabular}{|c|c|c|c|c|c|c|c|}
\hline & 2008 & 2009 & $\ldots$ & 2011 & 2012 & 2013 & 2014 \\
\hline \multicolumn{8}{|l|}{ Coral recruits } \\
\hline $\begin{array}{l}9 \text { sites } \\
\text { (Short-term) }\end{array}$ & & & & & This study & This study & $\begin{array}{c}\text { Operation } \\
\text { Wallacea } \\
\text { (6 sites) }\end{array}$ \\
\hline $\begin{array}{l}\text { Hoga and Sampela } \\
\text { (Long-term) }\end{array}$ & $\begin{array}{l}\text { Salinas De León } \\
\text { et al. } 2011\end{array}$ & $\begin{array}{l}\text { Salinas De León } \\
\text { et al. } 2012\end{array}$ & & & & & \\
\hline \multicolumn{8}{|l|}{ Coral juveniles } \\
\hline Hoga and Sampela & & $\begin{array}{l}\text { Salinas De León } \\
\text { et al. } 2012\end{array}$ & & This study & This study & This study & \\
\hline
\end{tabular}

Settlement panels were used as the sampling unit in the data analysis. In the short-term (20122013) survey, the data were also compared between the sites while for the long-term survey (data collected between 2008 and 2014) the data were analysed at reef system level with two replicate sites per reef. 
Recruit and juvenile surveys followed the same data collection methodology described in Chapter 2. Settlement panels were used to collect recruit data and were deployed at $6 \mathrm{~m}$ depth in July-August each year the study was conducted and collected in June-July of the following year. Juvenile data were collected using $20 \times 0.25 \mathrm{~m}^{2}$ quadrats placed haphazardly along a 50 $\mathrm{m}$ transect at $6 \mathrm{~m}$ depth. All the coral colonies less than $40 \mathrm{~mm}$ in length were considered juveniles (after Bak \& Engel 1979; Edmunds 2000a) and identified to family or genus where possible. The main recruit and juvenile families identified were Acroporidae, Pocilloporidae and Poritidae; Agariciidae and Faviidae were identified only at juvenile level. All the other colonies were grouped in an 'Other' category.

\subsubsection{Data analysis}

Temporal variability in recruitment and juvenile abundance and assemblage composition data were analysed in the PRIMER v.6 (Plymouth Marine Laboratory, UK) environment. Data were first normalized and transformed by square root, then analysed with a PERMANOVA based on a Bray-Curtis dissimilarity matrix. For the long-term survey, three factors were used: year (random), reef (fixed), and site nested in reef. For the short-term survey only two factors were used: year (random) and site (fixed); reef was not considered a relevant factor for this analysis as the nine sites were considered independent from each other due to the differences in their environmental characteristics.

Multidimensional Scaling (MDS) was used on the Bray-Curtis dissimilarity matrix to investigate the differences in the coral recruit assemblage across years at each site. Variability in coral population assemblage composition was investigated by comparing the relative percentage of the main coral families at each reef system for each year.

\subsection{Results}

\subsubsection{Short-term recruitment survey: Temporal variability in coral recruitment over two years}

Overall, 127 recruits were recorded at $6 \mathrm{~m}$ depth in 2012 and 181 in 2013, while the overall mean values were $45.44( \pm 12.23 \mathrm{SE})$ rec. $\mathrm{m}^{-2}$ and $64.08( \pm 9.69 \mathrm{SE})$ rec. $\mathrm{m}^{-2}$, respectively. Values ranged from $78.12( \pm 27.75 \mathrm{SE})$ rec. $\mathrm{m}^{-2}$ found at $\mathrm{B} 3$ to $21.83( \pm 6.9 \mathrm{SE})$ rec. $\mathrm{m}^{-2}$ at $\mathrm{S} 2$ in 2012 and $135.71( \pm 30.50 \mathrm{SE})$ rec. $\mathrm{m}^{-2}$ found at $\mathrm{B} 1$ and $6.25( \pm 2.20 \mathrm{SE})$ rec. $\mathrm{m}^{-2}$ at $\mathrm{S} 1 \mathrm{in}$ 2013 (Figure 3.1). When analysing the recruit abundance at each site individually, there was 
no significant temporal variability between the two years (PERMANOVA, $\mathrm{df}=1, \mathrm{P}>0.05$ ). However, significant spatial variability was found in overall recruit abundance (PERMANOVA, $\mathrm{df}=1, \mathrm{P}=0.0023$ ) and assemblage composition (PERMANOVA, $\mathrm{df}=1$, $\mathrm{P}=0.0001$ ) across sites in both years (Table 3.2).

Table 3.2 Result of the PERMANOVA analysis for the spatial distribution of coral recruits between two years (2012 and 2013) and nine sites in the Wakatobi MNP

\begin{tabular}{lrrrrc}
\hline \multicolumn{1}{c}{ Factor } & df & SS & MS & Pseudo-F & P \\
\hline $\begin{array}{l}\text { Recruit abundance } \\
\text { Year }\end{array}$ & 1 & 371.9 & 371.9 & 1.1308 & 0.2940 \\
Site & 8 & 15192 & 1899.1 & 8.7364 & $\mathbf{0 . 0 0 2 3}$ \\
Year*Site & 8 & 1739 & 217.4 & 0.6610 & 0.7488 \\
Recruit assemblage & & & & & \\
Year & 1 & 419.8 & 419.8 & 0.4435 & 0.6909 \\
Site & 8 & 24155 & 3019.3 & 3.4859 & $\mathbf{0 . 0 0 0 1}$ \\
Year*Site & 8 & 7572.8 & 946.6 & 1.0929 & 0.3689 \\
\hline
\end{tabular}

The pattern of recruitment rates across sites was not consistent between years. In 2012 the highest recruitment rate was found at Buoy 3, followed by Buoy 4 and Kaledupa 1, while in 2013 the highest values were recorded at Buoy 1 followed by Buoy 3 and Kaledupa 1. The sites at Sampela had the lowest recruitment rates in both years. Pak Kasim's, Ridge 1 and Kaledupa Double Spur had similar recruitment rates over time (Figure 3.1). However, the variation in recruitment rates at the same site between different years was variable; one site (Buoy 1) recorded an increase in rates between 2012 and 2013, while at all the other the rates decreased. 


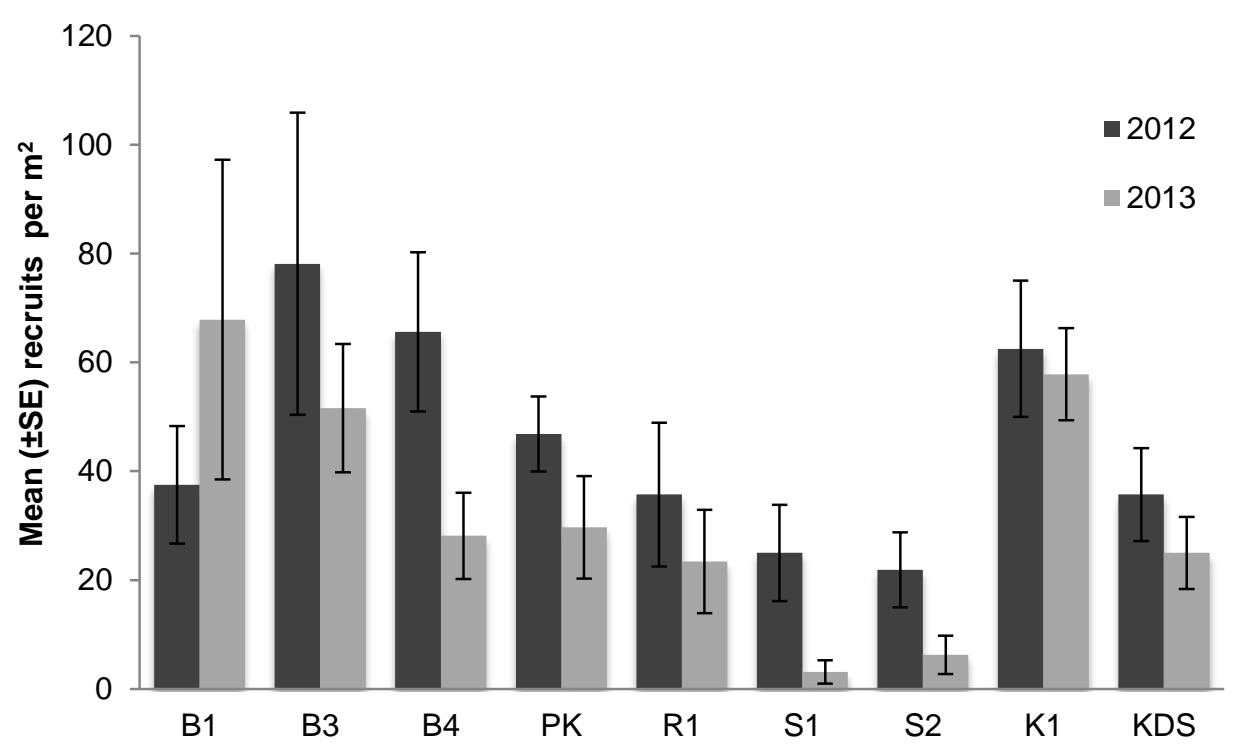

Figure 3.1 Mean $\left( \pm\right.$ Standard Error) recruitment rates per $\mathrm{m}^{2}$ recorded on settlement panels deployed for 12 months in 2012 and 2013 in the Wakatobi MNP (Indonesia) across nine sites (see Figure 1 in Chapter 2 for the information about the abbreviations used in the legend)

The MDS plot showed no clear difference in coral recruit assemblage composition sites across years, and assemblage composition remained similar at each site over the two-year period (Figure 3.2).

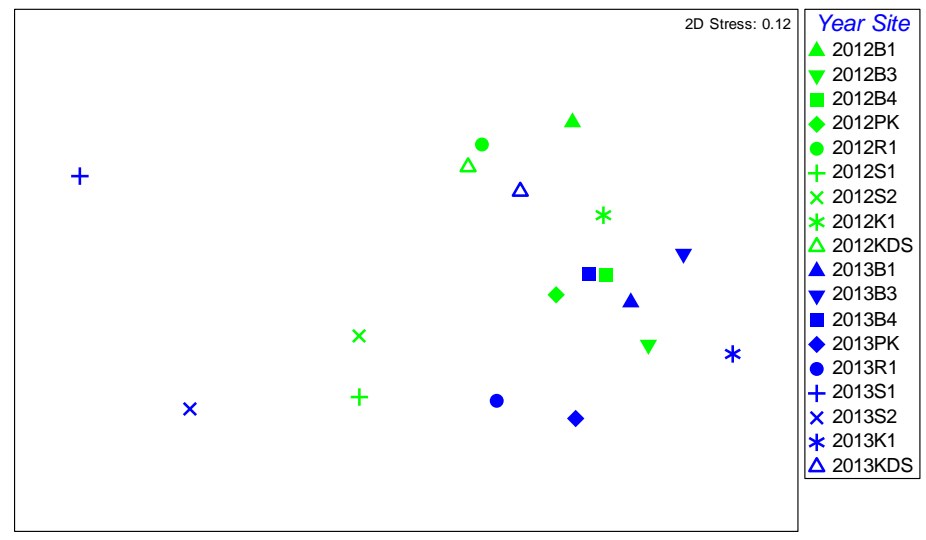

Figure 3.2 Multidimensional Scaling (MDS) plot to examine any differences in the assemblage composition of the main coral recruit families at each of the nine sites in two years. The legend describes the year of data collection (2012 or 2013) followed by the site. The distance between the points reproduces the distances on the Bray-Curtis matrix on a bidimensional plot, while the stress value estimate how well the configuration fit to the observed distance matrix, where 0.12 is an acceptable value.

The recruit assemblage composition was variable between the nine sites, although it is important to note that $39.4 \%$ of the recruits in 2012 and the $41.8 \%$ in 2013 were not identifiable. Despite these values are higher than those found in other coral recruitment studies, difficulties in coral recruit identification are common and due to the little development of corals in this early life history stage. Pocilloporidae was most abundant in both years (37\% and 29.7\%), followed by Poritidae (16.5\% and 19.8\%) and Acroporidae (7.1\% and 8.8\%). 
In 2012, Pocilloporidae was the most common family at most of the sites, it was second to Poritidae only at Sampela. In 2013 Poritidae was as common as Pocilloporidae. Acroporidae had a low settlement rate in 2012 and was not found Pak Kasim's, and Sampela 1 and 2, while in 2013 it was not found at Buoy 4, but was recorded at Pak Kasim's (Figure 3.3).

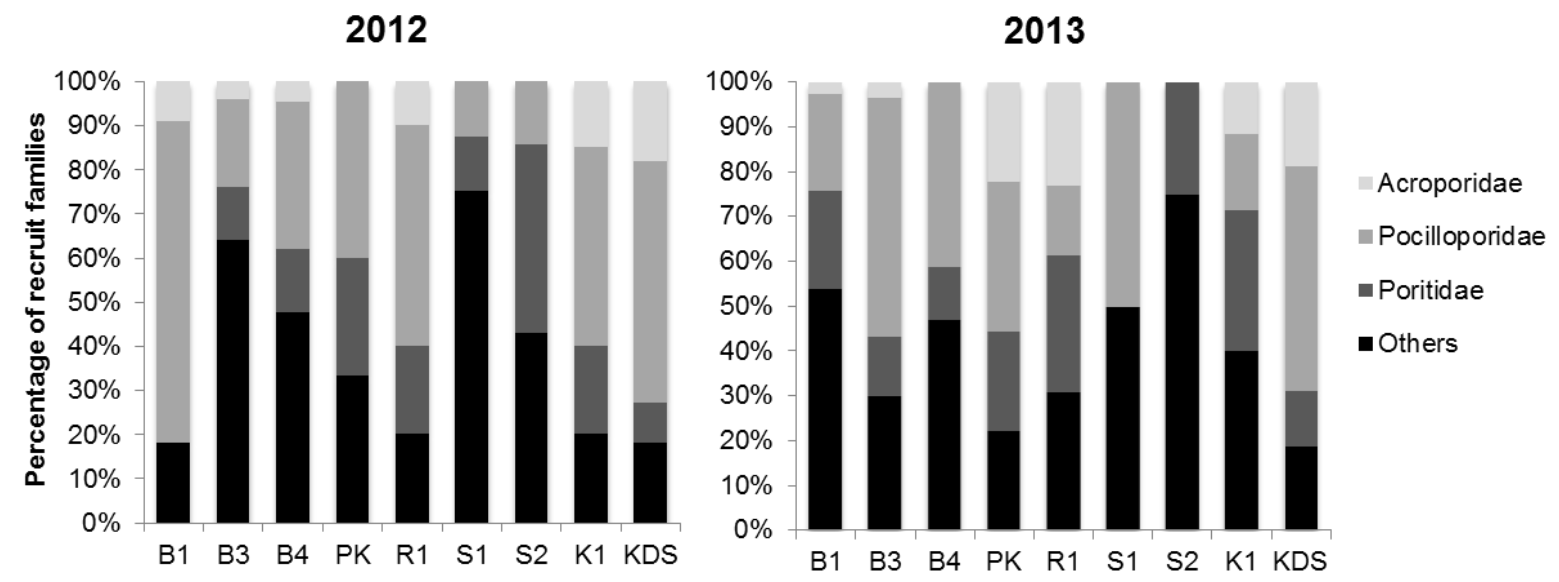

Figure 3.3 Percentage of coral recruits from different families recorded in 2012 and 2013 on settlement plates deployed for 12 months at $6 \mathrm{~m}$ depth at nine sites in the Wakatobi MNP (Indonesia)

At the sites where the overall coral recruitment was limited to only a few recruits, it was difficult to investigate the overall recruit population composition. For example, Sampela 1 and Sampela 2 had a total of 8 and 7 recruits in 2012 and 2 and 5 in 2013, respectively, but most of the recruits were unidentifiable, making it difficult to draw conclusions about the recruit assemblage composition at these sites. When analysing the temporal variability at each site, I found no significant differences in abundance or assemblage composition between 2012 and 2013, and recruitment rates appeared stable between these two years (Figure 3.4). 

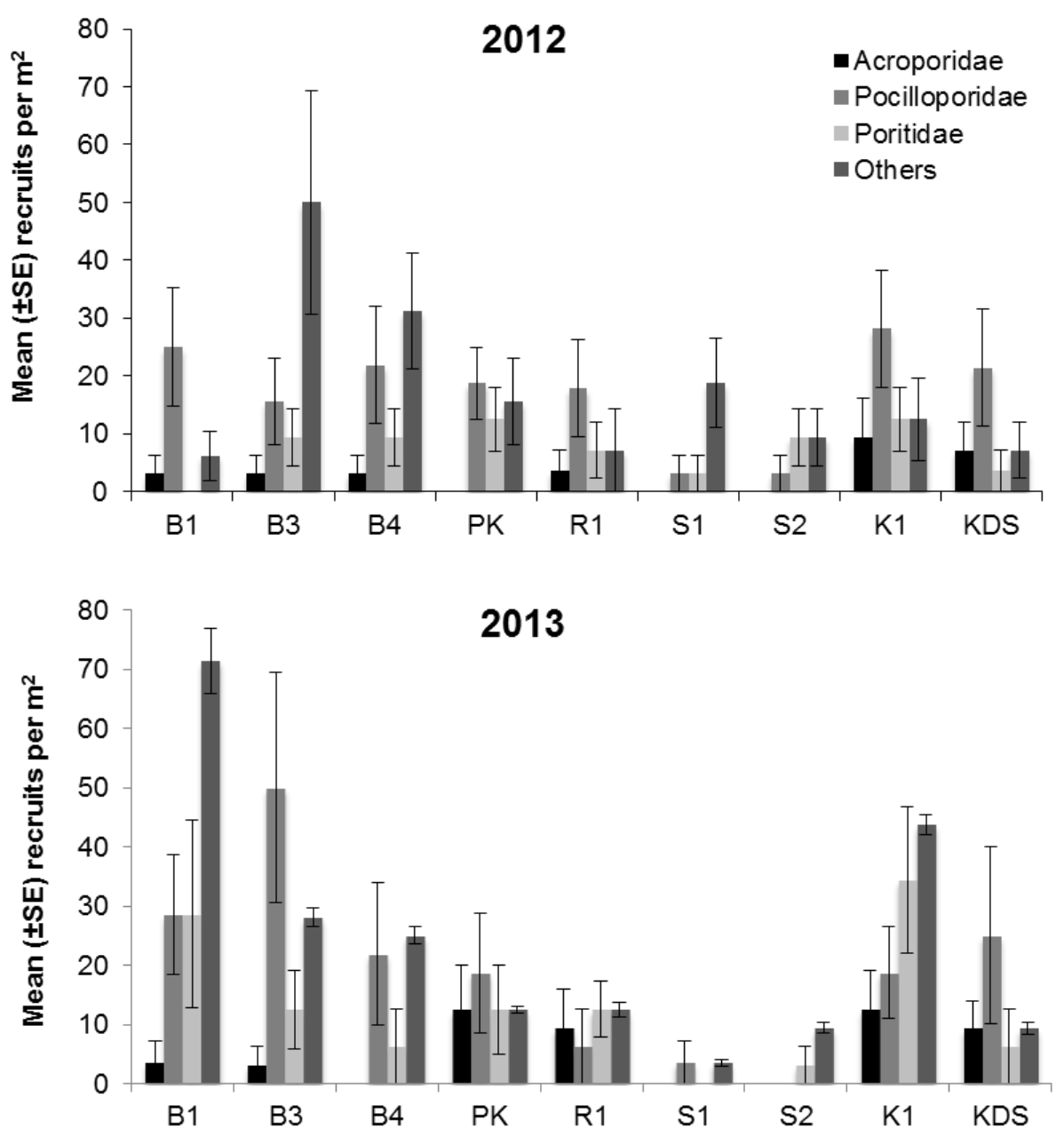

Figure 3.4 Mean ( \pm Standard Error) number of coral recruits per $\mathrm{m}^{2}$ for the most common coral families recorded in 2012 and 2013 at nine sites in the Wakatobi MNP

\subsubsection{Long-term survey on coral recruitment among two reef systems over seven years}

Overall, 580 recruits were found in the surveys over 7 years. The lowest value was 58 recorded in $2013\left(44.69 \pm 9.68 \mathrm{SE}\right.$ rec. $\left.\mathrm{m}^{-2}\right)$ and the highest was $268\left(209.38 \pm 101.56 \mathrm{SE} \mathrm{rec.} \mathrm{m}^{-2}\right)$ in 2009. The mean recruitment rates ranged from 71.9 ( $\pm 28.47 \mathrm{SE})$ rec. $\mathrm{m}^{-2}$ to $317.19( \pm 12.76$ $\mathrm{SE})$ rec. $\mathrm{m}^{-2}$ for Hoga and $9.6( \pm 8.21 \mathrm{SE})$ rec. $\mathrm{m}^{-2}$ and $101.6( \pm 13.27 \mathrm{SE})$ rec. $\mathrm{m}^{-2}$ for Sampela. Sampela had lower recruitment rates in all the years compared to Hoga, with the 2014 rates at Hoga being more than three time higher than at Sampela (Figure 3.5). 

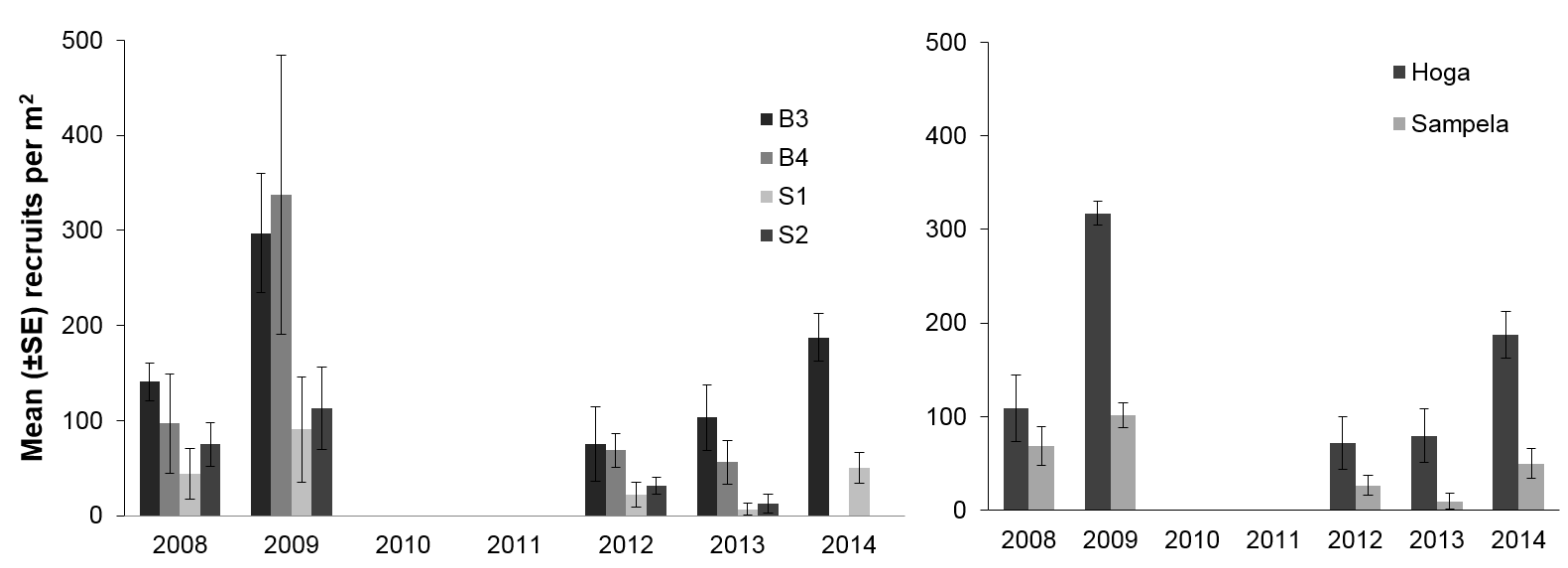

Figure 3.5 Mean ( \pm Standard Error) number of coral recruits per $\mathrm{m}^{2}$ recorded a) at the two reef systems (Hoga and Sampela) with two replicate sites each and b) overall mean at each reef system (Hoga: B3 and B4; and Sampela: S1 and S2) between 2008 and 2014. In 2010 and 2011 no data were collected, while in 2014 data were collected only at one site per reef

Overall, Pocilloporidae recruits were recorded in the greatest numbers at both reef systems, followed by Poritidae and Acroporidae recruits. At Hoga the 'Other' category included a minimum of $33 \%$ of the overall recruits found in 2012 and a maximum of 55\% in 2013, while at Sampela it included more than the $60 \%$ of the overall recruits found in all years. As the overall recruitment was low at Sampela, it is difficult to draw conclusions about the recruit assemblage composition (Figure 3.6). Variation in recruitment rates in any particular year at Hoga did not correspond to a similar variation in rates at Sampela.
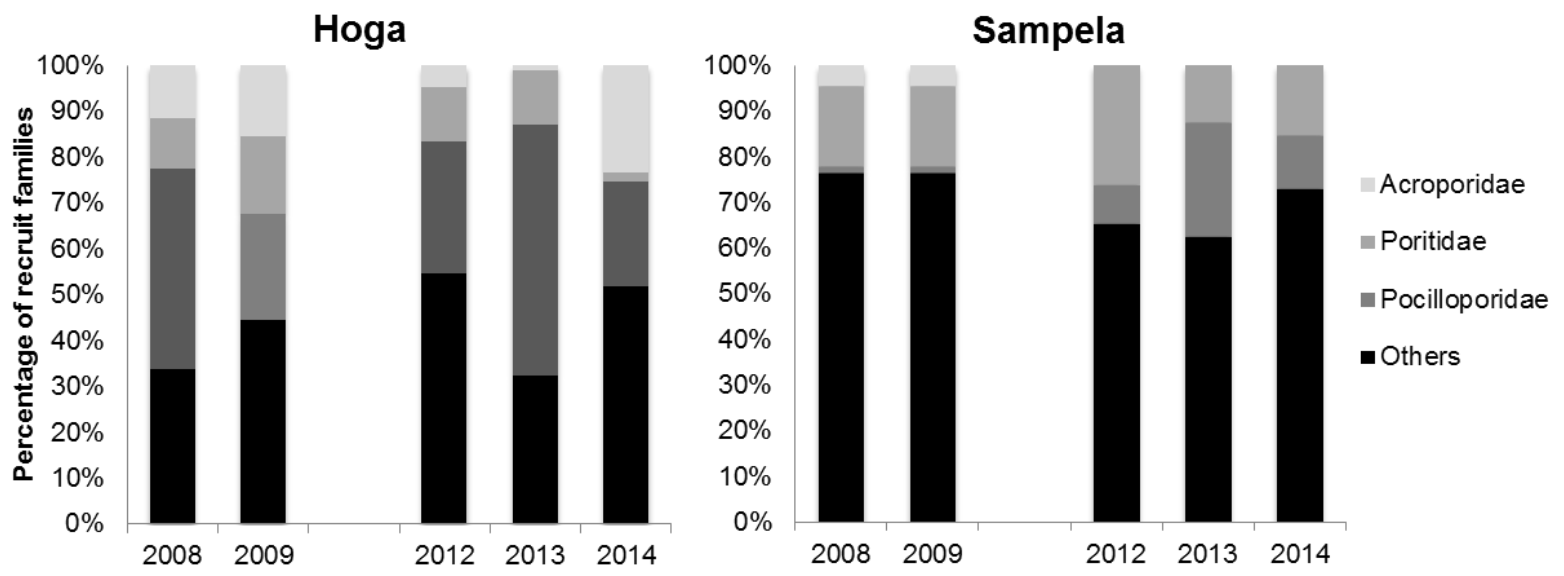

Figure 3.6 Percentage of the assemblage comprised of the main coral recruit families identified at two reef systems (Hoga and Sampela) between 2008 and 2014 in the Wakatobi MNP. In 2010 and 2011 no data were collected

Spatial and temporal variation were present in coral recruitment between the two reefs (PERMANOVA, $\mathrm{df}=4, \mathrm{P}=0.0044 ; \mathrm{df}=1, \mathrm{P}=0.0247$ ). Furthermore, there was an interaction between site and year for the coral recruit assemblage composition data (PERMANOVA, $\mathrm{df}=8$, 
$\mathrm{P}=0.0151$ ) and there were high levels of variability in the abundance of the main families across sites over the seven-year period (Table 3.3). Generally, the individual family abundances were always higher at Hoga than at Sampela, except for Poritidae in 2014: however, in that year only one replicate site per reef system was surveyed.

Table 3.3 Result to the PERMANOVA analysis for the spatial distribution of coral recruits between five years, two reefs (Hoga and Sampela) with four replicate sites (Buoy 3 and Buoy4 at Hoga reef and Sampela 1 ans Sampela 2 at Sampela reef) in the Wakatobi MNP

\begin{tabular}{lccccc}
\hline \multicolumn{1}{c}{ Factor } & df & SS & MS & Pseudo-F & P \\
\hline Year & 4 & 22937 & 5734.2 & 4.0527 & $\mathbf{0 . 0 0 4 4}$ \\
Reef & 1 & 6519.4 & 6519.4 & 7.3832 & $\mathbf{0 . 0 2 4 7}$ \\
Site (Reef) & 3 & 2226.2 & 742.1 & 0.6041 & 0.7562 \\
Year*Reef & 4 & 5221 & 1305.2 & 0.9225 & 0.5479 \\
Year*Site (Reef) $^{*}$ & 8 & 11323 & 1415.4 & 1.9278 & $\mathbf{0 . 0 1 5 1}$ \\
\hline
\end{tabular}

Pocilloporidae was the dominant family every year except 2009, when Poritidae and Acroporidae were more abundant. Poritidae recruits usually had relatively low abundance at both reefs, while Acroporidae was highly variable across years. In 2012 and 2013 Acroporidae abundance was very low at Hoga and it was not found at all at Sampela between 2012 and 2014 (Figure 3.7).
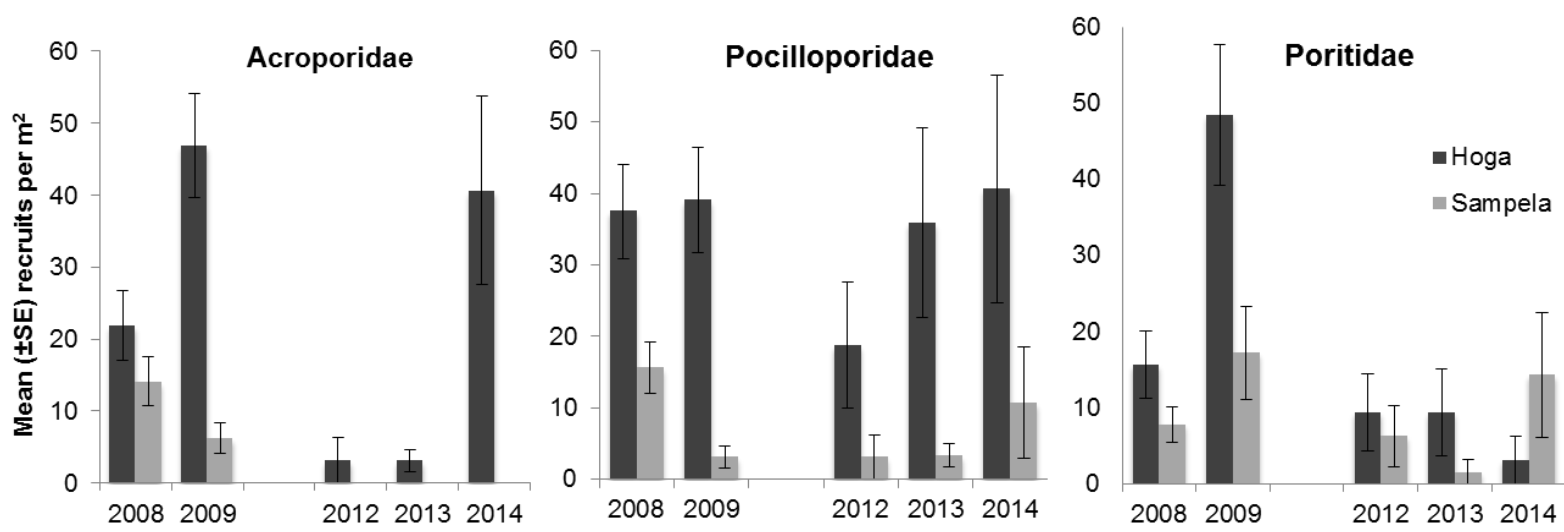

Figure 3.7 Mean ( \pm Standard Error) number of coral recruits for each of the three main families, Pocilloporidae, Poritidae and Acroporidae, per $\mathrm{m}^{2}$ recorded between 2008 and 2014 at two reef systems: Hoga and Sampela

High temporal variability in coral recruitment rates was present in Acroporidae (PERMANOVA, $\mathrm{df}=4, \mathrm{P}=0.0126$ ) and Poritidae (PERMANOVA, $\mathrm{df}=4, \mathrm{P}=0.0471$ ), while Pocilloporidae presented only a weak temporal variability when there was an interaction 
between year and site (PERMANOVA, $\mathrm{df}=8, \mathrm{P}=0.05$ ), variability across reefs was also significant (PERMANOVA, $\mathrm{df}=1, \mathrm{P}=0.0462$ ) (Table 3.4).

Table 3.4 Result of the PERMANOVA analysis for the spatial distribution of coral recruit families (Acroporidae, Pocilloporidae and Poritidae) between years, reefs, and replicate sites.

\begin{tabular}{|c|c|c|c|c|c|}
\hline Factor & df & SS & MS & Pseudo-F & $\mathbf{P}$ \\
\hline \multicolumn{6}{|l|}{ Acroporidae } \\
\hline Year & 4 & 7377 & 1844.2 & 6.4719 & 0.0126 \\
\hline Reef & 1 & 652.96 & 652.96 & 2.738 & 0.1161 \\
\hline Site (Reef) & 3 & 454.93 & 151.64 & 0.6491 & 0.774 \\
\hline Year*Reef & 4 & 3986.3 & 996.58 & 3.4972 & 0.0452 \\
\hline Year*Site (Reef) & 8 & 2280.6 & 285.07 & 2.0784 & 0.0389 \\
\hline \multicolumn{6}{|l|}{ Pocilloporidae } \\
\hline Year & 4 & 932.53 & 233.13 & 0.4870 & 0.7421 \\
\hline Reef & 1 & 1220.8 & 1220.8 & 5.3631 & 0.0462 \\
\hline Site (Reef) & 3 & 593.93 & 197.98 & 0.4978 & 0.6423 \\
\hline Year*Reef & 4 & 372.44 & 93.11 & 0.1945 & 0.9328 \\
\hline YearSite (Reef) & 8 & 3830.8 & 478.85 & 1.9495 & 0.05 \\
\hline \multicolumn{6}{|l|}{ Poritidae } \\
\hline Year & 4 & 2436.6 & 609.14 & 3.8971 & 0.0471 \\
\hline Reef & 1 & 89.52 & 89.52 & 0.4375 & 0.641 \\
\hline Site (Reef) & 3 & 246.95 & 82.32 & 0.4836 & 0.6884 \\
\hline Year*Reef & 4 & 1923.3 & 480.83 & 3.0762 & 0.0558 \\
\hline Year*Site (Reef) & 8 & 1250.2 & 156.28 & 0.7961 & 0.6092 \\
\hline
\end{tabular}

\subsubsection{Temporal variation in coral juvenile abundance and assemblage composition}

During the four surveys 938 coral juveniles were recorded at the two reef systems: 248 (24.8 $\pm 3.45 \mathrm{SE}$ rec. $\left.\mathrm{m}^{-2}\right)$ in $2009,255\left(12.75 \pm 1.69 \mathrm{SE}\right.$ rec. $\left.\mathrm{m}^{-2}\right)$ in $2011,267(14.51 \pm 1.67 \mathrm{SE}$ rec. $\left.\mathrm{m}^{-2}\right)$ in 2012 and $168\left(8.4 \pm 1.23 \mathrm{SE}\right.$ rec. $\left.\mathrm{m}^{-2}\right)$ in 2013. In 2013 lower values were recorded on both reefs (10.7 $\pm 6.1 \mathrm{SE}$ rec. $\mathrm{m}^{-2}$ at Hoga and 6.1 $\pm 1.22 \mathrm{SE}$ rec. $\mathrm{m}^{-2}$ at Sampela), while in 2009 higher values were recorded at both reefs $\left(31.8 \pm 3.99 \mathrm{SE}\right.$ rec. $\mathrm{m}^{-2}$ at Hoga and 17.8 $\pm 2.9 \mathrm{SE}$ rec. $\left.\mathrm{m}^{-2}\right)$.

Significant variability in the abundance and assemblage composition was found for coral juveniles between years (PERMANOVA, $\mathrm{df}=3, \mathrm{P}<0.05)$ and reef systems (PERMANOVA, $\mathrm{df}=1, \mathrm{P}<0.05$ ), but not between replicate sites (PERMANOVA, $\mathrm{df}=2, \mathrm{P}>0.05)$ (Table 3.5); 
there was no significant difference between Buoy 3 and Buoy 4 on the Hoga reef and Sampela 1 and Sampela 2 on the Sampela reef (Figure 3.8).

Table 3.5 Result of the PERMANOVA analysis for the spatial distribution of coral juveniles between years, reefs, and replicate sites

\begin{tabular}{lccrcc}
\hline \multicolumn{1}{c}{ Factor } & df & SS & \multicolumn{1}{c}{ MS } & Pseudo-F & P \\
\hline Year & 3 & 25965 & 8654.9 & 11.976 & 0.0024 \\
Reef & 1 & 16125 & 16125 & 10.444 & 0.0114 \\
Site (Reef) & 2 & 808.6 & 904.3 & 1.21 & 0.3876 \\
Year*Reef & 3 & 254.3 & 751.44 & 10.398 & 0.4412 \\
Year*Site(Reef) & 6 & 333.5 & 722.24 & 0.644 & 0.8479 \\
\hline
\end{tabular}

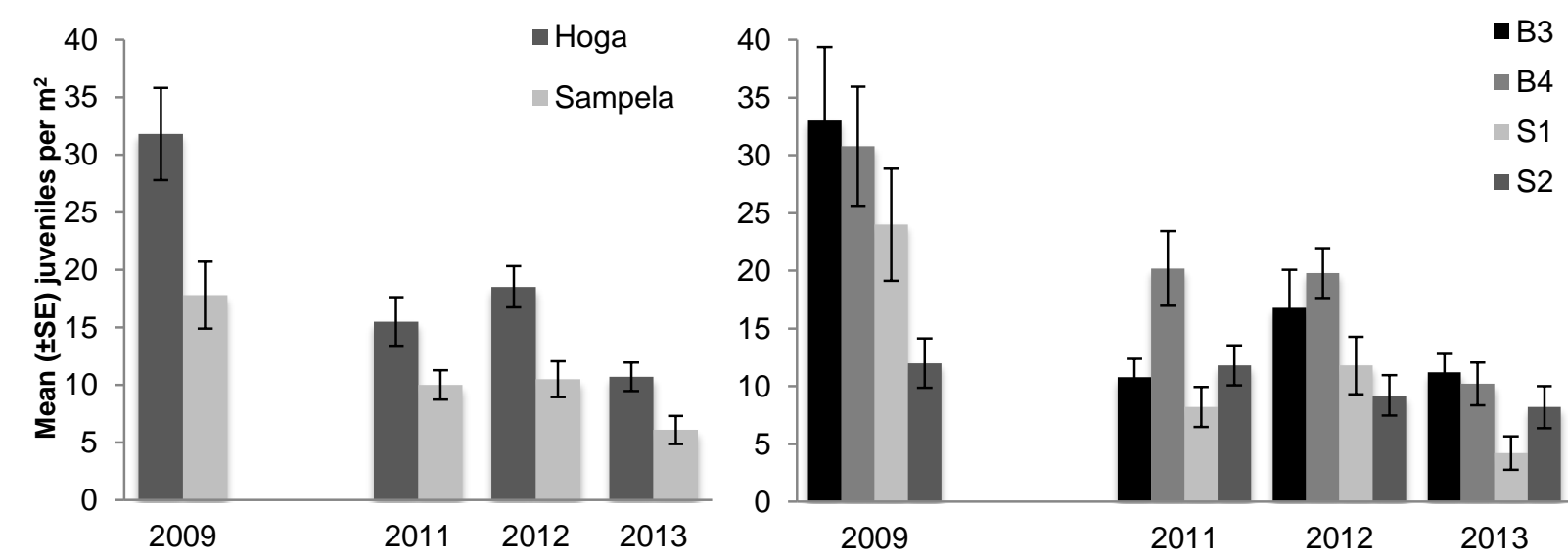

Figure 3.8 Mean ( \pm Standard Error) number of coral juveniles per $\mathrm{m}^{2}$ recorded across five years at Hoga and Sampela reef systems. Data were not collected in 2010

Table 3.6 Mean ( \pm Standard Error) number of coral juveniles per $\mathrm{m}^{2}$ recorded at each site with data pooled for each reef system. In the grey column the percentage of the variation in juvenile abundance is compared to the previous juveniles survey. The last column on the right shows the total variation in juvenile abundance between 2009 and 2013

\begin{tabular}{|c|c|c|c|c|c|c|c|c|}
\hline & 2009 & 2011 & & 2012 & & 2013 & & Overall \\
\hline Buoy 3 & $33( \pm 6.36)$ & $10.8( \pm 1.58)$ & -67.3 & $16.8( \pm 3.29)$ & 15.5 & $11.2( \pm 1.63)$ & -33.3 & -66.1 \\
\hline Buoy 4 & $30.8( \pm 5.16)$ & $20.2( \pm 3.24)$ & -34.4 & $19.8( \pm 2.14)$ & -1.9 & $10.2( \pm 1.91)$ & -48.5 & -66.9 \\
\hline Sampela 1 & $24( \pm 4.86)$ & $8.2( \pm 1.73)$ & -65.8 & $11.8( \pm 2.49)$ & 43.9 & $4.2( \pm 1.49)$ & -64.4 & -82.5 \\
\hline Sampela 2 & $12( \pm 2.15)$ & $11.8( \pm 1.73)$ & -1.7 & $9.2( \pm 1.75)$ & -22 & $8.2( \pm 1.88)$ & -10.9 & -31.7 \\
\hline Hoga & $31.9( \pm 3.99)$ & $15.5( \pm 2.11)$ & -51.4 & $18.3( \pm 1.79)$ & 18.1 & $10.7( \pm 1.24)$ & -41.5 & -66.5 \\
\hline Sampela & $18( \pm 2.91)$ & $10( \pm 1.27)$ & -44.4 & $10.5( \pm 1.55)$ & 5 & $6.2( \pm 1.22)$ & -40.9 & -65.6 \\
\hline
\end{tabular}


The relative abundance of the five main juvenile families represented $86.62 \%$ of the overall 443 juveniles found in $2009,77.42 \%$ of the 255 in $2011,69.75 \%$ of the 267 in 2012 and $70.1 \%$ of the 168 in 2013. There was an overall decline in the total abundance of coral juveniles and in the abundance of individual families over time (Table 3.6).

Analysing the abundance of the five main families separately, I found that Poritidae and Faviidae varied across years and between reefs, Agariciidae varied only across reefs and Acroporidae varied only across years, while Pocilloporidae did not show any significant variation across years or reef systems (Figure 3.9).

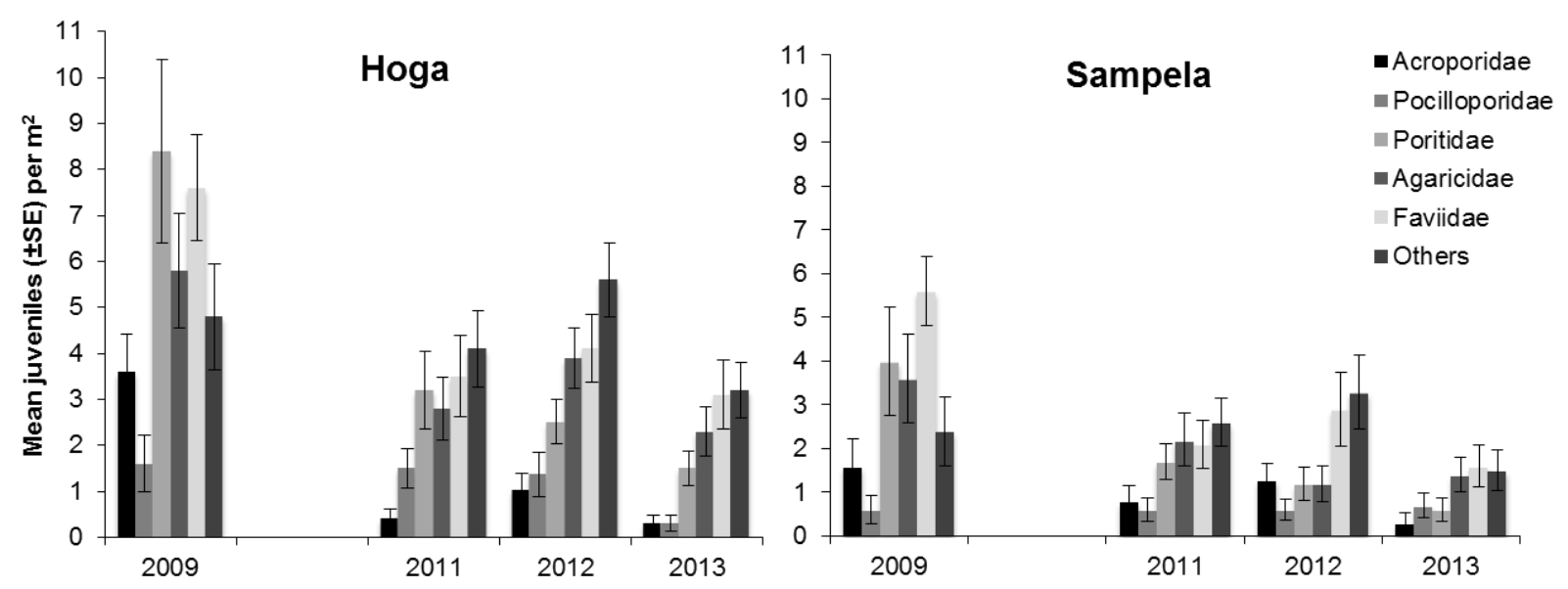

Figure 3.9 Mean ( \pm Standard Error) number of coral juveniles per $\mathrm{m}^{2}$ belonging to the five main families per $\mathrm{m}^{2}$ recorded at a) Hoga and b) Sampela reef systems between 2009 and 2013

\subsection{Discussion}

The short term survey found little temporal variability in coral recruit abundance across nine sites that are characterised by different environmental conditions, with recruitment rates being similar at each site over the two years of the survey. However, spatial variability was found at both years, even though the pattern of coral recruitment rate was not consistent, suggesting that local environmental characteristics were affecting the recruitment process. For the long-term survey, significant temporal and spatial variability in overall recruitment rate was found over the seven years and among the reef systems. Recruit assemblage composition changed between reefs and across years and this variation was consistent. Temporal variability in juvenile abundance and assemblage composition was recorded across years and between reefs. The five main coral juvenile families varied independently over the study period. These results demonstrate that the survival from recruit to juvenile varied over time and across reefs. I also 
found that recruit and juvenile patterns of abundance and assemblage composition varied independently between these two life history stages, sites, and coral families.

\subsubsection{Absence of trends in temporal variability in coral recruitment abundance and assemblage}

For the short-term survey conducted at nine sites experiencing different environmental conditions, differences in the recruitment rates between the sites were consistent over the two years of sampling, despite $43 \%$ more recruits being recorded in the second year. The recruitment rates at each site showed high levels of variation because of the high variability at the panel level. In contrast, in the long-term survey, recruitment rates fluctuated considerably at both reef systems over the study period. For example, in 2013 the recruitment rate at Hoga was slightly higher than in 2012, while at Sampela the rate was one-third lower. This is consistent with other studies where high variability in recruitment rates across consecutive years has been reported with up to fivefold increases in some cases (see Wallace 1985a; Gleason 1996; Glassom et al. 2004; Adjeroud et al. 2007a; Nakamura \& Sakai 2009). Although overall the variation in recruit abundance on the Hoga reef did correlate with those at Sampela, these rates did not show any obvious upward or downward trend.

There were differences in the abundance of the individual recruit families over time. Pocilloporidae recruits did not show any significant variation in abundance across years, consistent with a previous study that found that seasonal recruitment rates were consistent throughout the year (Salinas De León et al. 2012a). The absence of temporal variation in Pocilloporidae recruit abundance was also found at Ryukyu Archipelago in South Japan, where only spatial variation was present and the distribution of recruits was related to reproductive mode. As most of the Pocilloporidae corals are brooding species, the larvae settle only a short distance from the adult colonies and are affected by mortality in the water column due to the short time the larvae spend in the water (Nakamura \& Sakai 2009). However, these studies contrast with the results found in the Red Sea (Glassom et al. 2004), at Moorea (Adjeroud et al. 2007a), and on the Great Barrier Reef (Dunstan \& Johnson 1998), where temporal and spatial variation in recruit abundance has been reported and correlated with the reproductive mode of the local Pocilloporidae colonies, suggesting that the local species composition determines the scale of variability.

Acroporidae and Poritidae recruits showed wide temporal variability in abundance across years in this study, but other studies have found low or no variability (Green \& Edmunds 2011). High 
levels of temporal variability in abundance of Acroporidae recruits was found on the Great Barrier Reef (Dunstan \& Johnson 1998), in the Red Sea (Glassom et al. 2004), and in Japan (Nakamura \& Sakai 2009), however in my study there was variation in settlement rates across years. Years of low recruitment rate were followed with random years of higher recruitment rates, maintaining the population and reef diversity; this is likely to be due to the coral reproductive mode (Warner \& Chesson 1985; Harriott \& Banks 1995; Adjeroud et al. 2007a; Irizarry-Soto \& Weil 2009). However, in my study reproductive mode was not included as a factor in the analysis, and so could not be investigated as the main reason for the variation in recruitment rates.

Irizarry-Soto \& Weil (2009) found that reproductive success was more favourable for some coral taxa in some years while in other years other (non-coral) taxa were more successful. Furthermore, the success was independent of the reproduction mode adopted by the coral taxa. Therefore, significant temporal variability in recruitment rates was found whenever a successful year was included in a multi-year study. As a consequence variability was not present when only years of non-favourable conditions were analysed (low larval availability, high mortality or other post-settlement events), with low and consistent rates among consecutive unsuccessful years. It is possible that long-term surveys on recruitment rate can detect patterns wherever a sequence of successful and not-successful years is included.

The decline in coral cover, recorded since 2002 in the Wakatobi (Curtis-Quick 2013) could not be compared to the data on coral recruitment rates collected between 2008 and 2014, because of the lack of coral recruitment data before 2008 and in 2010 and 2011. As a consequence, it was no possible to assess the existence of the correlation between coral cover and recruitment rate suggested by Salinas De León et al. (2012a). While coral cover has been decreasing in the last decade, recruitment rates were highly variable between years. For example, the rates recorded in 2009 were double those in 2008. However, the lack of information on recruitment rates for some years in the long-term survey may mask some patterns.

\subsubsection{Temporal variability in the juvenile population}

The analysis of the juvenile data over a five year-period showed a decline in the abundance and change in assemblage composition. In particular, the relative proportions of the main families were variable and a shift occurred in dominance, from the Poritidae family, which was the most common in 2009, to the Faviidae family from 2011 onward. 
The abundance of juvenile families varied across both years and reefs. At the family level, a large decrease in density occurred between the recruit and the juvenile stages. Taxa such as Pocilloporidae usually have a high colonisation rate followed by high mortality, which seems to be independent of initial density (Edmunds 2000a; Irizarry-Soto \& Weil 2009). A previous study in the Caribbean found that juvenile survivorship was not correlated with the reproductive mode of corals (Edmunds 2000a; Irizarry-Soto \& Weil 2009) and the authors suggested that juvenile taxa responded differently to the local environmental conditions present at recruitment time. However, in my study juveniles were identified only to family level or to genus, and therefore it was not possible to analyse the survivorship of taxa based on reproductive mode.

Because of the missing data on juvenile abundance in 2010, it was not possible to determine if the decrease in juvenile density recorded between 2009 and 2011 was progressive, or if data recorded in 2009 represented a year of exceptionally high survivorship, or if a major disturbance occurred and affected the juvenile abundance. However, the decline in abundance was different for each coral family: Pocilloporidae was least affected and its abundance remained consistent at the same time Acroporidae abundance declined.

In my study, the dominant families at the juvenile stage, Agariciidae, Acroporidae and Faviidae, had low densities at the recruit stage, indicating that they have high survivorship. Acroporidae had a low recruitment and survival rate in the Wakatobi, however in other studies this family showed different levels of resistance to mortality, from very high to marginal. Because of the small number of colonies found in this study, it was not possible to gain a better understanding of its survival (Dunstan \& Johnson 1998; Glassom et al. 2004). Poritidae and Faviidae were variable across years and reefs, and both had low settlement rates, however Faviidae became a dominant family at the juvenile stage. Pocilloporidae had high mortality after high recruitment, but then it did not show further temporal or spatial variation, as populations seemed to have been less affected by post-settlement events.

\subsubsection{Impact of thermal anomalies on coral recruitment in the Wakatobi}

A decline in both recruit and juvenile abundance occurred between 2009 and 2012, where recruitment rates decreased by more than one-third at all sites. At Hoga in 2011 the juvenile population was less than half than 2009, while at Sampela the decrease was less pronounced and at both reefs a shift in juvenile assemblage composition occurred. 
Between 2009 and 2011 one of the strongest ENSO event of the last 50 years was recorded in the West Pacific and South East Asia and it affected many marine organisms, causing coral bleaching and fish mortality (Tan \& Heron 2011; Feng et al. 2013). The average Sea Surface Temperature (SST) in the Pacific area increased in 2011, peaking in February-March, when a rise of more than $2^{\circ} \mathrm{C}$ was recorded in Western Australia (Pearce et al. 2011) At the same time SST rose an average of $1.6^{\circ} \mathrm{C}$ in the Indo-Pacific area $\left(5^{\circ} \mathrm{N}-5^{\circ} \mathrm{S}, 120-170^{\circ} \mathrm{W}\right)$ (Feng et al. 2013).

As a consequence of the increase in water temperature, about $50 \%$ of the coral bleached in West Malaysia (Tan \& Heron 2011), while at Moorea the rise of water temperature that preceded the bleaching event was likely to have promoted larval production with a subsequent rise in recruitment rates (Adjeroud et al. 2007a).

In 2010 a particularly severe thermal anomaly was recorded in the Wakatobi where an increase of about $2^{\circ} \mathrm{C}$ water temperature was reported (Smith 2012, unpublished data; Curtis-Quick 2013). This temperature anomaly was followed by a bleaching event in the following year and the recruitment rates recorded were significantly lower. This unusual variation in temperature might explain the high recruitment rates found in my study in 2009, where larvae production might have been triggered by the increase of water temperature followed by the decline in both coral reproduction and survival of young coral colonies in the Park.

Unfortunately, the lack of data on recruitment rates for 2010 and 2011 prevented me from assessing any correlation between recruitment rates and these thermal anomalies. Furthermore, in the juvenile survey, a decrease in juvenile abundance was observed between 2009 and 2011.

\subsection{Conclusion}

The research reported in this chapter highlights the importance of annual monitoring of coral recruitment over a period of time and the need to include a sufficient number of sites to represent the overall variability in environmental conditions present in the area. The comparison of data from different years allows temporal variation in recruitment rate to be detected. Such information may allow predictions to be made for coral recruitment trends and aid with coral reef management. Knowing in advance the more favourable years for coral recruitment can help in planning intervention to reduce the disturbances resulting from more predictable stressors.

Despite it not being possible to control factors such as thermal anomalies, other causes of disturbances that might influence coral recruitment rate can be monitored. Specific rules to 
regulate activities such as fishing and sediment dredging can help to control predation and sedimentation rates, which also affect the recruitment process. Appropriate interventions would be particularly important in years when the coral recruitment rates are expected to be low due to uncontrollable factors (e.g. climatic conditions). Active reef management is particularly important in areas where recruitment rates are usually low or where reef rehabilitation is required.

In the future more specific studies should be conducted in order to better understand how predictable factors, such as predation and sedimentation, affect mortality in young coral populations. 


\section{Chapter 4 Importance of fish grazing to coral juvenile mortality}

\subsection{Abstract}

Fish grazing has been identified as an important impact responsible for coral recruit (corals recently settled) mortality in the early post-settlement phase and the size of the colony was correlated to the possibility to be affected by grazing activity. Grazers also regulate the growth of algae, which are competing with young coral colonies for available space. This chapter describes an investigation into the role of fish grazing in coral juvenile ( $<2$ years old) mortality and colony growth. I conducted a fish exclusion experiment using settlement panels with coral colonies settled in situ in the Wakatobi Marine National Park (Indonesia) and I measured variations in photosynthetic efficiency $(\mathrm{Fv} / \mathrm{Fm})$ of coral juveniles in order to assess physiological stress correlated to grazing activity. Only $3.49 \%$ of the juveniles were estimated to have died as result of grazing activity and colony size was not correlated with mortality rate. There was variation in coral colony size; this was influenced by the size of the colony at the beginning of the experiment but was independent of the caging treatment. Colonies increased or reduced in size over the experiment across all treatments, but the relationship between the magnitude of the change in colony size and initial size of the coral colony remained unclear. The lack of algal consumption by fish might have induced differential changes in size and decrease in photosynthetic efficiency that influenced the survival of colonies. Overall, grazing seems unlikely to have been the main cause of juvenile mortality in this experiment. During the experiment, $28.38 \%$ of coral juveniles have been overgrown by other benthic organisms, mostly algae. Overgrowth was consistent between treatments and did not caused mortality to coral juveniles, although a significant decrease of $44 \%$ and $22.2 \%$ in $\mathrm{Fv} / \mathrm{Fm}$ values was measured in all the juvenile colonies overgrown by green and turf algae respectively. It is important to consider that the coral sample size used in my study was small and unevenly distributed between treatments. Further studies could investigate better the role of grazers in algae regulation, the interaction between benthic organisms, especially algae, and coral juvenile, and the threshold of overgrown juvenile survivorship in the post-settlement stages.

\subsection{Introduction}

In recent years there has been increasing interest in coral reef restoration following their decline worldwide (review by Bruno \& Selig 2007; Burke et al. 2012; De'ath et al. 2012). The 
disturbances that threaten coral reefs include changes in climatic conditions and ocean acidification (Manzello 2010; Doropoulos et al. 2012a), and more local environmental impacts, such as increases in sedimentation as a result of changes in land use (Rogers 1990; Field et al. 2000; Erftemeijer et al. 2012) and direct human disturbances, such as coral mining (Crabbe et al. 2004; Halpern et al. 2008). Several studies have focused on the early life history stages of corals in order to better understand the ecological processes that drive coral recruitment and enhance its success (for example see review by Ritson-Williams et al. 2009a; and work by Rylaarsdam 1983 and van Woesik \& Jordán-Garza 2011).

Predation is thought to play an important role in controlling coral colony distribution; for example, corallivore activity can determine the final patterns of species abundance for coral recruits and juveniles (Gleason 1996; Penin et al. 2011; Davies et al. 2013). Coral early life history stages are more vulnerable to stress than adult colonies; the small size and the limited energy available to react to disturbances make them easy prey, and weak competitors for space and resources (Hughes \& Jackson 1985; Hughes 1994; Zilberberg \& Edmunds 2001; Doropoulos et al. 2012b). Therefore young corals are more sensitive to environmental variation, such as fluctuations in water temperature, irradiance and sedimentation rates (Rylaarsdam 1983; Vermeij 2005; Box \& Mumby 2007), than adult corals. In addition, it is likely that the causes of mortality in young corals vary with age and size (Cooper et al. 2014).

Previous research has suggested that in the first months after settlement coral recruit mortality is mostly caused by biological factors (Miller \& Hay 1998; Wilson \& Harrison 2005; Penin et al. 2011). Young corals that are affected by disturbance can suffer minor to major damage; visible signs of stress in corals include colony bleaching, decreased growth rate and a reduction in size. The consequences of stressors on corals vary according to their intensity; corals can usually recover when the impact is small and for a short time, but more intense disturbance could lead to partial or complete death of the colony (Connell 1997a; Baker et al. 2008; Penin et al. 2011; Johns et al. 2014), where partial mortality refers to the death of only a portion of coral colony polyps.

Different disturbances play important roles in determining the survivorship rate of coral colonies in the post-settlement stage, when mortality rates can exceed $50 \%$ just two days after settlement (Miller \& Hay 1998). Several studies have highlighted the impact of grazing fish on coral recruits (Lewis 1986; Gleason 1996; Nozawa 2008; Baria et al. 2010; Penin et al. 2011; Trapon et al. 2013c); while grazers feed on algae, especially on turf algae and crustose coralline 
algae (CCA), coral settlers can be accidentally removed from the substrate or inadvertently experience damage (Box \& Mumby 2007; Hoey \& Bellwood 2008).

Fish grazers sometimes actively avoid small colonies, although the threshold of the colony size that was resistant to grazing activity was variable by geographical location and fish species present on the reef (Birkeland 1977; Gleason 1996; Christiansen et al. 2008). For example, the fish families Acanthuridae and Scaridae, which exert a strong mortality pressure on young corals, were found to actively avoid small coral recruits in the Caribbean (Birkeland 1977), while the same two families caused high mortality in the coral recruit population in Moorea (Gleason 1996), although the overall feeding habit at fish family levels is influenced by fish species composition. In contrast, another study in the Caribbean found grazers feeding indiscriminately on juveniles regardless of their size (Bak \& Engel 1979).

A recent laboratory experiment to investigate the relationship between grazing and coral colony size suggested that accidental grazing was more frequent at coral early life history stages and it was found to negatively correlate with colony size (Christiansen et al. 2008). In that study, conducted in controlled conditions, blennies (family Blennidae) damaged only small colonies because older corals had a higher resilience, however blennies are likely to be more selective than big grazers (Christiansen et al. 2008). Single grazing events, such as a small fish bite, compromise the survival of entire juvenile coral colonies (Christiansen et al. 2008). Most of the scars typically found on corals are the result of parrotfish (family Scaridae) grazing, which are considered the main responsible for damages to corals (Miller \& Hay 1998; Penin et al. 2010; Trapon et al. 2013c). Parrotfish grazing activity include scrape and excavate, removing pieces on substrate with the algae and leaving evident scars; this activity promotes the accidental removal of coral recruit recently settled (Hoey \& Bellwood 2008). However, other grazers, including surgeonfish (family Acanthuridae), triggerfish (family Balistidae), rabbitfish (family Signatidae), and corallivores, including butterflyfish (family Chaetodontidae), starfish (e.g. Achantaster planci), echinoids and molluscs (e.g. Drupella), feed on coral (Sammarco 1985; Penin et al. 2011; Davies et al. 2013). Surgeonfish and rabbitfish usually feed on the upper layer of the algae leaving intact the lower portion and the substratum (Trapon et al. 2013c). In addition, grazers also control algal growth, potentially reducing the level of competition between algae and coral (Miller \& Hay 1998; Box \& Mumby 2007; Hughes et al. 2007; Baria et al. 2010; Davies et al. 2013). 
Algal abundance correlates with coral survivorship at all coral life history stages (McCook et al. 2001). Although some algae, such as CCA, promote coral recruitment at the settlement stage, other algae species compete for space with corals at all coral life history stages (River \& Edmunds 2001; Harrington et al. 2004; Haas et al. 2010). Macroalgae and turf algae can shade and overgrow young coral colonies, affecting coral growth rate by causing reductions in colony size, suffocation, and it may also induce mortality (Birrell et al. 2005; Vermeij 2006; Ferrari et al. 2012). Considering the strong impact of algae on coral, algal regulation provided by grazers plays an important role, particularly in early coral life history stages (Box \& Mumby 2007; Brandl et al. 2013; Trapon et al. 2013c; Cooper et al. 2014). However, algal abundance also increases sediments on coral reefs; for example, turf algae trap sediments that then smother coral recruits and reduce the space available for coral expansion (Birrell et al. 2005). Moreover, it has also been shown that sedimentation rate has a negative correlation with grazer abundance, where grazing activity was affected by the sediment layer present on the reef (Goatley \& Bellwood 2012). In summary, there is a strong correlation between coral recruit survivorship, grazers activity, and algae abundance.

The interaction between multiple factors increases the range of responses of coral colonies to these disturbances, from physiological stress to colony mortality, where the effects of these interactions are not just additive, but also synergistic (Ban et al. 2014). Therefore it is difficult to discriminate the effects of different disturbances, and this represents a major challenge in the study of post-settlement processes. Grazing has been identified as one of the main stressors at early coral life history stages and more studies need to focus on its association with other factors, such as algal abundance, in order to better understand how they are correlated (Gleason 1996; Box \& Mumby 2007; Venera-Ponton et al. 2011; Trapon et al. 2013c).

The importance of grazers as algae regulators has increased in the last few decades, principally because phase shifts from coral to algal dominated reefs have been observed in different geographical regions (Lirman 2001; Hughes et al. 2007; Ledlie et al. 2007; Bruno et al. 2009; Norström et al. 2009). In the Caribbean, a decline in grazers, due to overfishing and a die-off of the dominant bioeroder Diadema, caused the loss of coral cover and an increase of algae abundance in the early 1980s (Hughes 1984). This has not only affected coral recruitment but also the potential for reefs to recover (Adam et al. 2015).

Previous research has used manipulative experiments to investigate the impact of fish grazers on coral recruits (for example Miller \& Hay 1998; Baria et al. 2010; Trapon et al. 2013c). 
These studies focused mostly on recently settled coral colonies under controlled conditions in laboratories on clear tiles, where spatial competition was not present. However, the effect of grazing on older coral colonies, such as juveniles, settled in situ on more complex surfaces, more similar to real reef environments, has not been previously examined.

In this chapter, 1) I investigated the impact of fish grazing on coral juveniles by carrying out a fish exclusion study (caging treatment) similar to those used to investigate the effect of predation on coral recruit survivorship. My objectives were to: a) assess the overall full and partial mortality (damaged colonies) rate in the juvenile coral population due to grazers; $b$ ) to assess if initial size of coral juveniles influences the outcome of the interaction with grazers, in order to detect correlations between coral size and probability of accidental removal of juveniles from the surface or colony damage; c) to examine variations in coral colony size and determine whether treatment or the initial size had a role in this variation, and d) to assess stress due to fish grazing activity on coral juveniles by measuring variation in the photosynthetic efficiency $(\mathrm{Fv} / \mathrm{Fm})$.

Then, 2) I investigated the impact of spatial competition between coral juveniles and benthic organisms, focusing on algae, in different grazing regimes. My objectives were: a) to assess the predominant benthic groups overgrowing juvenile coral colonies in different fish grazing regime; and b) to determine sign of stress in overgrown coral juveniles by measuring variation in photosynthetic efficiency (Fv/Fm).

\subsection{Methods}

This study was conducted between June 2011- August 2013 in the Wakatobi Marine National Park (South Sulawesi, Indonesia). Thirty settlement panels, constructed following the modified method of Mundy (2000) (described in Chapter 2), were deployed in August 2011 on the reef at Buoy 4 at $6 \mathrm{~m}$ (see map in Chapter 2). Panels were left submerged for 22 months to allow settlement of coral larvae and development of coral juveniles.

In June 2013, settlement panels were then collected and taken to the laboratory in seawater. Juveniles were counted and wherever possible identified to family level; those not identifiable were pooled into an 'Others' group. For this experiment I only used coral juveniles on the back side of the panels, which were protected from grazing because of their cryptic position. The back side is usually preferred by coral larvae for settlement, so I expected to find a higher abundance of colonies than on the front side of the panels (see data on coral recruitment rate in 
Chapters 2 and 3). Coral juveniles with two or more polyps or a primary polyp with a robust skeleton raised from the surface, as opposed to flat recruits, were included in the study (see Figure 4.1).

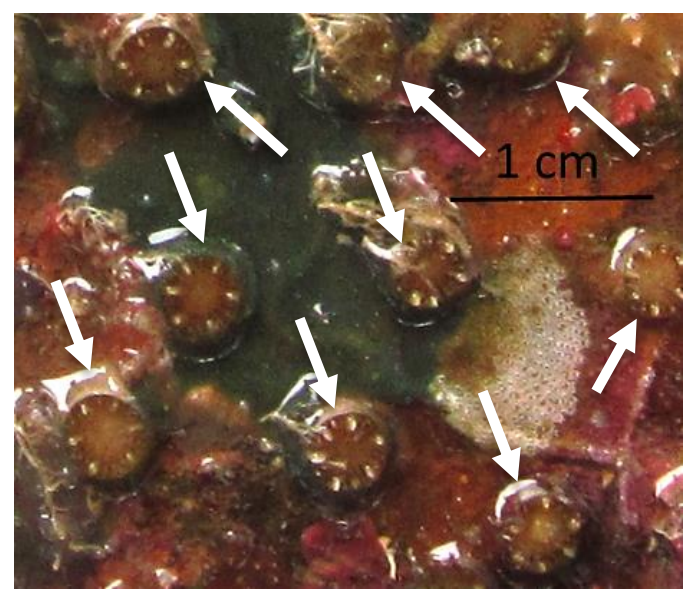

Figure 4.1 Primary polyps (indicated by white arrows) settled on settlement panel used for the fish exclusion experiment. The circular walls (corallites) with the septa of the polyps are visible in the image.

Environmental disturbances and interactions with other organisms cause stress to coral colonies which can display as decrease of coral colony size or a decline in the photosynthetic efficiency (Fv/Fm). The effects of these disturbances can be detected by assessing changes in the size of the coral settlers and variations in photosynthetic efficiency values (Philipp \& Fabricius 2003) measured by an Imaging PAM (I-PAM). Despite the great potential of using the I-PAM in the field of coral physiology, to date only a few publications report its use on coral colonies or fragments (Hill et al. 2004; Ralph et al. 2005; Cooper \& Ulstrup 2009). While more studies have used the I-PAM on coral extracts (Howells et al. 2011), none have used it on juvenile corals.

Digital images and measurements of the photosynthetic efficiency of the colonies were taken. $\mathrm{Fv} / \mathrm{Fm}$ values of the coral juveniles was measured using the MAXI version of the I-PAM (Heinz Walz GmbH, Effeltrich, Germany). The photosynthetic parameters were recorded for the overall tile by placing the tiles, one at a time, in a small tank of seawater in a dark chamber for about 10 minutes to allow acclimation of the photoreceptors before being examined under the I-PAM.

Samples were then placed under the I-PAM camera where the application of pulse amplitude modulated light (PAM) measured different fluorescence parameters on the surface of the tile. A measurement light (ML) captured the minimum fluorescence level (Fo), then, an actinic light (AL) was applied and the maximum fluorescence level $(\mathrm{Fm})$ was recorded. $\mathrm{Fv}$ was the difference between Fm and Fo and the ratio of Fv/Fm indicates the photosynthetic efficiency. The following settings were applied to the I-PAM: Measuring Intensity 1, Measuring 
Frequency 1, Gain 2, Damping 3, Saturating Intensity 10, Red Gain 205, Fm-Factor 1.030, FFactor 1.000 .

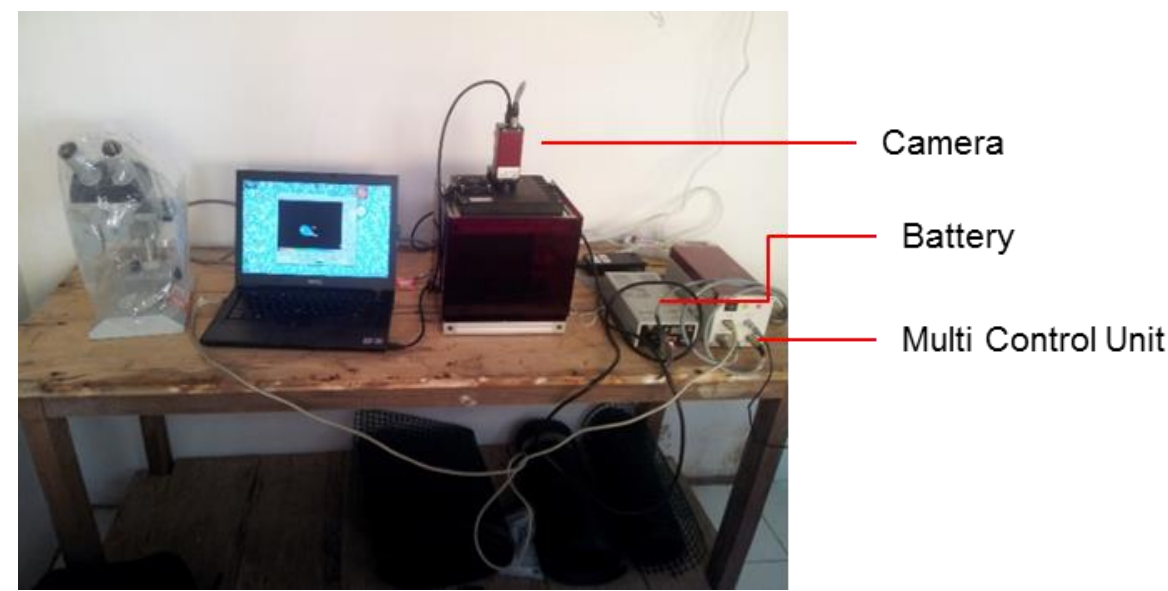

Figure 4.2 Set-up of the I-PAM in the laboratory. The MAXI version of the I-PAM used in my study consisted of: a multi control unit (1) that connects the measuring heads to the camera (2) and is powered by an external battery (3). Measuring heads are positioned on a mounting stand with a bottom plate where the sample is positioned. On the top is the CCD camera. The MCU is also connected to the computer

The segmentation of the frame, analysis and visualisation on a computer screen using the dedicated software ImagingWinGigE V2.45i (see Figure 4.2). Calculation of the photosynthetic values of different areas of the image was performed later using the recorded files. More areas of interest (AOI) were selected on the same image and the software automatically measured the average values of the different fluorescence parameters for each of the selected areas. Comparison of the values between different AOI allowed the detection of differences in fluorescence on the surface. Three different areas (AOI) of each coral juvenile was selected for the measurement of Fv/Fm and a mean was calculated (see Figure 4.3). 


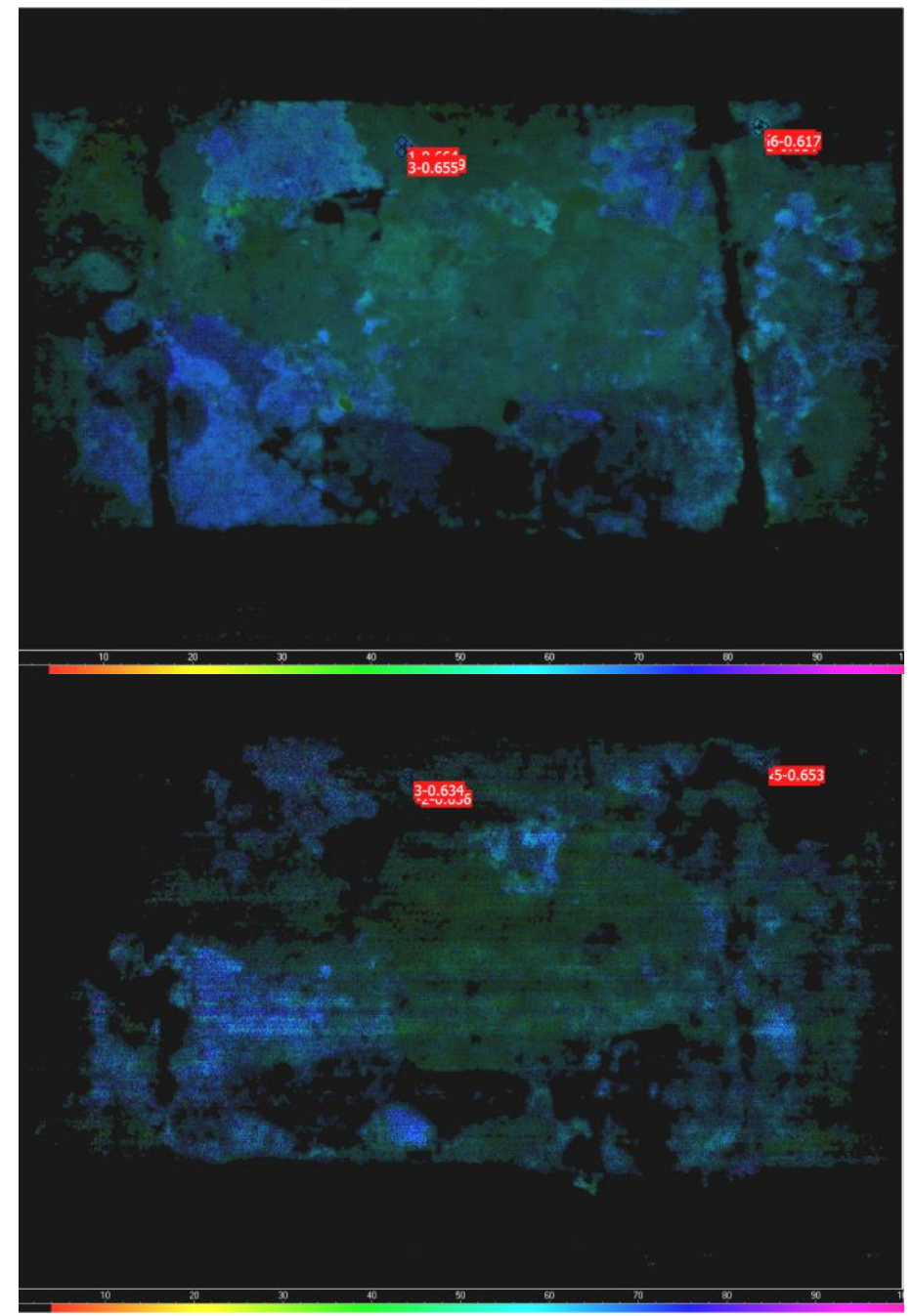

Figure 4.3 The output of the I-PAM analysis. The images were taken of the same tile before (top) and after (bottom) the manipulative experiment. In both digital image the surface of the tile is visible, while the coloration corresponds to the $\mathrm{Fv} / \mathrm{Fm}$ values for each point of the image (below each digital image is reported the scale bar with the corresponding Fv/Fm values). The red labels indicate the mean Fv/Fm values of three different measurements taken for each of the two coral juveniles present on the tile

The panels were then deployed back on reef at $6 \mathrm{~m}$; fifteen panels at each of the two adjacent replicate sites, Buoy 3 and Buoy 4. Panels at each site were randomly assigned to each of three treatments, which consisted of: 1) complete fish exclusion by full cage to protect the panels from grazing; 2) half-cage in order to test for any cage effect; and 3) control, which had no cages. Cages were built using a PVC net with $15 \mathrm{~mm}$ mesh, and were fixed with nails and cable tiles to the reef (see Figure 4.4). Caged tiles were not accessible by macro grazers, such as parrotfish, but smaller fish, such as blennies, may still have been able to pass through the mesh and feed on the tiles. Half-cages were used to assess any cage artefact on the experiment; the half-caged panels were accessible by grazers of all the sizes, as the cages had no tops. 
1)

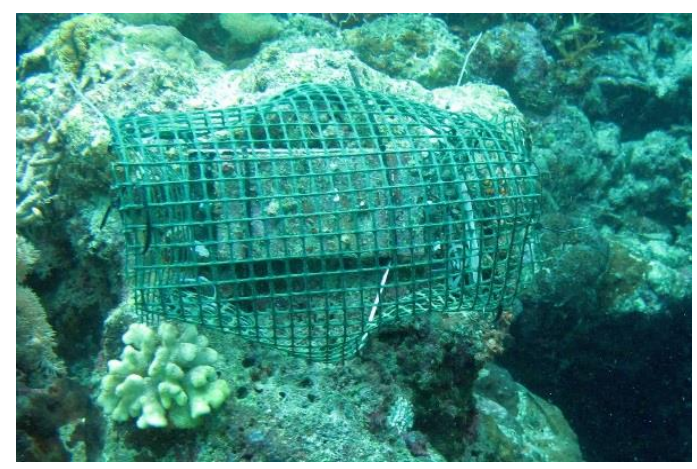

2)

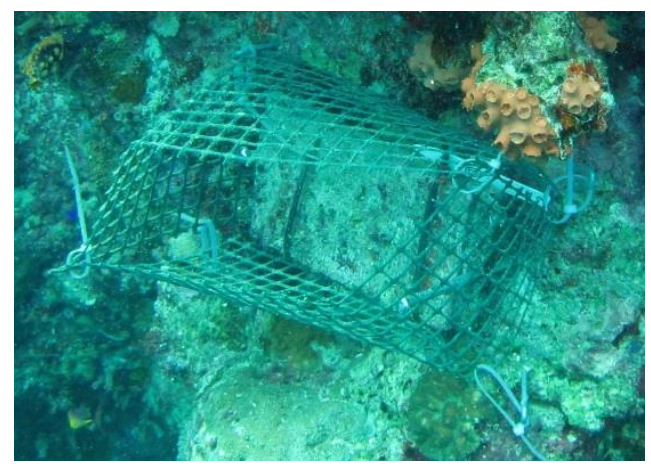

Figure 4.4 Photos of the cage treatments used for the fish exclusion experiment; 1) full cage 2) half-cage, built with a PVC mesh. Full cages completely exclude predation by large fish on the tiles, half-cages have the top side open. The settlement panels were first fixed on the reef wall, treatments (cage, half-cages or control) were then applied haphazardly to the panels

The experimental panels were checked weekly and the mesh of cage treatments was cleaned of algae in order to avoid light shading and sedimentation.

I collected the tiles after 6 weeks, in August 2013, and measured juvenile survival, damage, or change in size. Digital images and Fv/Fm measurement were repeated for each tile following the same procedure used at the beginning of the experiment. Tiles were then bleached following the procedure described in Chapter 2. At the end of the study some of the juvenile colonies were dead from sources other than grazing, such as overgrowth; therefore only coral colonies visible during the initial and the final observation times of the tiles in the laboratory were included in the data analysis for the change in colony size.

Digital images were analysed with Coral Point Count with Excel extensions (CPCe v.4.1; Kohler \& Gill 2006). The maximum length (with an error of $0.1 \mathrm{~mm}$ ) and area (measured using the tool lasso in the software) of each coral settler identified were measured from photos taken at the beginning and end of the experiment. At the end of the experiment, colonies were divided in three groups: survivors, complete mortality (missing colonies), and damaged or 'partial mortality' (which included colonies with either bare skeleton and loss of tissue or partial removal of the skeleton). The effective change in area was measured in $\mathrm{cm}^{2}$ for all the colonies found at the end of the experiment as relative percentage of area loss (the final size was multiplied by 100 , the result was then divided by the initial size). Missing colonies were recorded as having a size loss of $-100 \%$. 


\subsubsection{Data analysis}

Data analysis was limited by the small number of juveniles found at each of the replicate sites, therefore the data for the two replicate sites were pooled together to provide a more robust analysis.

The effect of the caging treatment on juvenile mortality and change in colony size were analysed within PRIMER v.6 (Plymouth Marine Laboratory, UK). The data were transformed by square root and a resemblance matrix was constructed based on a presence/absence matrix using the Jaccard coefficient, where absence indicated the colonies that had died. The effect of the fish exclusion treatment on juvenile mortality was assessed using PERMANOVA with one fixed factor (treatment) with three levels. The effects of the size of the coral and its interaction with the treatment on juvenile mortality were investigated by adding the initial size as covariate in the PERMANOVA analysis.

The effect of cage treatment on colony mortality was assessed by analysing the data on the change in juvenile size. The variation in size of the juvenile colonies were measured as a percentage, considering the initial size as $100 \%$. The data were transformed by square root and a Bray-Curtis dissimilarity matrix was produced. The change in juvenile size between treatments was assessed using PERMANOVA analysis with one fixed factor (treatment). The effect of the initial size of the juveniles on the change in size was investigated by adding the covariate 'initial size' to the PERMANOVA analysis with a one fixed factor (treatment). The interaction between treatment and colony size was also analysed. Wherever a significant difference between treatments was found, a pair-wise post hoc test was carried out in order to examine which treatment was responsible for the differences found.

PERMANOVA analysis was performed in order to assess significant differences in the variation of average Fv/Fm values between treatments. Differences in Fv/Fm values in coral juveniles available to predation were analysed one fixed factor, treatment, with three levels; cage, half-cage and control. Differences in Fv/Fm values in coral juvenile overgrowth were analysed using treatment as fixed factor and overgrowing organisms as a random factor with seven levels.

Turf algae coverage was measured with CPCe, between the digital images taken of each experimental tile before and after the experiment. Variations in coverage were expressed as percentage. I also measured the proportion of coral colonies overgrown by other organisms 
during the experiment and identified the main benthic categories overgrowing the coral colonies.

\subsection{Results}

\subsubsection{Distribution pattern of coral juveniles at the start of the experiment}

Overall, 229 juveniles were found on the back side of the 30 panels used in the experiment; 77 colonies were on tiles in the cages, 77 on the control tiles, and 75 in the half-caged tiles. Other colonies were found partially covered by other benthic organisms or had not developed a recognisable skeleton, and these were excluded from the analysis. Juveniles appeared to have settled randomly on the tiles; some settled directly on the tile surface while others settled on the top of other benthic organisms, such as bivalves and CCA. Since juveniles were not equally distributed between replicate sites and treatments, data were pooled together from the two sites.

Colony number found on individual tiles ranged from 0-64. No colonies were recorded on 6 tiles ( 4 of the control tiles and two of the caged tiles). A total of 64 juveniles colonies were found on a single tile in the control treatment. These juvenile colonies belonged primarly to Family Faviidae and were likely have settled at different times during the experiment due to the range of sizes recorded. The other families identified were Acroporidae, Agariciidae, Pocilloporidae, Poritidae and Dendrophylliidae.

\subsubsection{Mortality of juveniles and importance of colony size}

Four juveniles were missing at the end of the experiment: two in the cage treatment and two in the control. Damaged coral juveniles (considered as partial mortality of the colony) due to predation was rare across all the treatments: two colonies in the cage treatment, one in the control, and one in the half-cage lost tissue and part of the skeleton. Partial mortality with tissue loss from the skeleton that remained bare was never found (Table 4.1).

Overall mortality, both full and partial, was therefore low, only $3.49 \%$ of coral juvenile colonies, and not significantly different between treatments (PERMANOVA, $\mathrm{df}=2, \mathrm{P}=0.11$ ) (Table 4.2). 
Table 4.1 Summary of the total number of coral juveniles present in each treatment (cage, half-cage and control) at the beginning of the experiment and the abundance of the colonies affected by mortality: full (missing coral colonies), partial (tissue loss sometimes followed by skeleton loss) and overall mortality

\begin{tabular}{lcccc}
\hline & Total juveniles at & \multicolumn{3}{c}{ Mortality } \\
& $\begin{array}{l}\text { the beginning of } \\
\text { the experiment }\end{array}$ & Full & Partial & Overall \\
\cline { 3 - 5 } & 77 & $2(2.6 \%)$ & $1(1.3 \%)$ & $3(3.9 \%)$ \\
Cage & 75 & 0 & $2(2.7 \%)$ & $2(2.7 \%)$ \\
Half cage & 77 & $2(2.6 \%)$ & $1(1.3 \%)$ & $3(5.8 \%)$ \\
\hline
\end{tabular}

Table 4.2 Result of the PERMANOVA analysis assessing differences in coral juvenile mortality between three treatments (cage, half-cage and control) in a fish exclusion experiment. Experiment was conducted at $6 \mathrm{~m}$ depth for 6 weeks in the Wakatobi MNP

\begin{tabular}{lccccc}
\hline \multicolumn{1}{c}{ Factor } & df & SS & MS & Pseudo-F & P \\
\hline Treatment & 2 & 436.0 & 218.50 & 1.96 & 0.11 \\
Residual & 82 & 9093.4 & 110.90 & & \\
Total & 84 & 9529.4 & & & \\
\hline
\end{tabular}

Overall, the mean size of juveniles was variable between treatments as a consequence of the different time of settlement and variable growth rate between coral families. In the cage treatment the size of the colonies varied considerably, while in the other two treatments the juveniles were more similar to each other in size (Figure 4.5).

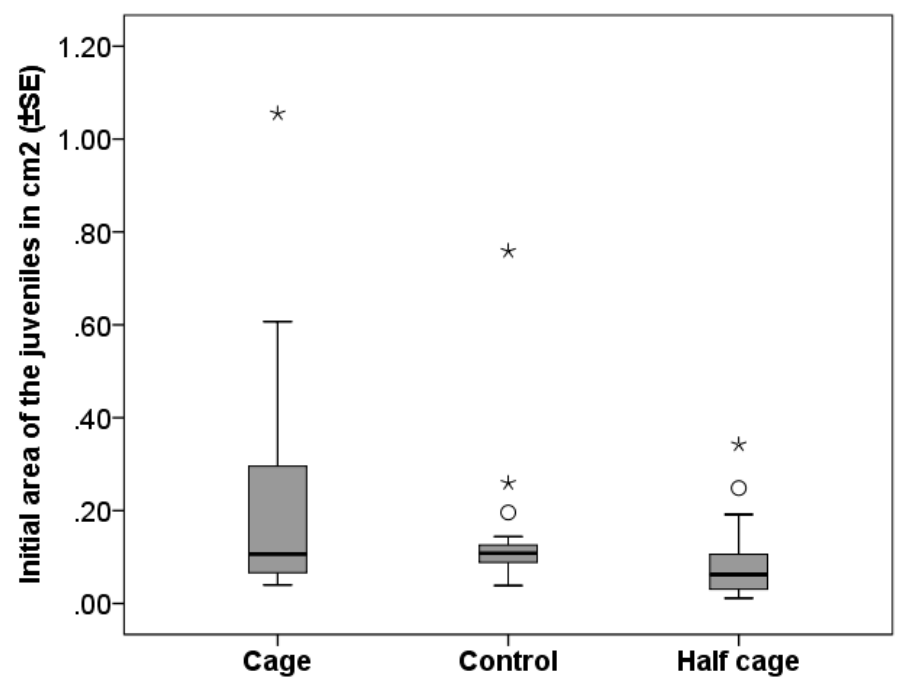

Figure 4.5 Coral juvenile area measured in June 2013, at the beginning of the experiment, in $\mathrm{cm}^{2}( \pm \mathrm{SE})$ of coral juveniles in the three treatments (cage, half-cage and control) used in the experiment. Circles and stars indicate minor and major outlier values, respectively 
Treatment did not affected mortality rate (PERMANOVA, $\mathrm{df}=2, \mathrm{P}=0.0535$ ) and overall the size of the colonies was not a significant factor for the coral mortality (PERMANOVA, $\mathrm{df}=1$, $\mathrm{P}=0.2135)$. The interaction between colony size and treatment was not significant in determining differences in mortality (PERMANOVA, $\mathrm{df}=2, \mathrm{P}=0.6769$ ) (Table 4.3).

Table 4.3 Result of the PERMANOVA analysis assessing the effect of size on the differences in mortality between treatments. Colony size was used as covariate and treatment as the main factor

\begin{tabular}{lccccc}
\hline \multicolumn{1}{c}{ Factor } & df & SS & MS & Pseudo-F & P \\
\hline Colony size & 1 & 105.27 & 105.27 & 0.9529 & 0.2135 \\
Treatment & 2 & 662.95 & 331.47 & 3.0007 & 0.0535 \\
Colony size x Treatment & 2 & 34.46 & 17.23 & 0.1559 & 0.6769 \\
Residual & 81 & 8761.20 & 108.16 & & \\
Total & 84 & 9529.40 & & & \\
\hline
\end{tabular}

\subsubsection{Effect of fish exclusion treatment on variation in coral colony size}

Variation in coral juvenile size was different between treatments, only in the half cage treatment coral juveniles increase their size of an average of $36.86 \%( \pm 10.552 \mathrm{SE})$. In the cage and control treatments I recorded a decrease in coral juvenile size of -8.96 ( $\pm 16.77 \mathrm{SE})$ and $-2.31( \pm 4.64 \mathrm{SE})$ respectively (Figure 4.6).

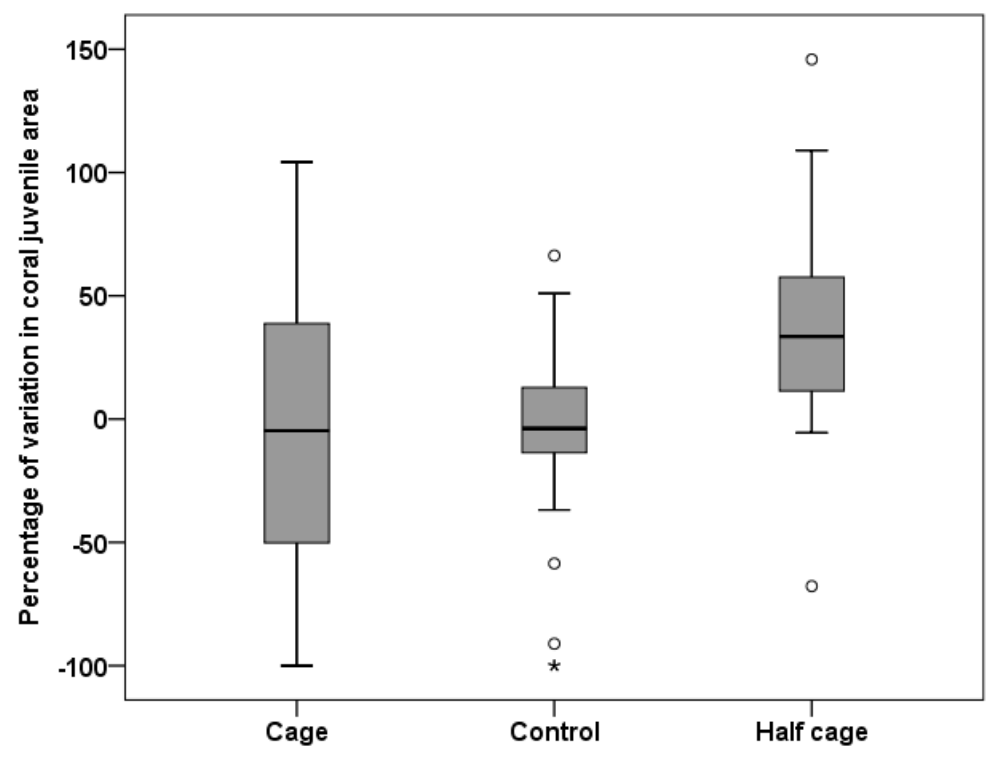

Figure 4.6 Variation in size of coral juvenile colonies showed by treatment (cage, half-cage and control). The average variation by treatment correspond to the black line in the box plots, while the bars show the range of the fluctuation. Circles and stars represents outlier values. Circles and stars indicate minor and major outlier values, respectively 
Overall, the variation in the area of coral juveniles that occurred during the experiment in all the treatments was not significant (PERMANOVA, $\mathrm{df}=2, \mathrm{P}=0.0551$ ) (Table 4.4).

Table 4.4 Result of the PERMANOVA analysis assessing the differences in the variation in area in coral juvenile colonies divided in three treatments (cage, control and half cage) between the beginning and the end of a fish exclusion experiment. Treatments were applied to settlement panels deployed on the reef at $6 \mathrm{~m}$ depth for 6 weeks in the Wakatobi MNP

\begin{tabular}{lccccc}
\hline \multicolumn{1}{c}{ Factor } & df & SS & MS & Pseudo-F & P \\
\hline Treatment & 2 & 627.2 & 313.62 & 2.7407 & 0.0551 \\
Residual & 74 & 8468 & 114.43 & & \\
Total & 76 & 9095.3 & & & \\
\hline
\end{tabular}

When the initial size of the juveniles was included as covariate in the analysis, treatment was found to be statistically significant for differences in the change in size between treatments (PERMANOVA, $\mathrm{df}=1, \mathrm{P}=0.0472$ ) showing that initial size influence the variation of colony size. Overall the initial size of the colony was found to influence relative change in size. Smaller coral colonies increased in size faster than bigger colonies. However, the interaction between colony size and treatment was not statistically significant; change in size was random between treatments (Table 4.5).

Table 4.5 Result of the PERMANOVA analysis detecting the effect of the initial size of juvenile colonies on the change in size for three different treatment groups (cage, control and half cage) in a fish exclusion experiment

\begin{tabular}{lccccc}
\hline \multicolumn{1}{c}{ Factor } & df & SS & MS & Pseudo-F & P \\
\hline Colony size & 1 & 3297.20 & 3297.20 & 46.5160 & $\mathbf{0 . 0 0 0 1}$ \\
Treatment & 2 & 402.24 & 201.12 & 2.8327 & $\mathbf{0 . 0 4 7 2}$ \\
Colony size * Treatment & 2 & 363.03 & 181.51 & 0.0972 & 0.0972 \\
Residual & 71 & 5032.80 & 70.88 & & \\
Total & 76 & 9095.30 & & & \\
\hline
\end{tabular}

The pair-wise test showed that the control and half-cage treatments were the two groups most different from each other with respect to the change in colony size (Table 4.6). 
Table 4.6 Pair-wise post hoc comparison to detect the treatments responsible for the differences found with the PERMANOVA analysis that detected the effect of the initial size of juvenile colonies on the change in size for three different treatment groups (cage, control and half cage)

\begin{tabular}{lcc}
\hline \multicolumn{1}{c}{ Groups } & $\mathbf{t}$ & $\mathbf{P}$ \\
\hline Cage, Control & 1.5568 & 0.1149 \\
Cage, Half cage & 0.2207 & 0.9693 \\
Control, Half cage & 2.3465 & 0.0164 \\
\hline
\end{tabular}

\section{Effect of treatment on variation in Fv/Fm in coral juveniles not affected by grazers}

Measurements of the variation in photosynthetic efficiency of coral juveniles were conducted on only 42 of the $84(50 \%)$ colonies: $57.1 \%$ of the colonies $(n=8)$ in the cage group, $57.9 \%$ $(n=23)$ in half-cage treatments, and $44.2 \%(n=11)$ in the control group.

The largest difference in Fv/Fm values compared to the other treatments occurred in the control; variation in the half-cage treatment was evident, but it did not vary significantly from the others (Table 4.7 and Figure 4.7). Significant variability was found in the variation of average Fv/Fm values between treatments, especially between coral juveniles located in the cage and control group, showing that treatment had an effect on coral juveniles (Table 4.8 and 4.9). 
Table 4.7 Variation in photosynthetic efficiency (Fv/Fm) values occurred in coral juveniles located in three treatments (cage, half-cage and control) during a fish exclusion experiment. Coral juveniles were placed on settlement panels deployed at $6 \mathrm{~m}$ depth on the reef, treatments were applied to the panels haphazardly and the experiment pasted 6 weeks

\begin{tabular}{|c|c|c|c|c|c|}
\hline N. & Treatment & Start mean & End mean & $\Delta$ & Variation (\%) \\
\hline 1 & Cage & 0.430 & 0.444 & 0.014 & 3.18 \\
\hline 2 & Cage & 0.661 & 0.632 & -0.029 & -4.34 \\
\hline 3 & Cage & 0.656 & 0.638 & -0.018 & -2.69 \\
\hline 4 & Cage & 0.648 & 0.688 & 0.039 & 6.07 \\
\hline 5 & Cage & 0.605 & 0.634 & 0.029 & 4.74 \\
\hline 6 & Cage & 0.627 & 0.513 & -0.114 & -18.17 \\
\hline 7 & Cage & 0.560 & 0.638 & 0.077 & 13.80 \\
\hline 8 & Cage & 0.623 & 0.589 & -0.034 & -5.51 \\
\hline 9 & Control & 0.647 & 0.473 & -0.174 & -26.88 \\
\hline 10 & Control & 0.683 & 0.489 & -0.193 & - 28.32 \\
\hline 11 & Control & 0.608 & 0.449 & -0.159 & -26.19 \\
\hline 12 & Control & 0.637 & 0.459 & -0.178 & -27.94 \\
\hline 13 & Control & 0.614 & 0.448 & -0.166 & -26.98 \\
\hline 14 & Control & 0.664 & 0.578 & -0.086 & -12.90 \\
\hline 15 & Control & 0.594 & 0.421 & -0.173 & -29.12 \\
\hline 16 & Control & 0.581 & 0.513 & -0.068 & -11.70 \\
\hline 17 & Control & 0.643 & 0.479 & -0.164 & -25.51 \\
\hline 18 & Control & 0.643 & 0.429 & -0.214 & -33.28 \\
\hline 19 & Control & 0.489 & 0.452 & -0.037 & -7.57 \\
\hline 20 & Control & 0.584 & 0.464 & -0.120 & -20.55 \\
\hline 21 & Control & 0.566 & 0.537 & -0.029 & -5.18 \\
\hline 22 & Control & 0.625 & 0.377 & -0.249 & -39.76 \\
\hline 23 & Control & 0.535 & 0.422 & -0.114 & -21.21 \\
\hline 24 & Control & 0.595 & 0.506 & -0.089 & -14.96 \\
\hline 25 & Control & 0.623 & 0.471 & -0.152 & -24.40 \\
\hline 26 & Control & 0.557 & 0.455 & -0.102 & -18.31 \\
\hline 27 & Control & 0.656 & 0.547 & -0.109 & -16.62 \\
\hline 28 & Control & 0.612 & 0.406 & -0.206 & -33.61 \\
\hline 29 & Control & 0.643 & 0.490 & -0.153 & -23.79 \\
\hline 30 & Control & 0.617 & 0.640 & 0.023 & 3.73 \\
\hline 31 & Control & 0.663 & 0.647 & -0.015 & -2.31 \\
\hline 32 & Half-cage & 0.511 & 0.378 & -0.133 & -25.98 \\
\hline 33 & Half-cage & 0.432 & 0.294 & -0.138 & -32.00 \\
\hline 34 & Half-cage & 0.608 & 0.428 & -0.180 & -29.66 \\
\hline 35 & Half-cage & 0.675 & 0.418 & -0.257 & -38.09 \\
\hline 36 & Half-cage & 0.643 & 0.659 & 0.016 & 2.49 \\
\hline 37 & Half-cage & 0.677 & 0.641 & -0.036 & -5.27 \\
\hline 38 & Half-cage & 0.623 & 0.674 & 0.051 & 8.13 \\
\hline 39 & Half-cage & 0.620 & 0.626 & 0.006 & 0.97 \\
\hline 40 & Half-cage & 0.630 & 0.674 & 0.044 & 6.98 \\
\hline 41 & Half-cage & 0.672 & 0.658 & -0.014 & -2.13 \\
\hline 42 & Half-cage & 0.667 & 0.516 & -0.151 & -22.63 \\
\hline
\end{tabular}




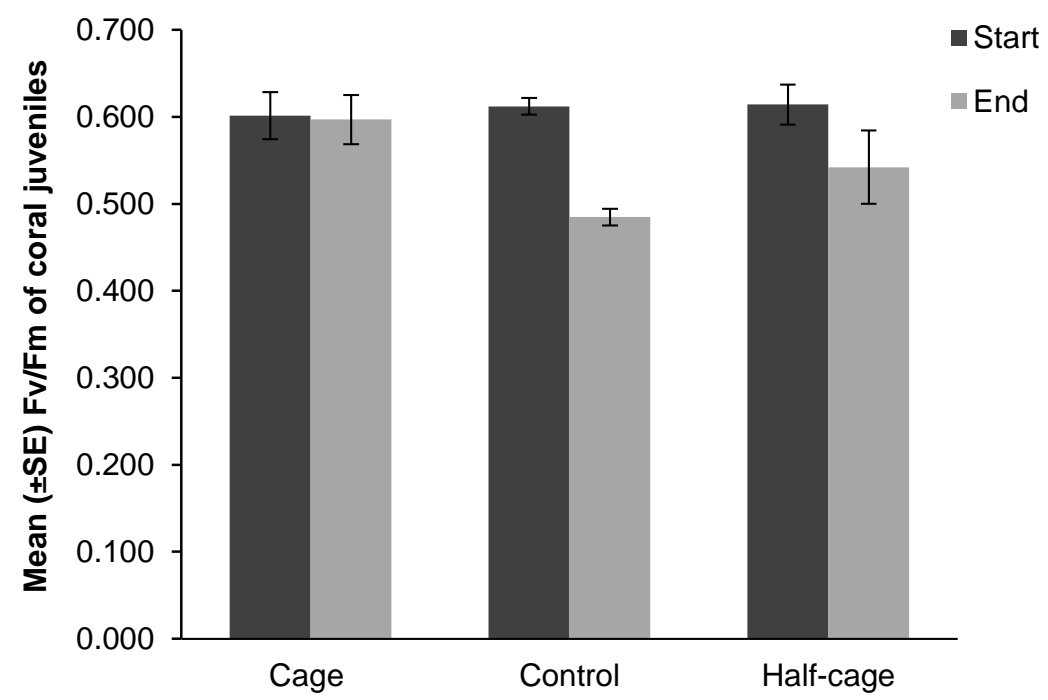

Figure 4.7 Mean ( \pm Standard Error) photosynthetic efficiency $(\mathrm{Fv} / \mathrm{Fm})$ values for coral juveniles placed in three treatments (cage, half-cage and control) at $6 \mathrm{~m}$ depth at Buoy 3 and Buoy 4 in a fish exclusion experiment that lasted 6 weeks. Values were measured at the beginning (dark gray bars) and at the end (light gray bars) of the experiment. A decrease in the mean $\mathrm{Fv} / \mathrm{Fm}$ values was recorded across all treatments and was more evident in the control and half-cage treatments

Table 4.8 Result of the PERMANOVA analysis assessing variations in photosynthetic efficiency (Fv/Fm) values in coral juveniles kept in three different treatments (cage, half-cage and control) occurred in a fish exclusion experiment lasted 6 weeks and conducted at $6 \mathrm{~m}$ depths

\begin{tabular}{lccccc}
\hline \multicolumn{1}{c}{ Factor } & df & SS & MS & Pseudo-F & P \\
\hline Treatment & 2 & 51.6 & 25.8 & 8.0415 & $\mathbf{0 . 0 0 1 4}$ \\
Residual & 39 & 125.0 & 3.21 & & \\
Total & 41 & 176.6 & & & \\
\hline
\end{tabular}

Table 4.9 Pair-comparisons between variation in average Fv/Fm values of coral juveniles between the beginning and end of a fish exclusion experiment using three different treatments (cage, half-cage and control)

\begin{tabular}{lcc}
\hline \multicolumn{1}{c}{ Groups } & $\mathbf{t}$ & $\mathbf{P}$ \\
\hline Cage, Control & 4.56 & $\mathbf{0 . 0 0 0 3}$ \\
Cage, Half-cage & 1.63 & 0.1223 \\
Control, Half-cage & 1.93 & 0.0600 \\
\hline
\end{tabular}

\subsubsection{Assessment of the main benthic categories overgrowing coral juveniles}

A total of $134(58.51 \%)$ of the juveniles initially identified were overgrown by other benthic organisms. These colonies were unevenly distributed between treatments: 56 juveniles were on the caged tiles $(72.8 \%$ of the colonies found at the beginning of the experiment in the cage treatment), 25 juveniles on the control tiles (32.5\% of the initial number of colonies) and 56 colonies on the half-caged tiles ( $74.7 \%$ of the initial number of colonies). Algae were covering 
$73.86 \%$ of the 134 overgrown juveniles, bryozoa $10.82 \%$, and the remainder were covered by sponges, tunicates and other organisms. Among the algae category, the most common taxa found overgrowing juveniles were turf algae (30.52\%), green algae (or macroalgae) (15.8\%) and CCA (11.09\%) (Figure 4.8).

Only 66 of the 134 coral juvenile colonies were overgrown during the experiment; 25 colonies in the cage treatment, 36 in the half-cage and 5 in the control. $80.3 \%$ of the coral colonies were overgrown by algae: $36.36 \%$ by turf algae, $16.67 \%$ by green algae, $18.18 \%$ by red algae and $9.01 \%$ by CCA (Figure 4.8 ).

The proportion of benthic groups overgrowing coral juveniles before the beginning of the experiment, measured at the first laboratory analysis, and during the experiment was similar. Benthic groups colonised exposed tiles similarly to before being exposed, however this finding can be due to grown of benthic organisms already present on the tiles. Sponge did not overgrown coral juveniles during the experiment duration; this could be due to their preferences for more cryptic habitat, such as the lower part of the settlement panel. There are few differences between treatments; tunicates overgrown juveniles only in the cage treatment, red algae and turf algae did not overgrown and juvenile in the half-cage treatment. These differences are more likely due to different exposition of the tiles rather than to cage effect.

During the experiment an increase in turf algal coverage was observed on the tiles, which was consistent between treatments (PERMANOVA, $\mathrm{df}=2, \mathrm{P}>0.05$ ). 


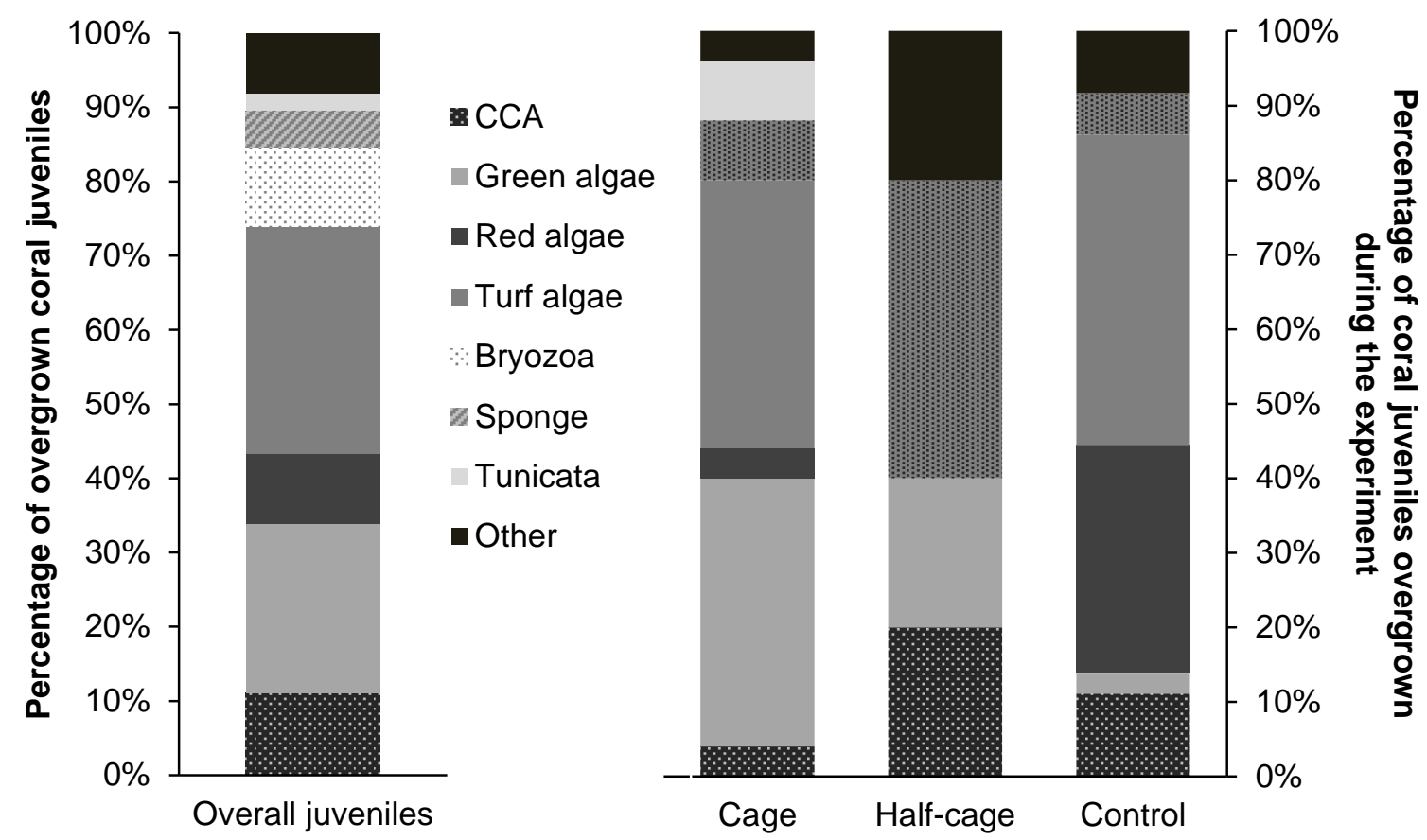

Figure 4.8 Percentages of the coral juveniles colonies overgrown by benthic families in three treatments (cage, half-cage and control) during a fish exclusion experiment conducted at $6 \mathrm{~m}$ depth. On the left: overall juvenile colonies found overgrown at the end of the experiment; on the right: juveniles colonies overgrown during the 6 weeks of experimental period.

\section{Effect of overgrowing benthic organisms on variation in Fv/Fm in coral juveniles}

Analysis of photosynthetic efficiency was assessed only on coral juvenile colonies not completely overgrown and where the Fv/Fm values were recordable both at the beginning and at the end of the experiment (Table 4.10).

Overall, a decrease in Fv/Fm values occurred in all the three treatments and there were no differences between treatments (Figure 4.9).

Table 4.10 Variation in Fv/Fm values between the beginning and the end of the experiment in coral juveniles overgrown by different benthic groups. Coral juvenile colonies were divided by treatment (cage, control and half-cage) and overgrown benthic group

\begin{tabular}{cllcccc}
\hline $\mathbf{N}$. & Treatment & Overgrown by & Start mean & End mean & $\boldsymbol{\Delta}$ & Variation (\%) \\
\hline 1 & Cage & Bryozoa & 0.519 & 0.664 & 0.145 & -0.15 \\
2 & Cage & Bryozoa & 0.549 & 0.690 & 0.141 & -0.14 \\
3 & Cage & CCA & 0.617 & 0.643 & 0.026 & -0.03 \\
4 & Cage & Green algae & 0.635 & 0.643 & 0.008 & -0.01 \\
5 & Cage & Green algae & 0.630 & 0.252 & -0.378 & 0.38
\end{tabular}




\begin{tabular}{|c|c|c|c|c|c|c|}
\hline N. & Treatment & Overgrown by & Start mean & End mean & $\Delta$ & Variation (\%) \\
\hline 6 & Cage & Green algae & 0.667 & 0.000 & -0.667 & 0.67 \\
\hline 7 & Cage & Green algae & 0.608 & 0.165 & -0.443 & 0.44 \\
\hline 8 & Cage & Green algae & 0.611 & 0.000 & -0.611 & 0.61 \\
\hline 9 & Cage & Green algae & 0.631 & 0.682 & 0.051 & -0.05 \\
\hline 10 & Cage & Green algae & 0.651 & 0.725 & 0.074 & -0.07 \\
\hline 11 & Cage & Green algae & 0.518 & 0.420 & -0.098 & 0.10 \\
\hline 12 & Cage & Green algae & 0.604 & 0.616 & 0.012 & -0.01 \\
\hline 13 & Cage & Green algae & 0.557 & 0.243 & -0.314 & 0.31 \\
\hline 14 & Cage & Green algae & 0.671 & 0.651 & -0.020 & 0.02 \\
\hline 15 & Cage & Green algae & 0.651 & 0.000 & -0.651 & 0.65 \\
\hline 16 & Cage & Green algae & 0.659 & 0.000 & -0.659 & 0.66 \\
\hline 17 & Cage & Tunicata & 0.631 & 0.671 & 0.040 & -0.04 \\
\hline 18 & Cage & Turf & 0.671 & 0.592 & -0.079 & 0.08 \\
\hline 19 & Cage & Turf & 0.639 & 0.616 & -0.023 & 0.02 \\
\hline 20 & Cage & Turf & 0.651 & 0.647 & -0.004 & 0.00 \\
\hline 21 & Cage & Turf & 0.622 & 0.675 & 0.053 & -0.05 \\
\hline 22 & Cage & Turf & 0.651 & 0.498 & -0.153 & 0.15 \\
\hline 23 & Cage & Turf & 0.243 & 0.235 & -0.008 & 0.01 \\
\hline 24 & Control & Bryozoa & 0.571 & 0.630 & 0.059 & -0.06 \\
\hline 25 & Control & Bryozoa & 0.578 & 0.510 & -0.068 & 0.07 \\
\hline 26 & Control & $\mathrm{CCA}$ & 0.447 & 0.361 & -0.086 & 0.09 \\
\hline 27 & Control & $\mathrm{CCA}$ & 0.572 & 0.374 & -0.198 & 0.20 \\
\hline 28 & Control & Green algae & 0.650 & 0.000 & -0.650 & 0.65 \\
\hline 29 & Control & Green algae & 0.635 & 0.482 & -0.153 & 0.15 \\
\hline 30 & Control & Green algae & 0.617 & 0.646 & 0.029 & -0.03 \\
\hline 31 & Control & Sponge & 0.552 & 0.341 & -0.210 & 0.21 \\
\hline 32 & Control & Sponge & 0.094 & 0.180 & 0.086 & -0.09 \\
\hline 33 & Control & Turf & 0.715 & 0.671 & -0.044 & 0.04 \\
\hline 34 & Control & Turf & 0.710 & 0.631 & -0.079 & 0.08 \\
\hline 35 & Control & Turf & 0.591 & 0.391 & -0.200 & 0.20 \\
\hline 36 & Control & Turf & 0.676 & 0.663 & -0.013 & 0.01 \\
\hline 37 & Control & Turf & 0.658 & 0.000 & -0.658 & 0.66 \\
\hline 38 & Control & Turf & 0.575 & 0.528 & -0.048 & 0.05 \\
\hline 39 & Half cage & Ascidian & 0.573 & 0.404 & -0.169 & 0.17 \\
\hline 40 & Half cage & $\mathrm{CCA}$ & 0.628 & 0.480 & -0.148 & 0.15 \\
\hline 41 & Half cage & CCA & 0.651 & 0.640 & -0.011 & 0.01 \\
\hline 42 & Half cage & $\mathrm{CCA}$ & 0.580 & 0.608 & 0.028 & -0.03 \\
\hline 43 & Half cage & Green algae & 0.627 & 0.510 & -0.117 & 0.12 \\
\hline 44 & Half cage & Green algae & 0.533 & 0.424 & -0.109 & 0.11 \\
\hline 45 & Half cage & Green algae & 0.549 & 0.435 & -0.114 & 0.11 \\
\hline 46 & Half cage & Green algae & 0.624 & 0.000 & -0.624 & 0.62 \\
\hline 47 & Half cage & Turf & 0.533 & 0.000 & -0.533 & 0.53 \\
\hline 48 & Half cage & Turf & 0.639 & 0.518 & -0.121 & 0.12 \\
\hline
\end{tabular}




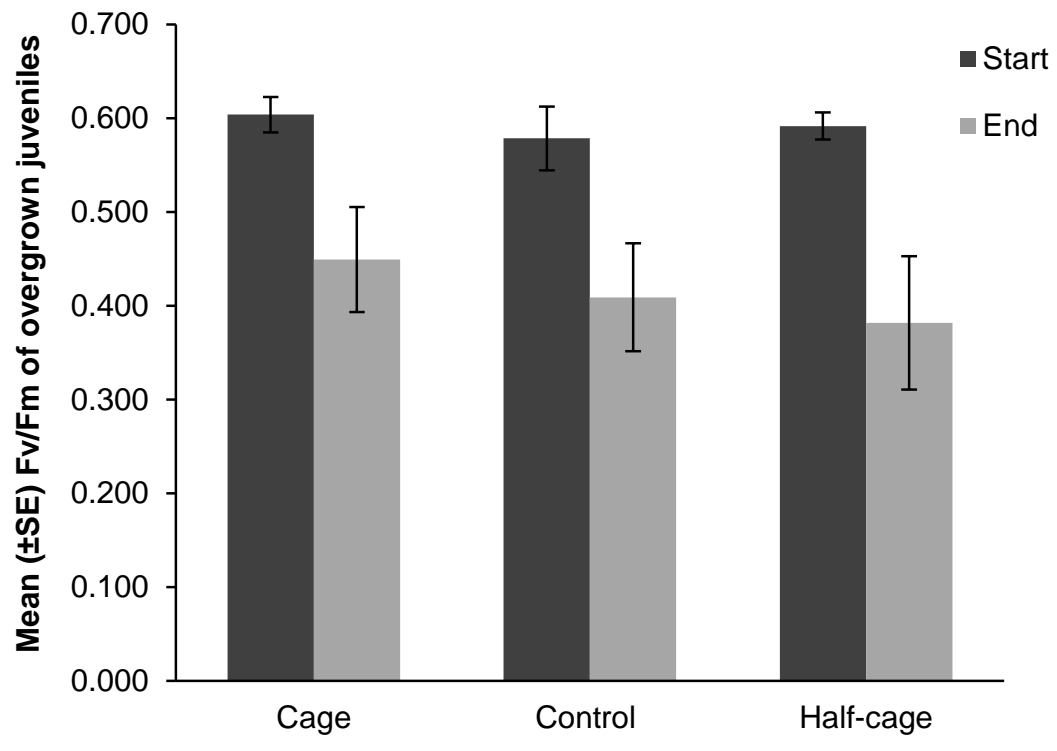

Figure 4.9 Variation in mean ( \pm Standard Error) Fv/Fm values in coral juveniles overgrown by benthic organisms and subjected to three different treatments (cage, control and half cage) in a fish exclusion experiment for 6 week at $6 \mathrm{~m}$ depth

Table 4.11 Summary of the average values of Fv/Fm recorded in coral juveniles subjected to three different treatments (cage, half-cage and control) and overgrown by different benthic organisms during a fish exclusion experiment. Because of the nature of this study, cases are distributed haphazardly between treatments and benthic groups

\begin{tabular}{|c|c|c|c|c|c|}
\hline \multirow{2}{*}{ Overgrown by } & \multirow{2}{*}{ Treatment } & \multicolumn{2}{|c|}{$\begin{array}{l}\text { Between benthic } \\
\text { groups }\end{array}$} & \multicolumn{2}{|c|}{$\begin{array}{c}\text { Benthic groups by } \\
\text { treatment }\end{array}$} \\
\hline & & Start & End & Start & End \\
\hline Ascidian (1) & Half-cage & 0.573 & 0.404 & 0.573 & 0.404 \\
\hline \multirow[t]{2}{*}{ Bryozoan (4) } & Cage (2) & & & 0.534 & 0.677 \\
\hline & Control (2) & 0.554 & 0.624 & 0.574 & 0.570 \\
\hline \multirow[t]{3}{*}{$\operatorname{CCA}(6)$} & Control (2) & & & 0.510 & 0.368 \\
\hline & Cage (1) & & & 0.617 & 0.643 \\
\hline & Half-cage (3) & 0.583 & 0.518 & 0.620 & 0.576 \\
\hline \multirow[t]{3}{*}{ Green algae (20) } & Cage (13) & & & 0.623 & 0.338 \\
\hline & Control (3) & & & 0.634 & 0.376 \\
\hline & Half-cage (4) & 0.616 & 0.345 & 0.583 & 0.342 \\
\hline Sponge (2) & Control (2) & 0.323 & 0.261 & 0.323 & 0.261 \\
\hline Tunicate (1) & Cage & 0.631 & 0.671 & 0.631 & 0.671 \\
\hline \multirow[t]{3}{*}{ Turf algae (14) } & Cage (6) & & & 0.580 & 0.544 \\
\hline & Control (6) & & & 0.654 & 0.481 \\
\hline & Half-cage (2) & 0.612 & 0.476 & 0.586 & 0.259 \\
\hline
\end{tabular}


The samples were divided by the benthic organism that had overgrown them and by treatment to investigate the effects of interactions between treatment and benthic group on the photosynthetic efficiency of coral juveniles (Table 4.11).

Overall, the variation in Fv/Fm values was evident by benthic groups overgrowing the coral juvenile colonies. Especially green and turf algae affected the photosynthetic efficiency of the colonies (Figure 4.10), losing 44\% and $22.2 \%$ of their initial Fv/Fm value.

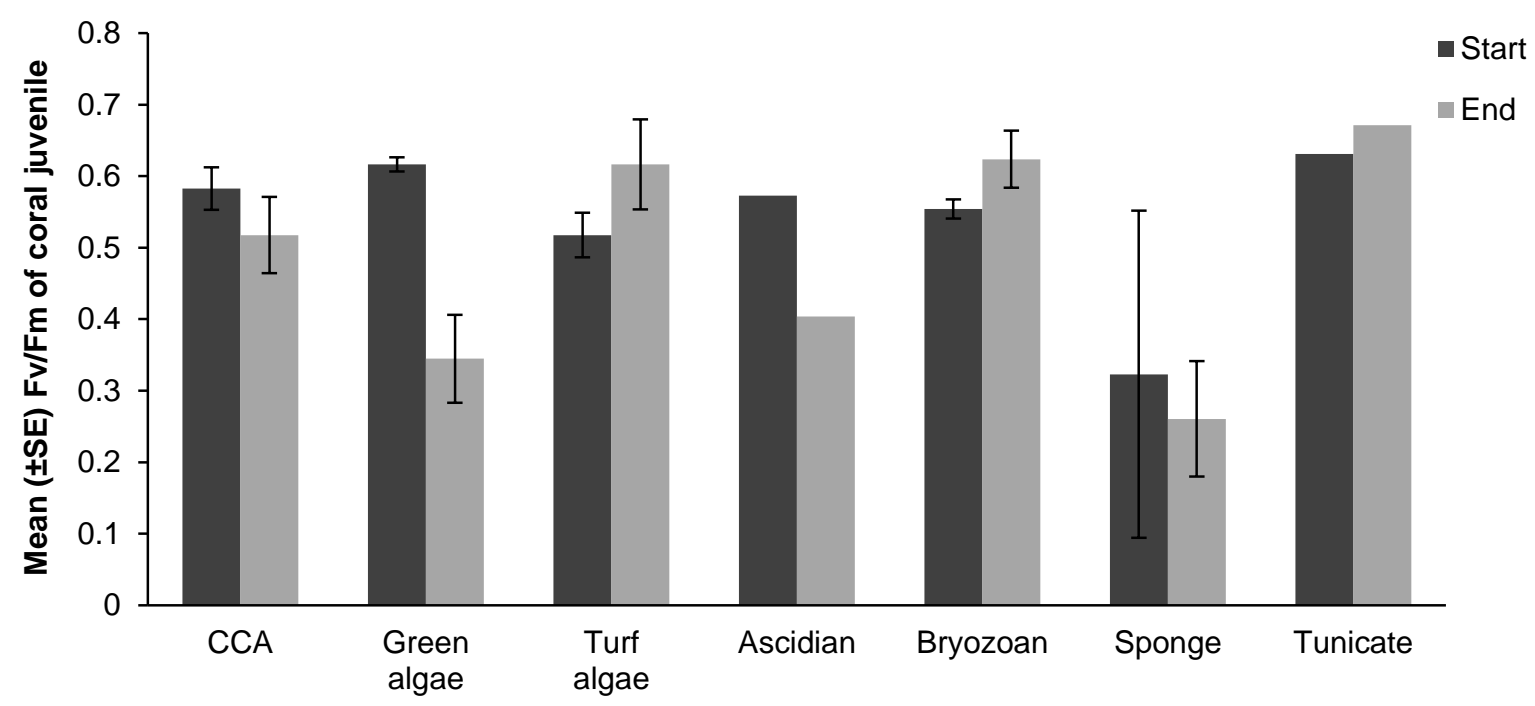

Figure 4.10 Mean ( \pm Standard Error) Fv/Fm values in coral juveniles overgrown by different benthic organisms during a fish exclusion experiment for 6 weeks. Ascidian and tunicate data are based on only one sample and therefore do not have error bars. The difference between the bars at the beginning and at the end of the experiment show the variation in Fv/Fm value that occurred for each benthic group involved in the interaction with coral juveniles

Despite the evident fluctuation in the Fv/Fm values, the PERMANOVA analysis of the differences in variation between treatment or benthic organisms overgrowing the coral did not show any significant differences (Table 4.12). This result might be due to the small number of samples or the absence of samples from some groups.

Table 4.12 Results of the PERMANOVA analysis assessing the variation in Fv/Fm in coral juveniles subjected to three different treatments (cage, control and half cage) and overgrown by different benthic organisms during a fish exclusion experiment

\begin{tabular}{lccccc}
\hline \multicolumn{1}{c}{ Factor } & df & SS & MS & Pseudo-F & P \\
\hline Treatment & 2 & 39.05 & 19.52 & 13.99 & 0.3388 \\
Overgrown by & 6 & 186.59 & 31.1 & 13.79 & 0.2482 \\
Treatment * Overgrown & 5 & 60.94 & 12.19 & 0.54 & 0.7436 \\
Residual & 34 & 766.66 & 22.55 & & \\
Total & 47 & 1098.50 & & & \\
\hline
\end{tabular}




\subsection{Discussion}

In this chapter, I investigated the impact of predation on coral juvenile survivorship. The fish exclusion treatment conducted did not increase juvenile survivorship rates. Mortality due to grazing activity, either full or partial (damaged colonies), affected only $3.49 \%$ of the juvenile. Juvenile mortality was found in all the treatments and the size of juvenile did not influence mortality rate. Changes in size were detected in the juvenile colonies not affected by predation; colony growth or reduction in size was also consistent between treatments. Initial colony size was important in determining differences in change in size between treatments. Differences in decrease in photosynthetic efficiency values between treatments suggest that coral juveniles exposed to fish grazing are more stressed. At the end of the experiment, $28.38 \%$ of the colonies initially identified were found overgrown by other benthic organisms, mostly algae. However, only green algae and turf algae caused significant stress in coral colonies.

Overall, grazing and corallivours fish did not induced mortality in coral juvenile population, although the grazing activity caused some stress to the colonies. The impact of the coral juvenile overgrowing process by other benthic organisms, particularly with algae, was likely to affect coral juveniles survivorship.

\subsubsection{Low impact of grazing fish on juvenile survivorship}

Predation by fish did not appear to be the main cause of mortality in young coral populations in the Wakatobi; the exclusion of grazers did not significantly affect coral survival between different treatment groups. Mortality between treatments was similar: only four recruits were completely missing at the end of the experiment and five were affected by partial mortality that was likely connected to grazing activity. In previous caging experiments conducted with recruits that were only a few weeks old, the mortality rate was correlated with exposure to grazers, with corals on control tiles having the highest mortality compared to those protected by cages (Penin et al. 2011; Trapon et al. 2013c). The authors suggested that grazing fish were the main group responsible for recruit mortality. However in my study, full mortality, despite its low rate, was found only in the cage and half-cage treatments, while no recruits were missing from the control tiles, despite them being fully exposed and available to predators.

A fish survey conducted in the Wakatobi in 2011 found the overall grazing fish biomass on the reef crest of my research site to be $83.71( \pm 10.89) \mathrm{kg} / 250 \mathrm{~m}^{2}$ with this values increasing to $102.55( \pm 15.02) \mathrm{kg} / 250 \mathrm{~m}^{2}$ when occasional grazers and corallivores were included (Curtis- 
Quick 2013). These values are much higher than those found at other locations: on the Great Barrier Reef parrotfish abundance was found to be up to $7.1( \pm 0.3) \mathrm{kg} / 250 \mathrm{~m}^{2}$ (Trapon et al. 2013c), while the overall grazing fish was $5 \mathrm{~kg} / 250 \mathrm{~m}^{2}$ (Hoey \& Bellwood 2008). At Lizard Island it was between $10.5( \pm 3.0) \mathrm{kg} / 250 \mathrm{~m}^{2}$ and $21.8( \pm 3.8) \mathrm{kg} / 250 \mathrm{~m}^{2}($ Brandl et al. 2013) and in the Caribbean it was over $5.25 \mathrm{~kg} / \mathrm{m}^{2}$ (Sandin \& McNamara 2012). Trapon et al. (2013c) found a correlation between parrotfish abundance and recruit mortality. In the Wakatobi, Achanturidae and Scaridae were the most common families, however unlike Trapon et al. (2013c) I did not observe scars left by bigger grazers like parrotfish on my experimental tiles. The lack of scars suggest that grazing could be due mostly to small fish that were able to move through the cage mesh. In my experiment, the corals on the caged tiles were apparently affected similarly to those in the control treatment, suggesting similar grazing effects between treatments. This result contrasts with the findings of a study by Hughes et al. (2007), who found the abundance of grazers in the cages to be lower than for other treatments, such as control and open cages, by up to seven times.

Baria et al. (2010) found that the exclusion of predators in cage treatments actually increased coral recruit mortality due to competition with algae. At the same time, they found that tiles in half-cages were accessible only to small fish and grazing invertebrates. These grazers were likely regulating the algal growth without removing recruits, resulting in low coral mortality (Miller \& Hay 1998). In my experiment the number of damaged colonies in the cages was low and might be due to the low abundance of small fish, such as blennies and wrasses, in the Wakatobi, however data on small size fish in the Wakatobi were not available.

For all of the treatments, size of the juveniles apparently did not influence the possibility of their being accidentally removed from the tiles or damaged by grazing fish. Differences in size were low between colonies, although the juveniles belonged to different families and settled at different times, as a consequence there was not really a sufficient number of colonies of different sizes to test the effect of the size.

In my experiment the complex substratum on the tiles presented several cryptic microhabitats that offered protection to the coral colonies. The efficiency of refuges in enhancing recruit survivorship against predation has been assessed in multiple studies (Nozawa 2008; Brandl et al. 2013; Cooper et al. 2014; Edmunds et al. 2014b). However, the benefit of refuges was available only to small recruits, which were the optimal size to occupy the more effective refuges (Gleason 1996), and the colonies that exceeded this size were more easily accessible 
by grazers and predators (Brandl et al. 2013). In my research most of the colonies were small and had only a few polyps, however I did not assess their position on the tiles to detect the effect of refuges on juvenile survivorship.

Overall, the small number of juveniles and their similarity in size did not allow me to obtain robust results and assess any correlation between mortality, colony size, and treatment. However I assessed that grazing might have a role on variation of coral Fv/Fm values; coral juveniles in fish exclusion treatment did not showed decline in Fv/Fm. This finding needs to be further investigated to assess the impact of grazing activity on coral juvenile physiology.

\subsubsection{Consistent change in size in coral colonies between treatments}

I also found that the change in coral colony size was not affected by the treatment but it was correlated with the size of the colonies. Despite smaller colonies being more likely to increase in size and bigger colonies being more likely to reduce in size, it was not possible to assess any specific correlation in my experiment.

Different benthic organisms, known to interfere with the coral growth rates, were present on the experimental tiles; for example, algae such as CCA and turf algae. During my study I found an increase in turf algae of approximately $15 \%$ on the experimental tiles and this was consistent between treatments. When algal regulation is missing (e.g. from grazers), algae increase in abundance and compete for the available space. In cases of contact between algae and coral colonies, often the first response of corals is to shrink before being eventually being overgrown by the algae (Davies et al. 2013). However, in my study I did not measure the interaction between benthic organisms and juveniles in order to assess the nature of their relationship (see Chapter 5).

\subsubsection{Low competence of coral juveniles for competition with other benthic organisms}

Over the course of my experiment, $28.38 \%$ of the juveniles initially identified were covered by other benthic organisms. Overgrowth was common in all the treatments. In accordance with previous studies (see Lirman 2001; Box \& Mumby 2007; Trapon et al. 2013c), a large proportion $(73.9 \%)$ of the overall overgrown juveniles were found partially or completely covered by algae, especially by turf algae and CCA. It was not possible to determine if overgrowth was the cause of colony death or if the coral died as a result of other stressors before being covered. 
Adult corals are stronger competitors than turf algae, and when turf algae was found overgrowing corals it usually indicated death from other causes (Hughes 1989; Coyer et al. 1993). It is also possible that coral juveniles are overgrown by turf algae only after colony death due to other reasons (reviewed by McCook et al. 2001). However, juvenile colonies overgrowth by either turf and green algae showed a decrease in Fv/Fm; it is not excluded that juveniles death is a consequence of overgrown, but full mortality takes longer than 6 weeks, which was the duration of this study. It is possible that initially coral juveniles are more resistant to overgrowing organisms and use their energy to react; this behaviour would explain the decrease in Fv/Fm without either mortality or overgrown. However, this study do not inform about later stages of the overgrowing process, so it is not possible to assess if the coral juvenile died and if this happens before or after being completely covered.

\subsubsection{Limitations of the experimental design}

The experimental design used in this study was improved after a preliminary study conducted in 2012 in order to assess the effect of predation and sedimentation on coral recruit survival (see Appendix I). In the present study I enhanced the previous experiment design with a new set-up and minimised disturbance. However, despite the precautions taken, it is possible that a certain amount of disturbance was still present.

The distribution of juveniles was unbalanced between my treatments. Coral larvae were left settling naturally on the submerged panels and the panels were randomly distributed between treatments to avoid any bias. As a consequence there was a high variability in abundance and species between experimental tiles. Although the overall number of juveniles was similar between treatments, it was different between sites. At the end of the experiment the number of juveniles available for the data analysis was unequal between treatments.

The age of the tiles had an impact on the outcome. In previously published experiments clean tiles were used to carry out similar studies with few-week old recruits, mostly settled in controlled conditions. Those tiles were first pre-conditioned in seawater in order to obtain a biofilm on the surface, which promoted larvae settlement (Baria et al. 2010; Penin et al. 2011; Trapon et al. 2013b) and also algal growth. In contrast, the panels used in my experiment presented a complex substratum after being submerged for two years; many benthic invertebrates and algae occupied the surfaces, sometimes overgrowing each other. The advantage of using older tiles was that they were more similar to natural conditions (Brandl et 
al. 2013), but as a consequence my results are not directly comparable with those of previous studies.

It is known that artefacts used in manipulative experiments can have an impact on the results (Hall et al. 1990; Lewis 1996; Connell 1997b; Cooper et al. 2014). In particular, the use of cages in order to examine the effect of predators on benthic invertebrate survivorship, such as that of coral, sponges and barnacles (Jenkins et al. 1999; Powell 2013; Cooper et al. 2014), has been long discussed. Half-cages are largely used to test the effect of the artefact; their open side allows access to big fish and other predators to the tiles, while small fish have the freedom to move within the cages in the half cage and control treatments. As a consequence, differences found between the half-cage and control treatments are likely to be due to the cage artefact.

Cages have also been criticised for their potential to modify water flow, reduce light availability, and change the amount of nutrients inside the cage (Connell 1997b; Box \& Mumby 2007). In order to minimise any effect due to the cages, in my experiment the full and halfcages were cleaned weekly to remove fouling organisms and algae that had settled on the mesh, which were likely to trap sediments and shade light from the tiles.

There were some impediments to the collection of data on photosynthetic efficiency of the coral colonies. Despite the great potential of the I-PAM I could not detect any variation in the photosynthetic efficiency of part of the coral juveniles. Panels were mostly covered by benthic organisms and, despite the $0.5 \mathrm{~mm}$ resolution of the I-PAM camera, it was difficult to localise juveniles on the images recorded by the I-PAM because of their short distance from the benthos. Some images, especially those taken at the end of the experiment, presented some noise, for example the fluorescence of the seawater in the tank might have disturbed the recordings. Despite the adjustment of the I-PAM settings, noise was still present. To improve the use of the I-PAM for a future experiment, more precise mapping of the position of the coral juveniles could be undertaken before the beginning of the experiment and the neighbouring benthic organisms could be scraped off from the tiles.

Some improvements were identified to enhance this experimental design for a future study. A longer duration for the experiment that included additional time for the initial examination of the tiles would allow more precise counts and measurements of the juveniles to be made, and would enable a more balanced redistribution of the juveniles between sites and treatments. In addition, I would also examine the position of the juveniles to see if they were located in crevices or in more exposed locations on the tiles. Furthermore, in order to better assess the 
effect of grazing, I would consider scraping off organisms that could interfere with juvenile survivorship, such as ascidians and sponges, from the tiles. This action would also improve the efficiency of the I-PAM measurements on the smaller juvenile colonies. During the experiment, periodic measurements of light availability and sedimentation rate inside the full and half-cages would also help to better understand the role of light in juvenile mortality.

This study explored the role of grazing on juvenile corals (as opposed to coral recruits or adults) using colonies grown in situ that had not been exposed to grazing before. Based on the outcomes (and the limitations identified above), predation is unlikely to be the driver of juvenile mortality and other factors apparently play a role in regulating the life history of corals in the post-settlement phase. The relationship with other benthic organisms likely influenced the juvenile growth and the mortality processes. Algae were the most common organisms associated with overgrown juvenile colonies, although I did not recorded mortality in overgrown coral colonies, green and turf algae cause high stress to juveniles and impacted their survivorship. 


\section{Chapter 5 Influence of ecological succession on coral recruitment}

\subsection{Abstract}

During the colonisation of new substrates, associative and competition processes occur that shape the benthic assemblage. Coral recruitment patterns are influenced by the development of the benthos and some benthic groups, such as crustose coralline algae (CCA), promote or inhibit coral settlement and growth. The interactions between juvenile corals and benthic organisms can influence coral survivorship. In this chapter, I investigated the initial colonisation of artificial bare substrate, the impact of the developing benthic assemblage on coral recruitment and the interactions occurring between benthic organisms and juveniles. Settlement panels were deployed for one and two year periods on reefs in the Wakatobi Marine National Park (South Sulawesi, Indonesia) to examine changes in the benthic community over time. Marked changes occurred in the relative coverage of the benthic organisms across years and on the sides of the panels. The front sides of panels were characterised by algae, especially CCA and turf algae, in both years, while on the back of the panels there was a shift from invertebrate dominance, mostly bryozoans, to equal coverage of invertebrates and algae. In the second year, benthic organisms grew both horizontally and vertically, and consequently the assemblage complexity increased, especially on the back of the panels. Approximately $10 \%$ of the panel substrate remained bare in the second year. The benthic coverage was not correlated with coral recruitment patterns, however in the second year recruitment rates were higher on the back side of the panels, where the benthic structure was more complex. There was an increase in the number of interactions between coral juveniles and benthic organisms in the second year, but this was not linearly correlated with the increase in juvenile abundance. The highest number of spatial interactions involving coral juveniles occurred with CCA and the most common outcomes were stand-offs, where no organism was prevailing on the others. Coral juveniles were rarely found overgrowing CCA, bryozoans and bivalves, but they were partially overgrown by CCA, sponges and tunicates, despite the high coral survival rate suggests that overgrowth was unlikely to be the main cause of juvenile mortality. Overall, my study showed that changes in the benthic assemblage was not correlated with coral recruitment rates, however changes in benthic structural complexity may promote coral juvenile survivorship. 


\subsection{Introduction}

Coral reefs support many organisms with complex interactions and species associations that are fundamental for maintaining diversity (Jackson \& Buss 1975). For example, reef fish diversity, abundance and biomass, and coral cover are positively correlated with reef complexity (Pratchett et al. 2014). High reef complexity provides refuges to many marine species from predation, shelters, and resources to reproduce and feed (Graham \& Nash 2013). Loss of reef complexity due to different stressors, such as bioerosion caused by high densities of sea urchins, leads to degradation and modification of the habitat (McClanahan \& Shafir 1990). Algal cover increases on bare reef substrate freed by the loss of other benthic organisms, such as corals; these changes affect the existing interactions and associations (Hughes et al. 2010). Therefore, the structure of the reef is considered an indicator of the health of the reef ecosystem.

Benthic assemblage composition is influenced by a range of physical and biological factors and the relationships, both intra- and inter-specific, between the different populations (Vermeij 2006). The processes that shape benthic assemblages are dynamic and vary in the time; they include seasonal abiotic and biological factors, such as larvae availability (Fairfull \& Harriott 1999; Glassom et al. 2004), fluctuations in environmental parameters (Haas et al. 2010), climatic events (Ban et al. 2014), associations between benthic organisms (Diaz-Castaneda \& Almeda-Jauregui 1999; Vermeij 2006; Easson et al. 2014), and competition for space and resources, such as light and nutrients (Tanner et al. 2009; Price 2010).

During the early developmental stages of benthic assemblages, new species join the benthic community until the maximum density/coverage is reached, however, the diversity continues to change over time through changes in dominance (Diaz-Castaneda \& Almeda-Jauregui 1999; Brandl et al. 2013; Williams et al. 2013). The succession of benthic assemblages is determined by the order of colonisation, growth rate, life span, and relationships between the benthic organisms (Connell 1997a; Fairfull \& Harriott 1999).

Recruitment is variable between species, but the interactions between benthic organisms are fundamental for successful recruitment. For example, some organisms have been found to recruit only next to adult conspecifics, while others require biological cues or the presence of specific conditions, such as specific light conditions or the presence of refuges (Maida et al. 1994; Brandl et al. 2013). The benthic groups present on a reef together create a complex three- 
dimensional structure with trophic webs that can also influence recruitment (Diaz-Castaneda \& Almeda-Jauregui 1999).

Competitive networks are thought to connect different populations in benthic communities and maintain reef diversity (Buss \& Jackson 1979). The associations between organisms are established at different life history stages (Bruno et al. 2003; Idjadi \& Edmunds 2006); these relationships can be temporary or last for the entire lifetime of the organisms involved and can bring individual or mutual benefits. For example, a tropical sponge has been found in a stable mutualistic association with a red algae; together they are able to live and persist in shallow water; the sponge is never found alone (Carballo \& Ávila 2004); the benefits of this associations are the transfer of nutrients and protection against predators (Wulff 1997).

The relationships between corals and other benthic organisms are important for coral recruitment patterns and coral survivorship; interactions with the benthos affect coral distribution patterns and determine survivorship through association and inhibition. Most of the previous studies in this area have investigated the relationships between adult corals and benthic groups, such as sponges and algae (for example Norström et al. 2009; González-Rivero et al. 2011). Only a few studies have examined the relationship between the reef benthic assemblages and the recruitment rate during the early stages of ecological succession (Fairfull \& Harriott 1999; Perkol-Finkel \& Benayahu 2007).

Coral colonisation can only occur through successful recruitment; available substrata and optimal conditions are needed that are free from sediment or other benthic organisms, with the exception of crustose coralline algae (CCA) that can promote settlement. Several aspects of the settlement and post-settlement phase have been widely investigated, such as the choice of an optimal space to settle (Edmunds 2007), chemical cues that promote settlement (Price 2010), preference for certain substrata (Harrington et al. 2004), and accidental mortality resulting from grazing (Sammarco 1981; Trapon et al. 2013c). Coral juvenile neighbours, benthic organisms bordering on the juveniles, are particularly important in the post-settlement processes, when mortality is usually high (Dunstan \& Johnson 1998). Different benthic groups promote coral recruitment, while others inhibit settlement or survivorship in the post-settlement phase. CCA has been widely studied; it promotes coral settlement by releasing biological cues, although it can also overgrow coral colonies (Buenau et al. 2011, 2012; O'Leary et al. 2012).

Some benthic organisms have associations with coral colonies and offer protection that promote coral recruitment and enhance survivorship. These other organisms can affect coral 
growth rates and survivorship, particularly for coral juveniles, which are more affected than adults. For example, macroalgae can affect coral growth, but at the same time offer protection against predation (Ferrari et al. 2012). Growth rates are usually lower in coral early life history stages (Zilberberg \& Edmunds 2001); small colonies are more easily overgrown by other organisms, which normally would not affect adult colonies (Box \& Mumby 2007; VeneraPonton et al. 2011). Vermeij et al. (2010a) showed that an increase in nutrient levels increased the growth rate of turf algae. When the growth rate of the turf algae was higher than the juvenile coral growth, the algae overgrew the juveniles.

Despite the importance of the processes that drive benthic community composition, little is known about how changes in benthic community assemblages affect associations with coral juveniles. There is little information about how the interactions between juvenile corals and benthic organisms vary during the initial phases of the colonisation process. In this chapter, I investigated the role of benthic community composition in shaping coral recruitment patterns. I focused on the initial stage of colonisation and on the impact of benthic community composition on the coral recruitment abundance. Specifically I have: 1) described the initial ecological succession of a benthic coral reef community; 2) determined the associations between coral recruitment rates and benthic assemblage composition; and 3) analysed the spatial interactions that occurred between juveniles and neighbouring benthic organisms by identifying for each interaction if there was any dominant organism (winner) prevailing on the other.

\subsection{Methods}

This study was carried out in the Wakatobi Marine National Park (WMNP) (see Chapter 2 for further information about the study area).

All of the data used in this chapter were collected from settlement panels deployed at two replicate sites, Buoy 3 (B3) and Buoy 4 (B4), at $6 \mathrm{~m}$ depth in June-August 2011, following the method described in Chapter 2.

Thirty-three panels were collected in June 2012 (15 panels at B3 and 18 B4) and a further thirty panels (15 panels at B3 and 15 at B4) were retrieved in June 2013. I examined both sides of the panels to identify any effect of orientation on the benthic organisms and coral juveniles; the front sides were more exposed to light and disturbance, while the back sides were more protected and comparable to a cryptic reef habitat. 


\subsubsection{Assessment of benthic community coverage}

The photographs taken from fresh tiles were analysed with Coral Point Count with Excel extension (CPCe, v. 4.1; Kohler \& Gill 2006) in order to determine the coverage of different benthic groups.

Two hundred points per tile (100 points for $100 \mathrm{~cm}^{2}$ ) were used on each tile. Three major benthic categories were used: Coral, Algae and Invertebrates. Each of them included different sub-benthic groups, such as type of algae or invertebrate 'group'. A further 'Unknown' group was defined, which included all the points where it was not possible to determine the organism present under the point, while points placed on the bare settlement tile were recorded as 'Substrate'. Points positioned in areas where the surface was shaded by other organisms or fragments or cable ties stuck to the tiles were recorded as 'Tape' and were not included in the subsequent analysis.

\subsubsection{Coral recruitment rate}

All the settlement tiles collected were analysed in order to assess the coral recruitment rate following the method described in Chapter 2. All the tiles were photographed when taken to the laboratory before and after the bleaching process. The abundance, position on the tile, size, and species of each coral colony were recorded. 


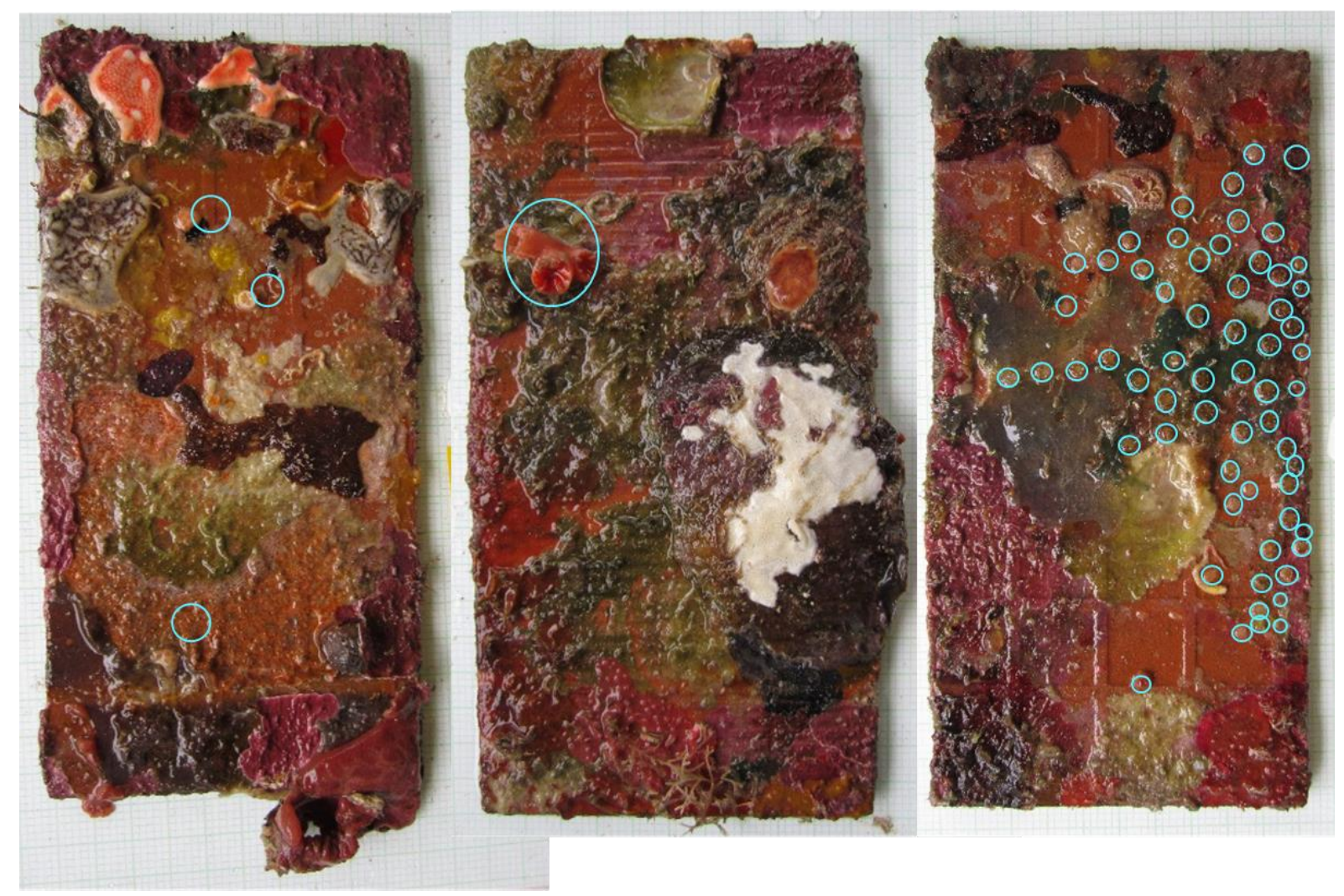

Figure 5.1 The digital images show the settlement panels at the moment of the analysis in the laboratory. Panels were deployed for one or two years at $6 \mathrm{~m}$ depths; after collection both front and back side of the panels were analysed in order to identify the benthic organisms and their coverage and all the coral recruits and juveniles present on the tiles (here showed in light blu circles). Graph paper in the image shows one line per 2 millimeters

\subsubsection{Interactions between coral juveniles and benthic neighbours}

All the coral colonies found on the settlement tiles were examined and all the cases where the coral colonies were either touching or were less than $1 \mathrm{~mm}$ away from another benthic organisms were considered to be interacting. These interactions were recorded in a contact matrix (Figure 5.2).

\begin{tabular}{|l|l|l|}
\hline & \multicolumn{2}{|c|}{ Benthic groups } \\
\hline Coral juveniles & Total number of stand-off events & $\begin{array}{c}\text { Total number of interactions won } \\
\text { by the benthic organisms (coral } \\
\text { overgrown) }\end{array}$ \\
\cline { 2 - 4 } & $\begin{array}{c}\text { Total number of interactions won } \\
\text { by the coral (coral overgrowth) }\end{array}$ & Total number of interactions \\
\hline
\end{tabular}

Figure 5.2 Example of a cell of the contact matrix. Interactions between coral juveniles and benthic organisms were recorded. Each cell of the matrix corresponded to the sum of the different interactions between coral colonies and benthic organisms. Rows represent each coral family, while columns represent the different non-coral benthic organisms 
The total number of interactions was recorded along with the outcome of the interactions; these included the number of events when the coral was winning over the benthic organism (defined as 'won'), the number of events when the other benthic organism was winning and the coral was the 'loser' (defined as 'lost'), and the overall stand-off interactions ('stand-off'), when the coral and the benthic organisms were touching but no dominance was recorded. The matrix produced in this survey is similar to contact matrices used in previous studies on inter- and intra-species interactions of bryozoans and sponges (Turner \& Todd 1994; Barnes \& Rothery 1996; Bell \& Barnes 2003).

\subsubsection{Data analysis}

Canonical analysis of principal coordinates (CAP) was conducted in PRIMER v6 (Kohler \& Gill 2006) to identify any differences in community composition. The same sides of tiles from each years were compared in order to assess any changes in community composition along with the different sides of tiles collected in the same year to assess variability in community composition between the front and back of the tiles. Vectors representing Spearman's rank correlations (>0.6) with the axes of the CAP analysis used to determine the individual benthic groups that characterised the benthic assemblage in each year.

Any differences in benthic assemblage composition between years were assessed further using PERMANOVA. Assemblage data were separated by panel side and PERMANOVA was performed with two factors: side of the panel (fixed, with two levels: front and back) and year (random with two levels).

Coral recruitment data were analysed separately in order to assess differences in coral recruit and juvenile (see definition of coral recruit and juvenile in the methods section of Chapter 2) abundance between years. The data were transform by square root and a dissimilarity matrix was produced. PERMANOVA analysis was then performed with two factors: side of the panel (fixed) and year (random). To detect any relationships between overall benthic assemblage composition and patterns of coral recruitment, the data on recruitment rates on the CAP plots were represented as 'bubbles'. The size of the bubble varied from 0 to 20 and corresponded to the recruitment rate, with bigger bubbles corresponding to higher recruitment rates.

The data obtained from the assessment of the interactions between coral colonies and benthic organisms were used to identify any relationships between the number of interactions and the coverage of benthic organisms. The recruitment rate on each tile was also correlated with the coverage of the benthic organisms that were interacting with the coral colonies. The number of 
interactions was correlated with the coverage of the same group at each tile level to assess if higher coverage was correlated with a higher number of interactions.

\subsection{Results}

\subsubsection{Benthic community composition}

Overall, total coverage of benthic organisms increased over time and benthic assemblage was variable between years and sides of the panels. Algae dominated the front sides in both years. On the back sides invertebrates dominated in the first year, but in the second year algae and invertebrate coverage was similar. All benthic groups identified were found in both years; some of them, such as bryozoans, sponges and tunicates, showed a preference for the back side of the panels. After one year approximately $15.77 \%( \pm 1.51 \mathrm{SE})$ of the panel substrate was still bare; this declined to $11.95 \%( \pm 0.93 \mathrm{SE})$ in the second year. This reduction in bare space was more pronounced on the back side of the panels, where bare substrate was half of the value found in the first year (Table 5.1).

Algae were the most abundant group in both years, and CCA, live and dead, was the most abundant taxa in this category, covering $27.46 \%( \pm 3.00 \mathrm{SE})$ and $28.0 \%( \pm 3.17 \mathrm{SE})$ of the tiles in the first and second year, respectively. On the front side of the panels, overall algae coverage was consistent between years, however the assemblage composition was different. In the first year the algal assemblage was composed mostly by live CCA, while in the second year live CCA coverage was low. Dead CCA coverage was fivefold higher in the second year. In contrast, on the back side of the panels, live CCA almost tripled in coverage, unfortunately the nature of this study do not allow to know if this increase was due to growth of already existing CCA or to new CCA on bare artificial substrate. Turf algae and non-coralline encrusting algae coverage was consistent between years on the front sides of the panels, while it increased on the back sides. Other algae taxa, including cyanobacteria, green encrusting algae and other macroalgae, covered less than $8 \%$ of the tiles in both years.

Thirteen different groups of invertebrates were found on the tiles (see Table 5.1). They occupied $7.01 \%( \pm 0.80 \mathrm{SE})$ and $16.97 \%( \pm 1.77 \mathrm{SE})$ of the surface on the front side in year one and year two, respectively, and $56.11 \%( \pm 2.20 \mathrm{SE})$ and $44.82 \%( \pm 22.17 \mathrm{SE})$ on the back side in year one and two, respectively. Both tunicates and sponges had higher coverage in year two, while bryozoan coverage had decreased. All other taxa did not cover more than $2.5 \%$ of the 
tiles in either year. In addition, bivalves and hydrocorals were only recorded on the back side of the panels.

Coral coverage was low in both years, although there was a slight increase in the second year and a preference for corals to settle on the back side in year two. Pocilloporidae was the most common coral family (Table 5.1). 
Table 5.1 Summary of the percentage of average benthic coverage across sites on settlement panels deployed at $6 \mathrm{~m}$ on the reef for one and two year periods respectively

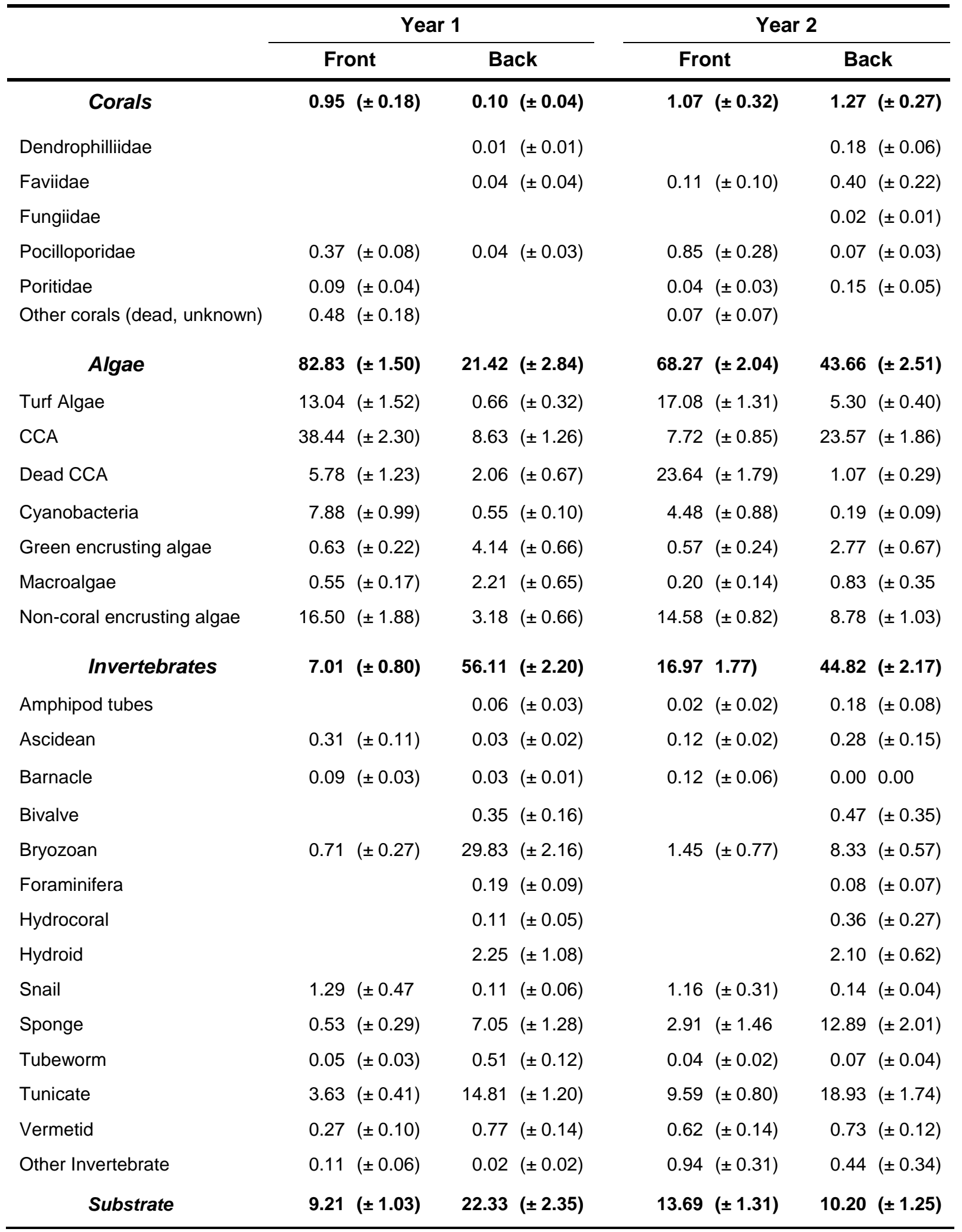


There were significant differences in community composition for the same side of the panels between the two year periods (PERMANOVA, $\mathrm{df}=1, \mathrm{P}>0.2883$ ) (Table 5.2).

Table 5.2 Result of the PERMANOVA analysis examining differences in community composition between the front and back sides of settlement panels submerged at $6 \mathrm{~m}$ depth for one and two year periods respectively

\begin{tabular}{lccccc}
\hline \multicolumn{1}{c}{ Factor } & df & SS & MS & Pseudo-F & P \\
\hline Year & 1 & 39528 & 39528 & 1.90 & 0.2548 \\
Side & 1 & 15519 & 15519 & 38.53 & $\mathbf{0 . 0 0 0 1}$ \\
Year ${ }^{*}$ Side & 1 & 20717 & 20717 & 51.44 & $\mathbf{0 . 0 0 0 1}$ \\
Res & 122 & 49135 & 402.75 & & \\
Total & 125 & $1.2625 \mathrm{E} 5$ & & & \\
\hline
\end{tabular}

\subsubsection{Coral recruitment rates}

In the first year, a total of 84 coral colonies were found on the settlement panels: 43 on the front side $\left(65.15 \mathrm{col} . \mathrm{m}^{-2}\right)$ and 41 on the back $\left(60.61 \mathrm{col} . \mathrm{m}^{-2}\right)$. In the second year, a total of 302 coral colonies were found on the settlement panels: 71 on the front side $\left(118.34 \mathrm{col} . \mathrm{m}^{-2}\right)$ and 231 on the back side $\left(385 \mathrm{col} . \mathrm{m}^{-2}\right)$. Excluding three back tiles collected in the second year that had 29, 50 and 64 coral juveniles respectively as outliers, overall recruitment rate was 162.96 $( \pm 0.44)$ col. $\mathrm{m}^{-2}$.

The relative percentages of different coral families in the first and second years respectively, were: $52.38 \%$ and $27.48 \%$ Pocilloporidae, $17.86 \%$ and $11.92 \%$ Faviidae, $9.52 \%$ and $7.95 \%$ Poritidae, $4.76 \%$ and $1.76 \%$ Acroporidae, $1.19 \%$ and $0.99 \%$ Agariciidae, $0.66 \%$ Fungiidae in the second year only, $1.99 \%$ Dendrophylliidae in the second year only, and $25.58 \%$ and $47.35 \%$ others. On the back side of the panels there was a higher number of coral families in both years; in the second year there were two new coral families on the back sides and one on the front sides not found in the first year (Table 5.3).

Abundance of the coral colonies was higher in the second year and there was a significant difference in coral juvenile abundance between the two year periods (Table 5.4). 
Table 5.3 Summary of the overall coral juvenile colonies recorded in the Wakatobi MNP (Indonesia) on settlement panels submerged for one and two year periods respectively (data combined from two sites). Columns report the abundance and relative percentage values on different sides of the panels (front and back) and total values.

\begin{tabular}{|c|c|c|c|c|c|c|}
\hline \multirow{3}{*}{$\begin{array}{c}\text { Coral juvenile } \\
\text { families }\end{array}$} & \multicolumn{6}{|c|}{ Abundance and relative percentage } \\
\hline & \multicolumn{3}{|c|}{ Year 1} & \multicolumn{3}{|c|}{ Year 2} \\
\hline & Front & Back & Total & Front & Back & Total \\
\hline \multirow[t]{2}{*}{ Pocilloporidae } & 34 & 10 & 44 & 48 & 35 & 83 \\
\hline & $79.07 \%$ & $24.39 \%$ & $52.38 \%$ & $67.61 \%$ & $15.15 \%$ & $27.48 \%$ \\
\hline \multirow[t]{2}{*}{ Poritidae } & 2 & 6 & 8 & 5 & 19 & 24 \\
\hline & $4.65 \%$ & $14.63 \%$ & $9.52 \%$ & $7.04 \%$ & $8.23 \%$ & $7.95 \%$ \\
\hline \multirow[t]{2}{*}{ Acroporidae } & 3 & 1 & 4 & 2 & 3 & 5 \\
\hline & $6.98 \%$ & $2.44 \%$ & $4.76 \%$ & $2.82 \%$ & $1.30 \%$ & $1.66 \%$ \\
\hline \multirow[t]{2}{*}{ Faviidae } & & 15 & 15 & 2 & 34 & 36 \\
\hline & & $36.59 \%$ & $17.86 \%$ & $2.82 \%$ & $14.72 \%$ & $11.92 \%$ \\
\hline \multirow[t]{2}{*}{ Agariciidae } & & 1 & 1 & & 3 & 3 \\
\hline & & $2.44 \%$ & $1.19 \%$ & & $1.30 \%$ & $0.99 \%$ \\
\hline \multirow[t]{2}{*}{ Fungiidae } & & & & & 2 & 2 \\
\hline & & & & & $0.87 \%$ & $0.66 \%$ \\
\hline \multirow[t]{2}{*}{ Dendrophylliidae } & & & & & 6 & 6 \\
\hline & & & & & $2.60 \%$ & $1.99 \%$ \\
\hline \multirow[t]{2}{*}{ Others } & 4 & 8 & 11 & 14 & 129 & 143 \\
\hline & $9.30 \%$ & $19.51 \%$ & $14.29 \%$ & $19.72 \%$ & $55.84 \%$ & $47.35 \%$ \\
\hline \multirow[t]{2}{*}{ Total } & 43 & 41 & 83 & 71 & 231 & 302 \\
\hline & $100 \%$ & $100 \%$ & $100 \%$ & $100 \%$ & $100 \%$ & $100 \%$ \\
\hline
\end{tabular}

Table 5.4 Result of the PERMANOVA analysis examining differences in coral recruitment rates between the two sides of settlement panels submerged for one and two year periods respectively

\begin{tabular}{lccccc}
\hline \multicolumn{1}{c}{ Factor } & df & SS & MS & Pseudo-F & P \\
\hline Year & 1 & 437.89 & 437.89 & 0.45 & 0.4986 \\
Side & 1 & 4193.3 & 4193.3 & 10.09 & 0.0007 \\
Year * Side & 1 & 985.06 & 985.06 & 2.37 & 0.1088 \\
Res & 122 & 50702 & 415.59 & & \\
Total & 125 & 56304 & & & \\
\hline
\end{tabular}




\subsubsection{Relationship between benthic community and coral recruitment pattern}

There was variability in community composition between tiles from different years and of different orientation (Figure 5.2). In order to better visualise differences, the analysis was conducted separately for each side of the panels. Recruitment occurred on most of the tiles in both years, with higher values in year two due to the accumulation of two years of recruitment and a preference for settlement on the back side of the panels (Figure 5.3).

Different benthic organisms characterised the community in each year. While in first year only one group was identified for each side of the panel, in year two more groups of organisms were found (Figure 5.2c). Despite this finding, coral recruitment rates were not correlated with the abundance of any benthic group found associated in the CAP plots and known to be previously associated with coral recruitment (CCA, sponges, turf algae and bryozoans) or with the percentage of the available bare substrate on the settlement panels (see Appendix II). 
a)

b)

Front side

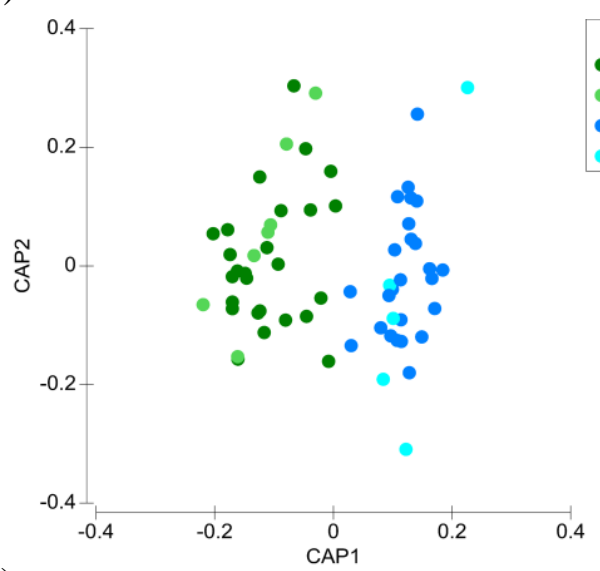

c)

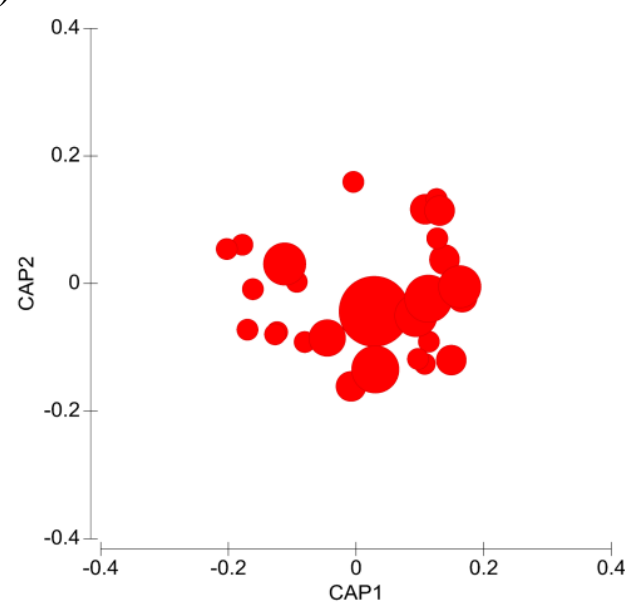

d)

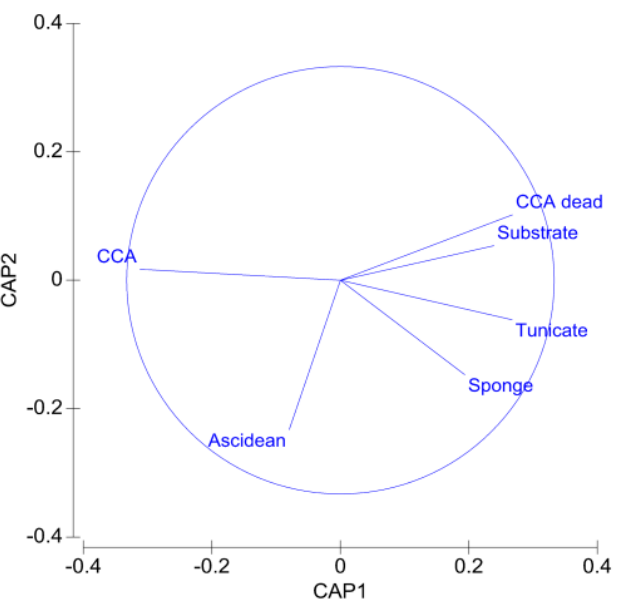

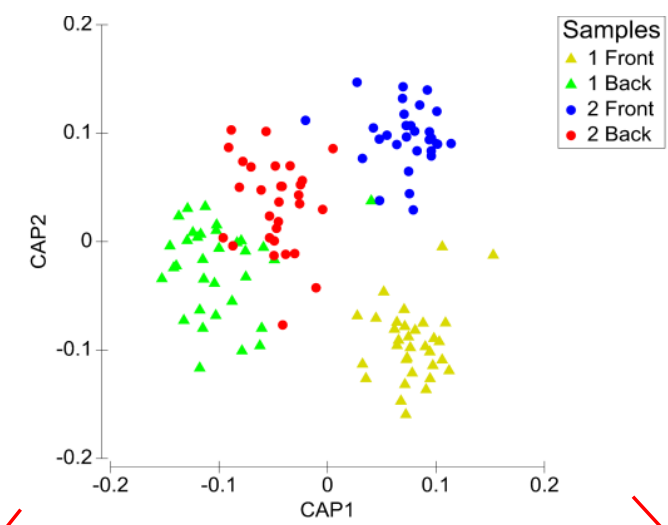

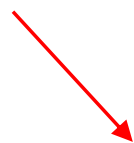

Back side

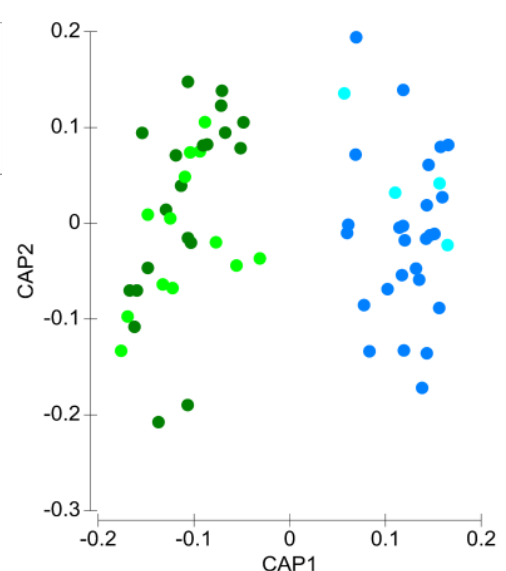

Coral abundance

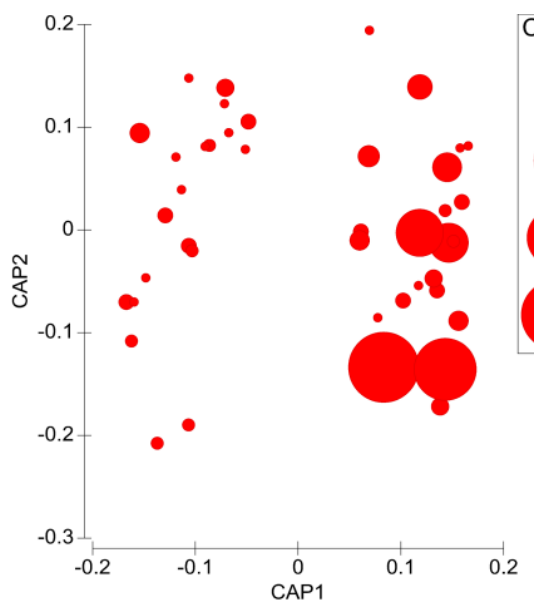

Coral abundance
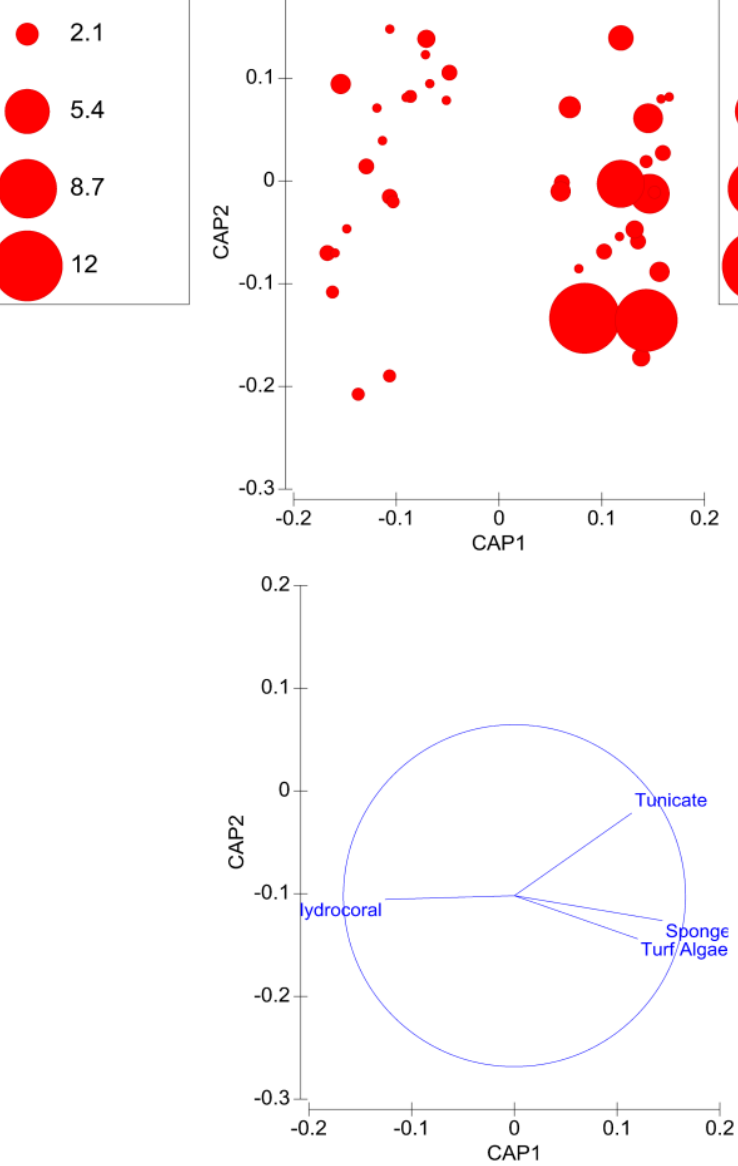


\subsubsection{Interactions between coral juveniles and benthic neighbours}

Overall, 442 interactions were observed: 118 on tiles deployed for one year (73 on the front sides and 45 on the back sides) and 324 on tiles deployed for two years (95 on the front sides and 229 on the back sides). No interactions with juvenile corals were found with foraminifera, hydrocorals, hydroids and barnacles. The average number of interactions per coral colony in the first year was $1.34( \pm 0.08 \mathrm{SE}): 1.43( \pm 0.129 \mathrm{SE})$ on the front side and $1.19( \pm 0.09 \mathrm{SE})$ on the back side; in the second year the average number was 1.05 ( $\pm 0.05 \mathrm{SE}): 1.62( \pm 0.12 \mathrm{SE})$ on the front side and $0.87( \pm 0.05 \mathrm{SE})$ on the back side.

In both years, the overall highest number of interactions occurred with algae. There was a predominance of interactions between corals and CCA; in the first year they represented $40.68 \%$ of the total interactions and they were mostly on the front sides, while in the second year they represented $29.32 \%$ of the total interactions and were mostly on the back sides (Table 5.5). Of the total interactions between CCA and corals, $71.33 \%$ were stand-offs, while only $20.28 \%$ resulted in a win for the coral, either by overgrowing or settling on CCA. In the second year there was also an increase in the number of interactions with dead CCA on the front side.

Table 5.5 Summary of the overall outcomes of the interactions occurring between coral juveniles and benthic organisms on both sides of settlement tiles submerged for one and two year periods respectively at $6 \mathrm{~m}$ (data of two replicate sites combined)

\begin{tabular}{cccccc}
\hline \multirow{2}{*}{ Year } & \multirow{2}{*}{ Side } & \multicolumn{4}{c}{ Outcome of the interactions } \\
\cline { 3 - 6 } & & Won & Lost & Stand-off & Total \\
\hline \multirow{2}{*}{1} & Front & 7 & 7 & 59 & 73 \\
& Back & 4 & 11 & 30 & 45 \\
& & & & & \\
2 & Front & 15 & 15 & 65 & 95 \\
& Back & 40 & 27 & 162 & 229 \\
\hline
\end{tabular}

Front page:

Figure 5.3 CAP plots showing a) the differences between benthic community composition on settlement panels submerged for one and two year periods respectively in the Wakatobi MNP. CAP axes discriminate between the samples data and show the maximum variability (see correlation of axes to data cloud inAppendix II); b) the benthic community composition separated by side of the panel in order to better visualise the differences in benthic communities on the front and back of panels; plots on the left side represent the front side of the panels, while those on the right side represent the back side. Samples (tiles) with and without recruitment are coloured differently; c) recruitment rates which have been imposed as bubbles on the CAP plots; and d) vectors representing Spearman's rank correlation of individual benthic groups with the CAP axes showing which factors are characteristics of the benthic community in each year 
Turf algae-coral interactions represented $9.4 \%$ of the overall interactions with algae. The number of interactions was higher in the second year and they were mostly stand-offs, where the algae was often surrounding the whole colony or where turf algae was overgrowing the coral. There were only a small number of interactions between green encrusting algae and corals in the first year and no interactions on the front sides in the second year. Few interactions between macroalgae and coral were found in either year, while interactions between corals and non-coralline encrusting algae were more abundant in the second year, especially on the back side of the panels. The outcome of most of the interactions with algae was a stand-off or algae overgrowing the corals.

Interactions between bryozoans and corals were found only on the back side of the panels; outcome of the interactions was mostly a stand-off or coral overgrowing the bryozoan. Bivalves were only recorded on the back side of the panels and interacted more with corals in the second year; in all the cases the coral colonies were found settling on the top of the shells. There were few interactions with sponges in the first year, but they increased in the second year on the back side of the panels. The outcome of most of these interactions was a stand-off or sponge overgrowing the coral. Colonial tunicates and vermetids interacted with corals mostly in the second year and most of the outcomes were stand-offs for both groups, or tunicate overgrowing the coral. Foraminifera and hydroids did not have any interactions with corals; this was probably due to these benthic organisms having low coverage (Table 5.6).

The coverage of the benthic organisms was not correlated with the number of interactions between coral juvenile abundance and coverage of different benthic groups, such as turf algae, CCA, sponge and bryozoans (Figure 5.4). 
Table 5.6 Summary of the interactions between coral colonies families and benthic organisms. Data were collected from settlement panels deployed at $6 \mathrm{~m}$ at two replicate sites (Buoy 3 and Buoy 4 ) in the Wakatobi MNP

\begin{tabular}{lcccc}
\hline & \multicolumn{4}{c}{ Coral juvenile } \\
\cline { 2 - 5 } & Won & Lost & Stand-off & Total \\
\hline \multicolumn{1}{c}{ Algae } & $\mathbf{3 6}$ & $\mathbf{4 0}$ & $\mathbf{2 0 0}$ & $\mathbf{2 7 6}$ \\
CCA & 29 & 12 & 102 & 143 \\
CCA Dead & 4 & 6 & 35 & 45 \\
Cyanobacteria & 1 & 2 & 9 & 12 \\
Green Encrusting Algae & 0 & 3 & 18 & 21 \\
Macroalgae & 0 & 3 & 3 & 6 \\
No Coralline Encrusting Algae & 2 & 6 & 15 & 23 \\
Turf Algae & 0 & 8 & 18 & 26 \\
& & & & \\
\multicolumn{1}{c}{ Invertebrates } & $\mathbf{3 0}$ & $\mathbf{1 9}$ & $\mathbf{1 1 1}$ & $\mathbf{1 6 0}$ \\
Bivalves & 7 & 0 & 4 & 11 \\
Bryozoans & 10 & 2 & 14 & 26 \\
Hydroids & 2 & 0 & 0 & 2 \\
Sponges & 3 & 10 & 54 & 67 \\
Tubeworms & 1 & 0 & 4 & 5 \\
Tunicates (colonial) & 1 & 5 & 15 & 21 \\
Tunicates (solitary) & 0 & 2 & 2 & 4 \\
Vermetids & 1 & 0 & 15 & 16 \\
Other Invertebrates & 5 & 0 & 3 & 8 \\
\hline
\end{tabular}
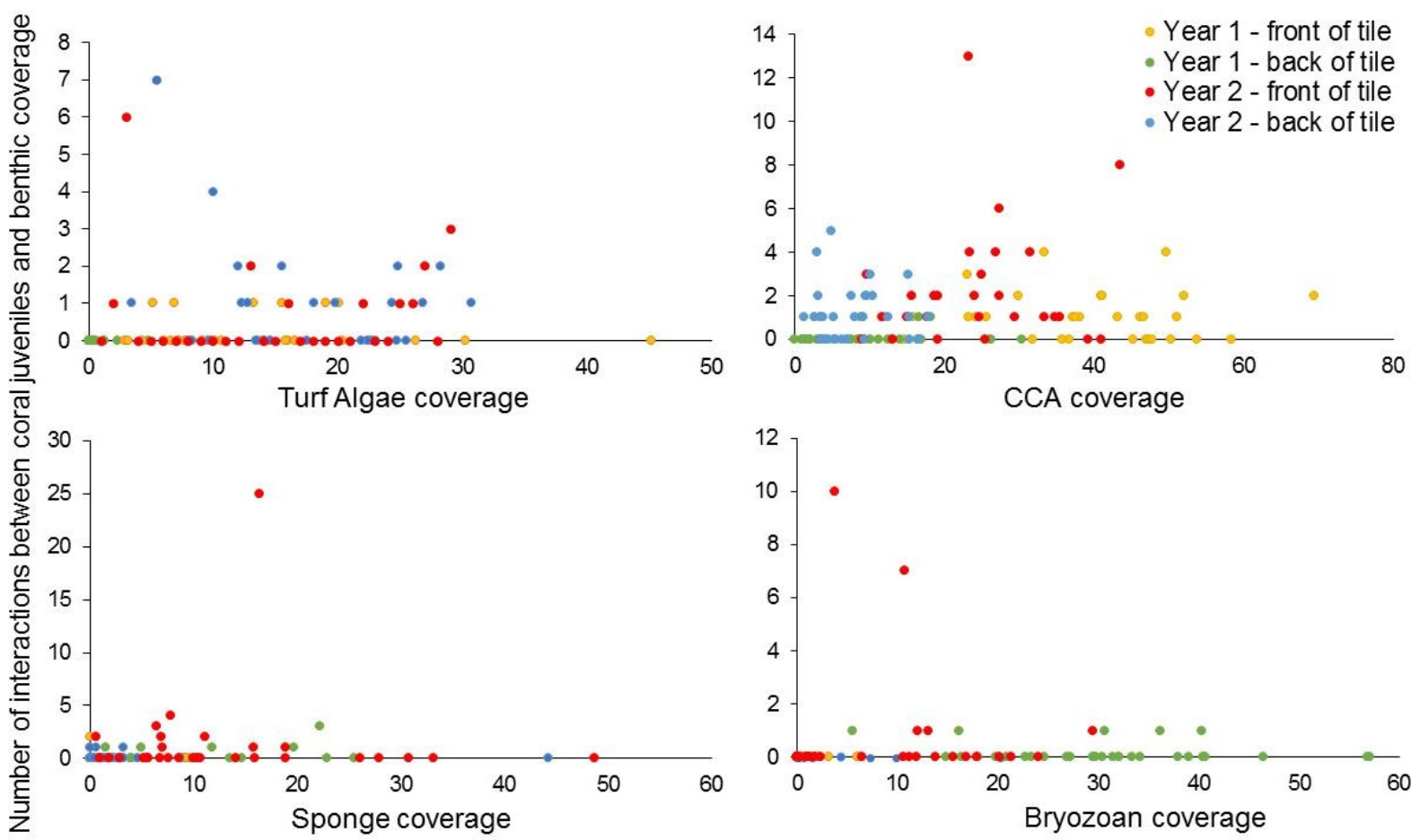

Figure 5.4 Correlations between the main benthic groups present on the settlement tiles and known to interact with corals, and the overall number of interactions with coral juveniles 


\subsection{Discussion}

In this study I investigated the impact of the initial colonisation process of a benthic coral reef community on coral recruitment. Benthic assemblage was significantly different between panel orientations and for panels deployed for one or two year periods on the reef. Higher coral juvenile abundance was recorded in year two and on the back side of the tiles, and this was probably due to two years of coral colony accumulation. Coral juvenile abundance was associated with different benthic assemblages on the two sides of the tiles for each time period and was not correlated with the coverage of the more abundant benthic groups. The number of interactions between coral juveniles and other biota was higher in year two; CCA and sponges were the principal benthic groups interacting with coral juveniles. The majority of these interactions were stand-offs, although juveniles were found to be overgrown rather than to have settled on other biota.

\subsubsection{Succession of benthic assemblages}

The benthic community changed significantly from the first to the second year. The overall number of benthic groups differed consistently across the duration of my study and there was a marked change in the relative coverage between years and orientation of the tiles (Figure 5.5). The front side of the tiles was dominated by algae, mainly CCA, while invertebrate coverage was higher on the panels collected in year two. The back sides of the panels were characterised by invertebrates, such as colonial tunicates, sponges and bryozoans. In the second year, algae coverage was similar to invertebrate coverage; CCA coverage was higher on the back side compared to year one. This finding could be due to light still reaching the back side of the panels and promoting algal growth. Some groups showed preferences for the front or back side of the panels. For example, bivalves and foraminifera were not found on the front side in the second year, while tubeworms had disappeared from the back sides by that point. This pattern could however be the result of post-settlement mortality rather than orientation choice at settlement time. 


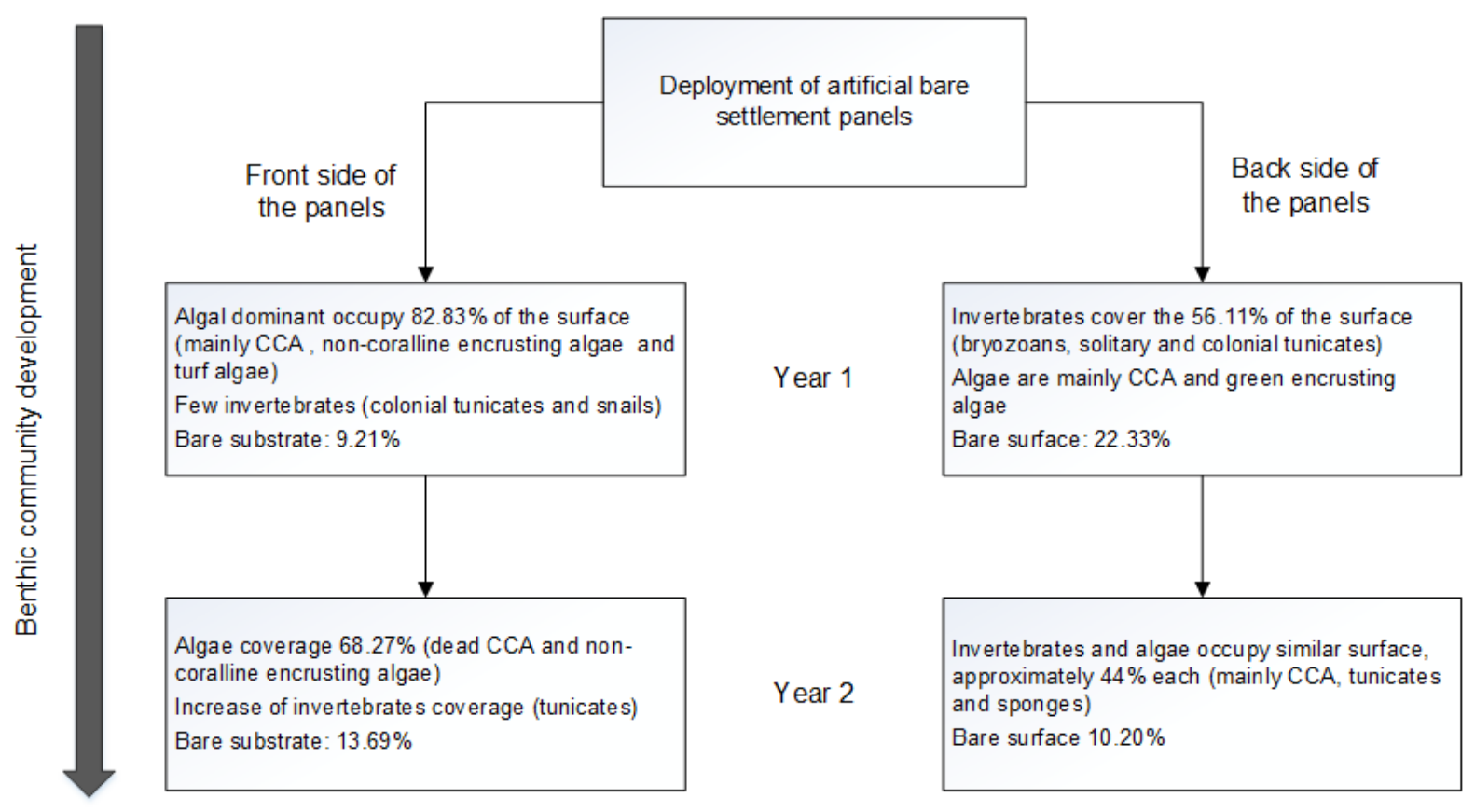

Figure 5.5 Diagram of the development of the benthic community on the artificial settlement panels deployed on the reef for one and two year periods respectively in the Wakatobi MNP (Indonesia).

All benthic groups found in this study were present in both years and it was not possible to assess if the availability of bare substrate on the panels was correlated with the number of benthic groups on the panels. Despite different species succeeding each other during the development of benthic communities, as described by Tanner et al. (1996) and Connell (1997a), in my study I was unable to record the order in which benthic organisms settled on the tiles or the time required to occupy the tile. Field et al. (2007) found that colonisation was faster in the first month, and then declined when free space decreased. In my research, the interval of 12 months between sampling times prevented fine temporal scale recording of the organisms that appeared and disappeared. Such groups might have had a short life span but could have still influenced the community development, as suggested by Sutherland (1974). Therefore, more than two sampling points would be recommended in future studies to assess correlations between colonisation and free space. In addition, the taxonomic level used for identification pooled several species, and did not allow any assessment of differences at species level.

Previous studies on ecological succession on both natural and artificial substrates in different environments (Tanner et al. 1996; Diaz-Castaneda \& Almeda-Jauregui 1999; Bowden et al. 2006) have identified various factors that affect the development of the community. These factors include time of tile deployment (Field et al. 2007), seasonal supply of larvae (Bowden 
et al. 2006), presence of biological cues (Price 2010), specific assemblages that promote recruitment (Carballo \& Ávila 2004; O’Leary et al. 2012), and time when the panels were analysed after deployment (Martinez \& Abelson 2013). In order to better understand the trends of ecological succession, data from more consecutive years would be useful. In addition, frequent observations and identification of biota to a higher taxonomic level would improve the understanding of the dynamics and order of colonisation.

\subsubsection{Relationship between coral recruitment and benthic community composition}

The overall coral recruitment rate in the first year was similar for the front and the back sides of the settlement panels (43 and 41 respectively). In previous surveys conducted in the same area, recruitment rates have always been higher on the back side (see recruitment rates in Chapters 2 and 3). Panels with higher recruitment on the front side rather the back side were found occasionally. In year two, higher coral juvenile abundance was recorded on both sides compared to year one, probably due to the accumulation of juveniles that survived from the first year and new recruits that settled in the second year (Perkol-Finkel \& Benayahu 2007). The high coral recruitment rate on the back side was mostly due to three tiles, which had 29, 50 and 64 juveniles respectively and together accounted for $62 \%$ of the total recruits on the back side in that year. In addition, two new families, not commonly found on settlement panels deployed for one year, were recorded on the back side of the panels in the second year.

Higher coral recruitment rates were associated with specific benthic assemblage compositions, which differed between sides of the panels; however, individual benthic groups that characterised those assemblages were not correlated with coral recruitment rates. This result is consistent with studies conducted in the Red Sea (Glassom et al. 2004; Field et al. 2007) and in the Caribbean (Birkeland 1977). In contrast, on the Great Barrier Reef, the coverage of the dominant benthic groups (bryozoan, ascidians and barnacles) were negatively correlated with coral recruitment (Harriott \& Banks 1995).

In this study I did not find any correlation between CCA and coral juvenile abundance, which has been reported in other areas, such as in the Antilles Islands in the Caribbean (Morse et al. 1994), in the Mombasa Marine National Park in Kenya (O'Leary et al. 2012), and at Lizard Island in the Great Barrier Reef (Harrington et al. 2004). In other locations, such as Bonaire in the Caribbean (Morse et al. 1994), in the Gulf of Aden in Yemen (Benzoni et al. 2011), at Pelorus Island located in the central Great Barrier Reef (Baird \& Morse 2004) and at Moorea in French Polynesia (Price 2010), CCA is not considered important for high coral recruitment 
rates. Other studies have shown that although some species of CCA promote coral recruitment by releasing chemical cues, others release inhibiting cues that affect coral survivorship (Raimondi \& Morse 2000; Harrington et al. 2004; Ritson-Williams et al. 2009b; Benzoni et al. 2011; O'Leary \& Potts 2011). Harrington et al. (2004) investigated the relationship between two coral species and five CCA species and found a positive correlation between recruitment and post-settlement survivorship, while O'Leary et al. (2012) found that coral density was correlated with the abundance of only one CCA species.

My study did not consider the recruits that died or were removed from the tiles, or potentially scraped off by predators before the sampling time. It is possible that initial coral recruitment was correlated with either CCA or available space, but early mortality occurred and modified the initial pattern. As a consequence, coral recruitment patterns at the observation time may have been different from the original settlement pattern (Kuo \& Soong 2010).

Studies by Coyer et al. (1993) and Davies et al. (2013) highlighted the importance of macroalgae in protecting young corals from fish grazers and at the same time competing with coral juveniles. Erect macroalgae, found also on my settlement tiles, affects the growth rate of coral juveniles by contact and induces tissue loss by abrasion (Sammarco 1980; Birrell et al. 2005; Diaz-Pulido et al. 2010). However, the declining fish abundance found in the Wakatobi and low coverage of macroalgae on the back surfaces suggest that macroalgae were not important for juvenile survivorship (see Chapter 4 for information on fish abundance).

The abundance of new coral recruits in year two was higher than in year one, when benthic assemblage complexity was higher, but also when spatial competition was likely to be more intense as there was less free space. This is in accordance with research conducted by Kuo \& Soong (2010), who showed that coral recruitment and juvenile survivorship were higher on older tiles, which probably produced cues that promoted recruitment not present on younger tiles.

\subsubsection{Interactions between coral juveniles and benthic neighbours}

The number of interactions between coral colonies and benthic organisms was not correlated with the number of colonies. Despite the increase in coral colony abundance and community assemblage complexity, the average number of interactions per colony was similar across years. In both years there were coral colonies without interactions with other benthic organisms, however in year two, more coral juveniles were in contact with only one benthic organism; in these cases juveniles were mostly overgrowing or surrounded by it. 
Benthic group coverage was not positively correlated with the total number of interactions between benthic groups and coral juveniles. For example, bryozoans had no interactions on the front side of the panels in both years, while on the back side, despite the coverage in year two being a quarter of the coverage in year one, the interactions tripled. While CCA coverage tripled in year two compared with year one, the number of interactions was seven times higher. Similarly, while sponge cover almost doubled in year two, their interactions with coral juveniles were almost sixfold higher.

Stand-off events occurred in the majority of the interactions between coral juveniles and algal groups and sponges. This is in contrast with research conducted on the Great Barrier Reef, where the most common outcome on the back side of settlement panels was mortality of coral juveniles caused by overgrowth by bryozoan, sponges and tunicates (Fairfull \& Harriott 1999; Wilson \& Harrison 2005). Some stand-off interactions benefit coral juveniles, for example by offering protection, but at the same time the benthic organisms, such as macroalgae and vermetids, can affect coral growth rate (Coyer et al. 1993; Lenihan et al. 2011). A study conducted with adult Montastrea coral colonies found that stand-offs between coral colonies and sponges were the most common outcome of the interactions, however sponge promoted slow mortality in coral polyps engaged in the interaction (Suchanek et al. 1983; Aerts 2000).

In my study, the majority of the interactions occurred between coral juveniles and CCA. Most of these were stand-offs, where CCA was touching the juveniles or surrounding it. Only in a few cases was CCA partially overgrowing the coral juveniles. Buenau et al. (2011) suggested that CCA overgrows only corals smaller than a specific threshold size, beyond which they are less vulnerable. In contrast, Harrington et al. (2004), using a manipulative experiment, assessed the relationship between coral recruits and five different CCA species. CCA was rarely overgrowing recruits, suggesting the limited role of CCA in young coral survivorship. Only coral recruits settled on CCA, while juveniles were never found on CCA. Chemical cues that promote coral larval settlement might have a negative effect on coral juvenile post-settlement survivorship (Harrington et al. 2004). In addition, other factors, such as epithelial shedding that occurs in some CCA species, might remove coral recruits from the surfaces before they reach a bigger size (Keats et al. 1997; McCook et al. 2001). More coral juveniles were recorded as having settled on dead CCA in year two, although it is unknown if the CCA was still alive at the time the larvae settled. Heyward \& Negri (1999) suggested that dead CCA releases chemical cues that both inhibit coral recruitment and induce mortality in coral juveniles that had settled on the CCA when it was still alive. It is possible that juvenile mortality occurred in 
coral colonies settled on already dead CCA and could not be detected by this study. Additional juvenile mortality can occur in juveniles settled on living CCA, in case of death of the coralline algae.

In this study, size of the coral colony, growth rates, and amount of coral colony perimeter in contact with other benthic organisms were not investigated. Therefore, it is unknown how these factors affect the number and outcome of the interactions over time. Previous investigations found that larger organisms usually win in competitive interactions (Zilberberg \& Edmunds 2001; Box \& Mumby 2007). Aerts (1998), Lirman (2001) and Ferrari et al. (2012) investigated the effect of the amount of coral colony perimeter involved in interactions with benthic organisms. Ferrari et al. (2012) found that, in small corals, the percentage of perimeter in touch with another organism did not change the intensity of the interaction. In this study, I only examined interactions between coral juveniles and other benthic organisms less than $1 \mathrm{~mm}$ apart, however some interactions occur without the necessity of contact. For example, erect macroalgae affect coral growth rate by abrasion with algal filaments, reducing the growth rate in coral juveniles and causing tissue loss and variations in size (Lirman 2001; River \& Edmunds 2001; Box \& Mumby 2007).

In this chapter, I have assessed the effect of the succession of benthic assemblages on patterns of coral recruitment. I found that coral recruitment rates were higher on tiles where benthic community was more developed. Despite higher coral recruitment rates being associated with specific benthic assemblage compositions, recruitment rates were not correlated with the individual benthic groups that characterised those assemblages. 
Chapter 5 Influence of ecological succession on coral recruitment 


\section{Chapter 6 General discussion}

In this thesis I have investigated patterns of spatio-temporal variability in coral recruitment and examined the abiotic and biological factors that affect the distribution of coral recruits and juveniles. I then focused on the impact of fish grazing on the young coral population and I have studied the associations between benthic community composition and coral recruits and juveniles during the initial phases of colonisation of bare substrate.

The key findings of my research are: 1) the identification of high levels of variability in coral recruit and juvenile abundance across space and time (Chapters 2 and 3); 2) that coral recruit and juvenile abundance patterns are not easily explained by individual factors, but seem to be the result of multiple factors resulting in complex interactions (Chapter 2); 3) that predation is not an important factor influencing coral post-settlement mortality in the Wakatobi Marine National Park (Chapter 4); and 4 that the benthic assemblage influences coral recruitment abundance through interactions that promote or inhibit coral survivorship (Chapters 4 and 5).

In this chapter I discuss the variability in the scale of variation in coral recruits and juveniles in the Coral Triangle and the Indo-Pacific area. I also explain the contribution of my research to our understanding of the environmental factors that affect the coral recruitment processes, focusing particularly on the role of fish predation and spatial competition. Finally, I discuss the implications of my results for coral reef management.

\subsection{Changes in spatial variability in coral population along recruitment}

Earlier research on coral population dynamics has suggested that coral larvae can travel both long and short distances, depending on the species (Christie et al. 2010; Saenz-Agudelo et al. 2012). This larval dispersal maintains reef connectivity and generates spatial variability between coral reefs at most scales (Dunstan \& Johnson 1998; Graham et al. 2008; O'Leary \& Potts 2011). For example, at wide scales, reefs at high latitude in the Pacific have lower coral recruitment rates compared to tropical reefs, while on the Great Barrier Reef a latitudinal gradient in spatial variability was found in coral recruit abundance and assemblage composition across $1700 \mathrm{~km}$ (Hughes et al. 1999b, 2002). At smaller scales, high levels of spatial variability in coral recruitment rates was found between islands $5 \mathrm{~km}$ apart in Moorea, but not within sites on the same island, 5-8 km apart (Penin \& Adjeroud 2013), generating a more patchy 
distribution. Variability in coral recruitment rate is correlated to the scale of variability of biological and abiotic factors driving the recruitment process. The correlation between coral recruitment rate spatial variability and scale of variability in factors was examined Moorea (Penin et al. 2010), at Ryukyu Island (Nakamura \& Sakai 2009) and Fiji (Quinn \& Kojis 2008) with different results, highlighting the high variability existent between and within locations.

A number of studies (for example, Bak \& Engel, 1979; Fairfull \& Harriott, 1999; Perkol-Finkel \& Benayahu, 2007) have suggested a correlation between physical and biological factors and coral recruit distribution, however only a few, such as this one, have investigated and described the strength of this correlation (for example Lirman 2001; Harrington et al. 2004; Buenau et al. 2012). My research also highlights the high variability in environmental factors at small localised scales and in the relationship between coral recruit and juvenile distributions, regardless the distance between sites, which varied from a few hundred meters up to $5 \mathrm{~km}$. Howerver, despite sites sharing similar abiotic and biotic conditions were expected to have similar distribution patterns and coral composition (Chapters 2 and 3), this was not what I found.

A prevalence of self-recruitment on coral reefs would support a correlation between adult coral cover and young coral colony density (Tioho et al. 2001; Carlon 2002). However, this correlation has only been found at the coral family level, at Seychelles (Chong-Seng et al. 2014), Moorea (Edmunds et al. 2010), Ryukyu Island (Nakamura \& Sakai 2009) or when only considering seasonal coral recruitment data, such as in the Wakatobi (Salinas De León et al. 2012a) and in Singapore (Bauman et al. 2015). I did not find a linear correlation between coral cover and coral recruit or juvenile density (Chapter 2). Furthermore, the patterns of spatial variability in coral densities were consistent across the seven years of my study for both recruit and juvenile populations, despite the high fluctuations in the actual coral density values between years (Chapter 3).

Studies conducted in Moorea (Penin \& Adjeroud 2013), Taiwan (Nozawa et al. 2013) and the Wakatobi (Salinas De León et al. 2012a) and this thesis) have assessed the differences in coral density and assemblage composition between corals in early life history stages and adult coral populations. Correlations between coral recruits, juveniles and adults are variable across locations; in Japan (Nakamura \& Sakai 2009), Moorea (Edmunds et al. 2010) and the Seychelles (Chong-Seng et al. 2014) coral recruit abundance was found to be correlated with adult distribution or with juveniles. In Tonga (Adjeroud et al. 2013), Taiwan (Nozawa et al. 
2013), Moorea (Penin et al. 2007) and the Wakatobi (Salinas De León et al. 2012a) juvenile abundance was similar to the adult coral distribution patterns. The only case were all coral life hisoty stages, recruit, juvenile and adult, were correlated, was in Taiwan, where apparently coral recruitment apparently is not strongly affected by post-settlement mortality(Nozawa et al. 2013). This is supported by fact the majority of the coral recruit were found on the exposed side of the panels

Some coral families had higher mortality rates than others. Coral post-settlement mortality was selective and not consistent across years and spatial variability in coral colony distribution was maintained, with differences in coral assemblage composition at each site (Chapters 2 and 3). However, these correlations are biased by the time the measurements were taken. For example, in a coral recruitment study a longer time period left between the main spawning event and the coral density measurement do not mean a higher mortality rate. From the time of settlement, coral recruits are immediately affected by post-settlement mortality, which might cancel any observable correlations existent between the coral spat at settlement time and physical and biological factors (e.g. coral cover) (López-Pérez et al. 2007; Penin et al. 2010; Martinez \& Abelson 2013).

Spatial and temporal changes in coral assemblage composition between recruit and juvenile stages highlighted the action of selective mortality. Although Pocilloporidae is the most common family on settlement panels in most coral reef studies, at the juveniles and adult stages other families have greater dominance. Pocilloporidae was the most common coral recruit family in most locations, with exceptions for Ryukyus Island (Nakamura \& Sakai 2009), Taiwan (Ho \& Dai 2014) and Fiji (Quinn \& Kojis 2008) with Acroporidae, and Moorea with Poritidae (Edmunds et al. 2010), while other coral families were represented in different proportions at each location. In the Caribbean, coral recruit assemblage was mainly comprised of Agariciidae, while Pocilloporidae was rare.

Coral juvenile assemblage composition is more varied than recruit composition and similar results have been found across in the Indo-Pacific, where coral recruit populations were dominated by Pocilloporidae, Poritidae and Acroporidae colonies that varied by location. Faviidae and Agariciidae colonies tend to dominate at juvenile coral populations, despite being rarely found at recruitment time (Arnold et al. 2010). In the Caribbean, coral recruit assemblage was mainly comprised of Agariciidae, while Pocilloporidae was rare.This finding suggests that 
different processes drive coral recruitment across wide areas, such as the Indo-Pacific and the Caribbean, and smaller regions.

Tables 6.1 and 6.2 summarise the studies on coral recruitment conducted in the last 10 years and mentioned previously in this chapter, with a focus on the Pacific Ocean. Studies were divided by coral early life history stage, recruit and juvenile, and examined by the locations where studies were conducted, depth of the surveys, time of deployment of settlement panels and distance between sites.

Overall the Pacific area, coral recruitment means were highly variable and it was not possible to find any existent pattern or trend. This studies suggest that different processes drive coral recruitment across wide areas, such as the Indo-Pacific and the Caribbean, and smaller regions. However, I could not identify any observable distribution pattern in coral recruit assemblage at different locations in the Indo-Pacific.

Comparisons with other studies are difficult because of differences in definitions of coral life history stages vary by authors and there is a wide variability in data collection. Surveys conducted in the same locations in different years with different protocol, such as different depth, variable duration of panel deployment, gave different results, such as in Moorea (Edmunds et al. 2010; Penin \& Adjeroud 2013) and Taiwan (Nozawa et al. 2013; Ho \& Dai 2014).

The high variability found highlight the lack of information about the coral recruitment process. Better identification of coral recruits, continuous monitoring of different life history stages of corals and the choice of study sites by using information about spatial variability of ecological factors could improve the current knowledge about coral recruitment and provide a better understanding of the overall process. 
Table 6.1 Summary of the studies on coral recruitment conducted in the last decade in the Indo-Pacific regions and the Caribbean. Since the Coral Triangle is known for its richness and high diversity in corals, research from this area was separated from the rest of the Indo-Pacific region in order to more easily compare the data. For each study I report location, the depth at which the settlement panels were deployed, the distance between sites used in the study, the mean coral recruit density, the outcome of the analysis on the differences in spatial variation in coral recruits between sites, the preference for orientation (side of the settlement panels presenting more settled coral recruits) and the assemblage composition of the coral recruit population

\begin{tabular}{|c|c|c|c|c|c|c|c|c|c|}
\hline Author & Location & $\begin{array}{l}\text { Depth } \\
\text { (m) }\end{array}$ & $\begin{array}{l}\text { Duration } \\
\text { (months) }\end{array}$ & $\begin{array}{c}\text { Site } \\
\text { distance }\end{array}$ & Mean $\left(m^{2}\right)$ & Spatial variability & Correlations & $\begin{array}{l}\text { Orientation } \\
\text { preference }\end{array}$ & Assemblage \\
\hline \multicolumn{10}{|c|}{ Coral Triangle } \\
\hline This study & $\begin{array}{l}\text { Wakatobi } \\
\text { (Indonesia) }\end{array}$ & $6 ; 12$ & $\begin{array}{l}12 \\
\text { (repeated } \\
\text { for } 3 \text { years) }\end{array}$ & $\begin{array}{l}200 \mathrm{~m}-5 \\
\mathrm{~km}\end{array}$ & 61.09 & $\begin{array}{l}\text { Spatial variability across } \\
\text { sites, not across depths. } \\
\text { Temporal variability not } \\
\text { always found }\end{array}$ & No correlations found & $\begin{array}{l}64.15 \% \text { on the back side } \\
\text { of the tiles, rarely front } \\
\text { and back side presented } \\
\text { similar abundance }\end{array}$ & $\begin{array}{l}\text { Pocilloporidae 25.47\%; } \\
\text { Poritidae 19.18\%; Faviidae } \\
\text { 15.72\%; Acroporidae } 8.5 \% \text {; } \\
\text { Agariciidae } 4.71 \%\end{array}$ \\
\hline $\begin{array}{l}\text { Sawall et al. } \\
\text { (2013) }\end{array}$ & $\begin{array}{l}\text { Sulawesi } \\
\text { SW } \\
\text { (Indonesia) }\end{array}$ & $3-4$ & $\begin{array}{l}4 \text { (repeated } \\
\text { for } 2 \text { years) }\end{array}$ & & $705-286$ & $\begin{array}{l}\text { Temporal variability. } \\
\text { Seasonal variability }\end{array}$ & $\begin{array}{l}\text { No correlation with benthic } \\
\text { community, although recruits } \\
\text { mostly settled next to complex } \\
\text { benthic community (back side) }\end{array}$ & $\begin{array}{l}\text { Preference for back side } \\
\text { of tiles }\end{array}$ & $\begin{array}{l}\text { Pocilloporidae } 63 \% \\
\text { Acroporidae } 14.6 \% \\
\text { Poritidae } 7.8 \%\end{array}$ \\
\hline $\begin{array}{l}\text { Salinas De Leén } \\
\text { et al. (2012) }\end{array}$ & $\begin{array}{l}\text { Wakatobi } \\
\text { (Indonesia) }\end{array}$ & $5-7$ & $\begin{array}{l}12 \\
\text { (repeated } \\
\text { for } 2 \text { years) }\end{array}$ & $1.5 \mathrm{~km}$ & $\begin{array}{l}89(2008) \\
209(2009)\end{array}$ & $\begin{array}{l}\text { Spatial and temporal } \\
\text { variability. } \\
\text { Seasonal variability }\end{array}$ & $\begin{array}{l}\text { Positive correlation between } \\
\text { recruits/coral cover }\end{array}$ & $\begin{array}{l}\text { Back, both sides were } \\
\text { counted }\end{array}$ & $\begin{array}{l}\text { Acroporidae } 25-12 \% \\
\text { Pocillopora } 21-10 \% \\
\text { Poritidae } 13-16 \%\end{array}$ \\
\hline Fox (2004) & $\begin{array}{l}\text { Komodo } \\
\text { (Indonesia) }\end{array}$ & $6-10$ & $\begin{array}{l}6 \text { (repeated } \\
\text { twice) }\end{array}$ & $\begin{array}{l}9 \text { blasted } \\
\text { and } 6 \\
\text { unblasted } \\
\text { sites up to } \\
20 \mathrm{~km} \text { apart }\end{array}$ & $285-772$ & $\begin{array}{l}\text { Spatial and seasonal } \\
\text { variability between blasted } \\
\text { and unblasted sites. }\end{array}$ & $\begin{array}{l}\text { No correlation with coral juvenile } \\
\text { abundance at blasted sites. }\end{array}$ & $\begin{array}{l}\text { Overall preference for } \\
\text { back side of the panels. } \\
\text { Acroporidae mostly on } \\
\text { front sides. }\end{array}$ & $\begin{array}{l}\text { Pocilloporidae } 44.7 \% \text {; } \\
\text { Acroporidae } 27.1 \% ; \\
\text { Poritidae } 12 \%\end{array}$ \\
\hline \multicolumn{10}{|c|}{ Indo-Pacific region } \\
\hline $\begin{array}{l}\text { Bauman et al. } \\
\text { (2015) }\end{array}$ & Singapore & $3-4$ & $\begin{array}{l}3 \text { (repeated } \\
\text { for } 2 \text { years) }\end{array}$ & $\begin{array}{l}7 \text { sites } \\
\text { along } 15 \mathrm{~km}\end{array}$ & 54.74 & $\begin{array}{l}\text { Consistent spatial pattern } \\
\text { amongst sites. } \\
\text { Seasonal variability }\end{array}$ & $\begin{array}{l}\text { No correlation between } \\
\text { recruits/coral cover during peak } \\
\text { season (found only for } \\
\text { Poritidae). }\end{array}$ & $\begin{array}{l}\text { Lateral sides } 41 \% \text {, back } \\
30.7 \% \text { and front } 27.6 \%\end{array}$ & $\begin{array}{l}\text { Pocilloporidae } 84 \% \text {; } \\
\text { Poritidae } 4 \% \text {; Acroporidae } \\
1 \% \text {; others } 10 \%\end{array}$ \\
\hline $\begin{array}{l}\text { Chong-Seng et } \\
\text { al. (2014) }\end{array}$ & Seychelles & 4 & 3 & $\begin{array}{l}\text { From few to } \\
\text { several } \mathrm{km}\end{array}$ & & $\begin{array}{l}\text { Variation between reefs, not } \\
\text { between sites on same reef }\end{array}$ & $\begin{array}{l}\text { Correlation between } \\
\text { Pocilloporidae recruits and } \\
\text { adults, no with juveniles }\end{array}$ & & \\
\hline $\begin{array}{l}\text { Ho \& Dai } \\
\text { (2014) }\end{array}$ & Taiwan & $\begin{array}{l}6-8,8- \\
10 ; 12- \\
13\end{array}$ & $\begin{array}{l}3 \text { and } 12 \\
\text { (repeated } \\
\text { for } 2 \text { years) }\end{array}$ & $\begin{array}{l}3 \text { sites } \\
\text { about } 500- \\
700 \mathrm{~m} \text { apart }\end{array}$ & $86-116$ & $\begin{array}{l}\text { Yes, but only in the first year } \\
\text { Seasonal variability }\end{array}$ & $\begin{array}{l}\text { Abundance negatively correlated } \\
\text { with depth }\end{array}$ & $\begin{array}{l}\text { Both sides counted, } \\
\text { preference for front } 53 \% \text {, } \\
42 \% \text { vertical, } 5 \% \text { back }\end{array}$ & $\begin{array}{l}\text { Acroporidae } 77 \% \text {, } \\
\text { Pocillopora } 18 \% \text {, Poritidae } \\
6 \%\end{array}$ \\
\hline
\end{tabular}




\begin{tabular}{|c|c|c|c|c|c|c|c|c|c|}
\hline Author & Location & $\begin{array}{l}\text { Depth } \\
\text { (m) }\end{array}$ & $\begin{array}{l}\text { Duration } \\
\text { (months) }\end{array}$ & $\begin{array}{c}\text { Site } \\
\text { distance }\end{array}$ & Mean $\left(m^{2}\right)$ & Spatial variability & Correlations & $\begin{array}{l}\text { Orientation } \\
\text { preference }\end{array}$ & Assemblage \\
\hline $\begin{array}{l}\text { Nozawa \& Chung } \\
\text { (2013) }\end{array}$ & Taiwan & $5 ; 15$ & 4 & $\begin{array}{l}\text { Up to } 10 \mathrm{~km} \\
\text { apart }\end{array}$ & & $\begin{array}{l}\text { Yes, no differences between } \\
\text { different depths at same site }\end{array}$ & $\begin{array}{l}\text { At } 5 \mathrm{~m} \text { no correlation with } \\
\text { juvenile and adult composition; } \\
\text { at } 15 \mathrm{~m} \text { similar composition }\end{array}$ & Preference for front side & $\begin{array}{l}\text { At } 5 \mathrm{~m} \text { : Pocilloporidae and } \\
\text { Poritidae }(80 \%) \text {. At } 15 \mathrm{~m} \text { : } \\
\text { Acroporidae }(48-65 \%) \text { and } \\
\text { Pocilloporidae }\end{array}$ \\
\hline $\begin{array}{l}\text { Penin et al. } \\
\text { (2013) }\end{array}$ & $\begin{array}{l}\text { Moorea } \\
\text { (French } \\
\text { Polynesia) }\end{array}$ & $\begin{array}{l}6,12 \text { and } \\
18\end{array}$ & $\begin{array}{l}3 \text { (repeated } \\
\text { twice) }\end{array}$ & $\begin{array}{l}5 \mathrm{~km} \\
\text { between } \\
\text { islands; 3-8 } \\
\mathrm{km} \text { within } \\
\text { islands }\end{array}$ & 568.54 & $\begin{array}{l}\text { Yes, at regional and island } \\
\text { levels }\end{array}$ & $\begin{array}{l}\text { Abundance variable with depth, } \\
\text { no pattern found }\end{array}$ & $\begin{array}{l}\text { Both sides counted, no } \\
\text { preference specified }\end{array}$ & $\begin{array}{l}\text { Pocillopora } 67 \% \text {, } \\
\text { Acroporidae } 23 \% \text {, Poritidae } \\
10 \% \text {. Seasonal variability }\end{array}$ \\
\hline $\begin{array}{l}\text { Edmunds } \\
\text { (2010) }\end{array}$ & $\begin{array}{l}\text { Moorea } \\
\text { (French } \\
\text { Polynesia) }\end{array}$ & $1.5-2$ & $\begin{array}{l}5-7 \\
\text { (repeated } \\
\text { for } 2 \text { years) }\end{array}$ & $\begin{array}{l}10 \text { sites } \\
\text { along } 20 \mathrm{~km} \\
\text { coast }\end{array}$ & 23.74 & Only seasonal variability & $\begin{array}{l}\text { Coral cover correlated only with } \\
\text { part of the seasonal data }\end{array}$ & $\begin{array}{l}96 \% \text { on back, } 4 \% \text { on } \\
\text { lateral sides and } 1 \% \text { on } \\
\text { front }\end{array}$ & $\begin{array}{l}\text { Poritidae } 34 \% \text {, Acroporidae } \\
27 \% \text {; Pocilloporidae } 23 \%\end{array}$ \\
\hline $\begin{array}{l}\text { Kuo } \\
(2010)\end{array}$ & Taiwan & $4-5$ & $\begin{array}{l}2 \text { years, } \\
\text { panels of } \\
\text { different } \\
\text { age }\end{array}$ & & 32.5 & $\begin{array}{l}\text { Age of the tile and seasonal } \\
\text { variability }\end{array}$ & $\begin{array}{l}\text { Older panels have more } \\
\text { Pocilloporidae recruits }\end{array}$ & $\begin{array}{l}\text { Tiles fixed in vertical } \\
\text { position, only back side } \\
\text { included }\end{array}$ & $\begin{array}{l}\text { Pocilloporidae } 51 \% \text {, } \\
\text { Poritidae } 31 \% \text {, } \\
\text { Astrocoeniidae } 6 \% \text {, } \\
\text { Acroporidae } 2 \%\end{array}$ \\
\hline $\begin{array}{l}\text { Nakamura } \\
\text { (2009) }\end{array}$ & $\begin{array}{l}\text { Ryukyu } \\
\text { (Japan) }\end{array}$ & 5 & 8 weeks & $\begin{array}{l}\text { Between } \\
\text { location: } \\
0.3-0.6 ; \\
\text { between } \\
\text { sites: } 0.5-2 \\
\text { km }\end{array}$ & N/A & Yes, across sites and years & $\begin{array}{l}\text { Pocilloporidae: correlation } \\
\text { recruit/adult. Correlation } \\
\text { between surface and current } \\
\text { direction/recruitment pattern }\end{array}$ & $\begin{array}{l}\text { No recruits found on the } \\
\text { front side }\end{array}$ & $\begin{array}{l}\text { Acroporidae } 78.8 \%-61.3 \% \text {, } \\
\text { Poritidae } 10 \%-16 \% \text {, } \\
\text { Pocilloporidae } 10.7-13.7 \%\end{array}$ \\
\hline $\begin{array}{l}\text { Kojis \& Quinn } \\
\text { (2008) }\end{array}$ & Fiji & $\begin{array}{l}5,15 \text { and } \\
25\end{array}$ & $\begin{array}{l}6 \text { (repeated } \\
\text { for } 2.5 \\
\text { years) }\end{array}$ & $\begin{array}{l}\text { Few } \mathrm{km} \\
\text { within site, } \\
70-200 \mathrm{~km} \\
\text { between } \\
\text { sites }\end{array}$ & $\begin{array}{l}570 \\
\text { (summer); } \\
93 \text { (winter) }\end{array}$ & $\begin{array}{l}\text { Yes, between sites } \\
5 \text { (winter) - } 1749 \text { (summer) }\end{array}$ & $\begin{array}{l}\text { Correlation with depth, Poritidea } \\
\text { mostly in deep water and with } \\
\text { coral cover }\end{array}$ & $\begin{array}{l}\text { All sites counted, no data } \\
\text { on orientation preference }\end{array}$ & $\begin{array}{l}\text { Acroporidae } 52.2 \% \text {, } \\
\text { Pocillopora } 30.3 \% \text {, Poritidae } \\
3.4 \% \text {, Faviidae } 0.5 \%\end{array}$ \\
\hline $\begin{array}{l}\text { Mangubhai et al. } \\
\text { (2007) }\end{array}$ & Kenya & $0-7$ & $\begin{array}{l}3 \text { (repeated } \\
\text { for } 27 \\
\text { months) }\end{array}$ & $\begin{array}{l}\text { Two sites } 7 \\
-8 \mathrm{~km} \\
\text { apart }\end{array}$ & $\begin{array}{l}101 \\
\text { (degraded } \\
\text { reef) } \\
908 \text { (healthy } \\
\text { reef) }\end{array}$ & $\begin{array}{l}\text { Spatial and temporal } \\
\text { variability } \\
\text { Seasonal variability }\end{array}$ & $\begin{array}{l}\text { No latitudinal gradient in recruit } \\
\text { density. Seasonal correlation } \\
\text { with serpulids and oysters. Weak } \\
\text { interaction with oyster density. }\end{array}$ & $\begin{array}{l}\text { Only recruit on back side } \\
\text { ( } 92 \% \text { of total recruits) } \\
\text { included in analysis. }\end{array}$ & $\begin{array}{l}\text { Pocilloporidae } 93.7 \% \text {; } \\
\text { Poritidae } 3.2 \% \text {; Acroporidae } \\
\text { 1.4\%; Faviidae } 0.1 \%\end{array}$ \\
\hline $\begin{array}{l}\text { Adjeroud et al. } \\
\text { (2007) }\end{array}$ & $\begin{array}{l}\text { Moorea } \\
\text { (French } \\
\text { Polynesia) }\end{array}$ & $\begin{array}{l}6,12 \text { and } \\
18\end{array}$ & $\begin{array}{l}3 \text { (repeated } \\
\text { for } 3 \text { years) }\end{array}$ & $\begin{array}{l}\text { Three sites } \\
\text { about } 10 \mathrm{~km} \\
\text { apart }\end{array}$ & $\begin{array}{l}40.77 \\
\text { Overall } \\
\text { decrease in } \\
\text { recruitment } \\
\text { rates over } 3 \\
\text { years }\end{array}$ & $\begin{array}{l}\text { Spatial and temporal } \\
\text { variability. } \\
\text { Variability in depth not } \\
\text { consistent across years. } \\
\text { Seasonal variability }\end{array}$ & & $\begin{array}{l}57.1 \% \text { on back, } 28.4 \% \text { on } \\
\text { lateral sides and } 14.5 \% \\
\text { on front }\end{array}$ & $\begin{array}{l}\text { Pocilloporidae: } 60.4 \% \text {, } \\
\text { Poritidae: } 18.8 \% \text {, } \\
\text { Acroporidae: } 11.2 \% \\
\text { Pocilloporidae and Poritidae } \\
\text { decrease over } 3 \text { years. }\end{array}$ \\
\hline
\end{tabular}




\begin{tabular}{|c|c|c|c|c|c|c|c|c|c|}
\hline Author & Location & $\begin{array}{l}\text { Depth } \\
\text { (m) }\end{array}$ & $\begin{array}{l}\text { Duration } \\
\text { (months) }\end{array}$ & $\begin{array}{c}\text { Site } \\
\text { distance }\end{array}$ & Mean $\left(m^{2}\right)$ & Spatial variability & Correlations & $\begin{array}{l}\text { Orientation } \\
\text { preference }\end{array}$ & Assemblage \\
\hline $\begin{array}{l}\text { López-Pérez et } \\
\text { al. (2007) }\end{array}$ & $\begin{array}{l}\text { Huatulco } \\
\text { (Pacific } \\
\text { coast) } \\
\text { Mexico }\end{array}$ & & $\begin{array}{l}11-13 \\
\text { (some tiles } \\
\text { replaced } \\
\text { every } \\
\text { second } \\
\text { month) }\end{array}$ & $1.5-6$ & $\begin{array}{l}0.85-20.4 \\
\text { (higher } \\
\text { recruitment } \\
\text { rate on two- } \\
\text { months } \\
\text { tiles) }\end{array}$ & Yes & $\begin{array}{l}\text { No correlation in assemblage } \\
\text { composition between recruit and } \\
\text { adult }\end{array}$ & & $\begin{array}{l}290 \text { out of } 291 \text { Porites and } \\
\text { one Pocillopora }\end{array}$ \\
\hline $\begin{array}{l}\text { Dunstan \& } \\
\text { Johnson (1998) }\end{array}$ & $\begin{array}{l}\text { Heron } \\
\text { island } \\
\text { (GBR, } \\
\text { Australia) }\end{array}$ & $\begin{array}{l}9-12 \text { or } \\
2-3 \\
\text { (lagoon) }\end{array}$ & $\begin{array}{l}3 \text { and } 10 \\
\text { months } \\
\text { after } \\
\text { spawning } \\
\text { peak (for } 4 \\
\text { years) }\end{array}$ & $\begin{array}{l}\text { Three } \\
\text { zones with } \\
\text { three sites } \\
\text { (400-600m } \\
\text { apart) each }\end{array}$ & & $\begin{array}{l}\text { Spatial and temporal } \\
\text { variability } \\
\text { No spatial variability within } \\
\text { sites in } 10 \text { months old } \\
\text { recruits }\end{array}$ & $\begin{array}{l}\text { No consistent pattern within } \\
\text { zones across years } \\
\text { Negative correlation between } \\
\text { coral recruit abundance and } \\
\text { bryozoan and oyster cover }\end{array}$ & & $\begin{array}{l}\text { Pocilloporidae } 80.1 \% \\
\text { Acroporidae } 16.4 \%\end{array}$ \\
\hline \multicolumn{10}{|c|}{ Caribbean } \\
\hline $\begin{array}{l}\text { Green \& } \\
\text { Edmunds (2011) }\end{array}$ & $\begin{array}{l}\text { Virgin } \\
\text { Island }\end{array}$ & $5-6$ & $\begin{array}{l}6 \text { (repeated } \\
\text { for } 2 \text { years) }\end{array}$ & $\begin{array}{l}10 \text { sites } \\
\text { randomly } \\
\text { distributed } \\
\text { along } 10 \mathrm{~km}\end{array}$ & 76 & $\begin{array}{l}\text { Yes, across sites, years and } \\
\text { seasons }\end{array}$ & $\begin{array}{l}\text { Correlation with water motion } \\
\text { (analysis of temperature and } \\
\text { flow) }\end{array}$ & $\begin{array}{l}\text { All on the back side of the } \\
\text { tiles }\end{array}$ & $\begin{array}{l}\text { Poritidae } 43 \% \text {, Agariciidae } \\
29 \% \text {, Faviidae } 17 \% \text {. } \\
\text { Seasonal variability }\end{array}$ \\
\hline $\begin{array}{l}\text { Arnold et al. } \\
(2010)\end{array}$ & Bonaire & 10 & $\begin{array}{l}\text { Repeated } \\
\text { for } 7 \text { years }\end{array}$ & $\begin{array}{l}\text { Few km } \\
\text { apart }\end{array}$ & $128( \pm 32)$ & & Correlation with juvenile density & Mostly on back side & $\begin{array}{l}\text { Agaricia } 88.8 \% \text {, Porites } \\
8.3 \%\end{array}$ \\
\hline $\begin{array}{l}\text { Irizarry-Soto \& } \\
\text { Weil (2009) }\end{array}$ & Puerto Rico & $\begin{array}{l}0-3,3-5, \\
5-10 \text { and } \\
>15\end{array}$ & $\begin{array}{l}\text { Up to } 2 \\
\text { years }\end{array}$ & & 2.24 & & & & \\
\hline
\end{tabular}


Table 6.2 Summary of studies on coral juvenile abundance conducted in the last decade in the Indo-Pacific region and the Caribbean. For each study I report location, the depth where the survey was carried out, the definition of juvenile used in the data collection (maximum diameter in $\mathrm{mm}$ ), the mean coral juvenile density, the outcome of the analysis on differences in spatial variation in coral juveniles between sites, the number of families/genera/species detected and the assemblage composition of the coral juvenile population

\begin{tabular}{|c|c|c|c|c|c|c|c|c|}
\hline Author & Location & $\begin{array}{l}\text { Depth } \\
\text { (m) }\end{array}$ & $\begin{array}{l}\text { Juvenile } \\
\text { size }(\mathrm{mm})\end{array}$ & $\begin{array}{l}\text { Mean } \\
\text { (juv. } \mathbf{m}^{-2} \text { ) }\end{array}$ & Spatial variability & Correlations & Families (Genera) & Assemblage \\
\hline \multicolumn{9}{|c|}{ Indo-Pacific } \\
\hline This study & $\begin{array}{l}\text { Wakatobi } \\
\text { (Indonesia) }\end{array}$ & $6 ; 12$ & $<40$ & $9.63( \pm 0.24 \mathrm{SE})$ & $\begin{array}{l}\text { Spatial and temporal } \\
\text { variability } \\
\text { Pocilloporidae and } \\
\text { Acroporidae varied across } \\
\text { sites, Faviidae and } \\
\text { Agariciidae across depths }\end{array}$ & $\begin{array}{l}\text { No correlation with coral cover } \\
\text { or recruits, }\end{array}$ & $13(28)$ & $\begin{array}{l}\text { Agariciidae 20.84\%; Faviidae } \\
19.85 \% \text {; Poritidae } 13.77 \% \text {; } \\
\text { Pocilloporidae } 12.16 \% \text { and } \\
\text { Acroporidae } 4.59 \%\end{array}$ \\
\hline $\begin{array}{l}\text { Chong-Seng et al. } \\
\text { (2014) }\end{array}$ & Seychelles & & $<50$ & $\begin{array}{l}2.4( \pm 1.1)-33.1 \\
( \pm 7.3)\end{array}$ & $\begin{array}{l}\text { Between reefs dominated } \\
\text { by coral, macroalgae or } \\
\text { rubble }\end{array}$ & $\begin{array}{l}\text { No correlation with adult } \\
\text { assemblage }\end{array}$ & 3 & $\begin{array}{l}\text { Faviidae, Agariciidae, Poritidae, } \\
\text { Siderastreidae, Astrocoenidae, } \\
\text { Acroporidae and Meandrinidae }\end{array}$ \\
\hline $\begin{array}{l}\text { Adjeroud et al. } \\
\text { (2013) }\end{array}$ & Tonga & $2-3$ & $10-50$ & 5.5 & Yes & $\begin{array}{l}7 \text { dominant genera correlated } \\
\text { between juvenile and adult } \\
\text { stage }\end{array}$ & (28) & $\begin{array}{l}\text { Acropora } 22 \% \text {; Porites } 21 \% \text {; } \\
\text { Montipora } 18 \% \text {; Favia 10\% }\end{array}$ \\
\hline $\begin{array}{l}\text { Nozawa et al. } \\
(2013)\end{array}$ & Taiwan & $5 ; 15$ & $10-50$ & & $\begin{array}{l}\text { Not specified, but high } \\
\text { variability between sites }\end{array}$ & $\begin{array}{l}\text { At } 5 \mathrm{~m} \text { similar composition to } \\
\text { adult ( } \mathrm{p}=0.01) \text {; but different from } \\
\text { recruits; at } 15 \mathrm{~m} \text { no differences. } \\
\text { Strong recruits-adults- } \\
\text { correlation for broooding } \\
\text { species. }\end{array}$ & 3 & $\begin{array}{l}\text { At } 5 \mathrm{~m} \text { : Pocilloporidae and } \\
\text { Poritidae (80\%). At } 15 \mathrm{~m} \text { : } \\
\text { Acroporidae (48-65\%) and } \\
\text { Pocilloporidae (12-38\%) }\end{array}$ \\
\hline $\begin{array}{l}\text { Salinas De León et } \\
\text { al. (2012) }\end{array}$ & $\begin{array}{l}\text { Wakatobi } \\
\text { (Indonesia) }\end{array}$ & 6 & $<40$ & 24.8 & Yes & $\begin{array}{l}\text { Juvenile abundance correlated } \\
\text { with coral cover }\end{array}$ & 5 & $\begin{array}{l}\text { Faviidae } 28.3 \% \text {; Poritidae } 24.5 \% \text {; } \\
\text { Agariciidae } 18.9 \% \text {; Acroporidae } \\
10.7 \% \text { Pocilloporidae } 4.22 \%\end{array}$ \\
\hline $\begin{array}{l}\text { Penin et al. } \\
(2007 ; 2010)\end{array}$ & Moorea & $\begin{array}{l}6 ; 12 \text { and } \\
18\end{array}$ & $<50$ & $\begin{array}{l}7.9 \\
\text { (higher density } \\
\text { at } 18 \mathrm{~m})\end{array}$ & Yes & Correlation with coral adults & (14) & $\begin{array}{l}\text { Acropora, Fungia, Montipora, } \\
\text { Pavona (no: Pocillopora and } \\
\text { Porites) }\end{array}$ \\
\hline $\begin{array}{l}\text { Roth \& Knowlton } \\
\text { (2009) }\end{array}$ & Palmyra & $\begin{array}{l}10 ; 14 \\
\text { and } 18\end{array}$ & $<50$ & $\begin{array}{l}\text { Range: } 0-59.5 \\
\text { (higher at } 14 \mathrm{~m} \\
\text { on fore reef) }\end{array}$ & Yes $(p<0.001)$ & $\begin{array}{l}\text { Pattern not correlated with } \\
\text { depth, juveniles mainly on CCA } \\
\text { or bare substrate }\end{array}$ & & $\begin{array}{l}\text { Montipora; Acropora; Porites: 55.9- } \\
61.4 \%\end{array}$ \\
\hline
\end{tabular}




\begin{tabular}{|c|c|c|c|c|c|c|c|c|}
\hline Author & Location & $\begin{array}{l}\text { Depth } \\
(\mathrm{m})\end{array}$ & $\begin{array}{c}\text { Juvenile } \\
\text { size }(\mathrm{mm})\end{array}$ & $\begin{array}{c}\text { Mean } \\
\text { (juv.m-2) }\end{array}$ & Spatial variability & Correlations & Families (Genera) & Assemblage \\
\hline \multicolumn{9}{|c|}{ Caribbean } \\
\hline $\begin{array}{l}\text { Lozano-Cortés \& } \\
\text { Zapata (2015) }\end{array}$ & $\begin{array}{l}\text { San Andres } \\
\text { Island } \\
\text { (Colombia) }\end{array}$ & $1-6$ & $<40$ & $5.75( \pm 3.47 \mathrm{SD})$ & & $\begin{array}{l}\text { No correlation with adult corals } \\
\text { abundance and assemblage }\end{array}$ & $\begin{array}{l}7 \\
15 \text { species }\end{array}$ & Favia, Agaricia and Porites: $85.8 \%$ \\
\hline Arnold et al. (2010) & Bonaire & 10 & $<40$ & $13.2( \pm 2.2)$ & & Correlation with recruit density & & \\
\hline Green et al. (2010) & Virgin Islands & 5 & $<40$ & 36.82 & $N / A$ & $\begin{array}{l}\text { Correlation with the substratum } \\
\text { (igneous or carbonate) }\end{array}$ & & \\
\hline $\begin{array}{l}\text { Irizarry-Soto \& Weil } \\
\text { (2009) }\end{array}$ & Puerto Rico & $\begin{array}{l}0-3 ; 3-5 ; \\
5-10 \text { and } \\
>15\end{array}$ & $<50$ & $4.8 \pm 0.24$ & $\begin{array}{l}\text { Spatial and temporal } \\
\text { variability (excluded } 10 \mathrm{~m} \text { ) }\end{array}$ & & 31 species & \\
\hline
\end{tabular}




\subsection{Importance of different environmental factors at different phases of the coral recruitment process}

Several studies have investigated the causes of the selective mortality that affects coral recruitment, resulting in a decrease in coral densities between the recruit and juvenile stage and changes in assemblage composition (Hughes \& Jackson 1985; Quinn \& Kojis 2008; Penin \& Adjeroud 2013). Fish predation and spatial competition have been identified as two of the main drivers that influence the recruitment process (Lewis 1986; Lirman 2001; Mumby 2009; Lenihan et al. 2011; Brandl et al. 2013). For example, on the Great Barrier Reef, parrotfish abundance was correlated with coral recruit densities (Trapon et al. 2013c), while associations of different strength were found between the abundance of young coral colonies and benthic organisms, such as serpulids and oysters in Kenya (Mangubhai et al. 2007), serpulids, bryozoans and bivalves in the Red Sea (Glassom et al. 2004) and bryozoans and oysters in the Great Barrier Reef (Dunstan \& Johnson 1998). However, most of these studies focused on coral colonies that had recently settled, which are known to be affected by high mortality rates because of their vulnerability, and did not investigate the later phases of the recruitment process.

Despite the use of statistical and experimental methods, the drivers of coral recruitment process remain poorly understood. In Chapter 2, using a modelling approach, I did not find any dominant factor or combination of factors that adequately explained the spatial variability in either coral recruit or juvenile distribution. Furthermore, in a complementary manipulative experiment, fish predation or accidental removal from the reef was not found to be a cause of mortality in coral colonies aged up to two years (Chapter 4). However, this result does not exclude the possibility that overall fish abundance, or grazer abundance, might have a major influence in the first few days or weeks after the corals initially settle.

Spatial competition was expected to affect coral juvenile distribution and survivorship only in later stages when there was a lack of available substrate necessary for growth, expansion and competition for resources (e.g. nutrients, light). However, I found coral recruits began interacting with other benthic organisms, such as CCA and turf algae, very soon after settlement, when there was still a large proportion of free space on the settlement panels (Chapter 5). Although CCA is known to promote coral settlement (Price 2010; O'Leary et al. 2012), I found no specific association between CCA or the common benthic organisms present on the panels, such as bryozoans, turf algae, sponges, and coral colony density (Chapter 5). 
However, the succession of organisms interacting with coral colonies, the outcome of these interactions, and the impact on coral survivorship and coral growth rate still need further investigation (Figure 6.1).
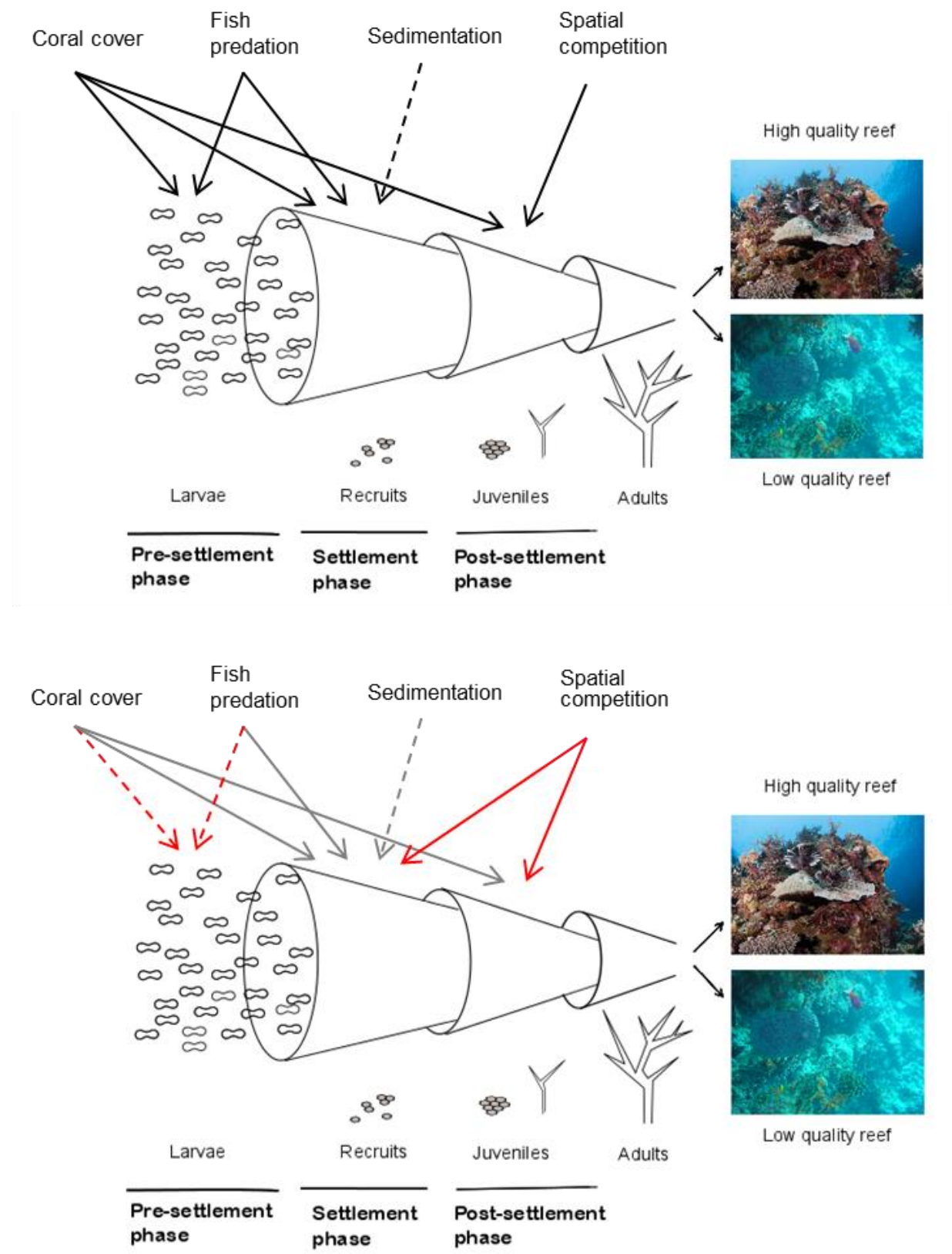

Figure 6.1 Summary of the main findings of my research (modified from Pineda et al. 2008). In the top half of the figure, the arrows show the correlations that were already known to exist before my study between environmental factors with coral populations at different stages of the coral recruitment process. The lack of studies were coral life history stages were studied separately did not allowed to understand the role and impact of factors, such as coral cover, fish predation, sedimentation and spatial competition, at different stages of the recruitment process. In the bottom half, the arrows show the outcomes of my study. No clear correlation was found between coral cover and recruitment rates, no evidence of self-recruitment, although coral cover might be correlated to the larvae availability. Mortality by fish grazing activity is likely to impact on coral recruit, no information about predation of coral larvae by fish. Sedimentation might have a role at coral settlement, but more investigations are needed about further effects on coral recruit survivorship. Spatial competition influences coral spatial variability from settlement across all the life history stages. Interactions and correlations between coral colonies and benthic organisms play an important role in determining the final composition and pattern of coral population. Black lines: knowledge before my study. Black dotted line: suggested correlation. Red lines: findings of this study; grey lines: correlations not found. Red dotted line: correlations that need more investigation. 


\subsection{Implications for reef management}

My data for coral recruit and juvenile abundances collected over a seven-year period represent an important step in the development of a monitoring program for coral recruitment in the Wakatobi. My data can be compared with data collected in the future to assess longer temporal coral recruitment trends and identify range fluctuations in coral recruit densities. Any future decreases in coral densities or change in coral assemblage composition can then be compared with my time series data to determine if it falls within patterns of previously observed variability or if it is a cause for greater concern. In addition, if there were ever a major bleaching event or other major disturbance, my data can serve as a reference point for the coral recruitment state in normal conditions when planning a coral recovery project.

Overall, my research provides a better understanding of the role and importance of grazing activity and spatial competition in regulating coral recruitment. It highlights the importance of investigating local ecological factors at different localities on small scales (e.g. a few hundred meters), since even small distances between sites can result in high variability in recruitment patterns. My study shows that fish predation is not an important cause of mortality in coral recruits and juveniles in the Wakatobi. As a consequence, any future changes in coral densities in these early coral life history stages are not likely to be attributable to fish activity, but rather to other or factors that remain currently unidentified.

Interactions with other benthic organisms, especially algae, need to be monitored through time. Although my study did not find any specific organisms that affected coral recruits and juvenile distribution and survivorship, on more complex surfaces such interactions between coral colonies and organisms might have a higher impact than what I found in a developing community. More studies are required to understand the association between environmental disturbances with different stages of coral recruitment in the Wakatobi.

My study identified sites with higher recruitment rates which are important for conservation purposes and need to be maintained healthy through a monitoring program repeated in time in order to prevent declines in recruitment rates.

At the same time, degraded sites, which present low recruitment rates, need proactive management to implement plans to reduce stressors, such as sedimentation caused by coral mining and land-based pollution, and avoid further deterioration of the current reef conditions.

Once disturbances have been reduced and reef status is continuously monitored, a coral restoration project could improve reef recovery at degraded sites in order to increase 
recruitment possibility. Decrease of disturbances promotes the growth of coral colonies artificially deployed on reef substrate, but also of the natural coral colonies.

In addition to these suggestions, reef managers could improve the site selection for development or conservation and implement more strategic and proactive approach that delivers long-term benefits. For example implementation of a fish zonation plan in the overall Wakatobi could protect the area important for coral reproduction and recruitment, especially during the spawning season. A better regulation of fisheries could benefit grazing fish population and they important role in regulating algae growth.

In the last decade, genetic and environmental data have been combined in order to investigate the scale of connectivity and variability in coral recruitment and model the patterns of coral recruitment variability. A genetic study on reef connectivity in the Wakatobi would give insight into the sources and movement of coral larvae. These genetic data combined with my data on spatial variability could provide important information on the regulation of the recruitment process occurring in the Wakatobi. Measuring relationships between reef connectivity, scale of variability in coral recruitment, and environmental factors would make it possible to predict recruitment trends (Golbuu et al. 2012) and identify areas that should be given priority for conservation and reef restoration.

\subsection{Conclusions}

The results of my study provide important insights into the processes regulating coral populations in the Wakatobi and the changes occurring over time. My research demonstrates that there is a high variability in abundance and assemblage composition between coral early life history stages and this variability is likely driven by local environmental factors.

In the future, the establishment of a regular coral recruit and juvenile monitoring program, combined with my seven-year dataset, will prove invaluable for conserving and managing coral populations in this region, and would generate useful information for assessing the health of the coral reef. 


\section{References}

Adam, T.C., Burkepile, D.E., Ruttenberg, B.I. \& Paddack, M.J. (2015) Herbivory and the resilience of Caribbean coral reefs: knowledge gaps and implications for management. Marine Ecology Progress Series, 520, 1-20.

Adjeroud, M., Briand, M.J., Kayal, M. \& Dumas, P. (2013) Coral assemblages in Tonga: spatial patterns, replenishment capacities, and implications for conservation strategies. Environmental monitoring and assessment, 185, 5763-73.

Adjeroud, M., Penin, L. \& Carroll, A. (2007a) Spatio-temporal heterogeneity in coral recruitment around Moorea, French Polynesia: Implications for population maintenance. Journal of Experimental Marine Biology and Ecology, 341, 204-218.

Adjeroud, M., Pratchett, M.S., Kospartov, M.C., Lejeusne, C. \& Penin, L. (2007b) Small-scale variability in the size structure of scleractinian corals around Moorea, French Polynesia: patterns across depths and locations. Hydrobiologia, 589, 117-126.

Aerts, L.A.M. (2000) Dynamics behind standoff interactions in three reef sponge species and the coral Montastraea cavernosa. Marine Ecology, 21, 191-204.

Aerts, L.A.M. (1998) Sponge/coral interactions in Caribbean reefs: Analysis of overgrowth patterns in relation to species identity and cover. Marine Ecology Progress Series, 175, $241-249$.

Almany, G.R., Berumen, M.L., Thorrold, S.R., Planes, S. \& Jones, G.P. (2007) Local replenishment of coral reef fish populations in a marine reserve. Science (New York, N.Y.), $316,742-4$.

Anderson, M.J. (2001) Permutation tests for univariate or multivariate analysis of variance and regression. Canadian Journal Of Fisheries \& Aquatic Sciences, 58, 626-639.

Anderson, M.J. \& Willis, T.J. (2003) Canonical analysis of principal coordinates: A useful method of constrained ordination for ecology. Ecology, 84, 511-525.

Andutta, F.P., Kingsford, M.J. \& Wolanski, E. (2012) "Sticky water" enables the retention of larvae in a reef mosaic. Estuarine, Coastal and Shelf Science, 101, 54-63.

Anthony, K.R.N. \& Connolly, S.R. (2004) Environmental limits to growth: physiological niche boundaries of corals along turbidity-light gradients. Oecologia, 141, 373-84.

Arnold, S.N., Steneck, R.S. \& Mumby, P.J. (2010) Running the gauntlet: inhibitory effects of algal turfs on the processes of coral recruitment. Marine Ecology Progress Series, 414, 91-105.

Babcock, R.C., Baird, A.H., Piromvaragorn, S., Thomson, D.P. \& Willis, B.L. (2003) Identification of Scleractinian Coral Recruits from Indo-Pacific Reefs. Zoological Studies, $42,211-226$. 
Babcock, R.C., Bull, G.D., Harrison, P.L., Heyward, A.J., Oliver, J.K., Wallace, C.C. \& Willis, B.L. (1986) Synchronous Spawnings of 105 Scleractinian Coral Species on the GreatBarrier-Reef. Marine Biology, 90, 379-394.

Babcock, R.C. \& Davies, P. (1991) Effects of Sedimentation on Settlement of AcroporaMillepora. Coral Reefs, 9, 205-208.

Babcock, R.C. \& Mundy, C.N. (1996) Coral recruitment: Consequences of settlement choice for early growth and survivorship in two scleractinians. Journal of Experimental Marine Biology and Ecology, 206, 179-201.

Baggett, L.S. \& Bright, T.J. (1985) Coral recruitment at the East Flower Garden reef (Northwestern Gulf of Mexico). Fifth International Coral Reef Congress, Tahiti (ed. by C. Gabrie) and M. Harmelien), p. Vol. 4. Antenne Museum - Ephe, Moorea, French Polynesia.

Baird, A.H. \& Babcock, R.C. (2000) Morphological differences among three species of newly settled pocilloporid coral recruits. Coral Reefs, 19, 179-183.

Baird, A.H. \& Hughes, T.P. (1997) Spatial variation in coral recruitment around Lizard Island, Australia. 8th International Coral Reef Symposium (ed. by H. Lessions) and I.G. Macintyre), pp. 1207-1210. Smithsonian Tropical Research Institute, Balboa, Republic of Panama.

Baird, A.H. \& Morse, A.N.C. (2004) Induction of metamorphosis in larvae of the brooding corals Acropora palifera and Stylophora pistillata. Marine and Freshwater Research, 55, $469-472$.

Bak, R.P.M. \& Engel, M.S. (1979) Distribution, Abundance and Survival of Juvenile Hermatypic Corals (Scleractinia) and the Importance of Life History Strategies in the Parent Coral Community. Marine Biology, 352, 341-352.

Baker, A.C., Glynn, P.W. \& Riegl, B. (2008) Climate change and coral reef bleaching: An ecological assessment of long-term impacts, recovery trends and future outlook. Estuarine, Coastal and Shelf Science, 80, 435-471.

Ban, S.S., Graham, N.A.J. \& Connolly, S.R. (2014) Evidence for multiple stressor interactions and effects on coral reefs. Global Change Biology, 20, 681-697.

Barber, P.H. (2009) The challenge of understanding the Coral Triangle biodiversity hotspot. Journal of Biogeography, 36, 1845-1846.

Baria, M.V.B., Guest, J.R., Edwards, A.J., Aliño, P.M., Heyward, A.J. \& Gomez, E.D. (2010) Caging enhances post-settlement survival of juveniles of the scleractinian coral Acropora tenuis. Journal of Experimental Marine Biology and Ecology, 394, 149-153.

Barnes, D.K.A. \& Rothery, P. (1996) Competition in encrusting Antarctic bryozoan assemblages: Outcomes, influences and implications. Journal of Experimental Marine Biology and Ecology, 196, 267-284.

Bauman, A.G., Guest, J.R., Dunshea, G., Low, J., Todd, P.A. \& Steinberg, P.D. (2015) Coral Settlement on a Highly Disturbed Equatorial Reef System. PloS one, 1-19. 
Bell, J.J. \& Barnes, D.K.A. (2003) The importance of competitor identity, morphology and ranking methodology to outcomes in interference competition between sponges. Marine Biology, 143, 415-426.

Bellwood, D.R., Hughes, T.P., Folke, C. \& Nyström, M. (2004) Confronting the coral reef crisis. Nature, 429, 827-833.

Benayahu, Y. \& Loya, Y. (1984) Substratum preferences and planulae settling of two red sea alcyonaceans: Xenia macrospiculata Gohar and Parerythropodium Fulvum fulvum (Forskal). Journal of Experimental Marine Biology and Ecology, 83, 249-260.

Benzoni, F., Basso, D., Caragnano, A. \& Rodondi, G. (2011) Hydrolithon spp. (Rhodophyta, Corallinales) overgrow live corals (Cnidaria, Scleractinia) in Yemen. Marine Biology, $158,2419-2428$.

Birkeland, C.E. (1977) The Importanceof rate of biomass accumulation in early successional stages of benthic communities to the survival of coral recruits. 3rd ICRS, pp. 15-21.

Birrell, C.L., McCook, L.J. \& Willis, B.L. (2005) Effects of algal turfs and sediment on coral settlement. Marine Pollution Bulletin, 51, 408-414.

Bohonak, A.J. (1999) Dispersal, Gene Flow, and Population Structure. The Quarterly review of Biology, 74, 21-45.

Bowden, D.A., Clarke, A., Peck, L.S. \& Barnes, D.K.A. (2006) Antarctic sessile marine benthos: colonisation and growth on artificial substrata over three years. Marine Ecology Progress Series, 316, 1-16.

Box, S.J. \& Mumby, P.J. (2007) Effect of macroalgal competition on growth and survival of juvenile Caribbean corals. Marine Ecology-Progress Series, 342, 139-149.

Brandl, S.J., Hoey, A.S. \& Bellwood, D.R. (2013) Micro-topography mediates interactions between corals, algae, and herbivorous fishes on coral reefs. Coral Reefs, 33, 421-430.

Brock, R.E. (1979) An experimental study on the effects of grazing by parrotfishes and role of refuges in benthic community structure. Marine Biology, 51, 381-388.

Browne, N.K., Smithers, S.G. \& Perry, C.T. (2012) Spatial and temporal variations in turbidity on two inshore turbid reefs on the Great Barrier Reef, Australia. Coral Reefs, 32, 195210.

Bruno, J.F. \& Selig, E.R. (2007) Regional decline of coral cover in the Indo-Pacific: Timing, extent, and subregional comparisons. PloS one, 2(8), e711.

Bruno, J.F., Stachowicz, J.J. \& Bertness, M.D. (2003) Inclusion of facilitation into ecological theory. Trends in Ecology and Evolution, 18, 119-125.

Bruno, J.F., Sweatman, H., Precht, W.F., Selig, E.R. \& Schutte, V.G.W. (2009) Assessing evidence of phase shifts from coral to macroalgal dominance on coral reefs. Ecology, 90, $1478-1484$. 
Buenau, K.E., Price, N.N. \& Nisbet, R.M. (2011) Local interactions drive size dependent space competition between coral and crustose coralline algae. Oikos, 120, 941-949.

Buenau, K.E., Price, N.N. \& Nisbet, R.M. (2012) Size dependence, facilitation, and microhabitats mediate space competition between coral and crustose coralline algae in a spatially explicit model. Ecological Modelling, 237-238, 23-33.

Burke, L., Reytar, K., Spalding, M. \& Perry, A. (2012) Reefs at Risk Summary For decision makers. Global, World Resources Institute, Washington D.C.

Buss, L.W. \& Jackson, J.B.C. (1979) Competitive networks: nontransitive competitive relationships in cryptic coral reef environments. The American Naturalist, 113, 223-234.

Caley, M.J., Carr, M.H., Hixon, M.A., Hughes, T.P. \& Menge, B.A. (1996) Recruitment and the local dynamics of open marine populations. Annual Review of Ecology and Systematics, 27, 477-500.

Carballo, J.L. \& Ávila, E. (2004) Population dynamics of a mutualistic interaction between the sponge Haliclona caerulea and the red alga Jania adherens. Marine Ecology Progress Series, 279, 93-104.

Carleton, J.H. \& Sammarco, P.W. (1987) Effects of substratum irregularity on success of coral settlement: quantification by comparative geomorphological techniques. Bulletin of Marine Science, 40, 85-98.

Carlon, D.B. (2002) Production and supply of larvae as determinants of zonation in a brooding tropical coral. Journal of Experimental Marine Biology and Ecology, 268, 33-46.

Carlon, D.B. \& Olson, R.R. (1993) Larval dispersal distance as an explanation for adult spatial pattern in two Caribbean reef corals *. Journal of Experimental Marine Biology and Ecology, 173, 247-263.

Cesar, H.S.J. (2000) Coral Reefs: Their Functions, Threats and Economic value. Collected Essays on the Economics of Coral Reefs, pp. 14-39.

Chiappone, M. \& Sullivan, K.M. (1996) Distribution, abundance and species composition of juvenile scleractinian corals in the Florida reef tract. Bulletin of Marine Science, 58, 555569.

Chong-Seng, K.M., Graham, N.A.J. \& Pratchett, M.S. (2014) Bottlenecks to coral recovery in the Seychelles. Coral Reefs, 33, 449-461.

Christiansen, N.A., Ward, S., Harii, S. \& Tibbetts, I.R. (2008) Grazing by a small fish affects the early stages of a post-settlement stony coral. Coral Reefs, 28, 47-51.

Christie, M.R., Johnson, D.W., Stallings, C.D. \& Hixon, M.A. (2010) Self-recruitment and sweepstakes reproduction amid extensive gene flow in a coral-reef fish. Molecular ecology, 19, 1042-57. 
Clarke, K.R., Somerfield, P.J. \& Chapman, M.G. (2006) On resemblance measures for ecological studies, including taxonomic dissimilarities and a zero-adjusted Bray-Curtis coefficient for denuded assemblages. Journal of Experimental Marine Biology and Ecology, 330, 55-80.

Connell, J.H. (1997a) Disturbance and recovery of coral assemblages. Coral Reefs, 16, S101S113.

Connell, S.D. (1997b) Exclusion of predatory fish on a coral reef: the anticipation, pre-emption and evaluation of some caging artefacts. Journal of Experimental Marine Biology and Ecology, 213, 181-198.

Connolly, S.R. \& Roughgarden, J. (1999) Theory of marine communities: Competition, predation, and recruitment-dependent interaction strength. Ecological Monographs, 69, 277-296.

Cooper, T.F. \& Ulstrup, K.E. (2009) Mesoscale variation in the photophysiology of the reef building coral Pocillopora damicornis along an environmental gradient. Estuarine, Coastal and Shelf Science, 83, 186-196.

Cooper, W.T., Lirman, D., VanGroningen, M.P., Parkinson, J.E., Herlan, J. \& McManus, J.W. (2014) Assessing techniques to enhance early post-settlement survival of corals in situ for reef restoration. Bulletin of Marine Science, 90, 651-664.

Cowen, R.K., Gawarkiewicz, G., Pineda, J., Thorrold, S.R. \& Werner, F.E. (2007) Population Connectivity in Marine Systems. Oceanography, 20, 14-21.

Cowen, R.K., Lwiza, K.M., Sponaugle, S., Paris, C.B. \& Olson, D.B. (2000) Connectivity of marine populations: open or closed? Science (New York, N.Y.), 287, 857-9.

Cowen, R.K., Paris, C.B. \& Srinivasan, A. (2006) Scaling of connectivity in marine populations. Science (New York, N.Y.), 311, 522-7.

Cowen, R.K. \& Sponaugle, S. (2009) Larval Dispersal and Marine Population Connectivity. Annual Review of Marine Science, 1, 443-466.

Coyer, J.A., Ambrose, R.F., Engle, J.M. \& Carroll, J.C. (1993) Interactions between corals and algae on a temperate rocky reef : mediation by sea urchins zone. Journal of Experimental Marine Biology and Ecology, 167, 21-37.

Crabbe, M.J.C., Karaviotis, S. \& Smith, D.J. (2004) Monitoring growth of hard corals as performance indicators for coral reefs. Journal of Biological Education, 38, 113.

Crabbe, M.J.C. \& Smith, D.J. (2005) Sediment impacts on growth rates of Acropora and Porites corals from fringing reefs of Sulawesi, Indonesia. Coral Reefs, 24, 437-441.

Cullen, L.C. (2007) Marine resource dependence, resource use patterns and identification of economic performance criteria within a small Indo-Pacific island community.

Curtis-Quick, J. (2013) Drivers of change of reef fish assemblages within the Coral Triangle.

Dart, J.K.G. (1972) Echinoids, Algal Lawn and Coral Recolonization. Nature, 239, 50-51. 
Davies, S.W., Matz, M. V \& Vize, P.D. (2013) Ecological complexity of coral recruitment processes: effects of invertebrate herbivores on coral recruitment and growth depends upon substratum properties and coral species. PloS one, 8, e72830.

De'ath, G., Fabricius, K.E., Sweatman, H. \& Puotinen, M. (2012) The 27-year decline of coral cover on the Great Barrier Reef and its causes. Proceedings of the National Academy of Sciences of the United States of America.

Diaz-Castaneda, V. \& Almeda-Jauregui, C. (1999) Early Benthic Organism Colonization on a Caribbean Coral Reef (Barbados, West Indies): a Plate Experimental Approach. Marine Ecology, 20, 197-220.

Diaz-Pulido, G., Harii, S., McCook, L.J. \& Hoegh-Guldberg, O. (2010) The impact of benthic algae on the settlement of a reef-building coral. Coral Reefs, 29, 203-208.

Doropoulos, C., Ward, S., Diaz-Pulido, G., Hoegh-Guldberg, O. \& Mumby, P.J. (2012a) Ocean acidification reduces coral recruitment by disrupting intimate larval-algal settlement interactions. Ecology letters, 338-346.

Doropoulos, C., Ward, S., Marshell, A., Diaz-Pulido, G. \& Mumby, P.J. (2012b) Interactions among chronic and acute impacts on coral recruits: the importance of size-escape thresholds. Ecology, 93, 2131-2138.

Dubinsky, Z. \& Stambler, N. (1996) Marine pollution and coral reefs. Global Change Biology, $2,511-526$.

Dulvy, N.K., Sadovy, Y. \& Reynolds, J.D. (2003) Extinction vulnerability in marine populations. Fish and Fisheries, 4, 25-64.

Dunstan, P.K. \& Johnson, C.R. (1998) Spatio-temporal variation in cores recruitment at different scales on Heron Reef, southern Great Barrier Reef. Coral Reefs, 17, 71-81.

Easson, C.G., Slattery, M., Baker, D.M. \& Gochfeld, D.J. (2014) Complex ecological associations: Competition and facilitation in a sponge-algal interaction. Marine Ecology Progress Series, 507, 153-167.

Edmunds, P.J. (2007) Evidence for a decadal-scale decline in the growth rates of juvenile scleractinian corals. Marine Ecology-Progress Series, 341, 1-13.

Edmunds, P.J. (2000a) Patterns in the distribution of juvenile corals and coral reef community structure in St. John, US Virgin Islands. Marine Ecology Progress Series, 202, 113-124.

Edmunds, P.J. (2000b) Recruitment of scleractinians onto the skeletons of corals killed by black band disease. Coral Reefs, 19, 69-74.

Edmunds, P.J., Adjeroud, M., Baskett, M.L., Baums, I.B., Budd, A.F., Carpenter, R.C., Fabina, N.S., Fan, T.-Y., Franklin, E.C., Gross, K., Han, X., Jacobson, L., Klaus, J.S., McClanahan, T.R., O’Leary, J.K., van Oppen, M.J.H., Pochon, X., Putnam, H.M., Smith, T.B., Stat, M., Sweatman, H., van Woesik, R. \& Gates, R.D. (2014a) Persistence and Change in Community Composition of Reef Corals through Present, Past, and Future Climates. PLoS ONE, 9, e107525. 
Edmunds, P.J., Leichter, J. \& Adjeroud, M. (2010) Landscape-scale variation in coral recruitment in Moorea, French Polynesia. Marine Ecology Progress Series, 414, 75-89.

Edmunds, P.J., Nozawa, Y. \& Villanueva, R.D. (2014b) Refuges modulate coral recruitment in the Caribbean and the Pacific. Journal of Experimental Marine Biology and Ecology, $454,78-84$.

Edwards, A.J. \& Gomez, E.D. (2007) Reef Restoration Concepts \& Guidelines,.

English, S.A., Wilkinson, C. \& Baker, V.J. (1997) Survey manual for tropical marine resources, Australian Institute of Marine Science, Townsville, Australia, Townsville.

Erftemeijer, P.L.A., Riegl, B., Hoeksema, B.W. \& Todd, P.A. (2012) Environmental impacts of dredging and other sediment disturbances on corals: A review. Marine pollution bulletin, 64, 1737-65.

Fairfull, S.J.L. \& Harriott, V.J. (1999) Succession, space and coral recruitment in a subtropical fouling community. Marine Freshwater Res., 50, 235-42.

Feary, D.A., Almany, G.R., McCormick, M.I. \& Jones, G.P. (2007) Habitat choice, recruitment and the response of coral reef fishes to coral degradation. Oecologia, 153, 727-37.

Feng, M., McPhaden, M.J., Xie, S.-P. \& Hafner, J. (2013) La Niña forces unprecedented Leeuwin Current warming in 2011. Scientific reports, 3, 1277.

Ferrari, R., González-Rivero, M. \& Mumby, P.J. (2012) Size matters in competition between corals and macroalgae. Marine Ecology Progress Series, 467, 77-88.

Field, M., Bothner, M., Jokiel, P.L. \& Ogston, A. (2000) Response of a Reef to Sediment Overload: Moloka 'i, Hawai'i. 9th International Coral Reef Symposium, Bali, Indonesia.

Field, S.N., Glassom, D. \& Bythell, J.C. (2007) Effects of artificial settlement plate materials and methods of deployment on the sessile epibenthic community development in a tropical environment. Coral Reefs, 26, 279-289.

Fisk, D.A. \& Harriott, V.J. (1993) Are Understorey Corals Communities Recruitment Limited? Proceedings of the Seveth International Coral Reef Symposium, Guam, pp. 1-4. University of Guam Press, Mangilao, Guam.

Fisk, D.A. \& Harriott, V.J. (1990) Spatial and Temporal Variation in Coral Recruitment on the Great-Barrier-Reef - Implications for Dispersal Hypotheses. Marine Biology, 107, 485490.

Fowler, a J. (1987) Coral Reefs of coral reef fishes . A case study. Coral Reefs, 6, 49-58.

Fox, H.E. (2004) Coral recruitment in blasted and unblasted sites in Indonesia: assessing rehabilitation potential. Marine Ecology Progress Series, 269, 131-139.

Gaines, S.D. \& Bertness, M.D. (1992) Dispersal of Juveniles and Variable Recruitment in Sessile Marine Species. Nature, 360, 579. 
Gardner, T.A., Côté, I.M., Gill, J.A., Grant, A., Watkinson, A.R. \& Cote, I.M. (2003) Longterm region-wide declines in Caribbean corals. Science (New York, N.Y.), 301, 958-60.

Gilmour, J.P. (1999) Experimental investigation into the effects of suspended sediment on fertilisation, larval survival and settlement in a scleractinian coral. Marine Biology, 0061, $451-462$.

Gilmour, J.P., Cooper, T.F., Fabricius, K.E. \& Smith, L.D. (2006) Early warning indicators of change in the condition of corals and coral communities in response to key anthropogenic stressors in the Pilbara, Western Australia. Executive summary and final recommendations, Australian Institute of Marine Science.

Glassom, D., Zakai, D. \& Chadwick-Furman, N.E. (2004) Coral recruitment: a spatio-temporal analysis along the coastline of Eilat, northern Red Sea. Marine Biology, 144, 641-651.

Gleason, M.G. (1996) Coral recruitment in Moorea, French Polynesia: The importance of patch type and temporal variation. Journal of Experimental Marine Biology and Ecology, 207, 79-101.

Goatley, C.H.R. \& Bellwood, D.R. (2012) Sediment suppresses herbivory across a coral reef depth gradient. Biology letters, 8, 1016-8.

Golbuu, Y. \& Richmond, R.H. (2007) Substratum preferences in planula larvae of two species of scleractinian corals, Goniastrea retiformis and Stylaraea punctata. Marine Biology, 152, 639-644.

Golbuu, Y., Wolanski, E., Idechong, J.W., Victor, S., Isechal, A.L., Oldiais, N.W., Idip, D., Richmond, R.H. \& van Woesik, R. (2012) Predicting Coral Recruitment in Palau's Complex Reef Archipelago. PLoS ONE, 7, 1-10.

Goldenheim, W.M. \& Edmunds, P.J. (2011) Effects of flow and temperature on growth and photophysiology of scleractinian corals in Moorea, French Polynesia. The Biological bulletin, 221, 270-9.

González-Rivero, M., Yakob, L. \& Mumby, P.J. (2011) The role of sponge competition on coral reef alternative steady states. Ecological Modelling, 222, 1847-1853.

Graham, E.M., Baird, A.H. \& Connolly, S.R. (2008) Survival dynamics of scleractinian coral larvae and implications for dispersal. Coral Reefs, 27, 529-539.

Graham, N.A.J. \& Nash, K.L. (2013) The importance of structural complexity in coral reef ecosystems. Coral Reefs, 32, 315-326.

Granja Fernandez, M.R. \& Lopez, J. V (2008) Sedimentation on reef communities at Bahìas de Huatulca, Oaxaca, Mexico. Revista De Biologia Tropical, 56, 1179-1187.

Green, D.H. \& Edmunds, P.J. (2011) Spatio-temporal variability of coral recruitment on shallow reefs in St. John, US Virgin Islands. Journal of Experimental Marine Biology and Ecology, 397, 220-229.

Grigg, R.W. (1981) Acropora in Hawaii. Part 2. Zoogeography. Pacific Science, 35, 15-24. 
Haas, A., El-Zibdah, M. \& Wild, C. (2010) Seasonal monitoring of coral-algae interactions in fringing reefs of the Gulf of Aqaba, Northern Red Sea. Coral Reefs, 29, 93-103.

Hall, S.J., Raffaelli, D. \& Turrell, W.R. (1990) Predator-Caging Experiments in Marine Systems: A Reexamination of Their Value. The American Naturalist, 136, 657.

Halpern, B.S., Walbridge, S., Selkoe, K.A., Kappel, C. V, Micheli, F., D’Agrosa, C., Bruno, J.F., Casey, K.S., Ebert, C., Fox, H.E., Fujita, R., Heinemann, D., Lenihan, H.S., Madin, E.M.P., Perry, M.T., Selig, E.R., Spalding, M., Steneck, R.S. \& Watson, R. (2008) A global map of human impact on marine ecosystems. Science (New York, N.Y.), 319, 94852 .

Harrington, L., Fabricius, K.E., De'Ath, G. \& Negri, A.P. (2004) Recognition and selection of settlement substrata determine post-settlement survival in corals. Ecology, 85, 34283437.

Harriott, V.J. (1992) Recruitment patterns of scleractinian corals in an isolated sub-tropical reef system. Coral Reefs, 11, 215-219.

Harriott, V.J. \& Banks, S.A. (1995) Recruitment of Scleractinian Corals in the Solitary-IslandsMarine-Reserve, a High-Latitude Coral-Dominated Community in Eastern Australia. Marine Ecology-Progress Series, 123, 155-161.

Harriott, V.J. \& Fisk, D.A. (1987) A Comparison of Settlement Plate Types for Experiments on the Recruitment of Scleractinian Corals. Marine Ecology-Progress Series, 37, 201208.

Harriott, V.J. \& Fisk, D.A. (1988) Recruitment Patterns of Scleractinian Corals: a Study of Three Reefs. Australian Journal of Marine and Freshwater Research, 39, 409-416.

Harrison, P.L., Babcock, R.C., Bull, G.D., Oliver, J.K., Wallace, C.C. \& Willis, B.L. (1984) Mass spawning in tropical reef corals. Science, 223, 1186.

Heck, K.L. \& McCoy, E.D. (1978) Long-distance dispersal and the reef-building corals of the Eastern Pacific. Marine Biology, 48, 349-356.

Hedgecock, D., Barber, P.H. \& Edmands, S. (2003) Genetic Approaches to Measuring Connectivity. Oceanography, 20, 70-79.

Hellberg, M.E. (1996) Dependence of Gene Flow on Geographic Distance in Two Solitary Corals with Different Larval Dispersal Capabilities. Evolution, 50, 1167-1175.

Hellberg, M.E. (2007) Footprints on water: the genetic wake of dispersal among reefs. Coral Reefs, 26, 463-473.

Hennige, S.J., Smith, D.J., Perkins, R., Consalvey, M., Paterson, D.M. \& Suggett, D.J. (2008) Photoacclimation, growth and distribution of massive coral species in clear and turbid waters. Marine Ecology-Progress Series, 369, 77-88.

Heyward, A.J. \& Negri, A.P. (1999) Natural inducers for coral larval metamorphosis. Coral Reefs, 18, 273-279. 
Hill, R., Schreiber, U., Gademann, R., Larkum, A.W.D., Kühl, M. \& Ralph, P.J. (2004) Spatial heterogeneity of photosynthesis and the effect of temperature-induced bleaching conditions in three species of corals. Marine Biology, 144, 633-640.

Hixon, M. a (2011) 60 Years of Coral Reef Fish Ecology: Past, Present, Future. Bulletin of Marine Science, 87, 727-765.

Hixon, M.A., Pacala, S.W. \& Sandin, S.A. (2002) Population Regulation: Historical Context and Contemporary Challenges of Open vs. Closed Systems. Ecology, 83, 1490-1508.

Ho, M. \& Dai, C. (2014) Coral recruitment of a subtropical coral community at Yenliao Bay, northern Taiwan. Zoological Studies, 53, 1-10.

Hodgson, G. (1990) Sediment and the Settlement of Larvae of the Reef Coral PocilloporaDamicornis. Coral Reefs, 9, 41-43.

Hoegh-Guldberg, O., Hoegh-Guldberg, H., Veron, J.E., Green, A., Gomez, E.D., Lough, J., King, M., Ambariyanto, Hansen, L., Cinner, J., Dews, G., Russ, G., Schuttenberg, H.Z., Penaflor, E.L., Eakin, C.M., Christensen, T.R.L., Abbey, M., Areki, M., Kosaka, R. a, Tewlik, A. \& Oliver, J. (2009) The coral triangle and climate change: Ecosystems, people and societies at risk,

Hoegh-Guldberg, O., Mumby, P.J., Hooten, A.J., Steneck, R.S., Greenfield, P., Gomez, E.D., Harvell, C.D., Sale, P.F., Edwards, A.J., Caldeira, K., Knowlton, N., Eakin, C.M., Iglesias-Prieto, R., Muthiga, N., Bradbury, R.H., Dubi, A. \& Hatziolos, M.E. (2007) Coral reefs under rapid climate change and ocean acidification. Science, 318, 1737-1742.

Hoey, A.S. \& Bellwood, D.R. (2008) Cross-shelf variation in the role of parrotfishes on the Great Barrier Reef. Coral Reefs, 27, 37-47.

Hohenlohe, P.A. (2004) Limits to gene flow in marine animals with planktonic larvae: models of Littorina species around Point Conception, California. Biological Journal of the Linnean Society, 82, 169-187.

Howells, E.J., Beltran, V.H., Larsen, N.W., Bay, L.K., Willis, B.L. \& van Oppen, M.J.H. (2011) Coral thermal tolerance shaped by local adaptation of photosymbionts. Nature Climate Change, 2, 116-120.

Hughes, T.P. (1994) Catastrophes, Phase Shift, and Large-Scale Degradation of a Caribbean Coral Reef. Science, 265, 1547-1551.

Hughes, T.P. (1989) Community Structure and Diversity of Coral Reefs : The Role of History. Ecology, 70, 275-279.

Hughes, T.P. (1984) Population Dynamics Based on Individual Size Rather than Age. A General Model with a Reef Coral Example. The American Naturalist, 123, 778-795.

Hughes, T.P., Baird, A.H., Bellwood, D.R., Card, M., Connolly, S.R., Folke, C., Grosberg, R.K., Hoegh-Guldberg, O., Jackson, J.B.C., Kleypas, J.A., Lough, J.M., Marshall, P.A., Nyström, M., Palumbi, S.R., Pandolfi, J.M., Rosen, B. \& Roughgarden, J. (2003) Climate change, human impacts, and the resilience of coral reefs. Science, 301, 929-33. 
Hughes, T.P., Baird, A.H., Dinsdale, E.A., Harriott, V.J., Moltschaniwskyj, N.A., Pratchett, M.S., Tanner, J.E. \& Willis, B.L. (2002) Detecting Regional Variation Using MetaAnalysis and Large-Scale Sampling: Latitudinal Patterns in Recruitment. Ecology, 83, 436-451.

Hughes, T.P., Baird, A.H., Dinsdale, E.A., Moltschaniwskyj, N.A., Pratchett, M.S., Tanner, J.E. \& Willis, B.L. (1999a) Patterns of recruitment and abundance of corals along the Great Barrier Reef. Nature, 397, 59-63.

Hughes, T.P., Baird, A.H., Dinsdale, E.A., Moltschaniwskyj, N.A., Pratchett, M.S., Tanner, J.E. \& Willis, B.L. (1999b) Patterns of recruitment and abundance of corals along the Great Barrier Reef. Nature, 397, 10-14.

Hughes, T.P., Baird, A.H., Dinsdale, E.A., Moltschaniwskyj, N.A., Pratchett, M.S., Tanner, J.E., Willis, B.L. \& Aug, N. (2000) Supply-side ecology works both ways: The link between benthic adults, fecundity, and larval recruits. Ecology, 81, 2241-2249.

Hughes, T.P. \& Connell, J.H. (1999) Multiple Stressors on Coral Reefs : A Long-Term Perspective. Limnology and Oceanography, 44, 932-940.

Hughes, T.P., Graham, N.A.J., Jackson, J.B.C., Mumby, P.J. \& Steneck, R.S. (2010) Rising to the challenge of sustaining coral reef resilience. Trends in Ecology and Evolution, 25, 633-642.

Hughes, T.P. \& Jackson, J.B.C. (1985) Population Dynamics and Life Histories of Foliaceous Corals. Ecological Monographs, 55, 141-166.

Hughes, T.P., Rodrigues, M.J., Bellwood, D.R., Ceccarelli, D., Hoegh-Guldberg, O., McCook, L.J., Moltschaniwskyj, N.A., Pratchett, M.S., Steneck, R.S. \& Willis, B.L. (2007) Phase shifts, herbivory, and the resilience of coral reefs to climate change. Current Biology, 17, 360-365.

Idjadi, J.A. \& Edmunds, P.J. (2006) Scleractinian corals as facilitators for other invertebrates on a Caribbean reef. Marine Ecology Progress Series, 319, 117-127.

IPCC (2007) IPCC, 2007: Climate Change 2007: Synthesis Report., Geneva, Switzerland.

Irizarry-Soto, E. \& Weil, E. (2009) Spatial and temporal variability in juvenile coral densities, survivorship and recruitment in La Parguera, southwestern Puerto Rico. Caribbean Journal of Science, 45, 269-281.

Jackson, J.B.C. (1992) Pleistocene perspective on coral-reef community structure. American Zoologist, 731, 719-731.

Jackson, J.B.C. (1997) Reefs since Columbus. Coral Reefs, 16, 23-32.

Jackson, J.B.C. \& Buss, L. (1975) Alleopathy and spatial competition among coral reef invertebrates. Proceedings of the National Academy of Sciences of the United States of America, 72, 5160-3. 
Jenkins, S.R., Norton, T.A. \& Hawkins, S.J. (1999) Settlement and post-settlement interactions between Semibalanus balanoides (L.) (Crustacea: Cirripedia) and three species of fucoid canopy algae. Journal of Experimental Marine Biology and Ecology, 236, 49-67.

Johns, K. a., Osborne, K.O. \& Logan, M. (2014) Contrasting rates of coral recovery and reassembly in coral communities on the Great Barrier Reef. Coral Reefs, 33, 553-563.

Johnson, K.G. (1992) Population dynamics of a free-living coral: recruitment, growth and survivorship of Manicina areolata (Linnaeus) on the Caribbean coast of Panama. Journal of Experimental Marine Biology and Ecology, 164, 171-191.

Jones, G.P. (1997) Relationships between recruitment and postrecruitment processes in lagoonal populations of two coral reef fishes. Journal of Experimental Marine Biology and Ecology, 213, 231-246.

Jones, G.P., Almany, G.R., Russ, G.R., Sale, P.F., Steneck, R.S., van Oppen, M.J.H. \& Willis, B.L. (2009) Larval retention and connectivity among populations of corals and reef fishes: history, advances and challenges. Coral Reefs, 28, 307-325.

Jones, G.P., Milicich, M.J., Emslie, M.J. \& Lunow, C. (1999) Self-recruitment in a coral reef fish population. Nature, 402, 802-804.

Jones, G.P., Planes, S. \& Thorrold, S.R. (2005) Coral reef fish larvae settle close to home. Current Biology, 15, 1314-1318.

Karlson, R.H. \& Hurd, L.E. (1993) Disturbance, coral reef communities, and changing ecological paradigms. Coral Reefs, 12, 117-125.

Keats, D.W., Knight, M.A. \& Pueschel, C.M. (1997) Antifouling effects of epithallial shedding in three crustose coralline algae (Rhodophyta, Coralinales) on a coral reef. Journal of Experimental Marine Biology and Ecology, 213, 281-293.

Kinlan, B.P. \& Gaines, S.D. (2007) Propagule dispersal in marine and terrestrial environments: a community perspective. Ecology, 84, 2007-2020.

Koehl, M., Strother, J., Reidenbach, M., Koseff, J. \& Hadfield, M. (2007) Individual-based model of larval transport to coral reefs in turbulent, wave-driven flow: behavioral responses to dissolved settlement inducer. Marine Ecology Progress Series, 335, 1-18.

Kohler, K.E. \& Gill, S.M. (2006) Coral Point Count with Excel extensions (CPCe): A Visual Basic program for the determination of coral and substrate coverage using random point count methodology. Computers and Geosciences, 32, 1259-1269.

Kuo, K. \& Soong, K. (2010) Post-Settlement Survival of Reef-Coral Juveniles in Southern Taiwan. Zoological Studies, 49, 724-734.

Largier, J.L. (2003) Consideration in estimating larval dispersal distances. Ecological Applications, 13, 71-89.

Ledlie, M.H., Graham, N.A.J., Bythell, J.C., Wilson, S.K., Jennings, S., Polunin, N.V.C. \& Hardcastle, J. (2007) Phase shifts and the role of herbivory in the resilience of coral reefs. Coral Reefs, 26, 641-653. 
Leis, J.M. (2000) Vertical distribution of fish larvae in the Great Barrier Reef Lagoon , Australia. 166, 157-166.

Lenihan, H.S., Holbrook, S.J., Schmitt, R.J. \& Brooks, A.J. (2011) Influence of corallivory, competition, and habitat structure on coral community shifts. Ecology, 92, 1959-71.

Lewis, J. (1996) Turbidity-controlled suspended sediment sampling for runoff-event load estimation. Water Resouces Research, 32, 2299-2310.

Lewis, S.M. (1986) The Role of Herbivorous Fishes in the Organization of a Caribbean Reef Community. Ecological Monographs, 56, 183-200.

Linares, C., Cebrian, E. \& Coma, R. (2012) Effects of turf algae on recruitment and juvenile survival of gorgonian corals. Marine Ecology Progress Series, 452, 81-88.

Lirman, D. (2001) Competition between macroalgae and corals: effects of herbivore exclusion and increased algal biomass on coral survivorship and growth. Coral Reefs, 19, 392-399.

López-Pérez, R.A., Mora-Pérez, M.G. \& Leyte-Morales, G.E. (2007) Coral (Anthozoa: Scleractinia) Recruitment at Bahías de Huatulco, Western México: Implications for Coral Community Structure and Dynamics 1. Pacific Science, 61, 355-369.

Lowe, W.H. \& Allendorf, F.W. (2010) What can genetics tell us about population connectivity? Molecular ecology, 19, 3038-51.

Maida, M., Coll, J.C. \& Sammarco, P.W. (1994) Shedding New Light on Scleractinian Coral Recruitment. Journal of Experimental Marine Biology and Ecology, 180, 189-202.

Mangubhai, S., Harrison, P.L. \& Obura, D.O. (2007) Patterns of coral larval settlement on lagoon reefs in the Mombasa Marine National Park and Reserve, Kenya. Marine EcologyProgress Series, 348, 149-159.

Manzello, D.P. (2010) Coral growth with thermal stress and ocean acidification: lessons from the eastern tropical Pacific. Coral Reefs, 29, 749-758.

Marshall, P.A. \& Baird, A.H. (2000) Bleaching of corals on the Great Barrier Reef: differential susceptibilities among taxa. Coral Reefs, 19, 155-163.

Martinez, S. \& Abelson, A. (2013) Coral recruitment : the critical role of early post-settlement survival. ICES Journal of Marine Science, 70, 1294-1298.

Mc Ardle, B.H. \& Anderson, M.J. (2001) Fitting multivariate models to community data: a comment on distance-based redundancy analysis. Ecology, 82, 290-297.

McClanahan, T.R. \& Shafir, S.H. (1990) Causes and Consequences of Sea-Urchin Abundance and Diversity in Kenyan Coral-Reef Lagoons. Oecologia, 83, 362-370.

McCook, L.J., Jompa, J. \& Diaz-Pulido, G. (2001) Competition between corals and algae on coral reefs: a review of evidence and mechanisms. Coral Reefs, 19, 400-417. 
McLeod, E., Moffitt, R., Timmermann, A., Salm, R., Menviel, L., Palmer, M.J., Selig, E.R., Casey, K.S. \& Bruno, J.F. (2010) Warming Seas in the Coral Triangle: Coral Reef Vulnerability and Management Implications. Coastal Management, 38, 518-539.

McMellor, S. (2007) A Conservation Value Index to facilitate coral reef evaluation and assessment.

McMellor, S. \& Smith, D.J. (2010) Coral reefs of the Wakatobi: abundance and biodiversity. Marine research and conservation in the Coral Triangle: the Wakatobi National Park (ed. by J. Clifton), R.K.F. Unsworth), and D.J. Smith), pp. 11-26. Nova Science Publishers, New York.

Miller, K.J. \& Mundy, C.N. (2003) Rapid settlement in broadcast spawning corals: implications for larval dispersal. Coral Reefs, 22, 99-106.

Miller, M.W. \& Hay, M.E. (1998) Effects of fish predation and seaweed competition on the survival and growth of corals. Oecologia, 113, 231-238.

Miller, M.W. \& Weil, E. (2000) Coral recruitment and juvenile mortality as structuring factors for reef benthic communities in Biscayne National Park, USA. Coral Reefs, 19, 115-123.

Montgomery, J.C., Jeffs, A.G., Simpson, S.D., Meekan, M. \& Tindle, C. (2006) Sound as an orientation cue for the pelagic larvae of reef fishes and decapod crustaceans. Advances in marine biology, 51, 143-96.

Mora, C. \& Sale, P.F. (2002) Are populations of coral reef fish open or closed? Trends in Ecology \& Evolution, 17, 422-428.

Morse, D.E., Morse, A.N.C., Raimondi, P.T. \& Hooker, N. (1994) Morphogen-based chemical flypaper for Agaricia humilis coral larvae. Biological Bulletin, 186, 172-181.

Mumby, P.J. (2009) Herbivory versus corallivory: are parrotfish good or bad for Caribbean coral reefs? Coral Reefs, 28, 683-690.

Munday, P.L. (2004) Habitat loss, resource specialization, and extinction on coral reefs. Global Change Biology, 10, 1642-1647.

Mundy, C.N. (2000) An appraisal of methods used in coral recruitment studies. Coral Reefs, $19,124-131$.

Mundy, C.N. \& Babcock, R.C. (1998a) Are vertical distribution patterns of scleractinian corals maintained by pre- or post-settlement processes? A case study of three contrasting species. Marine Ecology Progress Series, 198, 109-119.

Mundy, C.N. \& Babcock, R.C. (1998b) Role of light intensity and spectral quality in coral settlement: Implications for depth-dependent settlement? Journal of Experimental Marine Biology and Ecology, 223, 235-255.

Nakamura, M. \& Sakai, K. (2009) Spatiotemporal variability in recruitment around Iriomote Island, Ryukyu Archipelago, Japan: implications for dispersal of spawning corals. Marine Biology, 157, 801-810. 
Nathan, R., Perry, G., Cronin, J.T., Strand, A.E. \& Cain, M.L. (2003) Methods for estimating long-distance dispersal. OIKOS, 2, 261-273.

Nishikawa, A., Katoh, M. \& Sakai, K. (2003) Larval settlement rates and gene flow of broadcast- ( Stylophora pistillata ) corals. Marine Ecology Progress Series, 256, 87-97.

Norström, A. V, Nyström, M., Lokrantz, J. \& Folke, C. (2009) Alternative states on coral reefs: beyond coral-macroalgal phase shifts. Marine Ecology Progress Series, 376, 295-306.

Nozawa, Y. (2008) Micro-crevice structure enhances coral spat survivorship. Journal of Experimental Marine Biology and Ecology, 367, 127-130.

Nozawa, Y., Lin, C.-H. \& Chung, A.-C. (2013) Bathymetric variation in recruitment and relative importance of pre- and post-settlement processes in coral assemblages at Lyudao (Green Island), Taiwan. PloS one, 8, e81474.

Nyström, M., Folke, C. \& Moberg, F. (2000) Coral reef disturbance and resilience in a humandominated environment. Trends in ecology \& evolution, 15, 413-417.

Nzali, L.M., Johnstone, R.W. \& Mgaya, Y. (1998) Factors affecting scleractinian coral recruitment on a nearshore reef in Tanzania. Ambio, 27, 717-722.

O'Leary, J.K. \& Potts, D.C. (2011) Using hierarchical sampling to understand scales of spatial variation in early coral recruitment. Coral Reefs, 30, 1013-1023.

O’Leary, J.K., Potts, D.C., Braga, J.C. \& McClanahan, T.R. (2012) Indirect consequences of fishing: Reduction of coralline algae suppresses juvenile coral abundance. Coral Reefs, 31, 547-559.

Palumbi, S.R. (2003) Population genetics, demographic connectivity, and the design of marine reserves. Ecological Applications, 13, 146-158.

Pandolfi, J.M., Bradbury, R.H., Sala, E., Hughes, T.P., Bjorndal, K.A., Cooke, R.G., McArdle, D., McClenachan, L., Newman, M.J.H., Paredes, G.A., Warner, R.R. \& Jackson, J.B.C. (2003) Global trajectories of the long-term decline of coral reef ecosystems. Science (New York, N.Y.), 301, 955-8.

Pearce, A., Lenanton, R., Jackson, G., Moore, J., Feng, M. \& Gaughan, D. (2011) The "marine heat wave" off Western Australia during the summer of 2010/11,.

Penin, L. \& Adjeroud, M. (2013) Relative importance of recruitment and post-settlement processes in the maintenance of coral assemblages in an insular, fragmented reef system. Marine Ecology Progress Series, 473, 149-162.

Penin, L., Adjeroud, M., Pratchett, M.S. \& Hughes, T.P. (2007) Spatial distribution of juvenile and adult corals around Moorea (French Polynesia): Implications for population regulation. Bulletin of Marine Science, 80, 379-389.

Penin, L., Michonneau, F., Baird, A.H., Connolly, S.R., Pratchett, M.S., Kayal, M. \& Adjeroud, M. (2010) Early post-settlement mortality and the structure of coral assemblages. Marine Ecology Progress Series, 408, 55-64. 
Penin, L., Michonneau, F., Carroll, A. \& Adjeroud, M. (2011) Effects of predators and grazers exclusion on early post-settlement coral mortality. Hydrobiologia, 663, 259-264.

Perkol-Finkel, S. \& Benayahu, Y. (2007) Differential recruitment of benthic communities on neighboring artificial and natural reefs. Journal of Experimental Marine Biology and Ecology, 340, 25-39.

Philipp, E. \& Fabricius, K. (2003) Photophysiological stress in scleractinian corals in response to short-term sedimentation. Journal of Experimental Marine Biology and Ecology, 287, $57-78$.

Pineda, J., Hare, J. \& Sponaugle, S. (2007) Larval Transport and Dispersal in the Coastal Ocean and Consequences for Population Connectivity. Oceanography, 20, 22-39.

Pineda, J., Reyns, N.B. \& Starczak, V.R. (2008) Complexity and simplification in understanding recruitment in benthic populations. Population Ecology, 51, 17-32.

Polato, N.R., Concepcion, G.T., Toonen, R.J. \& Baums, I.B. (2010) Isolation by distance across the Hawaiian Archipelago in the reef-building coral Porites lobata. Molecular ecology, $19,4661-77$.

Potts, D.C., Done, T.J., Isdale, P.J. \& Fisk, D.A. (1985) Dominance of a coral community by the genus Porites ( Scleractinia ). Marine Ecology Progress Series, 23, 79-84.

Powell, A.L. (2013) The impact of predation and habitat degradetion on coral reef sponge assemblages in SE Sulawesi, Indonesia.

Powell, A.L., Smith, D.J., Hepburn, L.J., Jones, T., Berman, J., Jompa, J. \& Bell, J.J. (2014) Reduced diversity and high sponge abundance on a sedimented Indo-Pacific reef system: implications for future changes in environmental quality. PloS one, 9, e85253.

Pratchett, M.S., Hoey, A.S. \& Wilson, S.K. (2014) Reef degradation and the loss of critical ecosystem goods and services provided by coral reef fishes. Current Opinion in Environmental Sustainability, 7, 37-43.

Price, N. (2010) Habitat selection, facilitation, and biotic settlement cues affect distribution and performance of coral recruits in French Polynesia. Oecologia, 163, 747-58.

Quinn, N.J. \& Kojis, B.L. (2003) The dynamics of coral reef community structure and recruitment patterns around Rota, Saipan, and Tinian, western Pacific. Bulletin of Marine Science, 72, 979-996.

Quinn, N.J. \& Kojis, B.L. (2008) Variation in coral recruitment on Fijian reefs. 11th International Coral Reef Symposium, Florida, pp. 459-463.

Raimondi, P.T. \& Morse, A.N. (2000) The consequences of complex larval behaviour in a coral. Ecology, 81, 3193-3211.

Ralph, P.J., Schreiber, U., Gademann, R., Kühl, M. \& Larkum, A.W.D. (2005) Coral Photobiology Studied With a New Imaging Pulse Amplitude Modulated Fluorometer1. Journal of Phycology, 41, 335-342. 
Reyes, M.Z. \& Yap, H.T. (2001) Effect of artificial substratum material and resident adults on coral settlement patterns at Danjugan Island, Philippines. Bulletin of Marine Science, 69, $559-566$.

Richmond, R.H. (1993) Coral-Reefs - Present Problems and Future Concerns Resulting from Anthropogenic Disturbance. American Zoologist, 33, 524-536.

Risk, M.J. (2014) Assessing the effects of sediments and nutrients on coral reefs. Current opinion in Environmental Sustainability, 7, 108:117.

Ritson-Williams, R., Arnold, S.N., Fogarty, N.D., Steneck, R.S., Vermeij, M.J.A. \& Paul, V.J. (2009a) New Perspectives on Ecological Mechanisms Affecting Coral Recruitment on Reefs. Smithsonian Contributions to the Marine Sciences, 38, 437-457.

Ritson-Williams, R., Paul, V.J., Arnold, S.N. \& Steneck, R.S. (2009b) Larval settlement preferences and post-settlement survival of the threatened Caribbean corals Acropora palmata and A. cervicornis. Coral Reefs, 29, 71-81.

River, G.F. \& Edmunds, P.J. (2001) Mechanisms of interaction between macroalgae and scleractinians on a coral reef in Jamaica. Journal of Experimental Marine Biology and Ecology, 261, 159-172.

Roberts, C.M. (1997) Connectivity and management of Caribbean coral reefs. Science, 278, 1454-1457.

Rogers, C.S. (1990) Responses of coral reefs and reef organisms to sedimentation. Marine Ecology Progress Series, 62, 185-202.

Rogers, C.S., Fitz, H.C.I., Gilnack, M., Beets, J. \& Hardin, J. (1984) Scleractinian Coral Recruitment Patterns at Salt River Submarine Canyon, St. Croix, U.S. Virgin Islands. Coral Reefs, 3, 69-76.

Roth, M.S. \& Knowlton, N. (2009) Distribution, abundance, and microhabitat characterization of small juvenile corals at Palmyra Atoll. Marine Ecology Progress Series, 376, 133-142.

Roughgarden, J., Gaines, S.D. \& Possingham, H.P. (1988) Recruitment dynamics in complex life cycles. Science, 241.

Rylaarsdam, K.W. (1983) Life histories and abundance patterns of colonial corals on Jamaican reefs. Marine Ecology Progress Series, 13, 249-260.

Saenz-Agudelo, P., Jones, G.P., Thorrold, S.R. \& Planes, S. (2011) Connectivity dominates larval replenishment in a coastal reef fish metapopulation. Proceedings. Biological sciences / The Royal Society, 278, 2954-61.

Saenz-Agudelo, P., Jones, G.P., Thorrold, S.R. \& Planes, S. (2012) Patterns and persistence of larval retention and connectivity in a marine fish metapopulation. Molecular ecology, 21, 4695-705.

Salinas De León, P., Costales-Carrera, A., Zeljkovic, S., Smith, D.J. \& Bell, J.J. (2011) Scleractinian settlement patterns to natural cleared reef substrata and artificial settlement panels on an Indonesian coral reef. Estuarine, Coastal and Shelf Science, 93, 80-85. 
Salinas De León, P., Dryden, C., Smith, D.J. \& Bell, J.J. (2012a) Temporal and spatial variability in coral recruitment on two Indonesian coral reefs: consistently lower recruitment to a degraded reef. Marine Biology, 160, 97-105.

Salinas De León, P., Jones, T. \& Bell, J.J. (2012b) Successful determination of larval dispersal distances and subsequent settlement for long-lived pelagic larvae. PloS one, 7, e32788.

Sammarco, P.W. (1981) Damselfish territoriality and coral community structure: reduced grazing, coral recruitment, and effects on coral spat. Fourth International Coral Reef Symposium, Manila, p. Vol.2 525.

Sammarco, P.W. (1980) Diadema and its relationship to coral spat mortality: grazing, competition, and biological disturbance. Journal of Experimental Marine Biology and Ecology, 45, 245-272.

Sammarco, P.W. (1985) The great barrier reef vs the caribbean: comparisons of grazers coral recruitment and reef recovery. Fifth International Coral Reef Congress, Tahiti, pp. 391397, Vol. 4.

Sammarco, P.W. \& Andrews, J.C. (1988) Localized Dispersal and Recruitment in Great Barrier-Reef Corals - the Helix Experiment. Science, 239, 1422-1424.

Sammarco, P.W. \& Andrews, J.C. (1989) The Helix experiment: Differential localized dispersal and recruitment patterns in Great Barrier Reef corals. Limnology and Oceanography, 34, 896-912.

Sandin, S.A. \& McNamara, D.E. (2012) Spatial dynamics of benthic competition on coral reefs. Oecologia, 168, 1079-90.

Schmidt-Roach, S., Kunzmann, A., Martinez Arbizu, P. \& Arbizu, P.M. (2008) In situ observation of coral recruitment using fluorescence census techniques. Journal of Experimental Marine Biology and Ecology, 367, 37-40.

Shanks, A.L., Grantham, B.A. \& Cass, M.H. (2003) Propagule dispersal distance and the size and spacing of marine reserves. Ecological Applications, 13, 159-169.

Smith, D.J. (2012) Dramatic increases in the frequency and intensity of blast fishing in the Northern Wakatobi Marine National Park. Special Occasional Report to the Wakatobi Government,.

Soong, K., Chen, M., Chen, C., Dai, C.-F., Fan, T., Li, J. \& Fan, H. (2003) Spatial and temporal variation of coral recruitment in Taiwan. Coral Reefs, 22, 224-228.

Sponaugle, S., Cowen, R.K., Shanks, A., Morgan, S.G., Leis, J.M., Pineda, J., Boehlert, G.W., Kingsford, M.J., Lindeman, K.C., Grimes, C. \& Munro, J.L. (2002) Predicting selfrecruitment in marine populations: biophysical correlates and mechanisms. Bulletin of Marine Science, 70, 341-375.

Stanley, J.A., Radford, C.A. \& Jeffs, A.G. (2012) Location, location, location: finding a suitable home among the noise. Proceedings. Biological sciences / The Royal Society, $279,3622-31$. 
Steneck, R.S., Paris, C.B., Arnold, S.N., Ablan-Lagman, M.C., Alcala, A.C., Butler, M.J., McCook, L.J., Russ, G.R. \& Sale, P.F. (2009) Thinking and managing outside the box: coalescing connectivity networks to build region-wide resilience in coral reef ecosystems. Coral Reefs, 28, 367-378.

Strathmann, R.R., Hughes, T.P., Kuris, A.M., Lindeman, K.C., Morgan, S.G., Pandolfi, J.M. \& Warner, R.R. (2002) Evolution of local recruitment and its consequences for marine populations. Bulletin of Marine Science, 70, 377-396.

Suchanek, T.H., Carpenter, R.C., Witman, J.D. \& Harvell, C.D. (1983) Sponges as important space competitors in deep Caribbean coral reef communities. The ecology of deep and shallow coral reefs. NOAA Symp Ser Undersea Res, 1, 55-60.

Sutherland, J.P. (1974) The University of Chicago Multiple Stable Points in Natural Communities. The American Naturalist, 108, 859-873.

Swearer, S.E., Caselle, J.E., Lea, D.W. \& Warner, R.R. (1999) Larval retention and recruitment in an island population of a coral-reef fish. Nature, 402, 799-802.

Symonds, M.R.E. \& Moussalli, A. (2011) A brief guide to model selection, multimodel inference and model averaging in behavioural ecology using Akaike's information criterion. Behavioral Ecology and Sociobiology, 65, 13-21.

Tan, C.H. \& Heron, S.F. (2011) First observed severe mass bleaching in Malaysia, Greater Coral Triangle. Galaxea, Journal of Coral Reef Studies, 13, 27-28.

Tanner, J.E., Hughes, T.P. \& Connell, J.H. (2009) Community-level density dependence: an example from a shallow coral assemblage. Ecology, 90, 506-516.

Tanner, J.E., Hughes, T.P. \& Connell, J.H. (1996) The Role of History in Community Dynamics : A Modelling Approach. Ecology, 77, 108-117.

Tioho, H., Tokeshi, M. \& Nojima, S. (2001) Experimental analysis of recruitment in a scleractinian coral at high latitude. Marine Ecology-Progress Series, 213, 79-86.

Tomascik, T., van Woesik, R. \& Mah, A.J. (1996) Rapid coral colonization of a recent lava flow following a volcanic eruption, Banda Islands, Indonesia. Coral Reefs, 1614, 169175.

Trapon, M.L., Pratchett, M.S., Adjeroud, M., Hoey, A.S. \& Baird, A.H. (2013a) Postsettlement growth and mortality rates of juvenile scleractinian corals in Moorea, French Polynesia versus Trunk Reef, Australia. Marine Ecology Progress Series, 488, 157-170.

Trapon, M.L., Pratchett, M.S. \& Hoey, A.S. (2013b) Spatial variation in abundance, size and orientation of juvenile corals related to the biomass of parrotfishes on the Great Barrier Reef, Australia. PloS one, 8, e57788.

Trapon, M.L., Pratchett, M.S., Hoey, A.S. \& Baird, A.H. (2013c) Influence of fish grazing and sedimentation on the early post-settlement survival of the tabular coral Acropora cytherea. Coral Reefs, 32, 1051-1059. 
Turner, S.J. \& Todd, C.D. (1994) Competition for Space in encrusting bryozoan assemblages: the influence of encounter angle, site and year. Journal of the Marine Biological Association of the United Kingdom, 74, 603-622.

Underwood, J.N., Smith, L.D., van Oppen, M.J.H. \& Gilmour, J.P. (2009) Ecologically relevant dispersal of corals on isolated reefs: implications for managing resilience. Ecological Applications, 19, 18-29.

Underwood, J.N., Smith, L.D., van Oppen, M.J.H. \& Gilmour, J.P. (2007) Multiple scales of genetic connectivity in a brooding coral on isolated reefs following catastrophic bleaching. Molecular ecology, 16, 771-84.

Venera-Ponton, D.E., Diaz-Pulido, G., McCook, L.J. \& Rangel-Campo, A. (2011) Macroalgae reduce growth of juvenile corals but protect them from parrotfish damage. Marine Ecology Progress Series, 421, 109-115.

Vermeij, M.J.A. (2006) Early life-history dynamics of Caribbean coral species on artificial substratum: the importance of competition, growth and variation in life-history strategy. Coral Reefs, 25, 59-71.

Vermeij, M.J.A. (2005) Substrate composition and adult distribution determine recruitment patterns in a Caribbean brooding coral. Marine Ecology-Progress Series, 295, 123-133.

Vermeij, M.J.A., Marhaver, K.L., Huijbers, C.M., Nagelkerken, I. \& Simpson, S.D. (2010a) Coral larvae move toward reef sounds. PloS one, 5, e10660.

Vermeij, M.J.A., van Moorselaar, I., Engelhard, S., Hörnlein, C., Vonk, S.M. \& Visser, P.M. (2010b) The effects of nutrient enrichment and herbivore abundance on the ability of turf algae to overgrow coral in the Caribbean. PLoS ONE, 5, 1-8.

Vermeij, M.J.A. \& Sandin, S.A. (2008) Density-dependent settlement and mortality structure the earliest life phases of a coral population. Ecology, 89, 1994-2004.

Wallace, C.C. (1985a) Four years of juvenile coral recruitment to five reef front sites. Fifth International Coral Reef Congress, Tahiti, p. Vol. 4.

Wallace, C.C. (1985b) Seasonal Peaks and Annual Fluctuations in Recruitment of Juvenile Scleractinian Corals. Marine Ecology-Progress Series, 21, 289-298.

Waples, R.S. \& Gaggiotti, O. (2006) What is a population? An empirical evaluation of some genetic methods for identifying the number of gene pools and their degree of connectivity. Molecular ecology, 15, 1419-39.

Warner, R.R. \& Chesson, P.L. (1985) Coexistence Mediated by Recruitment Fluctuations : A Field Guide to the Storage Effect. The American Naturalist, 125, 769-787.

Warner, R.R. \& Cowen, R.K. (2002) Local retention of production in marine population: evidence, mechanisms and consequences. Bulletin of Marine Science, 70, 245-249.

Weber, M., Beer, D. De, Lott, C., Polerecky, L., Kohls, K. \& Abed, R.M.M. (2012) Mechanisms of damage to corals exposed to sedimentation. PNAS, 109. 
Weber, M., Lott, C. \& Fabricius, K.E. (2006) Sedimentation stress in a scleractinian coral exposed to terrestrial and marine sediments with contrasting physical, organic and geochemical properties. Journal of Experimental Marine Biology and Ecology, 336, 18 32.

Williams, G.J., Smith, J.E., Conklin, E.J., Gove, J.M., Sala, E. \& Sandin, S. a (2013) Benthic communities at two remote Pacific coral reefs: effects of reef habitat, depth, and wave energy gradients on spatial patterns. PeerJ, 1, e81.

Wilson, J. \& Harrison, P.L. (2005) Post-settlement mortality and growth of newly settled reef corals in a subtropical environment. Coral Reefs, 24, 418-421.

van Woesik, R. \& Jordán-Garza, A.G. (2011) Coral populations in a rapidly changing environment. Journal of Experimental Marine Biology and Ecology, 408, 11-20.

Wulff, J.L. (1997) Mutualisms among species of coral reef sponges. Ecology, 78, 146-159.

Zilberberg, C. \& Edmunds, P.J. (2001) Competition among small colonies of Agaricia: the importance of size asymmetry in determining competitive outcome. Marine Ecology Progress Series, 221, 125-133. 


\section{Appendix I}

\section{Effect of predation and sedimentation on coral recruits: Pilot study for Chapter 4}

Predation and sedimentation are two of the main detrimental environmental factors that affect coral reefs (Lenihan et al. 2011; Erftemeijer et al. 2012). Sedimentation has been increasing in recent years as a result of changes in land use (Rogers 1990) and it can slow the growth of corals and increase mortality. Prolonged exposure to high levels of sedimentation induces chronic stress, decreasing coral recovery potential and coral density, and resulting in changes to coral community composition (Bellwood et al. 2004). A preliminary experiment to investigate the effect of fish predation, sedimentation, and their interaction on coral recruits was conducted between June-August 2012.

\section{Experimental design}

Fifty settlement panels were used that had been submerged for 10 months at $6 \mathrm{~m}$ depth at two replicate sites on the Hoga reef: Buoy 3 and Buoy 4 (see map in Chapter 2). Four treatments were applied: control, increased sedimentation, fish exclusion, and increased sedimentation combined with fish exclusion. According to my findings (see results from Chapter 3) and previous research in the area (Salinas De León et al. 2011, 2012a), coral recruits settle mostly on the back and cryptic side of the panels rather than on the front and exposed side. Therefore, I performed my experiment using the back side of the panels. While still submerged, the panels were removed from the reef, turned upside down and fixed to the reef at the same depth. Six panels were assigned to each treatment and all the coral colonies visible to the naked eye were counted. Fish exclusion was achieved by fixing a plastic frame with 12 wooden spikes around the tiles using cable tiles. The spikes were positioned on the top side of the frame pointing up, in order to prevent big herbivorous fish reaching the tiles. Small fish were still able to access the tiles and feed on them (Figure 1). 


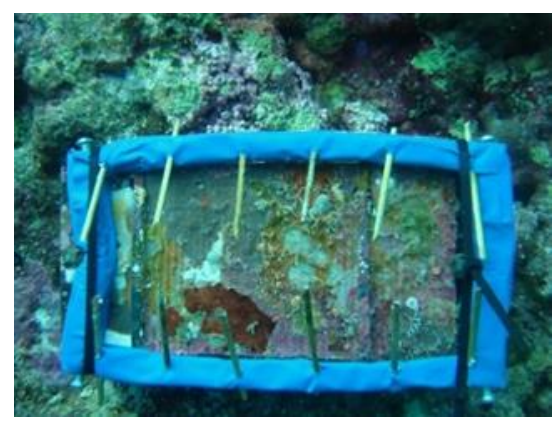

Figure 1 Set-up of the fish exclusion treatment on a settlement panel deployed on the reef at $6 \mathrm{~m}$

Sediment addition was carried out by pouring a measured amount of sediment, prepared in advance, onto the panel. The amount of sediment required to cover the surface of one side of the panel was assessed prior to conducting the experiment. Sediment was collected from the reef and taken to the lab to be filtered by sieves until the sediment particles with a diameter smaller than $0.63 \mu \mathrm{m}$ (silt) were separated. This size fraction was chosen because it was found in previous surveys to be the predominant size fraction in sediment from the Wakatobi (Operation Wallacea, unpublished data). Then the sediment was dried in an oven for 24 hours, weighed and separated in quantities of $2 \mathrm{~g}, 5 \mathrm{~g}, 10 \mathrm{~g}$ and $15 \mathrm{~g}$ into small plastic ziplock bags, three for each quantity. Ten grams were found to be a sufficient amount to cover the entire tile surface with a thin layer that had a good resilience to water flow (Figure 2).
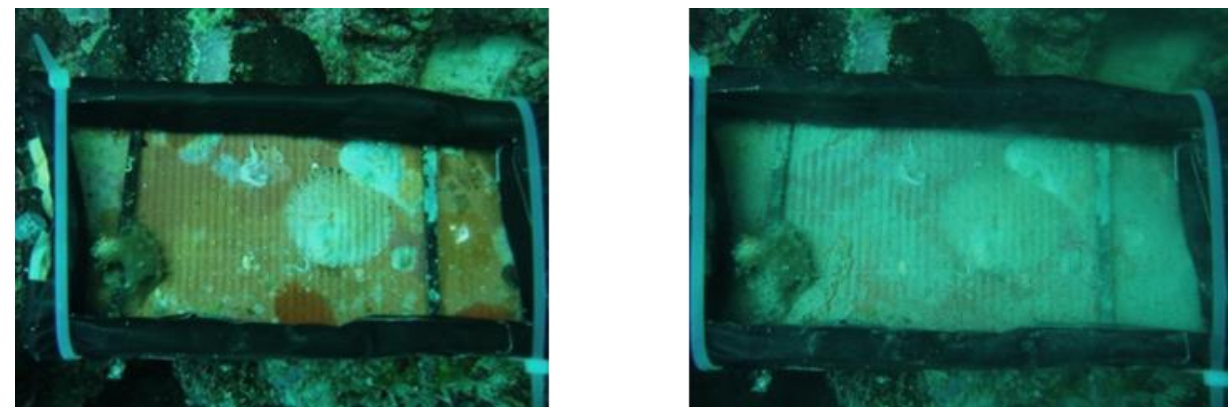

Figure 2 Standardisation of the amount of sediment to use for the sediment addition treatment. Digital images represent the experimental tile before (left) and after (right) the sediment addiction

Sediment was added to the experimental tile with care in order to obtain a thin and equal layer on the surface. All the panels were checked every second day and digital images of the tiles were taken in order to record variations in coral recruit patterns and sediment distribution.

At the end of the experiment, the tiles were collected and taken to the laboratory in seawater and analysed using the procedure described in Chapter 2. 


\section{Results}

When analysing the tiles, I did not observe variation in the status of the recruits identified at the beginning of the experiment. Recruits in the sediment addition treatment did not show detectable signs of bleaching or mortality and I did not observe bites of herbivorous fish on the tiles without fish exclusion or the controls. In addition, during the laboratory analysis, I found recruits not recorded in the initial count in situ.

The lack of any effect of fish predation and sedimentation on the tiles could be due to a number of reasons, including the limited abundance of recruits on the tiles, the small size of the recruits that makes them difficult to detect in situ, and the low presence of algae.

This experiment was conducted in a year characterised by low coral recruitment rates compared to recruitment data collected in 2008 and 2009 in the same area of the WMNP (see Chapter 3). The number of coral recruits found on the experimental tiles was lower than expected and there was not a sufficient number to generate robust results. Recruits were not easily detectable on the panels in situ and not all of them could be mapped at the beginning of the experiment because of their small size. Furthermore, the duration of the experiment of seven days was found to be insufficient to measure the effects of sedimentation on the corals, such as colony bleaching or mortality.

The observations collected at the end of this experiment were used to enhance the experimental design for the manipulative experiment conducted in the following year (see Chapter 4). The new experimental design included the use of settlement panels submerged for a longer time (up to 2 years) with older coral colonies settled on them and the use of a longer experiment duration. 


\section{Appendix II}

\section{Supporting data for Chapter 5}

Figure 1 Correlation between the coverage of four benthic groups (sponges, turf algae, CCA and bryozoans) and recruitment rates recorded at Buoy 3 and Buoy 4. Circles indicate different tiles
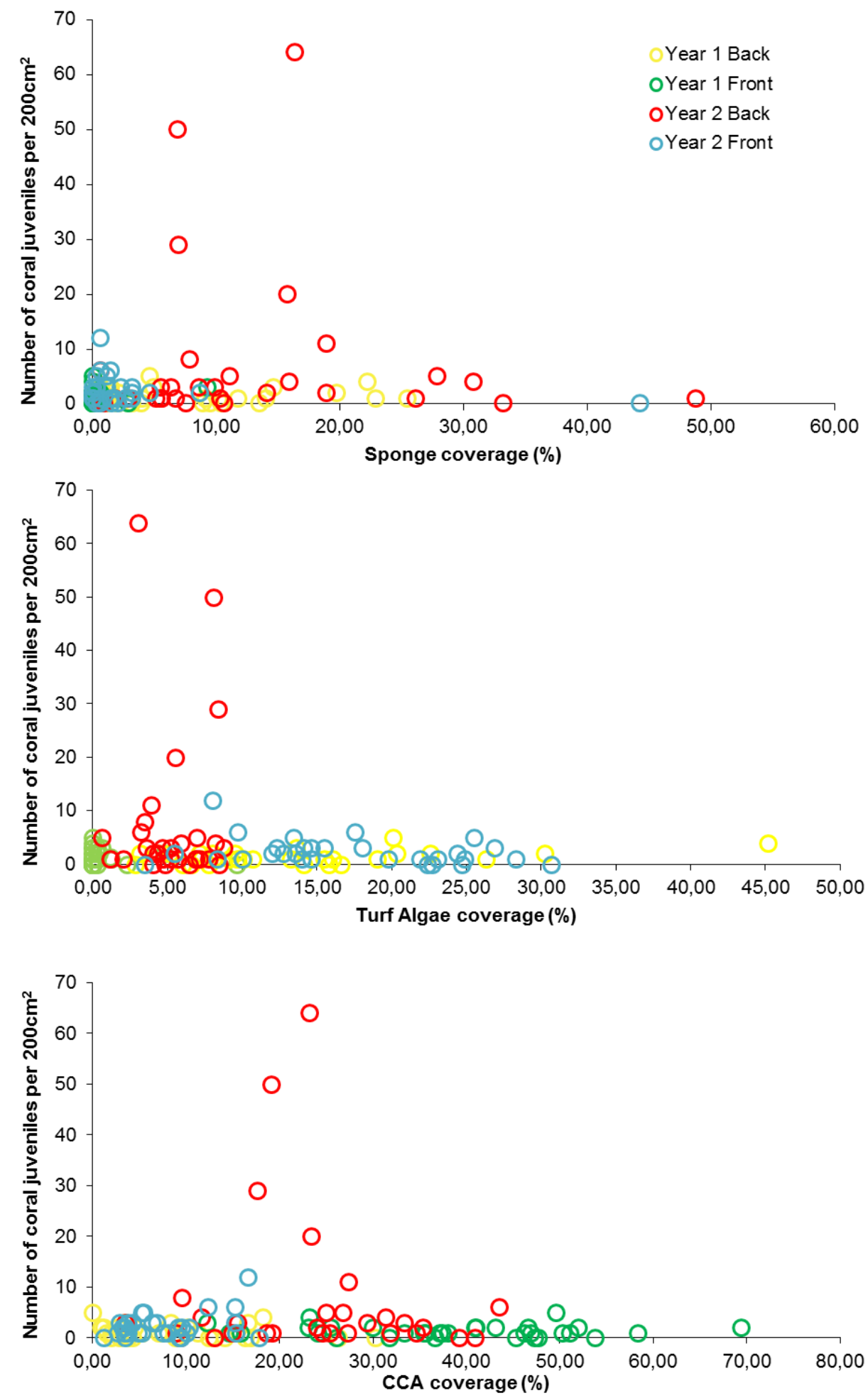

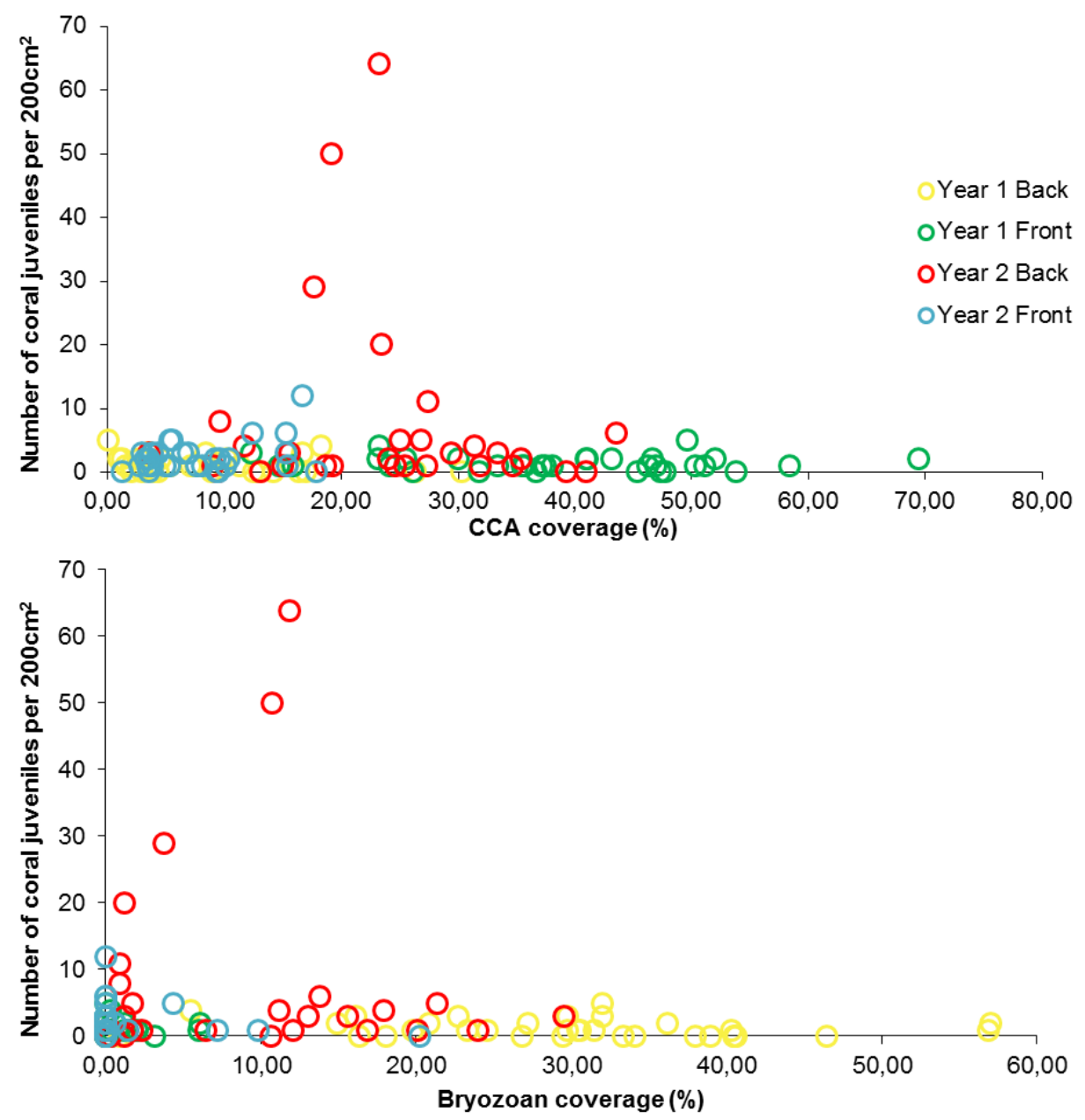
Table 1 Summary of the interactions between the coral juveniles and the benthic organisms. Data were pooled for Buoy 3 and Buoy 4 and data are divided by year (one or two) and side of the settlement panel (front or back). Coral families are in the rows and the benthic organisms in contact with the coral colonies in the columns. Explanations about how to read the table are in Methods in Chapter 5

Year 1 - Front side

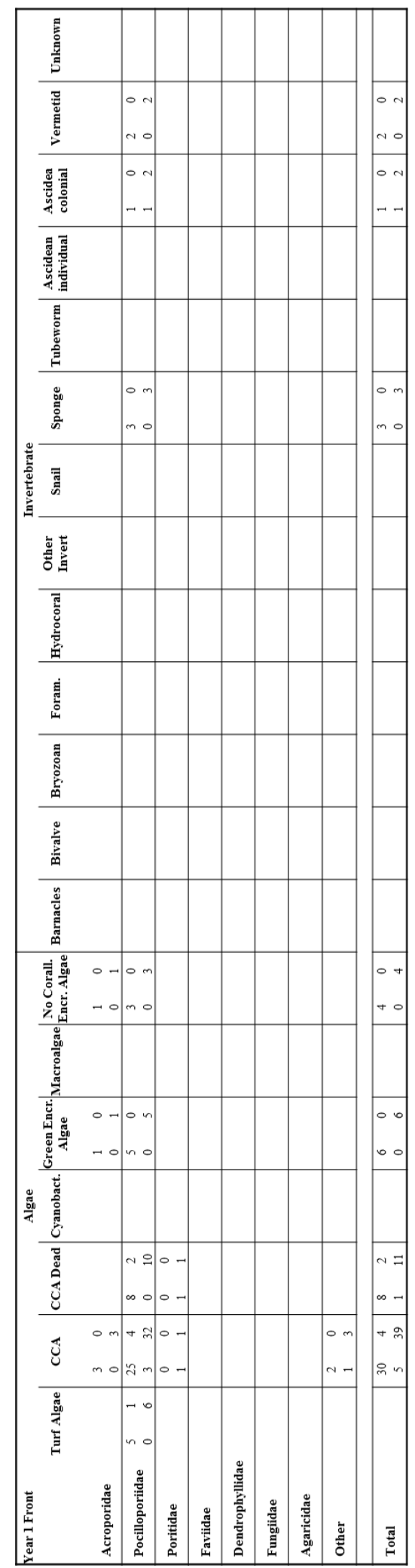

Year 1 - Back side

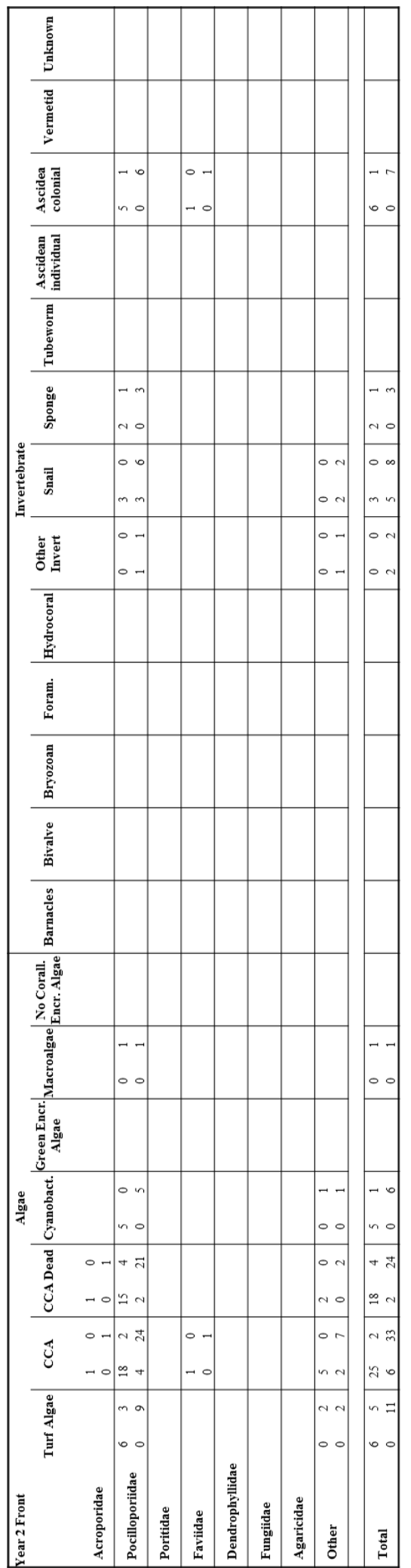


Year 2 - Front side

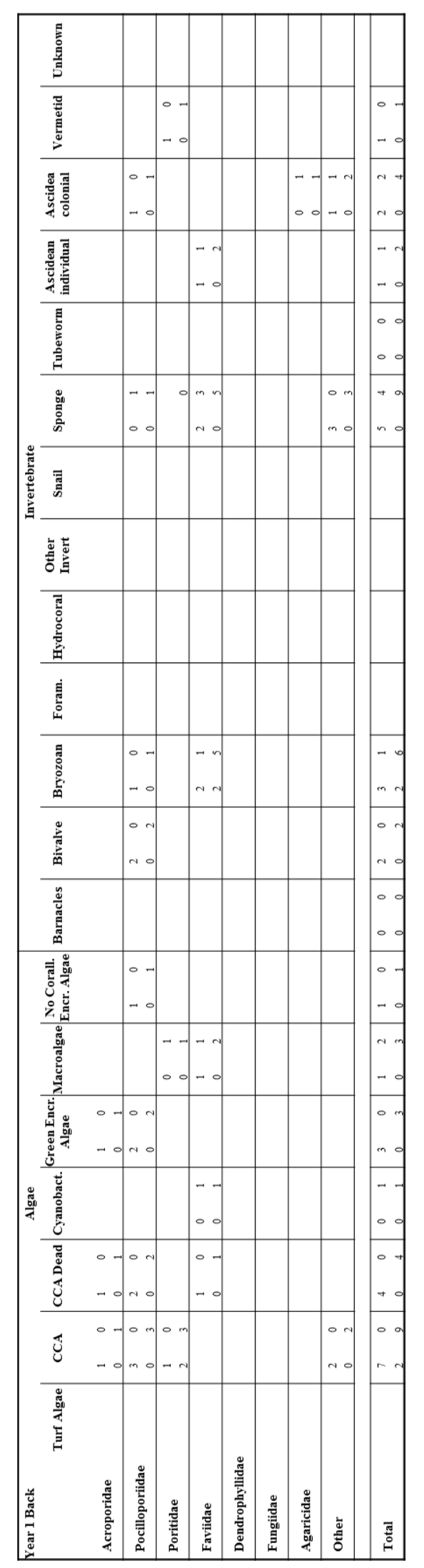

Year 2 - Back side

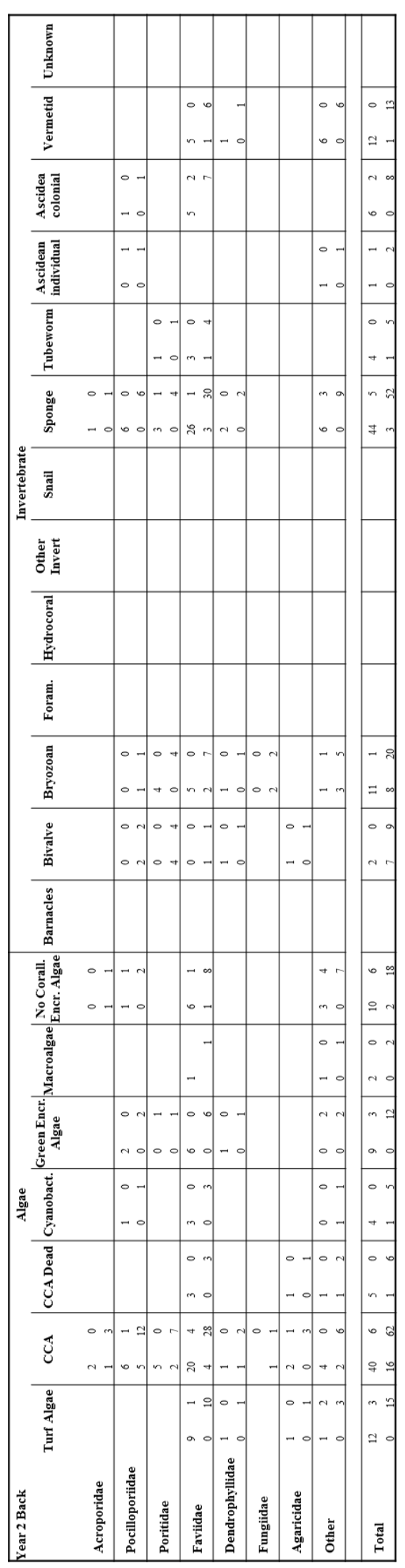


Table 2 Summary of the interactions between the coral juveniles and the benthic organisms. Data were pooled for Buoy 3 and Buoy 4 and divided by year, one or two. Coral families are in the row and the benthic organisms in contact with the coral colonies are in the columns. Explanations about how to read the table are in Methods in Chapter 5
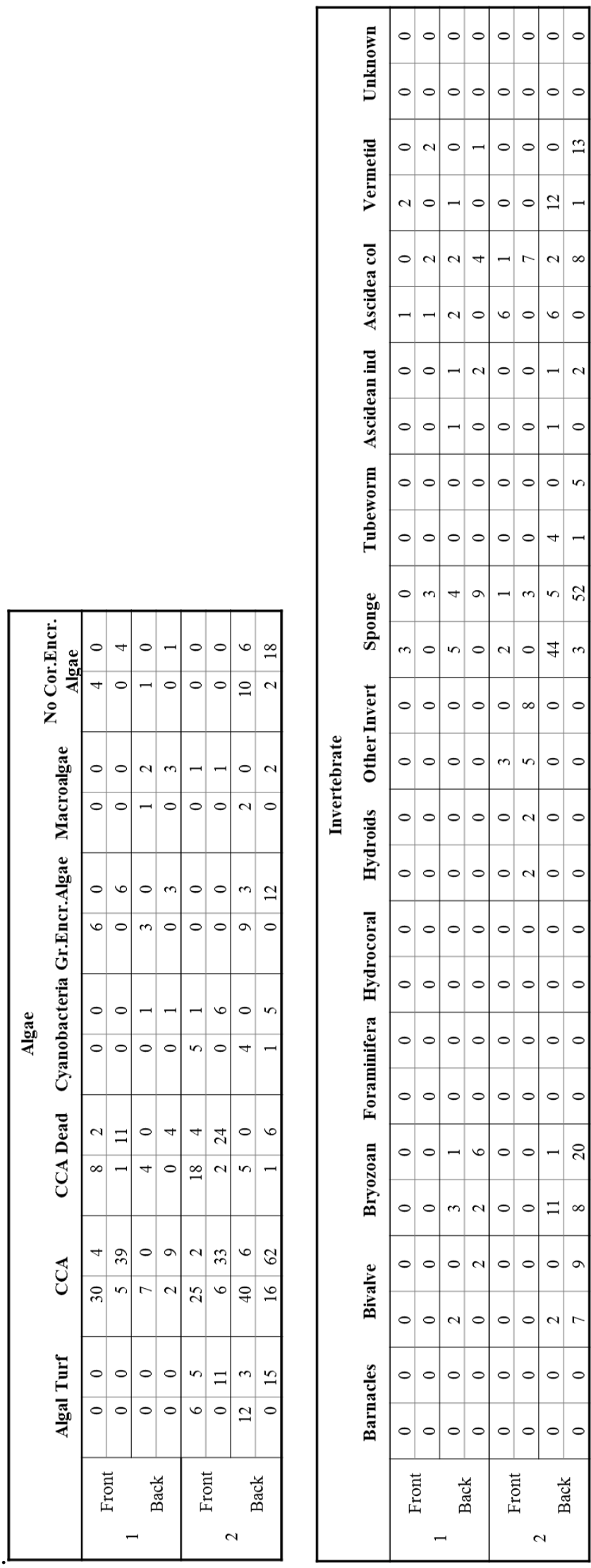
Figure 2 Correlation between CAP axes to data cloud from Figure 5.2 (Page 103). The results of the CAP analysis show that there is very strong and significant correlation between the benthic community composition and coral recruitment rates $(\mathrm{P}=0.0001)$. The strength of this association is indicated by the size of correlation of the axes to the data cloud, where values greater than 0.9 indicate strong correlation. The first axis is reasonably large $\left(\delta_{1}>0.9373\right)$.

\begin{tabular}{ccc}
\hline $\begin{array}{c}\text { Correlations } \\
\text { Eigenvalue }\end{array}$ & Correlation & Corr.Sq. \\
\hline 1 & 0.9373 & 0.8785 \\
2 & 0.8895 & 0.7912 \\
3 & 0.833 & 0.6938 \\
\hline
\end{tabular}

